\title{
Lifestyle and arterial stiffness in young adults: A life course approach
}

Citation for published version (APA):

van de Laar, R. J. J. M. (2013). Lifestyle and arterial stiffness in young adults: A life course approach. [Doctoral Thesis, Maastricht University]. Maastricht University. https://doi.org/10.26481/dis.20130307rl

Document status and date:

Published: 01/01/2013

DOI:

10.26481/dis.20130307rl

Document Version:

Publisher's PDF, also known as Version of record

\section{Please check the document version of this publication:}

- A submitted manuscript is the version of the article upon submission and before peer-review. There can be important differences between the submitted version and the official published version of record. People interested in the research are advised to contact the author for the final version of the publication, or visit the DOI to the publisher's website.

- The final author version and the galley proof are versions of the publication after peer review.

- The final published version features the final layout of the paper including the volume, issue and page numbers.

Link to publication

\footnotetext{
General rights rights.

- You may freely distribute the URL identifying the publication in the public portal. please follow below link for the End User Agreement:

www.umlib.nl/taverne-license

Take down policy

If you believe that this document breaches copyright please contact us at:

repository@maastrichtuniversity.nl

providing details and we will investigate your claim.
}

Copyright and moral rights for the publications made accessible in the public portal are retained by the authors and/or other copyright owners and it is a condition of accessing publications that users recognise and abide by the legal requirements associated with these

- Users may download and print one copy of any publication from the public portal for the purpose of private study or research.

- You may not further distribute the material or use it for any profit-making activity or commercial gain

If the publication is distributed under the terms of Article $25 \mathrm{fa}$ of the Dutch Copyright Act, indicated by the "Taverne" license above, 


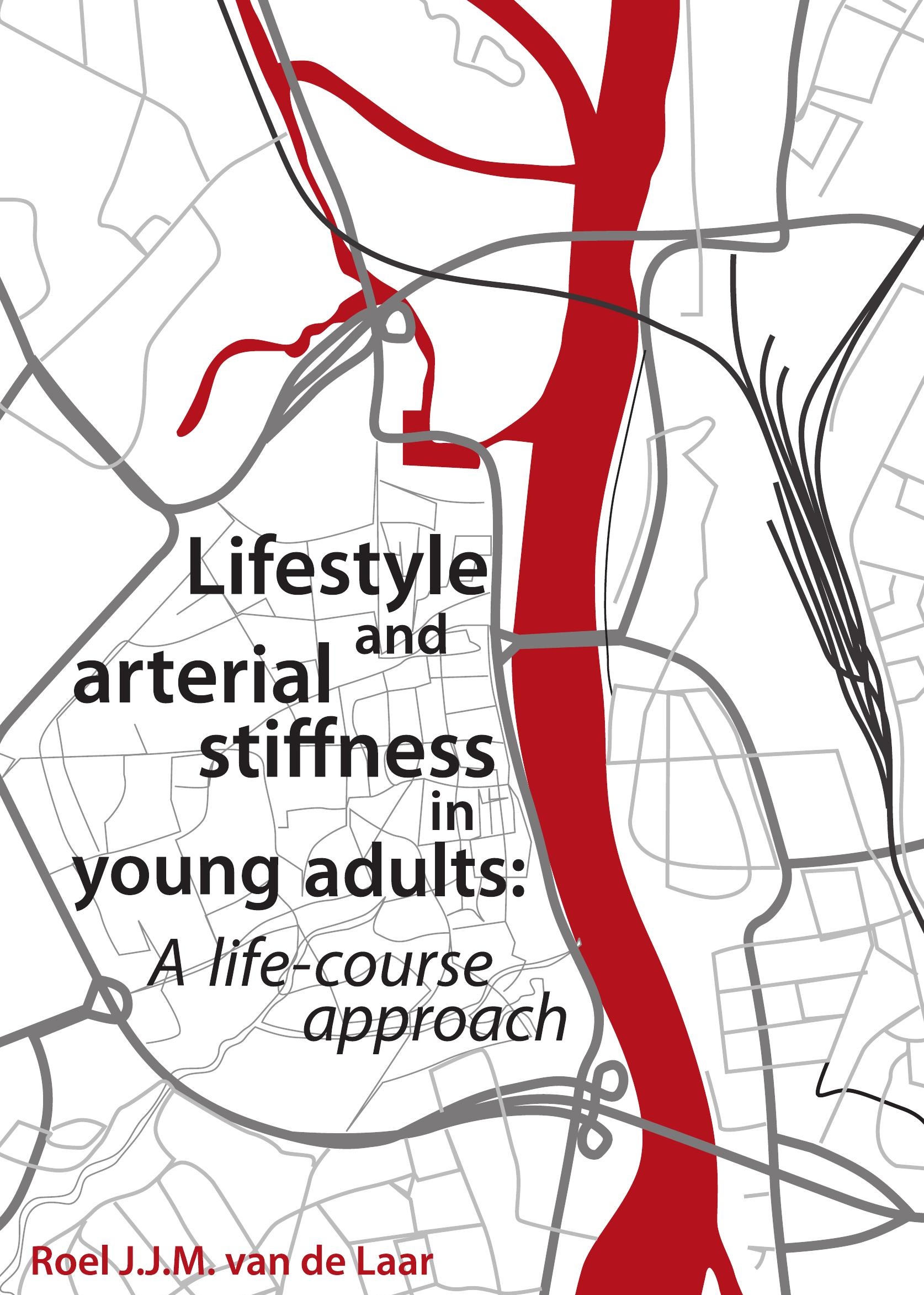


Lifestyle and arterial stiffness in young adults:

A life-course approach 
Copyright Roel J.J.M. van de Laar, Maastricht 2013

No part of this book may be reproduced or transmitted in any form or by any means, without prior permission in writing by the author, or when appropriate, by the publishers of the publications.

Layout: Tiny Wouters

Cover: Thierry Serra

Production: Ipskamp Drukkers B.V., Enschede.

ISBN: 978-94-6191-605-1

The research presented in this thesis was conducted at the CAPHRI School for Public Health and Primary Care and the CARIM School for Cardiovascular Disease, Maastricht University, Maastricht, the Netherlands.

Financial support by the Netherlands Heart Foundation for the publication of this thesis is greatly acknowledged.

In addition, printing of this thesis was financially supported by Esaote B.V.. 


\title{
Lifestyle and arterial stiffness in young adults:
}

\author{
A life-course approach
}

PROEFSCHRIFT

ter verkrijging van de graad van doctor aan de Universiteit Maastricht, op gezag van de Rector Magnificus, Prof. Dr. L.L.G. Soete volgens het besluit van het College van Decanen, in het openbaar te verdedigen op donderdag 7 maart 2013 om 14.00 uur

$$
\text { door }
$$

Roel J.J.M. van de Laar 


\section{Promotores}

Prof. dr. C.D.A. Stehouwer

Prof. dr. M.H. Prins

Prof. dr. J.W.R. Twisk, VUMC Amsterdam

\section{Copromotor}

Dr. I. Ferreira

\section{Beoordelingscommissie}

Prof. dr. H.A.J. Struijker-Boudier (voorzitter)

Prof. dr. Ir. P.A. van den Brandt

Prof. dr. J. Brug, VUMC Amsterdam

Prof. dr. S. Laurent, University Paris Descartes, Paris, France

Prof. dr. A.M.W.J. Schols 


\section{CONTENTS}

Chapter 1 General introduction

Chapter 2 Carotid stiffness in young adults: a life-course analysis of its early determinants

Chapter 3 Physical activities \& sedentary behaviour

Chapter 3.1 Lifetime vigorous but not light-to-moderate habitual physical activity impacts favourably on carotid stiffness in young adults

Chapter 3.2 Habitual physical activity and peripheral arterial compliance in young adults

Chapter 3.3 Time spent watching television is associated with higher arterial stiffness in young adults

\section{Chapter 4 Dietary habits}

Chapter 4.1 Lower lifetime dietary fiber intake is associated with arterial stiffness in young adults

Chapter 4.2 Adherence to a Mediterranean dietary pattern throughout the course of young life is associated with lower arterial stiffness in adulthood

\section{Chapter 5 Smoking}

Chapter 5.1 Continuing smoking between adolescence and young adulthood is associated with higher arterial stiffness in young adults

Dankwoord 



\section{Chapter 1}

General introduction 
Chapter 1 


\section{GENERAL INTRODUCTION}

Cardiovascular diseases (CVD) remain a major health burden in modern-time society. ${ }^{1-3}$ Approximately 17.3 million people died in 2008 from related complications, such as myocardial infarction, stroke and sudden cardiac death, representing about one third of the global mortality. ${ }^{4}$ In the Netherlands, approximately 39000 persons (29\%) died from CVD in 2010, which constituted the second most common cause of death after cancer. ${ }^{5}$

In general, these clinical outcomes occur after the fifth decade of life, but there is increasing evidence that some of the pathobiological processes underlying CVD start to develop much earlier, and are characterized by a preclinical period that may last for decades. ${ }^{6-9}$ Major technological developments in the last few decades ${ }^{10}$ have enabled the non-invasive imaging and measurement of surrogate markers of such processes, such as, atherosclerosis, arterial stiffness and endothelial dysfunction, ${ }^{11,12}$ leading to a gradual shift in focus to the study of early stages of disease development in epidemiological studies. For instance, such measures may serve as markers for the early identification of individuals at high risk for developing overt CVD in due time (i.e. prediction research questions), ${ }^{13,14}$ but also facilitate the study of the role of potential risk factors in the early stages of disease development among individuals in whom overt CVD will not develop for decades, such as in this thesis (i.e. etiological research questions).

Arterial stiffness, a measure of subclinical arterial injury, is primarily determined by aging and blood pressure, but may also be altered under the influence of several (lifestyle) cardiovascular risk factors. ${ }^{15,16}$ Stiffer arteries may cause CVD due to its contribution to systolic hypertension, left ventricular hypertrophy and impaired coronary perfusion, ${ }^{17}$ as we will describe in more detail below.

This thesis comprises a set of epidemiological studies that investigate the influence of lifestyle risk factors from adolescence to adulthood on adult levels of arterial stiffness. These studies may improve our understanding of the etiology of arterial stiffness in particular and the early stages of CVD in general, and provide tools to improve current primary prevention strategies targeted at the young with the most potential for health benefits in the long-term.

\section{IMPORTANCE OF LIFESTYLE RISK FACTORS}

Lifestyle practices may be very fundamental determinants of cardiovascular health. ${ }^{18}$ Indeed, these may affect traditional (e.g. blood pressure, body fatness, blood lipids) and non-traditional (e.g. inflammation, endothelial dysfunction, oxidative stress) biological risk factors, all of which in turn contribute to the development of CVD. The undisputable importance of lifestyle behaviours is perhaps most clearly illustrated by the worldwide increase in the prevalence of obesity observed in the last decades 
among humans of all ages. ${ }^{19-21}$ This has reflected the gradual changes in our society towards greater availability and consumption of (unhealthy) foods and less 'need' to be physically active. ${ }^{22}$ Obesity, a major health burden, ${ }^{19,22}$ results primarily from a positive balance between energy intake and energy expenditure, and its increase emphasizes dietary intake and physical activity as lifestyle risk factors playing a central role in (cardiovascular) health.

There is a large body of evidence showing that lifestyles, such as regular physical activity, ${ }^{23-27}$ dietary intake, ${ }^{28-33}$ and smoking, ${ }^{34-37}$ are independently associated with a wide range of the biological risk factors, as well as risk of cardiovascular morbidity and mortality. Moreover, overall healthy lifestyle patterns, as defined on the basis of a combination of data on smoking behaviour, physical activity, dietary intake, alcohol consumption and body weight, have been shown to be associated with lower risk of incident coronary heart disease, ${ }^{38,39}$ stroke, $^{40,41}$ and cardiovascular and all-cause mortality ${ }^{42-44}$ in large prospective cohort studies conducted in middle-aged and older individuals from the United States and Europe. In fact, a considerable $50-80 \%$ of the recorded events might had been avoided would everyone have adhered to each of the healthy lifestyles considered. ${ }^{38,39,41,43,44}$

\section{WHY INVESTIGATION OF LIFETIME LIFESTYLES AMONG THE YOUNG?}

It is increasingly recognized that the risk of CVD is not just determined by risk factors in adult life, but also by their levels at a young age. ${ }^{6-9,45}$ Indeed, (un)healthy lifestyle practices may be already established in childhood and/or adolescence and persist thereafter. ${ }^{45-51}$ From a primary prevention point of view, it is thus of particular relevance to investigate the extent to which the development of lifestyle practices throughout the course of early life may relate to (pre-clinical) cardiovascular outcomes in adulthood. Such a life-course approach allows investigation of the cumulative burden of risk exposure and may also provide useful information on the pathways through which such exposures confer increased risk. Specifically, risk factors affecting outcome later in life may develop at different critical or sensitive periods earlier in life when their harmful effects become apparent, or accumulate over time and influence subsequent exposure to the same or other risk factors that, together, or independently, may increase cardiovascular risk. ${ }^{45,52}$ Identifying such critical periods or chains of risk may be of utmost importance for targeted interventions with the most potential for health benefits in the long-term. Therefore, in this thesis we adopted a life-course approach to study lifestyle risk factors from adolescence into adulthood and their associations with arterial stiffness at adult age. 


\section{PRINCIPLES OF ARTERIAL STIFFNESS}

Arterial stiffness is one of the hallmarks of arterial aging. Indeed, with aging arteries thicken, dilate and become stiffer. ${ }^{15,53}$ While atherosclerosis is characterized by arterial thickening involving intimal hyperplasia, the dilation and stiffening of arteries characterize arteriosclerosis and are attributed to structural and functional changes occurring primarily in the medial layer of the arterial wall. Arterial stiffness is a generic term to describe the (loss of) elastic properties, or rigidity, of arterial walls. Several estimates of arterial stiffness have been introduced, all of which describe arteries' elastic behaviour, but have slightly different (physiological) meanings. ${ }^{54}$ Prior to a detailed description of the measures used in the present thesis, some basics of the arterial system and arterial stiffness are introduced.

\section{Arterial functions}

The arterial tree has two main functions: 1) to transport blood from the left ventricle through capillaries of the bodily organs and tissues according to their need (i.e. conduit function); and 2) to smoothen pulsatile pressure imposed by intermittent left ventricular contraction causing a nearly steady capillary blood flow (i.e. cushioning function). ${ }^{16,55}$ Indeed, with each left ventricular contraction a bolus of blood is ejected into the aorta that results in a sharp pressure increase in systole. This causes arteries to distend and act as an elastic reservoir. During diastole, when blood pressure is lower, the elastic properties of the arteries cause them to fall back to their resting diameter causing the blood to flow further through the systemic circulation.

\section{Arterial architecture}

The arterial wall consists of three layers: from inward to outward these are the tunicas intima, media and adventitia. ${ }^{55}$ The intima consists of a basement membrane and a single layer of endothelial cells. The latter are in contact with blood and play an important role in regulation of vascular tone, fibrinolysis and haemostasis, and production of cytokines and adhesion molecules that regulate inflammatory processes. ${ }^{56}$ The adventitia embeds the artery into the surrounding connective tissue consisting of nerves, small blood vessels and fibroblasts. The media is the load-bearing layer of the arterial wall and determines its elastic properties. Its main structural components are elastin, collagen, vascular smooth muscle cells (VSMCs) and ground substance. The arrangement of these components varies according to the distance from the heart: while in the proximal aorta elastin is the dominant component, the elastin-to-collagen ratio is reversed in the distal aorta, and in peripheral arteries collagen predominates. Thereafter, VSMCs form the main component. ${ }^{55,57}$ 


\section{Proximal versus distal arterial compartment}

Due to the marked differences in arterial structure, and related increasing stiffness gradient, the arterial tree is divided into a proximal 'elastic' part that has a dominant role in cushioning, and a distal 'stiffer' (or muscular) part contributing more to the distribution of blood. $^{57}$ Any such differences may explain why aging, ${ }^{58-61}$ cardiovascular risk factors, such as hypertension and diabetes, ${ }^{62}$ and vasoactive substances, such as nitric oxide, ${ }^{57}$ have discordant effects on these different types of arteries. Therefore, in this thesis we studied the associations between lifestyle risk factors and stiffness levels of both central and peripheral arterial sites and segments specifically.

\section{Pulse wave propagation}

With each left ventricular contraction a pressure wave is generated travelling from the aorta to peripheral arteries (i.e. forward pressure wave). At each point of discontinuity in the arterial tree, where a change in impedance occurs, a pressure wave is generated that travels back towards the ascending aorta (i.e. reflected pressure wave) ${ }^{55,57}$ Such impedance mismatch results from arterial-arteriolar junctions, arterial bifurcations, progressive decrease in elastin-to-collagen ratio along the arterial tree, and arterial tapering. ${ }^{55,63}$ The forward wave and the backward waves arising from multiple reflection sites are in constant interaction and determine the actual pressure wave at any point in the arterial tree. Under normal conditions, such as in young and healthy individuals, the reflected wave arrives at the ascending aorta during early diastole, thereby augmenting diastolic blood pressure and coronary perfusion. As arteries stiffen, the speed by which these pressure waves propagate throughout the arterial tree, i.e. the pulse wave velocity (PWV), causing the reflected wave to arrive during late systole, thereby contributing to disturbed heart-vessel coupling and increased risk of CVD (vide infra). ${ }^{57}$

\section{Pulse amplification}

Pulse pressure, defined as the difference between systolic and diastolic blood pressure, is higher in peripheral than in central arteries due to the increasing stiffness gradient along the longitudinal axis of the arterial tree and closer appearance of reflection sites in distal arteries; this phenomenon is called 'pulse pressure amplification' ${ }^{55,57}$ Its magnitude decreases with age, ${ }^{64,65}$ as aging confers stiffening more of central than of peripheral, arteries. ${ }^{58-61}$ Therefore, brachial pulse pressure, especially among the young, does not properly reflect the level of pulse pressure in the central part of the arterial tree. 


\section{Mechanisms of arterial stiffness}

Vascular stiffening results from a complex interplay between structural changes of proteins in the extracellular matrix (i.e. elastin and collagen), as well as endothelial cell signalling and VSMC function, as has been reviewed elsewhere. ${ }^{53,66}$ Mainly by stimulation of an inflammatory milieu, overproduction of collagen and diminished quantities of normal elastin contribute to arterial stiffness. ${ }^{66}$ Under the influence of cyclic stretch, elastin fibers become sparser and show signs of fragmentation and disorganization, which results in transfer of mechanical load to the stiffer collagen fibers. ${ }^{53}$ In addition, advanced glycation end-products (AGEs) may cause collagen and elastin fibers to cross-link, leading to accumulation of structurally inadequate collagen molecules and reductions in the elastic matrix of the arterial wall. In addition to these structural changes, arterial stiffness is strongly affected by disturbed endothelial cell signalling leading to decreased nitric oxide availability. This results in increased VSMC tone and hence higher functional stiffening, and in the long-term may further contribute to structural adaptations in the arterial wall. ${ }^{66}$

\section{Implications of arterial stiffness}

Increases in stiffness impair the cushioning capacity of arteries leading to increases in systolic and decreases in diastolic blood pressure, and thus increases in (central) pulse pressure. ${ }^{557,68}$ Indeed, for a given stroke volume, hearts ejecting into a stiffer arterial bed must generate higher end-systolic pressures. This leads to increased decay of pressure and volume during systole, causing a reduced arterial volume at the onset of diastole, which in turn causes an enhanced fall in diastolic pressure. In addition, higher PWV causes the reflected wave to arrive earlier, during late systole, thereby further augmenting systolic pressure and decreasing diastolic blood pressure. These hemodynamic changes may in turn contribute to the development of clinical outcomes related to arterial stiffness, such as left ventricular hypertrophy, heart failure, stroke and myocardial infarction. ${ }^{67,68}$ In this line, mainly stiffness of central (i.e. elastic) arterial sites and segments, such as the aorta and carotid arteries, have been shown to be associated with increased risk of incident cardiovascular events (i.e. coronary heart disease and stroke), ${ }^{69-77}$ and cardiovascular and/or all-cause mortality. ${ }^{69,70,72,78-84}$

\section{Measuring arterial stiffness: methods and estimates}

Arterial stiffness is often assessed by means of local and regional stiffness estimates, which are also used in this thesis and are described below. Other measures include those that describe systemic arterial compliance ${ }^{85-89}$ and pulse wave analyses, ${ }^{64,90}$ the latter of which allows determination of the augmentation index, a measure of 'early' wave reflection, and central arterial blood pressures. These methods are reviewed in detail elsewhere. ${ }^{17,91-94}$ 


\section{Local arterial stiffness estimates}

Stiffness estimates at specific arterial sites such as the (common) carotid, brachial and femoral arteries, are usually obtained by means of non-invasive ultrasonography and often described in terms of distensibility and compliance coefficients, which are defined as the relative and absolute changes in volume for a given pressure step, respectively. ${ }^{10,16,62,92}$ In practice, large arterial properties, such as arterial size (i.e. cross-sectional diameter), change in arterial size (i.e. distension), and wall thickness (i.e. assessed by means of intima-media thickness) are obtained. These arterial properties together with local pulse pressure are then used to calculate local arterial stiffness estimates, such as the distensibility coefficient (DC), the compliance coefficients (CC), and Young's elastic modulus (YEM; Figure 1.1). ${ }^{10,62}$ The DC reflects the pulsatile stress imposed on the arterial wall, and is a measure of the elastic properties of the artery as a hollow structure. The CC reflects the artery's buffering capacity, and reduction will lead to increases in systolic blood pressure and hence in mechanical afterload. The YEM describes the intrinsic elastic properties of the arterial wall. ${ }^{10,17,62}$ Another estimate is the $\beta$-stiffness index, which accounts for the non-linear elastic properties of the arterial wall and is assumed to be independent of distending pressure. ${ }^{91,93}$ Ultrasonography requires a high degree of operator skills and technical expertise, but it can be assessed with good levels of inter- and intra-observer reproducibility. . $^{10,95}$ With ultrasonography arterial stiffness can thus be directly estimated from relating changes in pressure to changes in arterial volume (area), such that functional and structural changes in a specific type of artery (i.e. elastic or muscular artery) can be investigated.

Given the pulse pressure amplification phenomenon, it is imperative to estimate local arterial pulse pressure when calculating the local arterial stiffness estimates. This may be achieved by calibration of pulse or distension waveforms obtained in the target (i.e. carotid and femoral) arteries and in the reference (i.e. brachial) artery, using validated methods as described in detail elsewhere. ${ }^{96,97}$

\section{Regional arterial stiffness estimates}

These estimates are obtained through measuring the speed by which the pulse wave propagates through a certain arterial segment length (i.e. the PWV), for instance the aorta, or upper and lower limbs. Conceptually, this measure is closely and inversely related to arteries' distensibility according to the Bramwell-Hill equation:

$$
P W V=V 1 / D C \cdot \rho
$$

where $\rho$ is the density of the blood. ${ }^{10,16}$ In practice, PWV is often measured by means of tonometry, mechanotransducers or ultrasonography using the foot-to-foot velocity method from various types of waveforms. For instance, pressure or distension waves are obtained at two arterial sites to record the time delay (i.e. transit time) it took between the feet of the two waveforms. This time delay between the two points is 
estimated either by simultaneous measurement, or by gating to the peak of the Rwave of the ECG. The travel distance is usually measured over the body surface, and PWV is then calculated as the ratio between distance and transit time (in $\mathrm{m} / \mathrm{s}$ ). ${ }^{93} \mathrm{PWV}$ is most often measured in the aorta (i.e. carotid-femoral PWV), which involves a mixture of predominantly elastic (i.e. ascending aorta) and muscular (i.e. descending aorta) parts. Yet, measurements are relatively easy to perform and have repeatedly been shown to predict adverse cardiovascular outcomes. ${ }^{17}$

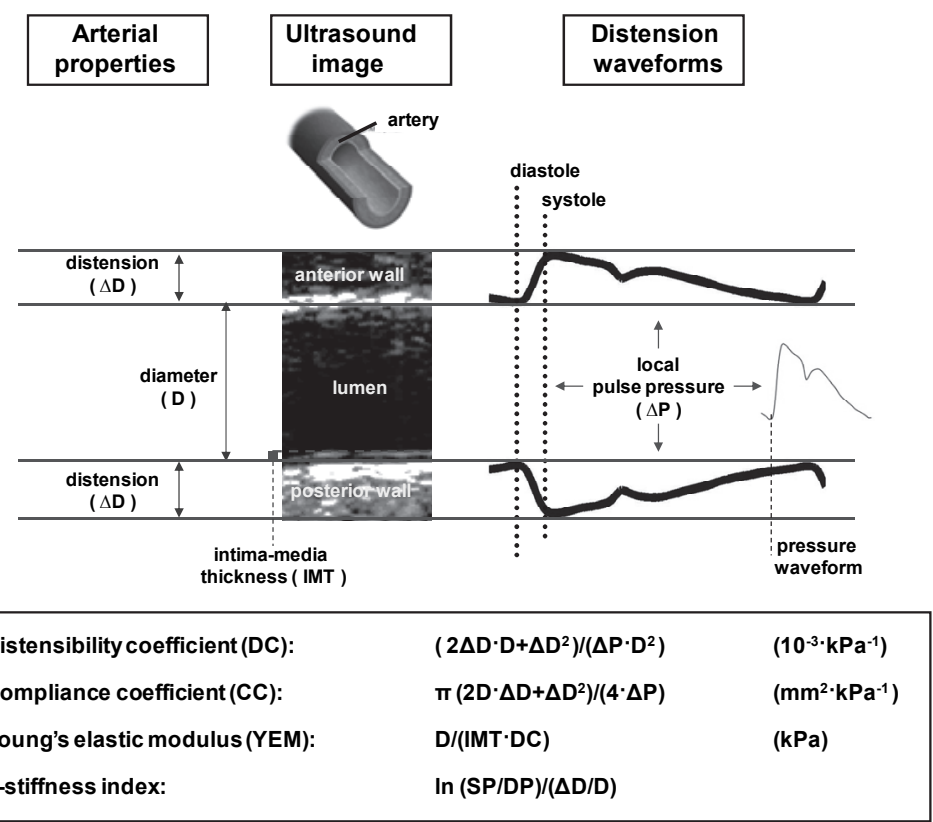

Figure 1.1 Estimates of local arterial stiffness as ascertained by means of non-invasive ultrasonography Adapted from. ${ }^{68}$

\section{Blood pressure dependency}

Arterial walls are characterized by non-linear elastic properties; that is, these become progressively stiffer as they are distended. Indeed, at lower pressures, it is mainly elastin fibers that build up tension, but at higher pressures the much stiffer collagen fibers are recruited. ${ }^{53,55}$ In vivo measurements of arterial stiffness are thus highly dependent on the background level of distending pressure (i.e. mean arterial pressure), which needs to be taken into account when disentangling effects of blood pressure from differences in stiffness properties of the arterial wall per se. ${ }^{68,93}$ 


\section{LIFESTYLE RISK FACTORS AND ARTERIAL STIFFNESS}

There is considerable evidence supporting the beneficial role of healthy lifestyle practices on arterial stiffness. ${ }^{98}$ Whether, and if so to what extent, lifestyles initiated early in life, and their development into adulthood, may affect arterial stiffness later in life remains largely unknown, however.

\section{Physical activity and sedentary behaviour}

Regular aerobic physical activity is favourably associated with arterial stiffness. Several cross-sectional studies have shown that individuals who are physically active have less stiff arteries compared with their non-active counterparts. ${ }^{99-113}$ In some studies mainly high intensity physical activities were found to be associated with lower arterial stiffness in healthy young, middle-aged and older adults, ${ }^{99,109,110}$ suggesting a differential role for different intensities of physical activity. Results from intervention studies have also supported a beneficial impact of aerobic exercise, ${ }^{89,111,114-124}$ although very few of these findings derived from randomized controlled trials. ${ }^{89,125-128}$ For instance, a single bout of exercise reduced arterial stiffness among healthy young adults. $^{89,114-116}$ Similarly, studies investigating the 'long term' effects of physical activity showed favourable arterial adaptations. ${ }^{111,117-124}$ Some intervention studies have shown no such effects, which may be explained by the low number of study participants, $^{129}$ the low intensity of physical activities performed, ${ }^{127}$ and/or established congestive heart failure ${ }^{125}$ or isolated systolic hypertension ${ }^{130}$ among study participants. The latter showing that aerobic exercise may not reverse arterial stiffness in the presence of disease suggest that increases in aerobic training may be most effective when initiated at a young age. It remains unclear whether beneficial adaptations differ for central vs. peripheral arteries as most of the studies so far have investigated the association between physical activity and stiffness estimates of one artery or arterial segment only, most often the carotid distensibility or compliance coefficients or the aortic PWV. The few that investigated both types of arteries, mainly intervention studies, found physical activity to be favourably associated with central $^{103,119}$ or peripheral ${ }^{99}$ arteries only, arguing in favour of a localized effect, or both types of arteries, ${ }^{89,107,114,116,121,124}$ arguing in favour of a generalized effect.

In contrast to aerobic exercise, resistance training may increase arterial stiffness. Indeed, resistance training yields major blood pressure increases (i.e. with highintensity training systolic blood pressure up to $400 \mathrm{mmHg}$ ), ${ }^{131}$ which in the long term may lead to maladaptive structural remodelling of arterial walls. ${ }^{16}$ The evidence thus far is inconclusive, however. In cross-sectional studies highly resistance trained individuals were characterized by higher arterial stiffness as compared with their nontrained counterparts. ${ }^{88,132,133}$ Intervention studies investigating the acute effects of resistance training showed conflicting evidence. Indeed, carotid stiffness increased immediately after a whole body resistance training work out, ${ }^{134}$ while single leg-press training yielded decreases in lower limb PWV of the exercised but not in the non- 
exercised leg. ${ }^{135}$ Prolonged high-intensity resistance training programs yielded adverse arterial adaptations. ${ }^{136-138}$ In contrast, prolonged moderate intensity resistance training, ${ }^{139}$ or combination of endurance and resistance training seems not to affect, ${ }^{140}$ or even decrease, ${ }^{141}$ arterial stiffness, which might be of particular relevance for the prevention and treatment of sarcopenia among the elderly.

On the other hand, more daytime spent in sedentary behaviours, which are 'activities' that usually involve prolonged sitting or lying and that yield very low energy expenditure, has emerged as a strong determinant of adverse (cardiovascular) health. ${ }^{142-144}$ In particular, there is increasing evidence suggesting that sedentary behaviour does not merely reflect lack of physical activity, but rather forms an independent determinant of adverse cardiovascular health, possibly through common but also specific/distinct mechanisms to those commonly attributed to physical activity. ${ }^{145}$ To what extent sedentary behaviour affects arterial stiffness, and whether any such association is independent of and/or qualitatively different from that commonly found for aerobic exercise, remains largely unknown, however.

\section{Dietary intake}

There is emerging evidence that dietary intake may influence arterial stiffness. With regard to alcohol consumption, the observational studies, all cross-sectional in design, yielded inconsistent results; while some found no association between alcohol consumption and arterial stiffness ${ }^{146,147}$ and aortic augmentation index, ${ }^{148,149}$ others showed moderate alcohol consumption to be associated with lower aortic PWV among postmenopausal women ${ }^{149}$ and middle- and older-aged men, ${ }^{150}$ higher carotid distensibility confined to women ${ }^{147}$ and individuals aged 55 years or older, ${ }^{151}$ and lower aortic augmentation index. ${ }^{152}$ No adverse effects of heavy drinking were observed in these studies, however. In two other studies heavy alcohol drinking was associated with higher brachial-ankle $\mathrm{PWV}^{153}$ and augmentation index. ${ }^{154}$ In an experimental setting, decreases in aortic PWV and augmentation index were observed after drinking regular but not dealcoholized red wine; ${ }^{148}$ similar decreases in aortic augmentation index and central systolic blood pressure were found for both types of wine among middle-aged men with coronary heart disease, however. ${ }^{155}$ It thus remains unclear whether the decreases in arterial stiffness are explained solely by alcohol, or by other components, such as flavonoids. In summary, the studies conducted thus far suggest that moderate alcohol consumption may favourably affect arterial stiffness. Comparison of results from the different studies is hampered, however, by the varying cut-offs adopted for alcohol consumption categories, methods of arterial stiffness ascertainment and specific characteristics of the study populations.

Most studies investigating dietary intake, other than alcohol consumption, in relation to arterial stiffness have focussed on single foods or nutrients. As has recently been summarized, ${ }^{156}$ intervention studies have shown that fish-oil with $n-3$ polyunsaturated fatty acids and soy isoflavones favourably affect arterial stiffness, 
though these were studies conducted among middle-aged and older individuals only, which were often at increased cardiovascular risk. In addition, salt restriction has been shown to reduce arterial stiffness among patients with untreated hypertension. ${ }^{127,157,158}$ In contrast, caffeine has detrimental acute effects on aortic PWV ${ }^{159,160}$ and chronic caffeine intake also has been shown to be associated with higher aortic PWV and augmentation index. ${ }^{161}$ To what extent intake of specific foods and/or nutrients or dietary patterns throughout the course of young life affects arterial stiffness remains largely unknown. The only study thus far investigating dietary intake in childhood/adolescence and in adulthood in relation to arterial stiffness in adulthood showed that consistently high vs. consistently low intake of fruits and vegetables in both periods was associated with lower adult aorto-popliteal PWV, albeit in analyses not adjusted for potential confounding variables. ${ }^{162}$ Whether these favourable associations could be attributed to the fiber portions of these foods, and thus hold true also for other fiber-rich foods, such as whole grain products, is uncertain. In addition, only one study thus far showed that a dietary pattern, as determined by means of principal components analyses, and characterized by high intake of meat and alcohol, and low fruits, sweetening products and dairy products was associated with higher aortic PWV 7.5 years later in healthy middle-aged individuals. ${ }^{163}$ In this line, investigation of dietary patterns might be of particular interest as the complex interplay of foods and nutrients may have synergistic effects that may not be captured when investigating foods and nutrients separately. ${ }^{164}$ Investigation of dietary patterns may better reflect individuals' true dietary intake and capture the joint health effects of usual dietary intake, reduce potential confounding bias by concomitant dietary habits, and may be more easily interpreted and translated into dietary modifications. ${ }^{164,165}$

\section{Smoking}

Studies thus far investigating the effects of smoking on arterial stiffness yielded inconsistent results. In experimental settings the acute increases in arterial stiffness after smoking one cigarette have consistently shown to increase arterial stiffness. ${ }^{166-168}$ However, while habitual smoking has shown to be associated with higher arterial stiffness ${ }^{167,169-171}$ and its progression, ${ }^{172}$ others did not find differences in carotid, brachial and femoral distensibility, ${ }^{173,174}$ brachial-ankle PWV, ${ }^{175}$ carotidfemoral PWV ${ }^{176}$ and large artery compliance ${ }^{177}$ between smokers and non-smokers. In part, these inconsistencies might be explained by the cross-sectional and/or retrospective assessment of smoking behaviour in these studies. In addition, whether starting to smoke in adolescence, and whether changes in smoking behaviour from adolescence into adulthood affect arterial stiffness at adult ages remains unknown. Studies investigating these issues, preferably with prospective assessment of smoking behaviour, are thus warranted. 


\section{RISK FACTORS AMONG THE YOUNG AND ARTERIAL STIFFNESS}

Several studies investigated the potential effect of risk factors in childhood and adolescence on arterial stiffness. These studies focussed on exposure to biological risk factors, however.

Small case-control studies showed that children with type 1 diabetes, ${ }^{178,179}$ familial hypercholesterolemia, ${ }^{180}$ obesity $^{181}$ and hypertension ${ }^{182}$ were characterized by greater carotid stiffness levels compared with their healthy counterparts. In addition, in population-based studies among children, total and LDL cholesterol, ${ }^{183}$ body fatness and related metabolic disturbances, ${ }^{184}$ and leptin ${ }^{185}$ were associated with lower brachial distensibility.

Only few prospective cohort studies measured biological and/or lifestyle risk factors from childhood/adolescence to adulthood and investigated their impact on arterial stiffness at adult ages. For instance, in the Cardiovascular Risk in Young Finns Study, a higher risk score in childhood (i.e. age range 3-18 years), as defined on the basis of a single measure of systolic blood pressure, sum of skinfolds, LDL and HDL cholesterol and smoking behaviour, was associated with higher carotid stiffness 21 years later. Only systolic blood pressure and the sum of skinfolds were independent predictors of adult carotid stiffness. The associations attenuated substantially (i.e. by $\sim 50 \%$ ), but remained statistically significant, when adjusted for the adult values of the risk factors considered, suggesting that the childhood risk factors in part directly, and in part via tracking into adulthood, affect arterial stiffness at adult ages. ${ }^{186}$ Another study showed that higher levels of LDL-cholesterol and triglycerides (i.e. type IIb dyslipidemia) from childhood/adolescence to adulthood (i.e. 2 to 4 repeated measures) was associated with higher carotid IMT, but not with carotid compliance and brachial flow mediated dilation. ${ }^{187}$ Finally, only recently Aatola et al showed that a higher number of lifestyle risk factors (i.e. based on vegetable consumption, fruit consumption, physical activity and smoking) in childhood/adolescence was directly associated with brachial-ankle PWV assessed in adulthood, independent of the number of adult lifestyle risk factors score. In particular, consistent high intake of fruits and vegetables from childhood into adulthood seemed to be associated with lower arterial stiffness in adulthood, but these analyses were not corrected for potential confounding factors. ${ }^{162}$

In the Bogalusa Heart Study, consisting of up to seven repeated cross-sectional surveys in childhood/adolescence and in adulthood, childhood body mass index, systolic blood pressure, and HDL-cholesterol, but not LDL-cholesterol and triglycerides, were associated with higher brachial-ankle PWV obtained during the last measurement round (age range 24-44 years; mean age 36 years); when mutually adjusted for each other only systolic blood pressure remained a significant predictor of adult PWV. Similar results were obtained when the cumulative exposure to each of these risk factors from childhood into adulthood was investigated. ${ }^{188}$ 
Previous studies conducted within the Amsterdam Growth and Health Longitudinal Study, showed that cardiorespiratory fitness in adolescence was associated with lower carotid intima-media thickness in men and greater femoral diameter at the age of 36 years, but no associations were found for the carotid and femoral stiffness estimates in multivariable models. ${ }^{95}$ However, changes in cardiorespiratory fitness between adolescence and adulthood were associated with greater compliance of these two arteries at the age of 36 years, and part of these favourable associations could explain the positive association between changes in total habitual physical activity and femoral compliance. ${ }^{189}$ In addition, anthropometric measures of a central pattern of body fat distribution during adolescence, was independently associated with lower carotid distensibility and compliance at the age of 36 years. ${ }^{190}$

All in all, risk factors among the young are associated with arterial stiffness in adulthood, but the evidence has been mainly derived for biological risk factors, such as blood pressure and body fatness, but less so for lifestyle variables. In addition, thus far no study specifically investigated the trajectories of such risk factors throughout the course of young life, which, as discussed before, may yield important insights with regard to the prevention of CVD.

In fact, such traditional risk factors, as well inflammation, endothelial dysfunction, and insulin resistance, all of which are intertwined, may at least in part explain (i.e. mediate) any association between lifestyle behaviours and arterial stiffness. Indeed, each of these may be involved in the process of arterial stiffening, ${ }^{16,17,68,191,192}$ and be, to a varying extent, influenced by physical activity, ${ }^{23,193-195}$ sedentary behaviour, ${ }^{143,196-198}$ smoking, ${ }^{35,199}$ and dietary intake. ${ }^{200-204}$ Therefore, in this thesis we aimed also to comprehensively investigate the extent to which such biological variables may mediate any association between lifestyles and arterial stiffness.

\section{OUTLINE AND STUDY AIMS OF THIS THESIS}

The general aim of this thesis was to investigate the associations between lifestyle risk factors throughout the course of young life (i.e. from adolescence to adulthood) and arterial stiffness in adulthood. Each of the risk factors of interest were examined separately to assess its independent association with arterial stiffness, and understand specific critical periods and pathways through which these lifestyle risk factors may affect or prevent arterial stiffening. In addition, we aimed at gaining more insight into the pathobiological mechanisms that may explain any such associations (Figure 1.2).

To this end, we first determined to what extent the life-course trajectories and mean exposures to a set of biological risk factors, i.e. blood pressure, body fatness, blood lipids, and physical fitness, may affect arterial stiffness in young adults (Chapter 2). Thereafter, these biological risk factors were considered as potential mediators of 
any association between lifetime lifestyle risk factors and arterial stiffness at adult age.

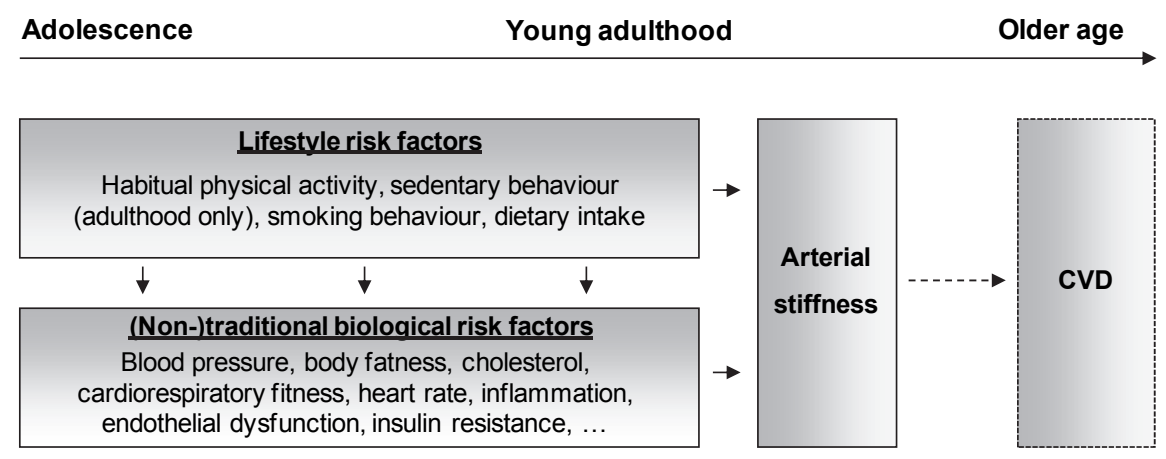

Figure 1.2 Conceptual framework of this thesis. The solid arrows are pathways investigated in this thesis.

Chapter 3 addresses the associations between physical activity and sedentary behaviour on the one hand and arterial stiffness on the other. Specifically, we investigated whether lifetime habitual physical activity (i.e. from adolescence to adulthood) of different intensities was associated with stiffness levels of the central (i.e. elastic) carotid artery (Chapter 3.1) and the peripheral (i.e. muscular) brachial and femoral arteries (Chapter 3.2) at the age of 36 years, and to what extent these could be explained by concomitant habitual physical activity-related associations with the biological risk factors. In addition, we investigated whether the time spent watching television, a predominant sedentary behaviour, was associated with arterial stiffness among young adults, and in particular whether any such association differed qualitatively from that of physical activity (Chapter 3.3).

In Chapter 4 we aimed at investigating the association between lifetime dietary intake in relation to arterial stiffness in young adults. Specifically, we investigated whether the consumption of fiber and fiber-rich foods (Chapter 4.1) and the adherence to the Mediterranean diet (Chapter 4.2) from adolescence up to adulthood was associated with stiffness of the carotid, brachial and femoral arteries in young adults, and, again, investigated to what extent these associations could be explained by traditional biological risk factors.

In Chapter 5 we investigated the potential impact of smoking behaviour in adolescence, and its changes from adolescence to adulthood, on arterial stiffness in young adults and determined whether any such association could be explained (i.e. mediated) by smoking-related levels of low-grade inflammation and/or endothelial dysfunction. 
Finally, in Chapter 6 the main findings of the studies presented in this thesis are summarized and discussed, and the public health implications and directions for future research are addressed.

\section{STUDY POPULATIONS}

The studies described in this thesis were conducted with data from two longitudinal cohort studies: the Amsterdam Growth and Health Longitudinal Study (AGAHLS; Chapters 2-4) and the Northern Ireland Young Hearts Project (NIYHP; Chapter 5).

The AGAHLS (Figure 1.3) is an ongoing study that started in 1977 with a group of approximately 600 boys and girls from two secondary schools in the Netherlands. Its initial goal was to describe the natural development of growth, health and lifestyle of adolescents and to investigate longitudinal relations between biological and lifestyle variables, as described in detail elsewhere. ${ }^{205}$ The mean age of the subjects at the beginning of the study was $13.1( \pm 0.8)$ years. Since then, measurements were obtained 2 to 8 times (i.e. at the ages of 13, 14, 15, 16, 21, 27, 32 and 36) during a 24-year follow-up period. At each measurement, anthropometrical, biological and lifestyle variables were assessed. In 2000, when subjects' mean age was 36.5 ( \pm 0.6 ) years, arterial properties of the carotid, brachial and femoral arteries were assessed for the first time in 377 subjects, ${ }^{95,206}$ complete arterial data were obtained for 373 subjects.

\section{Calendar age}

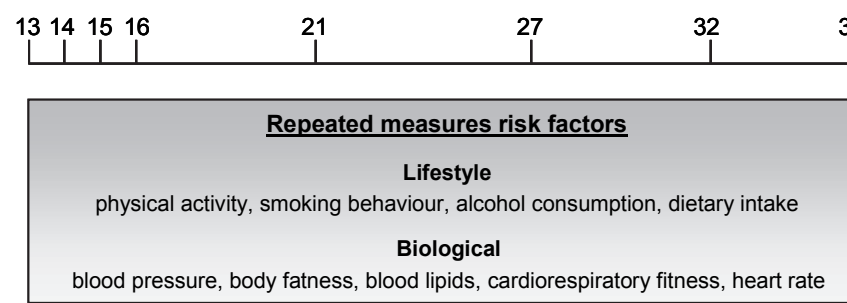

Arterial stiffness

$(n=373)$

\begin{tabular}{|c|c|c|c|c|}
\hline '80' 79' 78' 7 ' $^{\prime}$ & '85 & '91 & '96/'97 & ‘00 \\
\hline
\end{tabular}

Figure 1.3 Study design of the Amsterdam Growth and Health Longitudinal Study. 
The NIYHP (Figure 1.4) started in $1989 / 1990$ by sampling a $2 \%$ representative group of school children from Northern Ireland aged 12 and 15-years-old $(n=1015) .{ }^{207,208}$ In 1992/1993, the original cohort of 12 -year-old children (YH1) was reexamined at the age of 15 years under identical conditions (YH2), with complete data on 445 children. Between 1997 and 1999, all participants, then aged between 20 and 25 years (mean age $22.6 \pm 1.6$ years), were invited to participate in the third phase (YH3); 489 persons participated. Extensive information on both biological and lifestyle variables were ascertained at all three measurement rounds. Arterial stiffness, as assessed by means of PWV, and serum markers of inflammation and endothelial dysfunction, were assessed during the third screening phase only.

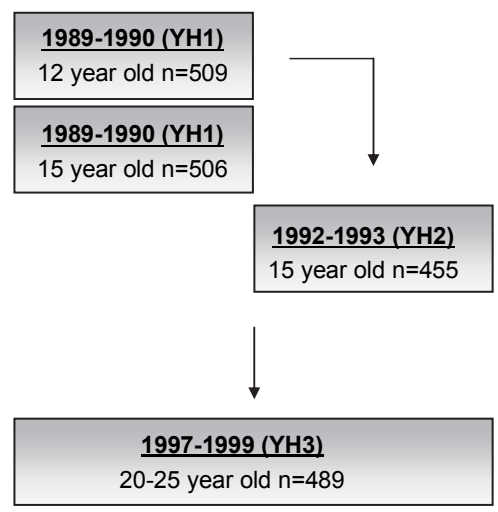

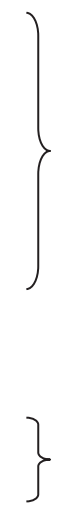

\section{Adolescence}

Lifestyle risk factors

Biological risk factors

\section{Adulthood}

As adolescence

Arterial stiffness (pulse wave velocity)

Inflammation \& endothelial dysfunction

Figure 1.4 Study design of the Northern Ireland Young Hearts Project. 


\section{REFERENCES}

1. Beaglehole R, Ebrahim S, Reddy S, Voute J, Leeder S. Prevention of chronic diseases: a call to action. Lancet. 2007;370:2152-2157.

2. Daar AS, Singer PA, Persad DL, et al. Grand challenges in chronic non-communicable diseases. Nature. 2007;450:494-496.

3. Yusuf S, Reddy S, Ounpuu S, Anand S. Global burden of cardiovascular diseases: part I: general considerations, the epidemiologic transition, risk factors, and impact of urbanization. Circulation. 2001;104:2746-2753.

4. Organization WH. http://www.who.int/mediacentre/factsheets/fs317/en/index.html. Accessed 30 November, 2011.

5. Statistiek CBvd. Doodsoorzaken. http://statline.cbs.nl/StatWeb/publication/?VW=T\&DM=SLNL\&PA= 7052 95\&D1=a\&D2=a\&D3=0\&D4=31,38-I\&HD=110413-1513\&HDR=G2,G1,G3\&STB=T. Accessed 30 November, 2011.

6. McGill HC, Jr., McMahan CA, Herderick EE, Malcom GT, Tracy RE, Strong JP. Origin of atherosclerosis in childhood and adolescence. Am J Clin Nutr. 2000;72:1307S-1315S.

7. Berenson GS, Srinivasan SR, Nicklas TA. Atherosclerosis: a nutritional disease of childhood. Am J Cardiol. 1998;82:22T-29T.

8. Berenson GS, Srinivasan SR, Bao W, Newman WP, 3rd, Tracy RE, Wattigney WA. Association between multiple cardiovascular risk factors and atherosclerosis in children and young adults. The Bogalusa Heart Study. N Engl J Med. 1998;338:1650-1656.

9. Celermajer DS, Ayer JG. Childhood risk factors for adult cardiovascular disease and primary prevention in childhood. Heart. 2006;92:1701-1706.

10. Reneman RS, Hoeks AP. Noninvasive vascular ultrasound: an asset in vascular medicine. Cardiovasc Res. 2000;45:27-35.

11. Cohn JN, Quyyumi AA, Hollenberg NK, Jamerson KA. Surrogate markers for cardiovascular disease: functional markers. Circulation. 2004;109:IV31-46.

12. Mancini GB, Dahlof B, Diez J. Surrogate markers for cardiovascular disease: structural markers. Circulation. 2004;109:IV22-30.

13. Bots ML, Dijk JM, Oren A, Grobbee DE. Carotid intima-media thickness, arterial stiffness and risk of cardiovascular disease: current evidence. J Hypertens. 2002;20:2317-2325.

14. de Graaf J, Holewijn S, Stalenhoef AF, Sniderman AD. Should preclinical vascular abnormalities be measured in asymptomatic adults to improve cardiovascular risk stratification? Curr Opin Lipidol. 2011;22:454-459.

15. Lakatta EG, Levy D. Arterial and cardiac aging: major shareholders in cardiovascular disease enterprises: Part I: aging arteries: a "set up" for vascular disease. Circulation. 2003;107:139-146.

16. Safar ME, O'Rourke MF, eds. Arterial Stiffness in Hypertension. Amsterdam: Elsevier; 2006. Birkenhäger WH, Reid JL, eds. Handbook of Hypertension; No. 23.

17. Laurent S, Cockcroft J, Van Bortel L, et al. Expert consensus document on arterial stiffness: methodological issues and clinical applications. Eur Heart J. 2006;27:2588-2605.

18. Mozaffarian D, Wilson PW, Kannel WB. Beyond established and novel risk factors: lifestyle risk factors for cardiovascular disease. Circulation. 2008;117:3031-3038.

19. Manson JE, Skerrett PJ, Greenland P, Vanltallie TB. The escalating pandemics of obesity and sedentary lifestyle. A call to action for clinicians. Arch Intern Med. 2004;164:249-258.

20. Ebbeling CB, Pawlak DB, Ludwig DS. Childhood obesity: public-health crisis, common sense cure. Lancet. 2002;360:473-482.

21. Wang $\mathrm{Y}$, Lobstein T. Worldwide trends in childhood overweight and obesity. Int J Pediatr Obes. 2006;1:11-25

22. Curbing the obesity epidemic. Lancet. 2006;367:1549.

23. Shephard RJ, Balady GJ. Exercise as cardiovascular therapy. Circulation. 1999;99:963-972.

24. Andersen LB, Harro M, Sardinha LB, et al. Physical activity and clustered cardiovascular risk in children: a cross-sectional study (The European Youth Heart Study). Lancet. 2006;368:299-304.

25. Bassuk SS, Manson JE. Epidemiological evidence for the role of physical activity in reducing risk of type 2 diabetes and cardiovascular disease. J Appl Physiol. 2005;99:1193-1204. 
26. Thompson PD, Buchner D, Pina IL, et al. Exercise and physical activity in the prevention and treatment of atherosclerotic cardiovascular disease: a statement from the Council on Clinical Cardiology (Subcommittee on Exercise, Rehabilitation, and Prevention) and the Council on Nutrition, Physical Activity, and Metabolism (Subcommittee on Physical Activity). Circulation. 2003;107:3109-3116.

27. Twisk JW, Ferreira I. Physical activity, physical fitness and cardiovascular health. In: Armstrong N, Van Mechelen W, eds. Paediatric Exercise Science and Medicine. 2nd ed. Oxford: Oxford University Press; 2008:339-352.

28. Fung TT, Chiuve SE, McCullough ML, Rexrode KM, Logroscino G, Hu FB. Adherence to a DASH-style diet and risk of coronary heart disease and stroke in women. Arch Intern Med. 2008;168:713-720.

29. He FJ, Nowson CA, MacGregor GA. Fruit and vegetable consumption and stroke: meta-analysis of cohort studies. Lancet. 2006;367:320-326.

30. Trichopoulou A, Costacou T, Bamia C, Trichopoulos D. Adherence to a Mediterranean diet and survival in a Greek population. N Engl J Med. 2003;348:2599-2608.

31. Ness AR, Powles JW. Fruit and vegetables, and cardiovascular disease: a review. Int J Epidemiol. 1997;26:1-13.

32. Mente A, de Koning L, Shannon HS, Anand SS. A systematic review of the evidence supporting a causal link between dietary factors and coronary heart disease. Arch Intern Med. 2009;169:659-669.

33. Hu FB, Rimm EB, Stampfer MJ, Ascherio A, Spiegelman D, Willett WC. Prospective study of major dietary patterns and risk of coronary heart disease in men. Am J Clin Nutr. 2000;72:912-921.

34. Doll R, Peto R, Boreham J, Sutherland I. Mortality in relation to smoking: 50 years' observations on male British doctors. BMJ. 2004;328:1519.

35. Ambrose JA, Barua RS. The pathophysiology of cigarette smoking and cardiovascular disease: an update. J Am Coll Cardiol. 2004;43:1731-1737.

36. Critchley JA, Capewell S. Mortality risk reduction associated with smoking cessation in patients with coronary heart disease: a systematic review. JAMA. 2003;290:86-97.

37. Edwards R. The problem of tobacco smoking. BMJ. 2004;328:217-219.

38. Stampfer MJ, Hu FB, Manson JE, Rimm EB, Willett WC. Primary prevention of coronary heart disease in women through diet and lifestyle. N Engl J Med. 2000;343:16-22.

39. Chiuve SE, McCullough ML, Sacks FM, Rimm EB. Healthy lifestyle factors in the primary prevention of coronary heart disease among men: benefits among users and nonusers of lipid-lowering and antihypertensive medications. Circulation. 2006;114:160-167.

40. Kurth T, Moore SC, Gaziano JM, et al. Healthy lifestyle and the risk of stroke in women. Arch Intern Med. 2006;166:1403-1409.

41. Chiuve SE, Rexrode KM, Spiegelman D, Logroscino G, Manson JE, Rimm EB. Primary prevention of stroke by healthy lifestyle. Circulation. 2008;118:947-954.

42. Khaw KT, Wareham N, Bingham S, Welch A, Luben R, Day N. Combined impact of health behaviours and mortality in men and women: the EPIC-Norfolk prospective population study. PLoS Med. 2008;5:e12.

43. Knoops KT, de Groot LC, Kromhout D, et al. Mediterranean diet, lifestyle factors, and 10-year mortality in elderly European men and women: the HALE project. JAMA. 2004;292:1433-1439.

44. van Dam RM, Li T, Spiegelman D, Franco OH, Hu FB. Combined impact of lifestyle factors on mortality: prospective cohort study in US women. BMJ. 2008;337:a1440.

45. Kuh D, Ben-Shlomo Y. A Life Course Approach To Chronic Disease Epidemiology. 2nd ed. New York: Oxford University Press Inc.; 2004.

46. Kelder SH, Perry CL, Klepp KI, Lytle LL. Longitudinal tracking of adolescent smoking, physical activity, and food choice behaviors. Am J Public Health. 1994;84:1121-1126.

47. te Velde SJ, Twisk JW, Brug J. Tracking of fruit and vegetable consumption from adolescence into adulthood and its longitudinal association with overweight. Br J Nutr. 2007;98:431-438.

48. DeWit DJ, Adlaf EM, Offord DR, Ogborne AC. Age at first alcohol use: a risk factor for the development of alcohol disorders. Am J Psychiatry. 2000;157:745-750

49. Pierce JP, Gilpin E. How long will today's new adolescent smoker be addicted to cigarettes? $\mathrm{Am} J$ Public Health. 1996;86:253-256.

50. Twisk JW, Kemper HC, van Mechelen W, Post GB. Tracking of risk factors for coronary heart disease over a 14-year period: a comparison between lifestyle and biologic risk factors with data from the Amsterdam Growth and Health Study. Am J Epidemiol. 1997;145:888-898. 
51. Birch LL. Development of food preferences. Annu Rev Nutr. 1999;19:41-62.

52. Kuh D, Ben-Shlomo Y, Lynch J, Hallqvist J, Power C. Life course epidemiology. J Epidemiol Community Health. 2003;57:778-783.

53. Greenwald SE. Ageing of the conduit arteries. J Pathol. 2007;211:157-172.

54. Gosling RG, Budge MM. Terminology for describing the elastic behavior of arteries. Hypertension. 2003;41:1180-1182.

55. O'Rourke MF, Nichols WW. McDonald's Blood Flow in Arteries: Theoretical, Experimental and Clinical Principles. 6th ed. New York: Oxford University Press Inc.; 2005.

56. Widlansky ME, Gokce N, Keaney JF, Jr., Vita JA. The clinical implications of endothelial dysfunction. J Am Coll Cardiol. 2003;42:1149-1160.

57. Safar ME, Levy BI, Struijker-Boudier H. Current perspectives on arterial stiffness and pulse pressure in hypertension and cardiovascular diseases. Circulation. 2003;107:2864-2869.

58. Benetos A, Laurent S, Hoeks AP, Boutouyrie PH, Safar ME. Arterial alterations with aging and high blood pressure. A noninvasive study of carotid and femoral arteries. Arterioscler Thromb. 1993;13: 90-97.

59. Bortolotto LA, Hanon O, Franconi G, Boutouyrie P, Legrain S, Girerd X. The aging process modifies the distensibility of elastic but not muscular arteries. Hypertension. 1999;34:889-892.

60. Vermeersch SJ, Rietzschel ER, De Buyzere ML, et al. Age and gender related patterns in carotidfemoral PWV and carotid and femoral stiffness in a large healthy, middle-aged population. $J$ Hypertens. 2008;26:1411-1419.

61. van der Heijden-Spek JJ, Staessen JA, Fagard RH, Hoeks AP, Boudier HA, van Bortel LM. Effect of age on brachial artery wall properties differs from the aorta and is gender dependent: a population study. Hypertension. 2000;35:637-642.

62. Reneman RS, Meinders JM, Hoeks AP. Non-invasive ultrasound in arterial wall dynamics in humans: what have we learned and what remains to be solved. Eur Heart J. 2005;26:960-966.

63. Segers $P$, Verdonck $P$. Role of tapering in aortic wave reflection: hydraulic and mathematical model study. J Biomech. 2000;33:299-306.

64. Wilkinson IB, Franklin SS, Hall IR, Tyrrell S, Cockcroft JR. Pressure amplification explains why pulse pressure is unrelated to risk in young subjects. Hypertension. 2001;38:1461-1466.

65. Avolio AP, Van Bortel LM, Boutouyrie $P$, et al. Role of pulse pressure amplification in arterial hypertension: experts' opinion and review of the data. Hypertension. 2009;54:375-383.

66. Zieman SJ, Melenovsky V, Kass DA. Mechanisms, pathophysiology, and therapy of arterial stiffness. Arterioscler Thromb Vasc Biol. 2005;25:932-943.

67. O'Rourke MF, Hashimoto J. Mechanical factors in arterial aging: a clinical perspective. J Am Coll Cardiol. 2007;50:1-13.

68. Stehouwer CD, Henry RM, Ferreira I. Arterial stiffness in diabetes and the metabolic syndrome: a pathway to cardiovascular disease. Diabetologia. 2008;51:527-539.

69. Willum-Hansen T, Staessen JA, Torp-Pedersen C, et al. Prognostic value of aortic pulse wave velocity as index of arterial stiffness in the general population. Circulation. 2006;113:664-670.

70. Sutton-Tyrrell K, Najjar SS, Boudreau RM, et al. Elevated aortic pulse wave velocity, a marker of arterial stiffness, predicts cardiovascular events in well-functioning older adults. Circulation. 2005;111:3384-3390.

71. Stefanadis C, Dernellis J, Tsiamis E, et al. Aortic stiffness as a risk factor for recurrent acute coronary events in patients with ischaemic heart disease. Eur Heart J. 2000;21:390-396.

72. Mattace-Raso FU, van der Cammen TJ, Hofman A, et al. Arterial stiffness and risk of coronary heart disease and stroke: the Rotterdam Study. Circulation. 2006;113:657-663.

73. Laurent S, Katsahian S, Fassot C, et al. Aortic stiffness is an independent predictor of fatal stroke in essential hypertension. Stroke. 2003;34:1203-1206.

74. Dijk JM, Algra A, van der Graaf Y, Grobbee DE, Bots ML. Carotid stiffness and the risk of new vascular events in patients with manifest cardiovascular disease. The SMART study. Eur Heart J. 2005;26: 1213-1220.

75. Boutouyrie P, Tropeano Al, Asmar R, et al. Aortic stiffness is an independent predictor of primary coronary events in hypertensive patients: a longitudinal study. Hypertension. 2002;39:10-15.

76. Barenbrock M, Kosch M, Joster E, Kisters K, Rahn KH, Hausberg M. Reduced arterial distensibility is a predictor of cardiovascular disease in patients after renal transplantation. J Hypertens. 2002;20:79-84. 
77. Yang EY, Chambless L, Sharrett AR, et al. Carotid Arterial Wall Characteristics Are Associated With Incident Ischemic Stroke But Not Coronary Heart Disease in the Atherosclerosis Risk in Communities (ARIC) Study. Stroke. 2012;43:103-108.

78. Shoji T, Emoto M, Shinohara K, et al. Diabetes mellitus, aortic stiffness, and cardiovascular mortality in end-stage renal disease. J Am Soc Nephrol. 2001;12:2117-2124.

79. Pannier B, Guerin AP, Marchais SJ, Safar ME, London GM. Stiffness of capacitive and conduit arteries: prognostic significance for end-stage renal disease patients. Hypertension. 2005;45:592-596.

80. Meaume S, Benetos A, Henry OF, Rudnichi A, Safar ME. Aortic pulse wave velocity predicts cardiovascular mortality in subjects $>70$ years of age. Arterioscler Thromb Vasc Biol. 2001;21: 2046-2050.

81. Laurent S, Boutouyrie $\mathrm{P}, \mathrm{Asmar} \mathrm{R}$, et al. Aortic stiffness is an independent predictor of all-cause and cardiovascular mortality in hypertensive patients. Hypertension. 2001;37:1236-1241.

82. Cruickshank K, Riste L, Anderson SG, Wright JS, Dunn G, Gosling RG. Aortic pulse-wave velocity and its relationship to mortality in diabetes and glucose intolerance: an integrated index of vascular function? Circulation. 2002;106:2085-2090.

83. Blacher J, Pannier B, Guerin AP, Marchais SJ, Safar ME, London GM. Carotid arterial stiffness as a predictor of cardiovascular and all-cause mortality in end-stage renal disease. Hypertension. 1998;32:570-574.

84. Blacher J, Guerin AP, Pannier B, Marchais SJ, Safar ME, London GM. Impact of aortic stiffness on survival in end-stage renal disease. Circulation. 1999;99:2434-2439.

85. de Simone G, Roman MJ, Koren MJ, Mensah GA, Ganau A, Devereux RB. Stroke volume/pulse pressure ratio and cardiovascular risk in arterial hypertension. Hypertension. 1999;33:800-805.

86. Cohn JN, Finkelstein S, McVeigh G, et al. Noninvasive pulse wave analysis for the early detection of vascular disease. Hypertension. 1995;26:503-508.

87. Duprez DA, De Buyzere ML, Rietzschel ER, et al. Inverse relationship between aldosterone and large artery compliance in chronically treated heart failure patients. Eur Heart J. 1998;19:1371-1376.

88. Bertovic DA, Waddell TK, Gatzka CD, Cameron JD, Dart AM, Kingwell BA. Muscular strength training is associated with low arterial compliance and high pulse pressure. Hypertension. 1999;33:1385-1391.

89. Kingwell BA, Berry KL, Cameron JD, Jennings GL, Dart AM. Arterial compliance increases after moderate-intensity cycling. Am J Physiol. 1997;273:H2186-2191.

90. O'Rourke MF, Pauca A, Jiang XJ. Pulse wave analysis. Br J Clin Pharmacol. 2001;51:507-522.

91. O'Rourke MF, Staessen JA, Vlachopoulos C, Duprez D, Plante GE. Clinical applications of arterial stiffness; definitions and reference values. Am J Hypertens. 2002;15:426-444.

92. Van Bortel LM, Duprez D, Starmans-Kool MJ, et al. Clinical applications of arterial stiffness, Task Force III: recommendations for user procedures. Am J Hypertens. 2002;15:445-452.

93. Oliver JJ, Webb DJ. Noninvasive assessment of arterial stiffness and risk of atherosclerotic events. Arterioscler Thromb Vasc Biol. 2003;23:554-566.

94. Mackenzie IS, Wilkinson IB, Cockcroft JR. Assessment of arterial stiffness in clinical practice. QJM. 2002;95:67-74.

95. Ferreira I, Twisk JW, Van Mechelen W, Kemper HC, Stehouwer CD. Current and adolescent levels of cardiopulmonary fitness are related to large artery properties at age 36: the Amsterdam Growth and Health Longitudinal Study. Eur J Clin Invest. 2002;32:723-731.

96. Van Bortel LM, Balkestein EJ, van der Heijden-Spek JJ, et al. Non-invasive assessment of local arterial pulse pressure: comparison of applanation tonometry and echo-tracking. J Hypertens. 2001;19: 1037-1044.

97. Kips J, Vanmolkot F, Mahieu D, et al. The use of diameter distension waveforms as an alternative for tonometric pressure to assess carotid blood pressure. Physiol Meas. 2010;31:543-553.

98. Tanaka H, Safar ME. Influence of lifestyle modification on arterial stiffness and wave reflections. Am J Hypertens. 2005;18:137-144.

99. Boreham CA, Ferreira I, Twisk JW, Gallagher AM, Savage MJ, Murray U. Cardiorespiratory fitness, physical activity, and arterial stiffness: the Northern Ireland Young Hearts Project. Hypertension. 2004;44:721-726.

100. Erol MK, Yilmaz M, Oztasyonar Y, Sevimli S, Senocak H. Aortic distensibility is increasing in elite athletes. Am J Cardiol. 2002;89:1002-1004. 
101. Gates PE, Tanaka H, Graves J, Seals DR. Left ventricular structure and diastolic function with human ageing. Relation to habitual exercise and arterial stiffness. Eur Heart J. 2003;24:2213-2220.

102. Giannattasio C, Failla M, Grappiolo A, et al. Effects of physical training of the dominant arm on ipsilateral radial artery distensibility and structure. J Hypertens. 2001;19:71-77.

103. Heffernan KS, Jae SY, Tomayko E, Ishaque MR, Fernhall B, Wilund KR. Influence of arterial wave reflection on carotid blood pressure and intima-media thickness in older endurance trained men and women with pre-hypertension. Clin Physiol Funct Imaging. 2009;29:193-200.

104. Kasikcioglu E, Kayserilioglu A, Oflaz H, Akhan H. Aortic distensibility and left ventricular diastolic functions in endurance athletes. Int J Sports Med. 2005;26:165-170.

105. Kozakova M, Palombo C, Mhamdi L, et al. Habitual physical activity and vascular aging in a young to middle-age population at low cardiovascular risk. Stroke. 2007;38:2549-2555.

106. Monahan KD, Tanaka H, Dinenno FA, Seals DR. Central arterial compliance is associated with age- and habitual exercise-related differences in cardiovagal baroreflex sensitivity. Circulation. 2001;104: 1627-1632.

107. Schmidt-Trucksass A, Schmid A, Brunner C, et al. Arterial properties of the carotid and femoral artery in endurance-trained and paraplegic subjects. J Appl Physiol. 2000;89:1956-1963.

108. Schmidt-Trucksass AS, Grathwohl D, Frey I, et al. Relation of leisure-time physical activity to structural and functional arterial properties of the common carotid artery in male subjects. Atherosclerosis. 1999;145:107-114.

109. Schmitz KH, Arnett DK, Bank A, et al. Arterial distensibility and physical activity in the ARIC study. Med Sci Sports Exerc. 2001;33:2065-2071.

110. Sugawara J, Otsuki T, Tanabe T, Hayashi K, Maeda S, Matsuda M. Physical activity duration, intensity, and arterial stiffening in postmenopausal women. Am J Hypertens. 2006;19:1032-1036.

111. Tanaka H, Dinenno FA, Monahan KD, Clevenger CM, DeSouza CA, Seals DR. Aging, habitual exercise, and dynamic arterial compliance. Circulation. 2000;102:1270-1275.

112. Vaitkevicius PV, Fleg JL, Engel JH, et al. Effects of age and aerobic capacity on arterial stiffness in healthy adults. Circulation. 1993;88:1456-1462.

113. Wijnen JA, Kuipers $\mathrm{H}$, Kool MJ, et al. Vessel wall properties of large arteries in trained and sedentary subjects. Basic Res Cardiol. 1991;86 Suppl 1:25-29.

114. Naka KK, Tweddel AC, Parthimos D, Henderson A, Goodfellow J, Frenneaux MP. Arterial distensibility: acute changes following dynamic exercise in normal subjects. Am J Physiol Heart Circ Physiol. 2003;284:H970-978.

115. Sugawara J, Otsuki T, Tanabe $T$, et al. The effects of low-intensity single-leg exercise on regional arterial stiffness. Jpn J Physiol. 2003;53:239-241.

116. Currie KD, Thomas SG, Goodman JM. Effects of short-term endurance exercise training on vascular function in young males. Eur J Appl Physiol. 2009;107:211-218.

117. Cameron JD, Dart AM. Exercise training increases total systemic arterial compliance in humans. Am J Physiol. 1994;266:H693-701.

118. Edwards DG, Schofield RS, Magyari PM, Nichols WW, Braith RW. Effect of exercise training on central aortic pressure wave reflection in coronary artery disease. Am J Hypertens. 2004;17:540-543.

119. Hayashi K, Sugawara J, Komine H, Maeda S, Yokoi T. Effects of aerobic exercise training on the stiffness of central and peripheral arteries in middle-aged sedentary men. Jpn J Physiol. 2005;55: 235-239.

120. Kakiyama T, Sugawara J, Murakami H, Maeda S, Kuno S, Matsuda M. Effects of short-term endurance training on aortic distensibility in young males. Med Sci Sports Exerc. 2005;37:267-271.

121. Madden KM, Lockhart C, Cuff D, Potter TF, Meneilly GS. Short-term Aerobic Exercise Reduces Arterial Stiffness in Older Adults with Type 2 Diabetes, Hypertension and Hypercholesterolemia. Diabetes Care. 2009;

122. Moreau KL, Donato AJ, Seals DR, DeSouza CA, Tanaka H. Regular exercise, hormone replacement therapy and the age-related decline in carotid arterial compliance in healthy women. Cardiovasc Res. 2003;57:861-868.

123. Westhoff TH, Schmidt S, Gross V, et al. The cardiovascular effects of upper-limb aerobic exercise in hypertensive patients. J Hypertens. 2008;26:1336-1342.

124. Yokoyama $H$, Emoto $M$, Fujiwara $S$, et al. Short-term aerobic exercise improves arterial stiffness in type 2 diabetes. Diabetes Res Clin Pract. 2004;65:85-93. 
125. Parnell MM, Holst DP, Kaye DM. Exercise training increases arterial compliance in patients with congestive heart failure. Clin Sci (Lond). 2002;102:1-7.

126. Sakuragi S, Abhayaratna K, Gravenmaker KJ, et al. Influence of adiposity and physical activity on arterial stiffness in healthy children: the lifestyle of our kids study. Hypertension. 2009;53:611-616.

127. Seals DR, Tanaka $H$, Clevenger $C M$, et al. Blood pressure reductions with exercise and sodium restriction in postmenopausal women with elevated systolic pressure: role of arterial stiffness. J Am Coll Cardiol. 2001;38:506-513.

128. Tanaka H, DeSouza CA, Seals DR. Absence of age-related increase in central arterial stiffness in physically active women. Arterioscler Thromb Vasc Biol. 1998;18:127-132.

129. Wijnen JA, Kool MJ, Kooman JP, et al. Vessel wall properties of large arteries and endurance training. J Hypertens Suppl. 1993;11:S88-89.

130. Ferrier KE, Waddell TK, Gatzka CD, Cameron JD, Dart AM, Kingwell BA. Aerobic exercise training does not modify large-artery compliance in isolated systolic hypertension. Hypertension. 2001;38:222-226.

131. MacDougall JD, Tuxen D, Sale DG, Moroz JR, Sutton JR. Arterial blood pressure response to heavy resistance exercise. J Appl Physiol. 1985;58:785-790.

132. Kawano $\mathrm{H}$, Tanimoto $\mathrm{M}$, Yamamoto $\mathrm{K}$, et al. Resistance training in men is associated with increased arterial stiffness and blood pressure but does not adversely affect endothelial function as measured by arterial reactivity to the cold pressor test. Exp Physiol. 2008;93:296-302.

133. Miyachi $\mathrm{M}$, Donato AJ, Yamamoto $\mathrm{K}$, et al. Greater age-related reductions in central arterial compliance in resistance-trained men. Hypertension. 2003;41:130-135.

134. DeVan AE, Anton MM, Cook JN, Neidre DB, Cortez-Cooper MY, Tanaka H. Acute effects of resistance exercise on arterial compliance. J Appl Physiol. 2005;98:2287-2291.

135. Heffernan KS, Rossow L, Jae SY, Shokunbi HG, Gibson EM, Fernhall B. Effect of single-leg resistance exercise on regional arterial stiffness. Eur J Appl Physiol. 2006;98:185-190.

136. Miyachi $\mathrm{M}$, Kawano $\mathrm{H}$, Sugawara J, et al. Unfavorable effects of resistance training on central arterial compliance: a randomized intervention study. Circulation. 2004;110:2858-2863.

137. Cortez-Cooper MY, DeVan AE, Anton MM, et al. Effects of high intensity resistance training on arterial stiffness and wave reflection in women. Am J Hypertens. 2005;18:930-934.

138. Okamoto $\mathrm{T}$, Masuhara M, Ikuta K. Effects of eccentric and concentric resistance training on arterial stiffness. J Hum Hypertens. 2006;20:348-354.

139. Casey DP, Beck DT, Braith RW. Progressive resistance training without volume increases does not alter arterial stiffness and aortic wave reflection. Exp Biol Med (Maywood). 2007;232:1228-1235.

140. Petersen SE, Wiesmann F, Hudsmith LE, et al. Functional and structural vascular remodeling in elite rowers assessed by cardiovascular magnetic resonance. J Am Coll Cardiol. 2006;48:790-797.

141. Cook JN, DeVan AE, Schleifer JL, Anton MM, Cortez-Cooper MY, Tanaka H. Arterial compliance of rowers: implications for combined aerobic and strength training on arterial elasticity. Am J Physiol Heart Circ Physiol. 2006;290:H1596-1600.

142. Dunstan DW, Salmon J, Owen N, et al. Associations of TV viewing and physical activity with the metabolic syndrome in Australian adults. Diabetologia. 2005;48:2254-2261.

143. Hamilton MT, Hamilton DG, Zderic TW. Role of low energy expenditure and sitting in obesity, metabolic syndrome, type 2 diabetes, and cardiovascular disease. Diabetes. 2007;56:2655-2667.

144. Hancox RJ, Milne BJ, Poulton R. Association between child and adolescent television viewing and adult health: a longitudinal birth cohort study. Lancet. 2004;364:257-262.

145. Biddle SJ. Sedentary behavior. Am J Prev Med. 2007;33:502-504.

146. Demirovic J, Nabulsi A, Folsom AR, et al. Alcohol consumption and ultrasonographically assessed carotid artery wall thickness and distensibility. The Atherosclerosis Risk in Communities (ARIC) Study Investigators. Circulation. 1993;88:2787-2793.

147. Mattace-Raso FU, van der Cammen TJ, van den Elzen AP, et al. Moderate alcohol consumption is associated with reduced arterial stiffness in older adults: the Rotterdam study. J Gerontol A Biol Sci Med Sci. 2005;60:1479-1483.

148. Mahmud A, Feely J. Divergent effect of acute and chronic alcohol on arterial stiffness. Am J Hypertens. 2002;15:240-243.

149. Sierksma A, Lebrun CE, van der Schouw YT, et al. Alcohol consumption in relation to aortic stiffness and aortic wave reflections: a cross-sectional study in healthy postmenopausal women. Arterioscler Thromb Vasc Biol. 2004;24:342-348. 
150. Sierksma A, Muller M, van der Schouw YT, Grobbee DE, Hendriks HF, Bots ML. Alcohol consumption and arterial stiffness in men. $J$ Hypertens. 2004;22:357-362.

151. Hougaku H, Fleg JL, Lakatta EG, et al. Effect of light-to-moderate alcohol consumption on ageassociated arterial stiffening. Am J Cardiol. 2005;95:1006-1010.

152. van Trijp MJ, Bos WJ, van der Schouw YT, Muller M, Grobbee DE, Bots ML. Alcohol and arterial wave reflections in middle aged and elderly men. Eur J Clin Invest. 2005;35:615-621.

153. Kurihara $\mathrm{T}$, Tomiyama $\mathrm{H}$, Hashimoto $\mathrm{H}$, Yamamoto $\mathrm{Y}$, Yano $\mathrm{E}$, Yamashina A. Excessive alcohol intake increases the risk of arterial stiffening in men with normal blood pressure. Hypertens Res. 2004;27:669-673.

154. van Trijp MJ, Beulens JW, Bos WJ, et al. Alcohol consumption and augmentation index in healthy young men: the ARYA study. Am J Hypertens. 2005;18:792-796.

155. Karatzi KN, Papamichael CM, Karatzis EN, et al. Red wine acutely induces favorable effects on wave reflections and central pressures in coronary artery disease patients. Am J Hypertens. 2005;18: 1161-1167.

156. Pase MP, Grima NA, Sarris J. The effects of dietary and nutrient interventions on arterial stiffness: a systematic review. Am J Clin Nutr. 2011;93:446-454.

157. He FJ, Marciniak M, Visagie E, et al. Effect of modest salt reduction on blood pressure, urinary albumin, and pulse wave velocity in white, black, and Asian mild hypertensives. Hypertension. 2009;54:482-488.

158. Gates PE, Tanaka H, Hiatt WR, Seals DR. Dietary sodium restriction rapidly improves large elastic artery compliance in older adults with systolic hypertension. Hypertension. 2004;44:35-41.

159. Mahmud A, Feely J. Acute effect of caffeine on arterial stiffness and aortic pressure waveform. Hypertension. 2001;38:227-231.

160. Vlachopoulos C, Hirata K, O'Rourke MF. Effect of caffeine on aortic elastic properties and wave reflection. J Hypertens. 2003;21:563-570.

161. Vlachopoulos C, Panagiotakos D, loakeimidis N, Dima I, Stefanadis C. Chronic coffee consumption has a detrimental effect on aortic stiffness and wave reflections. Am J Clin Nutr. 2005;81:1307-1312.

162. Aatola $\mathrm{H}$, Koivistoinen $\mathrm{T}$, Hutri-Kahonen $\mathrm{N}$, et al. Lifetime fruit and vegetable consumption and arterial pulse wave velocity in adulthood: the Cardiovascular Risk in Young Finns Study. Circulation. 2010;122:2521-2528.

163. Kesse-Guyot E, Vergnaud AC, Fezeu L, et al. Associations between dietary patterns and arterial stiffness, carotid artery intima-media thickness and atherosclerosis. Eur J Cardiovasc Prev Rehabil. 2010;17:718-724.

164. Jacobs DR, Jr., Tapsell LC. Food, not nutrients, is the fundamental unit in nutrition. Nutr Rev. 2007;65:439-450.

165. Hu FB. Dietary pattern analysis: a new direction in nutritional epidemiology. Curr Opin Lipidol. 2002;13:3-9.

166. Failla M, Grappiolo A, Carugo S, Calchera I, Giannattasio C, Mancia G. Effects of cigarette smoking on carotid and radial artery distensibility. J Hypertens. 1997;15:1659-1664.

167. Mahmud A, Feely J. Effect of smoking on arterial stiffness and pulse pressure amplification. Hypertension. 2003;41:183-187.

168. Stefanadis C, Tsiamis E, Vlachopoulos C, et al. Unfavorable effect of smoking on the elastic properties of the human aorta. Circulation. 1997;95:31-38.

169. Jatoi NA, Jerrard-Dunne P, Feely J, Mahmud A. Impact of smoking and smoking cessation on arterial stiffness and aortic wave reflection in hypertension. Hypertension. 2007;49:981-985.

170. Liang YL, Shiel LM, Teede H, et al. Effects of Blood Pressure, Smoking, and Their Interaction on Carotid Artery Structure and Function. Hypertension. 2001;37:6-11.

171. Wiesmann F, Petersen SE, Leeson PM, et al. Global impairment of brachial, carotid, and aortic vascular function in young smokers: direct quantification by high-resolution magnetic resonance imaging. J Am Coll Cardiol. 2004;44:2056-2064.

172. Tomiyama $\mathrm{H}$, Hashimoto $\mathrm{H}$, Tanaka $\mathrm{H}$, et al. Continuous smoking and progression of arterial stiffening: a prospective study. J Am Coll Cardiol. 2010;55:1979-1987.

173. Kool MJ, Hoeks AP, Struijker Boudier HA, Reneman RS, Van Bortel LM. Short- and long-term effects of smoking on arterial wall properties in habitual smokers. J Am Coll Cardiol. 1993;22:1881-1886. 
174. van der Berkmortel FW, Wollersheim H, van Langam H, de Boo T, Thien T. Dynamic vessel wall properties of large conduit arteries in habitual cigarette smokers. European Journal of Internal Medicine. 1999;10:159-165.

175. Yufu K, Takahashi N, Hara M, Saikawa T, Yoshimatsu H. Measurement of the brachial-ankle pulse wave velocity and flow-mediated dilatation in young, healthy smokers. Hypertens Res. 2007;30: 607-612.

176. Rehill N, Beck CR, Yeo KR, Yeo WW. The effect of chronic tobacco smoking on arterial stiffness. Br J Clin Pharmacol. 2006;61:767-773.

177. Li H, Srinivasan SR, Berenson GS. Comparison of the measures of pulsatile arterial function between asymptomatic younger adult smokers and former smokers: the Bogalusa Heart Study. Am J Hypertens. 2006;19:897-901.

178. Atabek ME, Kurtoglu S, Pirgon O, Baykara M. Arterial wall thickening and stiffening in children and adolescents with type 1 diabetes. Diabetes Res Clin Pract. 2006;74:33-40.

179. Parikh A, Sochett EB, McCrindle BW, Dipchand A, Daneman A, Daneman D. Carotid artery distensibility and cardiac function in adolescents with type 1 diabetes. J Pediatr. 2000;137:465-469.

180. Aggoun Y, Bonnet D, Sidi D, et al. Arterial mechanical changes in children with familial hypercholesterolemia. Arterioscler Thromb Vasc Biol. 2000;20:2070-2075.

181. Iannuzzi A, Licenziati MR, Acampora C, et al. Increased carotid intima-media thickness and stiffness in obese children. Diabetes Care. 2004;27:2506-2508.

182. Litwin M, Trelewicz J, Wawer Z, et al. Intima-media thickness and arterial elasticity in hypertensive children: controlled study. Pediatr Nephrol. 2004;19:767-774.

183. Leeson CP, Whincup PH, Cook DG, et al. Cholesterol and arterial distensibility in the first decade of life: a population-based study. Circulation. 2000;101:1533-1538.

184. Whincup PH, Gilg JA, Donald AE, et al. Arterial distensibility in adolescents: the influence of adiposity, the metabolic syndrome, and classic risk factors. Circulation. 2005;112:1789-1797.

185. Singhal A, Farooqi IS, Cole TJ, et al. Influence of leptin on arterial distensibility: a novel link between obesity and cardiovascular disease? Circulation. 2002;106:1919-1924.

186. Juonala M, Jarvisalo MJ, Maki-Torkko N, Kahonen M, Viikari JS, Raitakari OT. Risk factors identified in childhood and decreased carotid artery elasticity in adulthood: the Cardiovascular Risk in Young Finns Study. Circulation. 2005;112:1486-1493.

187. Juonala M, Viikari JS, Ronnemaa $\mathrm{T}$, et al. Associations of dyslipidemias from childhood to adulthood with carotid intima-media thickness, elasticity, and brachial flow-mediated dilatation in adulthood: the Cardiovascular Risk in Young Finns Study. Arterioscler Thromb Vasc Biol. 2008;28:1012-1017.

188. Li S, Chen W, Srinivasan SR, Berenson GS. Childhood blood pressure as a predictor of arterial stiffness in young adults: the bogalusa heart study. Hypertension. 2004;43:541-546.

189. Ferreira I, Twisk JW, Stehouwer CD, van Mechelen W, Kemper HC. Longitudinal changes in .VO2max: associations with carotid IMT and arterial stiffness. Med Sci Sports Exerc. 2003;35:1670-1678.

190. Ferreira I, Twisk JW, van Mechelen W, Kemper HC, Seidell JC, Stehouwer CD. Current and adolescent body fatness and fat distribution: relationships with carotid intima-media thickness and large artery stiffness at the age of 36 years. J Hypertens. 2004;22:145-155.

191. McEniery CM, Wallace S, Mackenzie IS, et al. Endothelial function is associated with pulse pressure, pulse wave velocity, and augmentation index in healthy humans. Hypertension. 2006;48:602-608.

192. Yasmin, McEniery CM, Wallace S, Mackenzie IS, Cockcroft JR, Wilkinson IB. C-reactive protein is associated with arterial stiffness in apparently healthy individuals. Arterioscler Thromb Vasc Biol. 2004;24:969-974.

193. Abramson JL, Vaccarino V. Relationship between physical activity and inflammation among apparently healthy middle-aged and older US adults. Arch Intern Med. 2002;162:1286-1292.

194. Gill JM, Malkova D. Physical activity, fitness and cardiovascular disease risk in adults: interactions with insulin resistance and obesity. Clin Sci (Lond). 2006;110:409-425.

195. Laughlin $\mathrm{MH}$, Newcomer SC, Bender SB. Importance of hemodynamic forces as signals for exerciseinduced changes in endothelial cell phenotype. J Appl Physiol. 2008;104:588-600.

196. Jakes RW, Day NE, Khaw KT, et al. Television viewing and low participation in vigorous recreation are independently associated with obesity and markers of cardiovascular disease risk: EPIC-Norfolk population-based study. Eur J Clin Nutr. 2003;57:1089-1096. 
197. Healy GN, Dunstan DW, Salmon J, Shaw JE, Zimmet PZ, Owen N. Television time and continuous metabolic risk in physically active adults. Med Sci Sports Exerc. 2008;40:639-645.

198. Hu FB, Li TY, Colditz GA, Willett WC, Manson JE. Television watching and other sedentary behaviors in relation to risk of obesity and type 2 diabetes mellitus in women. JAMA. 2003;289:1785-1791.

199. Yanbaeva DG, Dentener MA, Creutzberg EC, Wesseling G, Wouters EF. Systemic effects of smoking. Chest. 2007;131:1557-1566.

200. Esposito K, Giugliano D. Diet and inflammation: a link to metabolic and cardiovascular diseases. Eur Heart J. 2006;27:15-20.

201. Lichtenstein AH, Appel LJ, Brands $M$, et al. Diet and lifestyle recommendations revision 2006: a scientific statement from the American Heart Association Nutrition Committee. Circulation. 2006;114:82-96.

202. Slavin JL. Position of the American Dietetic Association: health implications of dietary fiber. J Am Diet Assoc. 2008;108:1716-1731.

203. Fung TT, McCullough ML, Newby PK, et al. Diet-quality scores and plasma concentrations of markers of inflammation and endothelial dysfunction. Am J Clin Nutr. 2005;82:163-173.

204. Willett WC. The Mediterranean diet: science and practice. Public Health Nutr. 2006;9:105-110.

205. Kemper HC. Amsterdam Growth and Health Longitudinal study (AGAHLS). A 23-year follow-up from teenager to adult about lifestyle and health. Basel: Karger; 2004.

206. Ferreira I, Henry RM, Twisk JW, van Mechelen W, Kemper HC, Stehouwer CD. The metabolic syndrome, cardiopulmonary fitness, and subcutaneous trunk fat as independent determinants of arterial stiffness: the Amsterdam Growth and Health Longitudinal Study. Arch Intern Med. 2005; 165:875-882.

207. Boreham C, Savage JM, Primrose D, Cran G, Strain J. Coronary risk factors in schoolchildren. Arch Dis Child. 1993;68:182-186.

208. Gallagher AM, Savage JM, Murray LJ, et al. A longitudinal study through adolescence to adulthood: the Young Hearts Project, Northern Ireland. Public Health. 2002;116:332-340. 


\section{Chapter}

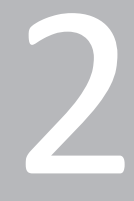

Carotid stiffness in young adults: a life-course

analysis of its early determinants

The Amsterdam Growth and Health Longitudinal Study

Isabel Ferreira, Roel J. van de Laar, Martin H. Prins, Jos W. Twisk, Coen D. Stehouwer Hypertension 2012;59:54-61 


\section{ABSTRACT}

Cardiovascular risk factors affecting arterial stiffness in adulthood may develop at different critical periods earlier in life. We examined whether the trajectories, from adolescence to young adulthood, of blood pressure, body fatness and fat distribution, blood lipids, cardiorespiratory fitness and heart rate determined levels of arterial stiffness in young adults. We investigated 373 apparently healthy adults in whom cardiovascular risk factors were repeatedly examined between the ages of 13 and 36 years and carotid stiffness estimates were obtained at the age of 36 years. Differences in the mean levels and the trajectories of risk factors throughout the 24-year longitudinal period between subjects with different levels of carotid stiffness at age 36 years were analyzed with generalized estimating equations. Compared with individuals with less stiff carotid arteries, those with stiffer carotid arteries at the age of 36 years were characterized from age 13 to 36 years by greater levels of and steeper increases in blood pressure and central fatness, independently of each other and other risk factors. These increases were already present in adolescence, preceded the development of poorer levels of blood lipids, cardiorespiratory fitness and heart rate, which were evident during adulthood only, and explained to a great extent the deleterious association between these risk factors and carotid stiffness at the age of 36 years. Multiple and intertwined mechanisms involved in the pathogenesis of arterial stiffness have their origins in early life. Blood pressure and central fatness have a pivotal role herein and should be specifically targeted to prevent arterial stiffening and its cardiovascular sequelae. 


\section{INTRODUCTION}

Arterial stiffness is an important cause of cardiovascular disease because of its contribution to systolic hypertension, left ventricular hypertrophy and impaired coronary perfusion. ${ }^{1-3}$ Arterial stiffness is primarily determined by ageing and mean arterial pressure (MAP) ${ }^{2,4}$ but other risk factors (RFs) may also contribute, notably body fatness and/or a central pattern of fat distribution, ${ }^{5-8}$ impaired glucose metabolism and insulin resistance, ${ }^{2}$ poor cardiorespiratory fitness ${ }^{9,10}$ and dyslipidemia. ${ }^{11,12}$ Recently, a systematic review suggested that the contribution to arterial stiffness of RFs other than blood pressure (BP) was only modest, though this evidence was derived from cross-sectional studies only. ${ }^{13}$ Therefore, a life-course rather than a single time-point approach to the study of (early) determinants of arterial stiffness is needed.

The negligible, if any, role of RFs other than BP on arterial stiffness was also emphasized in a prospective analysis conducted among men throughout middle and older age. ${ }^{14}$ However, some evidence suggests that arterial stiffness in adulthood has its roots early in life. Indeed, studies among the young have shown that greater levels of $\mathrm{BP}^{15,16}$ and body fatness and/or a central pattern of fat distribution ${ }^{5,15,17}$ measured in childhood/adolescence were associated with greater arterial stiffness in adulthood. However, how the life-course trajectories and cumulative burden of these, and also of other RFs such as dyslipidemia, cardiorespiratory fitness and resting heart rate (HR), which are all intertwined, affect arterial stiffness later in life is not known. For instance, RFs affecting arterial stiffness in adulthood may develop at different critical or sensitive periods earlier in life. ${ }^{18}$ In addition, elevations in some RFs occurring early in life may accelerate over time and trigger the development of other RFs, all of which may impact adversely on arterial stiffness later in life. From a preventive point of view, identifying such critical periods and triggering RFs early in life is of utmost importance to inform targeted interventions with the most potential for health benefits by breaking chains of risk and enabling establishment of healthier life-course trajectories. $^{18}$

To address these issues, we have therefore investigated in the Amsterdam Growth and Health Longitudinal Study (AGAHLS) the extent to which the life-course trajectories and their inter-(in)dependent associations, from ages 13 to 36 years, of $\mathrm{BP}$, body fatness and fat distribution, blood lipids, cardiorespiratory fitness and resting HR determined the levels of carotid artery stiffness at age 36 years. 


\section{SUBJECTS AND METHODS}

\section{Subjects and study design}

The AGAHLS is an observational longitudinal study that started in 1977 with a group of $\sim 600$ boys and girls from two secondary schools from the area of Amsterdam (The Netherlands). Its initial goal was to describe the natural development of growth, health and lifestyle of adolescents, and to investigate longitudinal relationships between biological and lifestyle RFs, as described in detail elsewhere. ${ }^{19}$ The mean age of the subjects at the beginning of the study was $13.1 \pm 0.8$ years. Since then, measurements have been obtained 2 to 8 times (up to the age of 36), during a 24-year follow-up period. At each measurement round, anthropometrical (body height, weight and skinfolds [SKF]), biological (serum lipoprotein levels, BP, cardiorespiratory fitness and heart rate) and lifestyle (nutritional habits, smoking behavior, daily physical activity) RFs were assessed according to standard procedures (for details, please see appendix 2.1). ${ }^{19-22}$ In the year 2000, when the subjects' mean ages were $36.5 \pm 0.6$ years, large artery properties were assessed for the first time in 373 (196 women) subjects according to guidelines for user procedures and with the use of reproducible and valid methods and devices. ${ }^{1}$ The following carotid stiffness estimates were calculated: the distensibility coefficient (DC), the compliance coefficient (CC), and the Young's elastic modulus (YEM) as described in detail elsewhere (please see also appendix 2.1). ${ }^{5,8,21,23}$

The study was approved by the medical ethical committee of the VU University Medical Center (Amsterdam, The Netherlands) and all subjects gave their written informed consent (provided by their parents when subjects were 13 to 16 years old).

\section{Statistical analyses}

We used generalized estimating equations ${ }^{24}$ to compare the trajectories and the mean levels of systolic pressure (SP), diastolic pressure (DP), and MAP, body fatness (i.e., the body mass index [BMI], sum of 4 SKF) and fat distribution (SKF ratio), blood lipids (total-to-high-density lipoprotein [HDL] cholesterol, triglycerides) and physical fitness (cardiorespiratoty fitness $-\mathrm{VO}_{2} \mathrm{max}$, resting $\mathrm{HR}$ ), between subjects with increasing levels of carotid stiffness at the age of 36 years. Subjects' were therefore grouped according to sex-specific tertiles ( $T$ ) of each carotid stiffness estimate.

Adopting generalized estimating equiations as method for data analyses allowed us to use all data available from the age of 13 to the age of 36 years, properly adjusting for the correlation between repeated observations taken in the same subject, and handling data from subjects with varying number and unequally timespaced observations. ${ }^{22,24}$ All analyses were first adjusted for sex, body height (to account for the subjects' growth) and time (modeled as a categorical variable to allow departures from linearity; model 1). This model thus reflects the cumulative burden of each RF on adult carotid stiffness. Subsequently, we compared the life-course 
trajectories of each RF between groups with increasing gradients of carotid stiffness by adding interaction terms between group and time; results hereby obtained were displayed graphically (smoothed line plots). ${ }^{20,21}$ These analyses enable us to pin-point the exact moment early in life when differences in RFs between groups emerged. To analyse the extent to which the concomitant life-course of other RFs explained any of the differences found between groups, analyses were further adjusted for potential confounders (i.e. lifestyle variables [model 2]) and/or mediators (i.e. sitting MAP, [central] body fatness, blood lipids and physical fitness [models $3 A-E$ ]). Finally, all analyses were also adjusted for the levels of MAP at which stiffness estimates were estimated (i.e. current $\mathrm{MAP}_{\text {supine }}$ [model 4]). Because $\mathrm{MAP}_{\text {supine }}$ is highly correlated with sitting MAP at age 36 years, which reflects attained levels of MAP at the end of the longitudinal period, this adjustment meant, for a great portion, removal of the effects of BP tracking.

In all generalized estimating equations analyses, an exchangeable correlation structure was used, which was deemed as the most parsimonious after examination of the inter-period correlation matrixes of the cardiovascular RFs throughout the 24-year study period. All results are reported for men and women combined since no significant interactions with sex were found. Triglycerides levels, which were positively skewed, were log-transformed before all analyses.

Statistical significance was set at $P<0.05$. All analyses were performed with the use of the STATA software package version 11 (STATA Corp, College Station, TX, USA).

\section{RESULTS}

From the lowest (T1) to the highest tertiles (T3), subjects' mean \pm SD levels of the carotid DC (in $10^{-3} / \mathrm{kPa}$ ) were $20.3 \pm 2.2,26.2 \pm 1.6$ and $33.4 \pm 4.1$, of the carotid CC (in $\mathrm{mm}^{2} / \mathrm{kPa}$ ) were $0.72 \pm 0.12,0.97 \pm 0.09,1.28 \pm 0.20$, and of the carotid YEM (in $10^{3} \cdot \mathrm{kPa}$ ) were $0.32 \pm 0.05,0.43 \pm 0.03$ and $0.58 \pm 0.09$ ( $P$ for linear trend $<0.001$ for all). Differences in the carotid DC and CC between subjects in the highest vs. lowest tertiles were equivalent to values observed in the course of one decade of ageing; ${ }^{25}$ groups herein defined as having stiffer arteries (i.e. in T1 for DC and CC or in T3 for YEM) and less stiff arteries (i.e. in T3 for DC and CC or in T1 for YEM) translate into potentially clinical relevant differences in carotid stiffness levels.

Table 2.1 shows the general characteristics of the study population throughout the longitudinal period stratified by levels of subjects' carotid DC at the age of 36 years. All data shown are those with groups defined on the basis of this stiffness estimate; qualitatively similar findings were found when groups were defined on the basis of the carotid CC or YEM instead (please see Supplemental Table 2.S1 - appendix 2.2). 


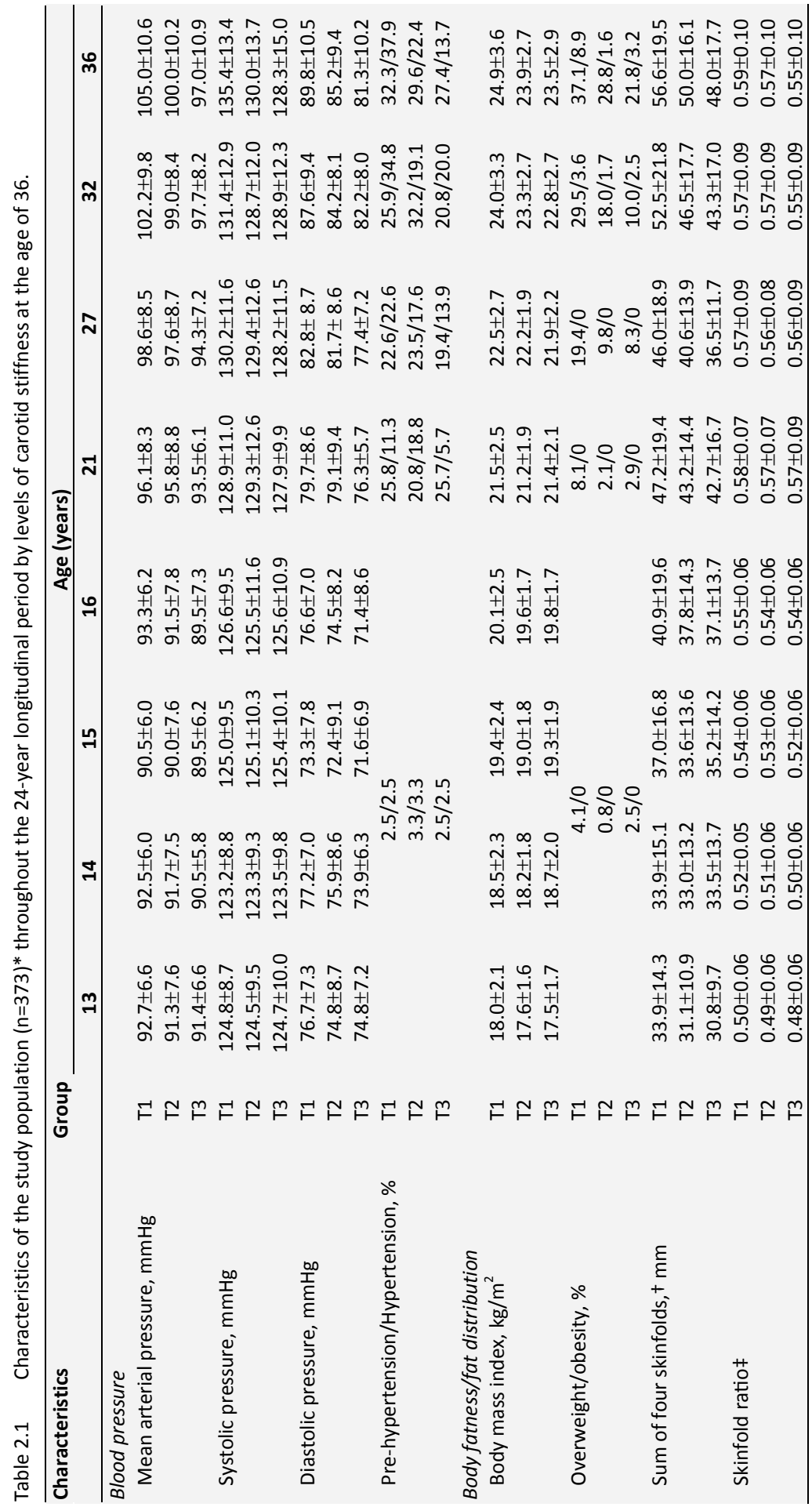




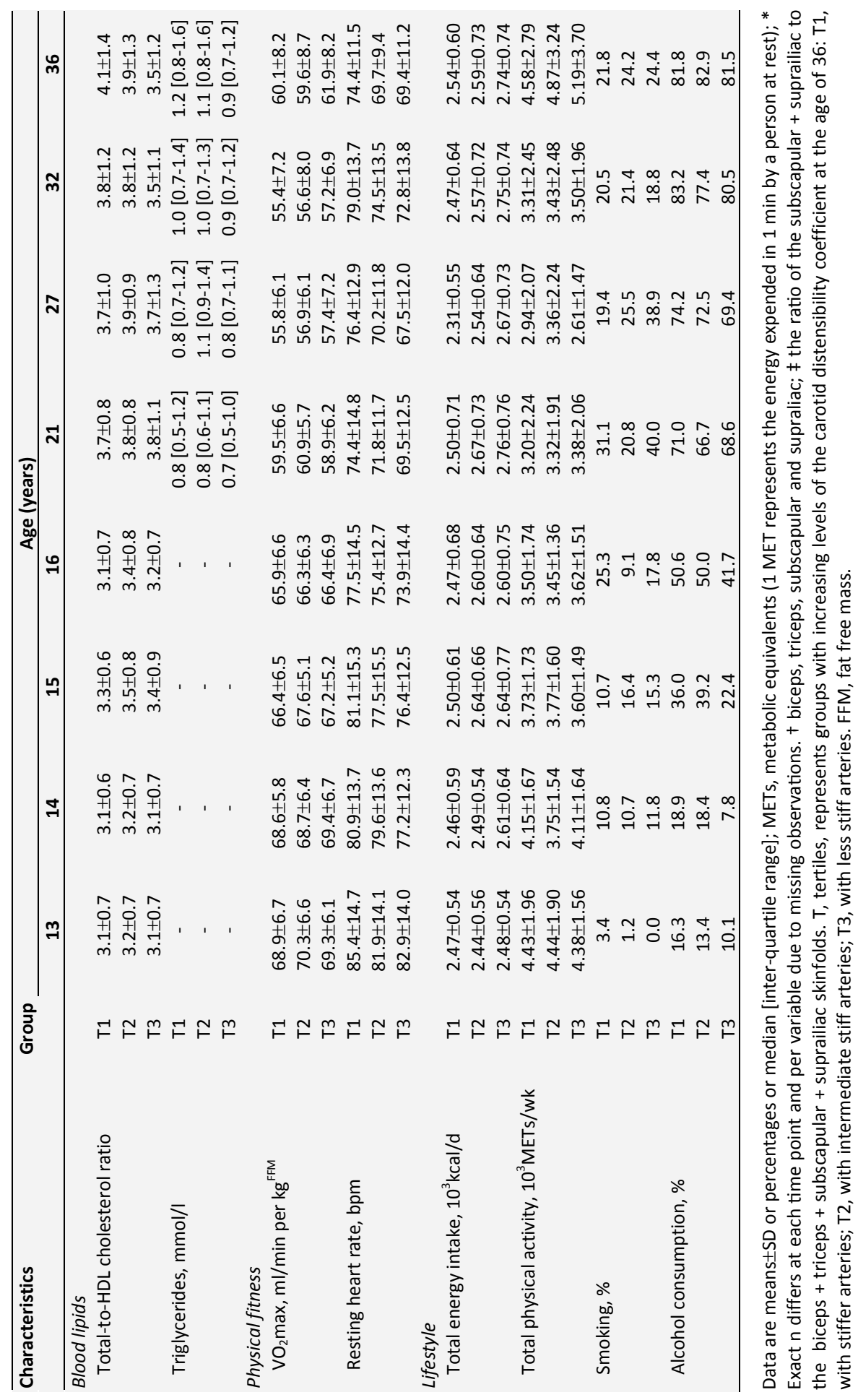




\section{Trajectories and cumulative burden of blood pressure}

Subjects with stiffer arteries (i.e. in T1 of the carotid DC) had on average and throughout the whole longitudinal period (in $\mathrm{mmHg}[95 \% \mathrm{Cl}]$ ) $5.3(3.9-6.8), 4.7$ (2.6-6.8) and 5.7 (4.3-7.1) greater levels of MAP, SP and DP, respectively, than those with less stiff arteries (T3; Table 2.2, model 1). Importantly, these differences were not constant over time, and although being already present during adolescence (e.g. at age 14 years: 3.5 [1.5-5.5] for MAP, 2.6 [0.1-5.1] for SP, and 4.0 [1.6-6.3] for DP), were further amplified from this age onwards and more strongly so in subjects with stiffer arteries (rate of BP increase in $\mathrm{mmHg} / \mathrm{yr}[95 \% \mathrm{Cl}]: 0.51$ [0.43-0.59] for MAP, 0.31 [0.21-0.40] for SP, and 0.61 [0.52-0.70] for DP) than with less stiff arteries (i.e. 0.28 [0.20-0.37] for MAP, 0.02 [-0.08-0.13] for SP, and 0.41 [0.32-0.51] for DP; Figure $2.1 \mathrm{~A}-\mathrm{C})$. These steeper increases in $\mathrm{BP}$ resulted in differences between the two groups that were about 2,5-fold greater at age 36 years (9.0 [6.5-11.4], 8.7 [5.5-11.8], and 9.1 [6.7-11.6], for MAP, SP and DP, respectively) vs. age 14 years. Adjustment for lifestyle variables did not materially change the mean differences over time between groups (model 2), and further adjustment for other RFs attenuated the differences in BP, mainly due to central fatness (model $3 \mathrm{~B}$ ), which nevertheless remained significant. Further adjustment for current $\mathrm{MAP}_{\text {supine }}$ attenuated the differences in BP between groups considerably though the differences in MAP and DP remained statistically significant (model 4).

\section{Trajectories and cumulative burden of fatness and fat distribution}

Subjects with stiffer arteries at the age of 36 had greater mean levels of BMI $\left(1.06 \mathrm{~kg} / \mathrm{m}^{2} ; 95 \% \mathrm{Cl}, 0.47-1.65\right)$, sum of 4 skinfolds ( $\left.\Sigma \mathrm{SKF}, 6.1 \mathrm{~mm} ; 95 \% \mathrm{Cl}, 2.9-9.4\right)$ and SKF ratio (*10; $0.36 ; 95 \% \mathrm{Cl}, 0.22-0.51)$ over the whole longitudinal period, as compared with those with less stiff arteries (Table 2.2, model 1). Subjects with stiffer arteries had also steeper increases in these estimates from adolescence to age 36 years (Figures 2.1D-F). For instance, BMI levels differed significantly from those with less stiff arteries already at age 15 years $\left(0.71 \mathrm{~kg} / \mathrm{m}^{2} ; 95 \% \mathrm{Cl}, 0.04-1.39\right)$, and this difference was about twice as much at age 36 years $\left(1.59 \mathrm{~kg} / \mathrm{m}^{2} ; 95 \% \mathrm{Cl}, 0.76-2.42\right)$. Similarly, the differences in SKF ratio $(* 10)$, which were already present at age 13 years $(0.26 ; 95 \% \mathrm{Cl}, 0.08-0.43)$, increased even more thereafter, being $\sim 2$-fold greater at age 36 years $(0.46 ; 95 \% \mathrm{Cl}, 0.28-0.65)$. Adjustments for lifestyle variables did not materially change the mean differences over time between groups (model 2) but further adjustment for other RFs (model 3), in particular MAP (model 3A) and total-to$\mathrm{HDL}$ cholesterol ratio (model 3B), attenuated the differences in BMI and $\Sigma \mathrm{SKF}$ considerably. Noteworthy, the differences in the SKF ratio were affected to a lesser extent by these adjustments (models 3 ), and remained significant, even when these included current $\mathrm{MAP}_{\text {supine }}$ (model 4). 


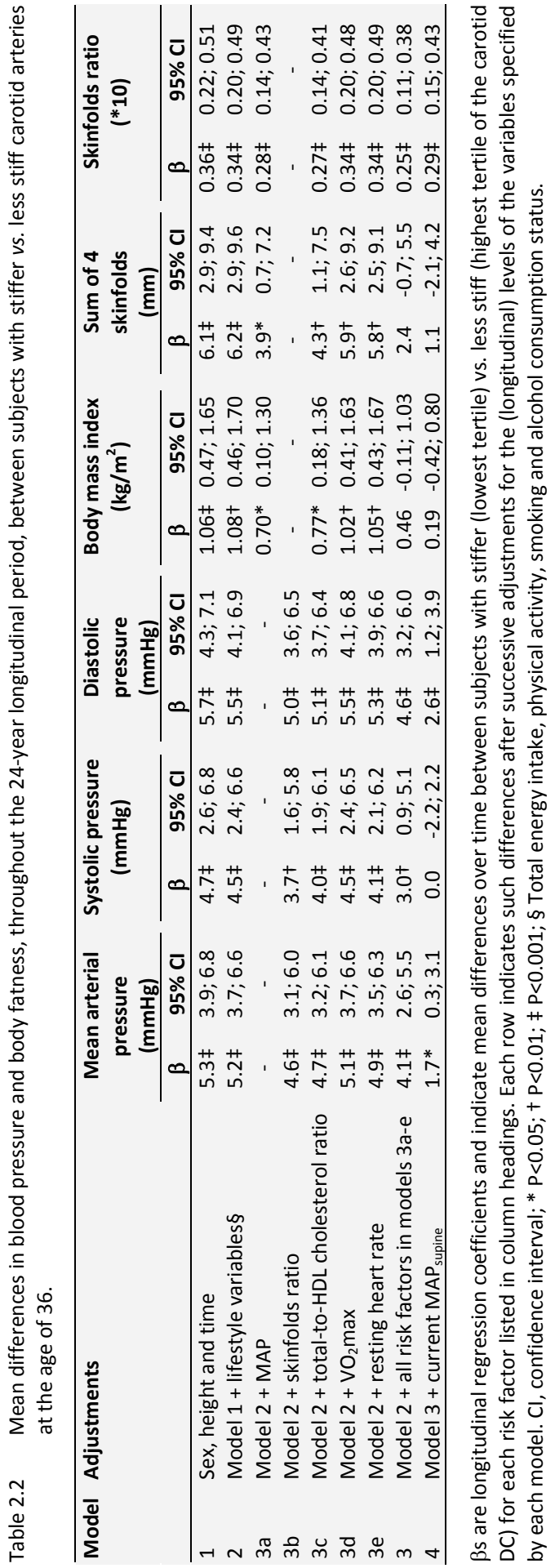


A

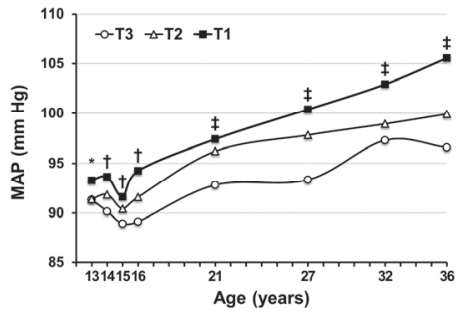

C

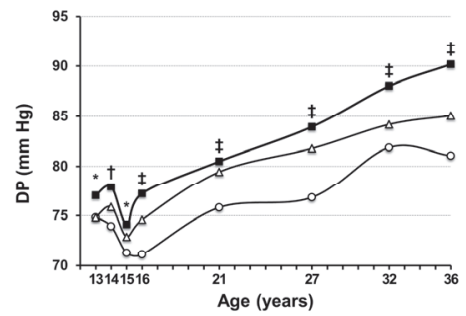

E

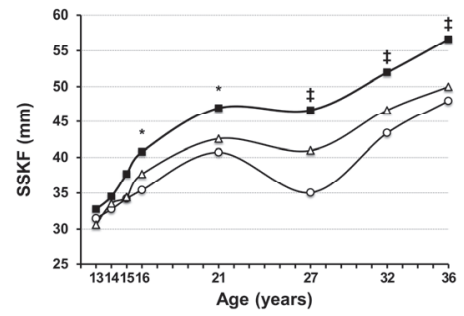

G

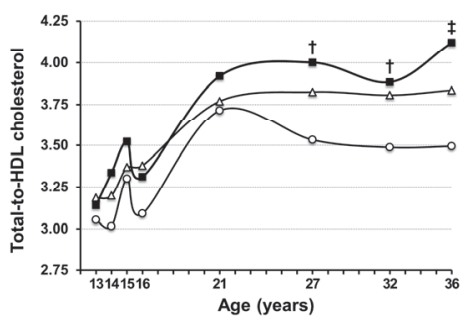

B

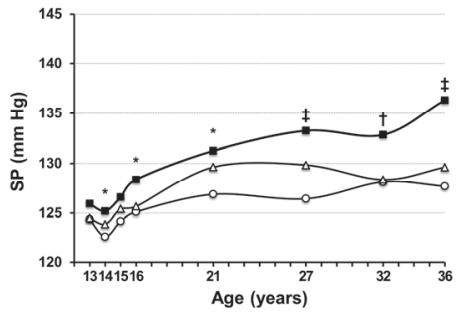

D

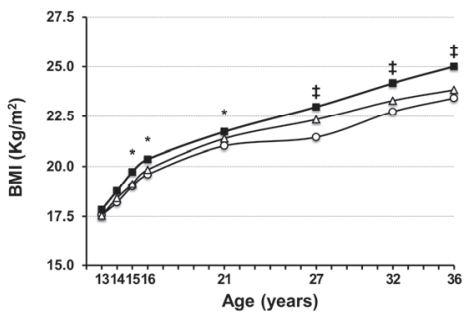

F

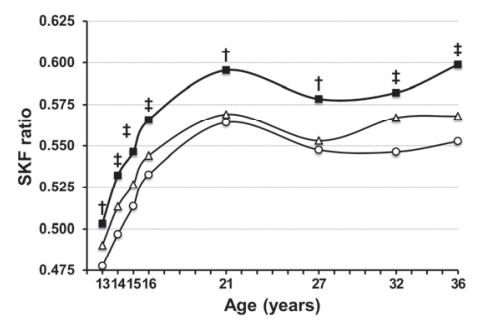

H

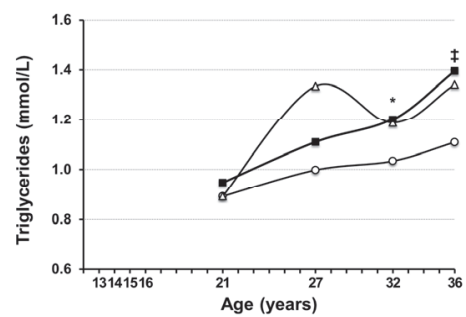



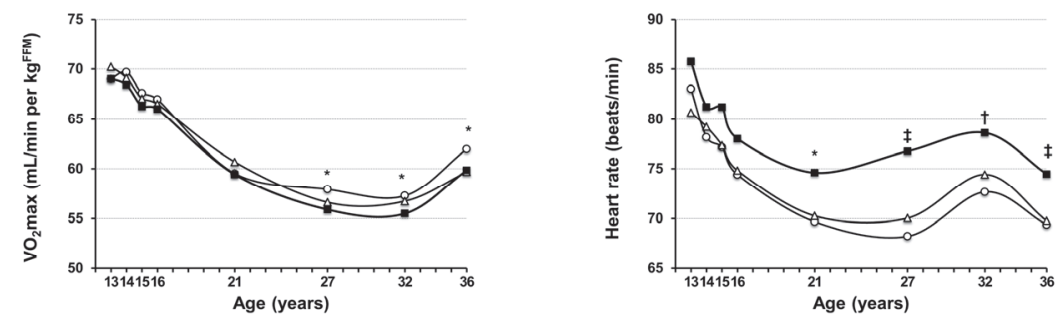

Figure 2.1 Comparison of the life-course trajectories of potential determinants of arterial stiffness between subjects with stiffer (i.e. lowest tertile [T1]) vs. less stiff carotid arteries (highest tertile [T3]) at age 36years: (A) mean arterial pressure (MAP); (B) systolic pressure (SP); (C) diastolic pressure (DP); (D) body mass index (BMI); (E) sum of four skinfolds ( $\Sigma S K F)$; (F) skinfolds (SKF) ratio; (G) total-to-HDL cholesterol ratio; (H) triglycerides; (I) cardiopulmonary fitness $\left(\mathrm{VO}_{2} \mathrm{max}\right)$; and $\mathrm{J}$ ) resting heart rate (HR). Lines for the middle tertile (T2) indicate patterns for subjects with intermediate levels of carotid stiffness. All data are adjusted for sex and height; values for triglycerides are geometric means.

* $P<0.05 ;+P<0.01 ; ¥ P<0.001$, for comparisons between subjects with stiffer vs. less stiff carotid arteries.

\section{Trajectories and cumulative burden of blood lipids and physical fitness}

Subjects with stiffer arteries, as compared with those with less stiff arteries, had on average $0.37(95 \% \mathrm{Cl}, 0.15-0.56)$ greater levels of total-to-HDL cholesterol ratio and $1.08(95 \% \mathrm{Cl}, 1.03-1.12)$ times greater levels of triglycerides, throughout the whole longitudinal period. The differences in total-to-HDL cholesterol ratio emerged after adolescence only, becoming significant from the age of 27 years onwards (Figure 2.1G); the differences in triglycerides, which were assessed in young adulthood only, were present at ages 32 and 36 years (Figure $2.1 \mathrm{H}$ ). The mean differences over time in both total-to-HDL cholesterol and triglycerides were independent of lifestyle variables (model 2), but were greatly reduced after adjustments for other RFs, in particular MAP and the SKF ratio (models 3A and 3B - Supplemental Table 2.S2 - appendix 2.2).

Subjects with stiffer arteries, as compared with those with less stiff arteries, had on average $1.39 \mathrm{ml} / \mathrm{min} / \mathrm{kg}^{\mathrm{FFM}}(95 \% \mathrm{Cl},-2.58 ;-0.19)$ lower levels of $\mathrm{VO}_{2}$ max and 4.7 bpm $(95 \% \mathrm{Cl}, 2.3-7.1)$ higher levels of $\mathrm{HR}$ throughout the whole longitudinal period. Although $\mathrm{VO}_{2}$ max and $\mathrm{HR}$ decreased from adolescence to age 36 years in all subjects, these trajectories were more adverse in individuals with stiffer arteries. However, significant differences between groups were only observed during adulthood (at age 27 years and onwards for $\mathrm{VO}_{2}$ max, Figure 2.1I; and at age 21 years and onwards for HR, Figure 2.1J]. Mean differences over time between groups were only slightly attenuated after adjustments for lifestyle RFs (model 2) but more markedly so after further adjustments for the other RFs (model 3; please see Supplemental Table 2.S2 appendix 2.2). 


\section{DISCUSSION}

We investigated the trajectories, from adolescence to adulthood, of potential determinants of carotid stiffness. We show that, as compared with individuals with less stiff arteries at age 36 years, those with stiffer arteries were characterized, from the ages 13 to 36 years, by greater levels of and steeper increases in BP and central fatness, and this independently of each other and other RFs. These increases were already present in adolescence, preceded the development of poorer levels of blood lipids, cardiorespiratory fitness and heart rate, which were evident during adulthood only, and explained, to a great extent, the deleterious association between these RFs and carotid stiffness at age 36 years. This is the first study to investigate and tease apart the relative role of several potential RFs for arterial stiffness with a longitudinal design. Our findings support the view of adolescence as a critical period for the development of elevated BP, mainly DP, and (central) fatness and its associated cardiovascular morbidities later in life. ${ }^{26-28}$

In agreement with previous observations, ${ }^{15-17}$ we show that subjects with stiffer arteries in adulthood were characterized by greater levels of BP early in life. Given the great dependence of arterial stiffness on the levels of transmural pressure at which they are measured, and given the phenomenon of BP tracking throughout age, the marked attenuation in $\mathrm{BP}$ differences after adjustment for current $\mathrm{MAP}_{\text {supine }}$ was largely expected. Increased arterial stiffness is primarily determined by the properties of the extracellular matrix (elastin, collagen) and vascular smooth muscular cell function. ${ }^{1,2,29}$ These properties are strongly affected by lifelong BP. ${ }^{4,13}$ Our longitudinal approach enabled us to pin-point adolescence as the period early in life when increases in predominantly DP, but also in SP pressure, and thus MAP, may be linked to greater arterial stiffness later in life. The observation of DP as a major determinant of arterial stiffness may reflect the phenomenon of 'downstream' increase in resistance at the level of the arterioles, leading to an 'upstream' increase in transmural pressure resulting in both structural and functional disruption of the arterial pressure load-bearing elastin-collagen network within the media layer, and thus greater arterial stiffness. ${ }^{4,29}$ Our data are thus also consistent with the subtypes of elevated SP and DP or isolated diastolic hypertension that typically characterize young adults. Still, with ageing, increased arterial stiffness may affect the BP-arterial stiffness relationship, such that, after the age of $\sim 50$ to 60 years, ${ }^{4}$ another phenotype becomes more prevalent, that of isolated systolic hypertension.

Another key finding of the present study was that the levels of central rather that of total body fatness during adolescence impacted on arterial stiffness in adulthood. Body fatness, in particular central fatness, is a well-recognized correlate of arterial stiffness, ${ }^{5-8}$ even though the mechanisms linking the two are incompletely understood. ${ }^{30}$ The impact of total or central body fatness on other cardiovascular RFs and their clustering may constitute one such mechanism. ${ }^{30}$ We have previously shown in this cohort that increases in total and central body fatness from adolescence to 
young adulthood were critical for the development of the metabolic syndrome in adulthood, ${ }^{20}$ which, in turn, was associated with greater arterial stiffness. ${ }^{23}$ In the present study, we show longitudinally that the levels of mainly MAP and dyslipidemia and to a lesser extent of physical fitness could explain a great part of the association between total body fatness (up to $\sim 60 \%$ ), but less so of the association between central body fatness and arterial stiffness ( $25 \%$ only). This could be appreciated by the change in the magnitude of the differences in BMI or the $\Sigma$ SKF and the SKF ratio after adjustment for those RFs (i.e. model 3 vs. 2 in Table 2). Other (central) adiposityrelated factors may thus also contribute to arterial stiffness. These may include adrenergic (sympathetic overactivity) and metabolic (e.g. insulin resistance, hypoadiponectinemia, hyperleptinemia, pro-inflammatory cytokines) pathobiological mechanisms. ${ }^{30}$ Measures of these potential explanatory mechanisms were not assessed throughout the whole longitudinal period covered in this study, however.

Noteworthy, subjects with stiffer arteries in adulthood were not only characterized by greater levels of BP and central fatness extending back to early age, which is supportive of tracking, but also by steeper increases in BP (mainly DP) and (central) fatness, particularly during young adulthood, supportive of a 'horse-racing' phenomenon around these RFs. ${ }^{31}$ These observations may have important implications for prevention. Tracking, i.e. the stability of rank of an individual in the RF distribution over time, has bearing in the early detection of subjects at risk, in the sense that RF levels in young adulthood will be good predictors of their levels later in life. ${ }^{22}$ Horse-racing suggests that also the rate of change of these RFs, in addition to their absolute levels at any given point in time, may contribute to the identification of subjects at risk and more likely to benefit from preventive measures, and thus should be monitored. $^{32}$ In support of this, in the present cohort the prevalence of (pre)hypertension or overweight/obesity during adolescence was very low and, per se, not predictive of significantly greater carotid stiffness (lowest vs. other tertiles) later in life (OR, 0.85; $95 \% \mathrm{Cl}, 0.32-3.26$; and $\mathrm{OR}, 2.54 ; 95 \% \mathrm{Cl}, 0.67-9.55$, respectively). Instead, increases in BP and (central) fatness observed between adolescence and young adulthood, even when occurring within the range of values below those commonly used as indicative or risk, seemed to be setting the grounds for greater arterial stiffness later in life. In this respect, and on the basis of these RFs, our data suggests that subjects with less stiff carotid arteries were those who, between adolescence and young adulthood: had relatively lesser increases in SP and DP (hardly exceeding the mean values of 130 and $85 \mathrm{mmHg}$, respectively at age 36 years), BMI (not exceeding the mean value of $24 \mathrm{~kg} / \mathrm{m}^{2}$ at age 36 years); and SKF ratio $<0.57$ throughout the adult period (for age specific references please see Figure 2.1); these values could be used as references for a healthy profile within the age-periods as examined herein. However, a note of caution is warranted here. The magnitude of the differences found in our study between individuals with stiffer vs. less stiffness carotid arteries were small relative to the observed variability in the lifelong levels of the RFs 
examined. Larger studies are needed to ascertain with more certainty the limits of such a healthy or desirable risk profile in young age.

Differences in total-to-HDL cholesterol ratio, triglycerides, cardiorespiratory fitness and resting HR between subjects with stiffer vs. less stiff carotid arteries in adulthood were only visible during adulthood. However, the deleterious impact of each of these RFs on arterial stiffness was, to a great extent, explained by concomitant trajectories of the other RFs, mainly the increases in BP and (the accentuation of a central pattern of) body fatness, which actually preceded and may thus have triggered the former.

There are limitations to the present study that need to be addressed. First, our findings were confined to subjects in whom complete data on arterial properties were obtained during the follow-up examination in the year 2000. However, levels of BP, total and central fatness, blood lipids, cardiorespiratory fitness and HR in these subjects did not differ, at any earlier time point, from those subjects who dropped-out (data not shown); this indicates that selection bias did not threatened the validity of our findings. Second, the trajectories of the RFs reported herein refer to subjects who were adolescents in the late 1970s. Given the current obesity epidemic in the youth, it is possible that the critical periods identified herein may have shifted to even earlier ages. From an etiological point of view, this does not hinder the validity of our findings; in fact, it just emphasizes the need for public health interventions targeting young people. ${ }^{26,27}$ Third, although we have adjusted our analyses extensively for several potential confounders we cannot fully exclude the possibility of residual confounding. Fourth, although the use of local pulse pressure by calibration of the distension waveforms ${ }^{25}$ instead of brachial pulse pressure for the calculations of the carotid stiffness estimates constitutes a strength to our study, this method may still not optimally reflect the level of pulse pressure at the level of the carotid artery. Finally, given its observational design, this study cannot prove causality; furthermore, because carotid stiffness levels were measured at age 36 years only, we cannot rule out the possibility of reverse causality (e.g. that subjects with stiffer arteries at any earlier time-point may have been less prone to adopt healthier lifestyles which could lead to better cardiovascular risk profiles). However, we deemed this less likely as the young subjects were, throughout the whole longitudinal period, unaware of and asymptomatic with regard to their stiffness levels.

\section{PERSPECTIVES}

Our findings support the existence of multiple and intertwined mechanisms in the pathogenesis of arterial stiffness that have their origins in early life. BP and a central pattern of body fatness have a pivotal role herein. Efforts to prevent arterial stiffening and its cardiovascular sequelae, may thus most usefully be targeted at the prevention of increases in blood pressure and central fatness starting in early age. 


\section{REFERENCES}

1. Laurent S, Cockcroft J, Van Bortel L, et al. Expert consensus document on arterial stiffness: methodological issues and clinical applications. Eur Heart J. 2006;27:2588-2605.

2. Stehouwer CD, Henry RM, Ferreira I. Arterial stiffness in diabetes and the metabolic syndrome: a pathway to cardiovascular disease. Diabetologia. 2008;51:527-539.

3. Vlachopoulos C, Aznaouridis K, Stefanadis C. Prediction of cardiovascular events and all-cause mortality with arterial stiffness: a systematic review and meta-analysis. J Am Coll Cardiol. 2010;55:1318-1327.

4. Franklin SS. Arterial stiffness and hypertension: a two-way street? Hypertension. 2005;45:349-351.

5. Ferreira I, Twisk JW, van Mechelen W, Kemper HC, Seidell JC, Stehouwer CD. Current and adolescent body fatness and fat distribution: relationships with carotid intima-media thickness and large artery stiffness at the age of 36 years. J Hypertens. 2004;22:145-155.

6. Wildman RP, Mackey RH, Bostom A, Thompson T, Sutton-Tyrrell K. Measures of obesity are associated with vascular stiffness in young and older adults. Hypertension. 2003;42:468-473.

7. Zebekakis PE, Nawrot T, Thijs L, et al. Obesity is associated with increased arterial stiffness from adolescence until old age. J Hypertens. 2005;23:1839-1846.

8. Schouten F, Twisk JW, de Boer MR, et al. Increases in central fat mass and decreases in peripheral fat mass are associated with accelerated arterial stiffening in healthy adults: the Amsterdam Growth and Health Longitudinal Study. Am J Clin Nutr. 2011;94:40-48.

9. Ferreira I, Twisk JW, Van Mechelen W, Kemper HC, Stehouwer CD. Current and adolescent levels of cardiopulmonary fitness are related to large artery properties at age 36: the Amsterdam Growth and Health Longitudinal Study. Eur J Clin Invest. 2002;32:723-731.

10. Boreham CA, Ferreira I, Twisk JW, Gallagher AM, Savage MJ, Murray L. Cardiorespiratory fitness, physical activity, and arterial stiffness: the Northern Ireland Young Hearts Project. Hypertension. 2004;44:721-726.

11. Aggoun Y, Bonnet D, Sidi D, et al. Arterial mechanical changes in children with familial hypercholesterolemia. Arterioscler Thromb Vasc Biol. 2000;20:2070-2075.

12. Leeson $\mathrm{CP}$, Whincup $\mathrm{PH}$, Cook DG, et al. Cholesterol and arterial distensibility in the first decade of life: a population-based study. Circulation. 2000;101:1533-1538.

13. Cecelja M, Chowienczyk P. Dissociation of aortic pulse wave velocity with risk factors for cardiovascular disease other than hypertension: a systematic review. Hypertension. 2009;54: 1328-1336.

14. McEniery CM, Spratt M, Munnery $M$, et al. An analysis of prospective risk factors for aortic stiffness in men: 20-year follow-up from the Caerphilly prospective study. Hypertension. 2010;56:36-43.

15. Juonala M, Jarvisalo MJ, Maki-Torkko N, Kahonen M, Viikari JS, Raitakari OT. Risk factors identified in childhood and decreased carotid artery elasticity in adulthood: the Cardiovascular Risk in Young Finns Study. Circulation. 2005;112:1486-1493.

16. Li S, Chen W, Srinivasan SR, Berenson GS. Childhood blood pressure as a predictor of arterial stiffness in young adults: the bogalusa heart study. Hypertension. 2004;43:541-546.

17. Raitakari OT, Juonala M, Viikari JS. Obesity in childhood and vascular changes in adulthood: insights into the Cardiovascular Risk in Young Finns Study. Int J Obes (Lond). 2005;29 Suppl 2:S101-104.

18. Kuh D, Ben-Shlomo Y. A life course approach to chronic disease epidemiology. 2nd ed. Oxford: Oxford University Press; 2004.

19. Kemper HC. Amsterdam Growth and Health Longitudinal study (AGAHLS). A 23-year follow-up from teenager to adult about lifestyle and health. Basel: Karger; 2004.

20. Ferreira I, Twisk JW, van Mechelen W, Kemper HC, Stehouwer CD. Development of fatness, fitness, and lifestyle from adolescence to the age of 36 years: determinants of the metabolic syndrome in young adults: the Amsterdam Growth and Health Longitudinal Study. Arch Intern Med. 2005;165: $42-48$.

21. van de Laar RJ, Ferreira I, van Mechelen W, Prins MH, Twisk JW, Stehouwer CD. Lifetime vigorous but not light-to-moderate habitual physical activity impacts favorably on carotid stiffness in young adults: the amsterdam growth and health longitudinal study. Hypertension. 2010;55:33-39. 
22. Twisk JW, Kemper HC, van Mechelen W, Post GB. Tracking of risk factors for coronary heart disease over a 14-year period: a comparison between lifestyle and biologic risk factors with data from the Amsterdam Growth and Health Study. Am J Epidemiol. 1997;145:888-898.

23. Ferreira I, Henry RM, Twisk JW, van Mechelen W, Kemper HC, Stehouwer CD. The metabolic syndrome, cardiopulmonary fitness, and subcutaneous trunk fat as independent determinants of arterial stiffness: the Amsterdam Growth and Health Longitudinal Study. Arch Intern Med. 2005; 165:875-882.

24. Twisk JWR. Applied longitudinal data analyses for epidemiology. A pratical guide. Cambridge: Cambridge University Press; 2003.

25. Vermeersch SJ, Rietzschel ER, De Buyzere ML, et al. Age and gender related patterns in carotidfemoral PWV and carotid and femoral stiffness in a large healthy, middle-aged population. J Hypertens. 2008;26:1411-1419.

26. Lawlor DA, Chaturvedi N. Treatment and prevention of obesity--are there critical periods for intervention? Int J Epidemiol. 2006;35:3-9.

27. Ovesen L. Adolescence: a critical period for long-term tracking of risk for coronary heart disease? Ann Nutr Metab. 2006;50:317-324.

28. Lurbe E, Cifkova R, Cruickshank JK, et al. Management of high blood pressure in children and adolescents: recommendations of the European Society of Hypertension. J Hypertens. 2009;27: 1719-1742.

29. Greenwald SE. Ageing of the conduit arteries. J Pathol. 2007;211:157-172.

30. Safar ME, Czernichow S, Blacher J. Obesity, arterial stiffness, and cardiovascular risk. J Am Soc Nephrol. 2006;17 Suppl 2:S109-111.

31. Peto R. The horse-racing effect. Lancet. 1981;2:467-468.

32. Hofman A. Blood pressure in childhood: an epidemiological approach to the aetiology of hypertension. J Hypertens. 1984;2:323-328. 


\section{Appendix 2.1}

Supplementary methods description 


\section{METHODS}

\section{Longitudinal measurements of cardiovascular risk factors}

Blood pressure was measured twice with a sphygmomanometer (Speidl-Keller, Franken \& Itallie, Amsterdam, The Netherlands) and a standard pressure cuff, after subjects had rested in a sitting position for at least $5 \mathrm{~min}$. The lowest value of the systolic (SP) and diastolic blood pressure (DP) values thus obtained were recorded and used in the analyses. ${ }^{1}$ Mean arterial pressure (MAP), throughout the longitudinal period, was calculated as $[(2 * D P)+S P] / 3$. Prevalence of pre-hypertension or hypertension was defined: using sex, age and height-specific cut-off values for SP and/or DP according to the Task Force for Blood pressure in Children criteria and during adolescence (considered present if exceeding those cut-off values in at least 3 moments during this period) ${ }^{2}$ if SP/DP $\geq 130 / 85$ or $\geq 140 / 90$ during adulthood. ${ }^{3}$

Anthropometric measures included standing height, body weight, and biceps, triceps, subscapular and suprailiac skinfolds and were performed by trained observers. We calculated, as indicators of total body fatness, the body mass index (BMI; in $\mathrm{kg} / \mathrm{m}^{2}$ ) and the sum of the thickness of the four skinfolds ( $\Sigma \mathrm{SKF}$, in $\mathrm{mm}$ ); the ratio of the subscapular + suprailiac skinfolds to the $\Sigma$ SKF (SKF ratio) was used as an estimate of central fat distribution. ${ }^{1,4-7}$ Prevalence of overweight or obesity was defined using age and sex-specific cut-off values for BMI according to the International Obesity Task Force criteria during adolescence, and as $\mathrm{BMI} \geq 25$ or $\geq 30 \mathrm{~kg} / \mathrm{m}^{2}$, respectively, during adulthood. ${ }^{8}$

Total and HDL-cholesterol and triglycerides, the latter from the age of 21 onwards only, were measured in non-fasting blood samples $(10 \mathrm{ml})$ drawn from the antecubital vein with the use of enzymatic techniques (Roche Diagnostics, Mannheim, Germany); throughout the years, external quality control of these measures took place with target samples from a World Health Organization reference laboratory. ${ }^{1,9,10}$

Throughout the years cardiorespiratory fitness was measured in the same laboratory with the same protocol and equipment: a maximal running test on a treadmill (Quinton, Bothel, Washington, USA, model 18-54) with direct measurements of oxygen uptake (Ergoanalyzer, Jager, Bunnik, The Netherlands). Subjects were instructed to run at a constant speed of $8 \mathrm{~km} / \mathrm{h}$ while the slope of the treadmill increased every 2 minutes in a stepwise fashion, and were encouraged to continue running to their maximum. Maximal oxygen uptake $\left(\mathrm{VO}_{2} \mathrm{max}\right)$ expressed by $\mathrm{kg}$ of fatfree mass (i.e. $\mathrm{ml} / \mathrm{min} / \mathrm{kg}^{\mathrm{FFM}}$ ) was used in the analyses as a measure of cardiorespiratory fitness. ${ }^{11}$ FFM was derived by subtracting fat mass, which was calculated from skinfold thickness according to age and sex-specific equations ${ }^{12,13}$ from total body weight. Resting heart rate (HR) was measured telemetrically (Telecust 36 and Sirecust BS1, Siemens, Amsterdam, The Netherlands) as the mean value from $15 \mathrm{R}-\mathrm{R}$ intervals in the last 15 seconds of the minute, after subjects had been sitting on a chair for 5 minutes. 
Information on habitual physical activity levels, total energy intake, alcohol consumption and smoking behavior were assessed by means of interviews and questionnaires. $^{14-16}$

\section{Arterial stiffness}

Briefly, all subjects had abstained from smoking and caffeine-containing beverages on the day the measurements were performed. Measurements took place after subjects had been resting in a supine position for $15 \mathrm{~min}$ in a quiet temperature-controlled room. Properties of the right common carotid artery $(10 \mathrm{~mm}$ proximal to the beginning of the bulb) were obtained by two trained vascular sonographers with the use of an ultrasound scanner equipped with a 7.5- $\mathrm{MHz}$ linear array probe (Pie Medical, Maastricht, The Netherlands). The ultrasound scanner was connected to a personal computer equipped with an acquisition system and a vessel wall movement detector software system (Wall Track System 2, Pie Medical, Maastricht, The Netherlands). This integrated device enabled measurements of arterial diameter (D), distension $(\Delta D)$, and intima-media thickness (IMT) as described in detail elsewhere. ${ }^{17}$

Throughout the entire period of ultrasound imaging, systolic (SP), diastolic (DP) and mean arterial pressure $\left(\mathrm{MAP}_{\text {supine }}\right)$ were assessed in the left arm at 5 minutes intervals with an oscillometric device (Colin Press-Mate, model BP-8800, Komaki-City, Japan). Brachial artery pulse pressure (PP) was defined SP - DP, and PP at the level of the common carotid artery was calculated by calibration of the diameter distension waveforms obtained at the brachial and carotid arteries. ${ }^{18}$ The mean $D, \Delta D, I M T$ and local PP of 3 consecutive measurements (each including 3 to 7 heart beats) were used to estimate the carotid distensibility (DC) and compliance (CC) coefficients, and the Young's elastic modulus (YEM) as follows: ${ }^{4,5,17}$

$$
\begin{array}{ll}
D C=\left(2 \Delta D \cdot D+\Delta D^{2}\right) /\left(P P \cdot D^{2}\right) & \text { in } 10^{-3} / \mathrm{kPa}, \\
C C=\pi \cdot\left(2 D \cdot \Delta D+\Delta D^{2}\right) / 4 P P & \text { in } \mathrm{mm}^{2} / \mathrm{kPa}, \\
Y E M=D /(I M T \cdot D C) & \text { in } 10^{3} \cdot \mathrm{kPa} .
\end{array}
$$




\section{REFERENCES}

1. van Lenthe FJ, van Mechelen W, Kemper HC, Twisk JW. Association of a central pattern of body fat with blood pressure and lipoproteins from adolescence into adulthood. The Amsterdam Growth and Health Study. Am J Epidemiol. 1998;147:686-693.

2. National High Blood Pressure Education Program Working Group on High Blood Pressure in Children and Adolescents. The fourth report on the diagnosis, evaluation, and treatment of high blood pressure in children and adolescents. Pediatrics. 2004;114:555-576.

3. Chobanian AV, Bakris GL, Black HR, Cushman WC, Green LA, Izzo JL Jr, Jones DW, Materson BJ, Oparil S, Wright JT Jr, Rocella EJ, and the National High Blood Pressure Education Program Coordinating Committee. Seventh report of the Joint National Committee on Prevention, Detection, Evaluation, and Treatment of High Blood Pressure. Hypertension; 2003;42;1206-1252.

4. Ferreira I, Henry RM, Twisk JW, van Mechelen W, Kemper HC, Stehouwer CD. The metabolic syndrome, cardiopulmonary fitness, and subcutaneous trunk fat as independent determinants of arterial stiffness: the Amsterdam Growth and Health Longitudinal Study. Arch Intern Med. 2005; 165:875-882.

5. Ferreira I, Twisk JW, van Mechelen W, Kemper HC, Seidell JC, Stehouwer CD. Current and adolescent body fatness and fat distribution: relationships with carotid intima-media thickness and large artery stiffness at the age of 36 years. J Hypertens. 2004;22:145-155.

6. Nooyens AC, Koppes LL, Visscher TL, Twisk JW, Kemper HC, Schuit AJ, van Mechelen W, Seidell JC. Adolescent skinfold thickness is a better predictor of high body fatness in adults than is body mass index: the Amsterdam Growth and Health Longitudinal Study. Am J Clin Nutr. 2007;85:1533-1539.

7. van Lenthe FJ, Kemper HC, van Mechelen W, Twisk JW. Development and tracking of central patterns of subcutaneous fat in adolescence and adulthood: the Amsterdam Growth and Health Study. Int $J$ Epidemiol. 1996;25:1162-1171.

8. Cole TJ, Bellizzi MC, Flegal KM, Dietz WH. Establishing a standard definition for child overweight and obesity worldwide: international survey. BMJ. 2000;320:1240-1243.

9. Twisk JW, Kemper HC, Mellenbergh GJ. Longitudinal development of lipoprotein levels in males and females aged 12-28 years: the Amsterdam Growth and Health Study. Int J Epidemiol. 1995;24:69-77.

10. Twisk JW, Kemper HC, van Mechelen W, Post GB. Tracking of risk factors for coronary heart disease over a 14-year period: a comparison between lifestyle and biologic risk factors with data from the Amsterdam Growth and Health Study. Am J Epidemiol. 1997;145:888-898.

11. Kemper HC, Twisk JW, Koppes LL, van Mechelen W, Post GB. A 15-year physical activity pattern is positively related to aerobic fitness in young males and females (13-27 years). Eur J Appl Physiol. 2001;84:395-402.

12. Durnin JV, Rahaman MM. The assessment of the amount of fat in the human body from measurements of skinfold thickness. Br J Nutr. 1967;21:681-689.

13. Durnin JV, Womersley J. Body fat assessed from total body density and its estimation from skinfold thickness: measurements on 481 men and women aged from 16 to 72 years. Br J Nutr. 1974;32:77-97.

14. van Mechelen W, Twisk JW, Post GB, Snel J, Kemper HC. Physical activity of young people: the Amsterdam Longitudinal Growth and Health Study. Med Sci Sports Exerc. 2000;32:1610-1616.

15. Kemper HC. Amsterdam Growth and Health Longitudinal study (AGAHLS). A 23-year follow-up from teenager to adult about lifestyle and health. Basel, Switzerland: Karger; 2004.

16. Ferreira I, Twisk JW, van Mechelen W, Kemper HC, Stehouwer CD. Development of fatness, fitness, and lifestyle from adolescence to the age of 36 years: determinants of the metabolic syndrome in young adults: the Amsterdam Growth and Health Longitudinal Study. Arch Intern Med. 2005;165: 42-48.

17. Brands PJ, Hoeks AP, Willigers J, Willekes C, Reneman RS. An integrated system for the non-invasive assessment of vessel wall and hemodynamic properties of large arteries by means of ultrasound. Eur $J$ Ultrasound. 1999;9:257-266.

18. Van Bortel LM, Balkestein EJ, van der Heijden-Spek JJ, Vanmolkot FH, Staessen JA, Kragten JA, Vredeveld JW, Safar ME, Struijker Boudier HA, Hoeks AP. Non-invasive assessment of local arterial pulse pressure: comparison of applanation tonometry and echo-tracking. J Hypertens. 2001;19: 1037-1044. 


\section{Appendix 2.2}

Supplemental tables 


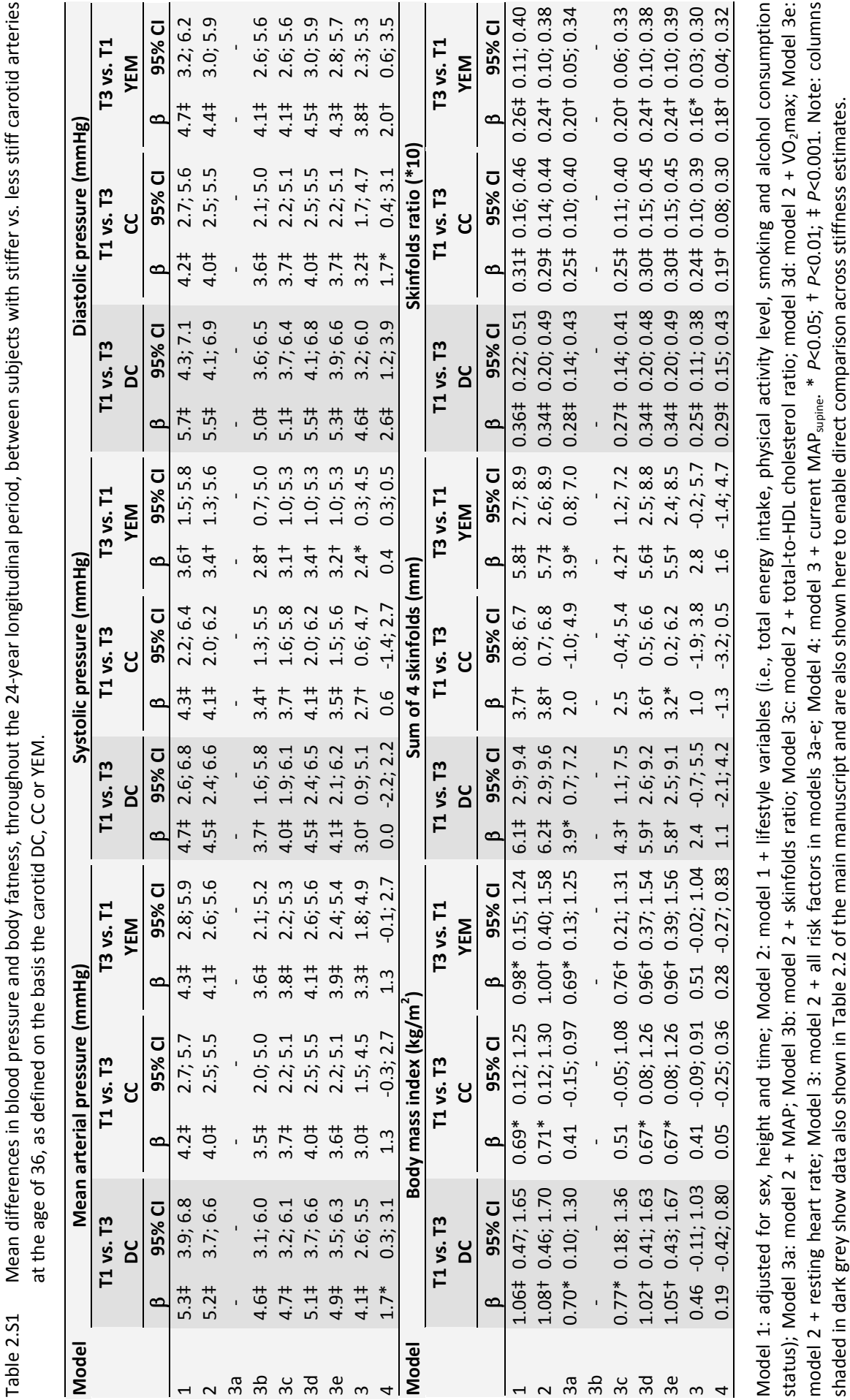




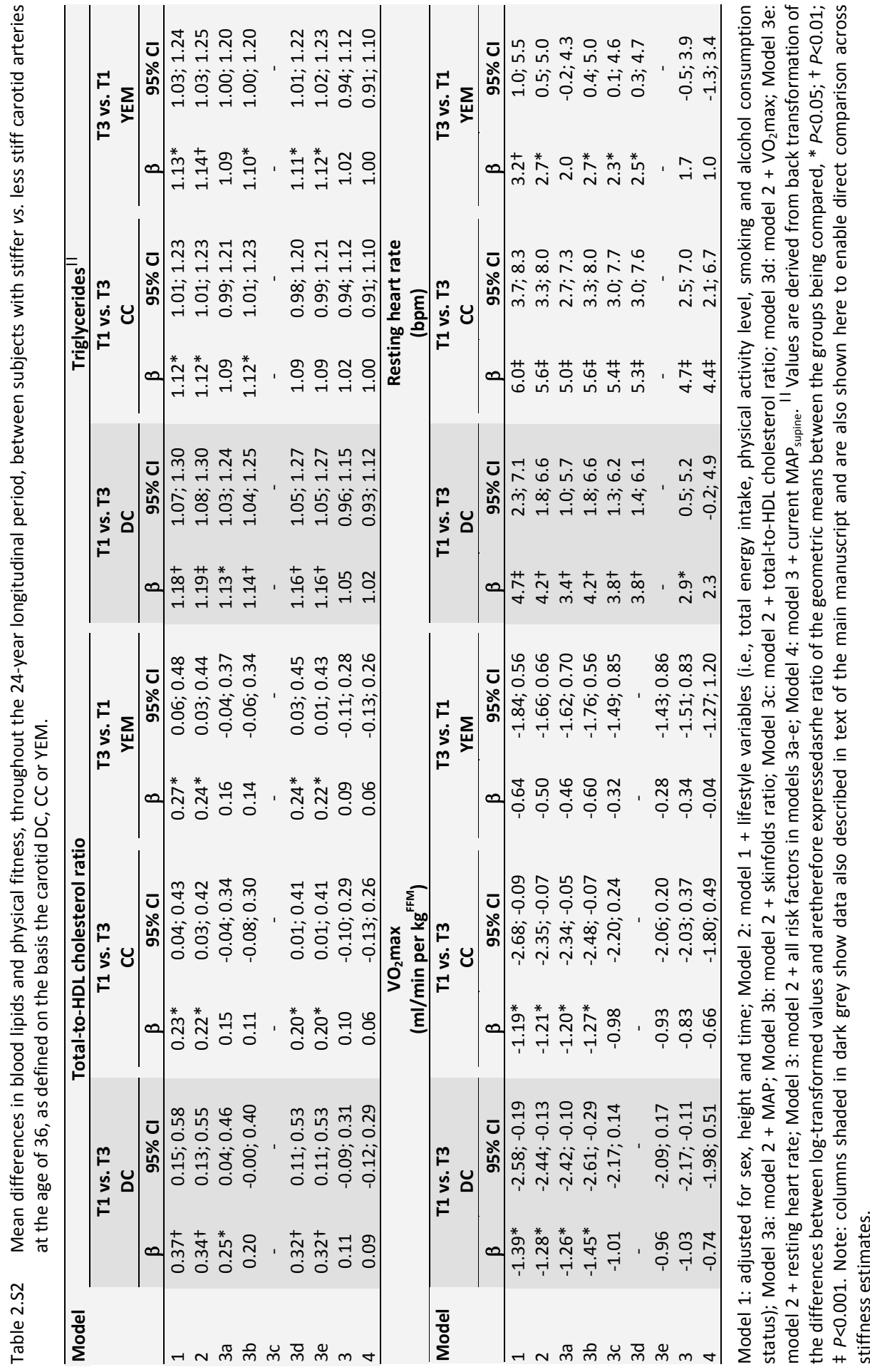




\section{Physical activities \& sedentary behaviour}




\section{Chapter}

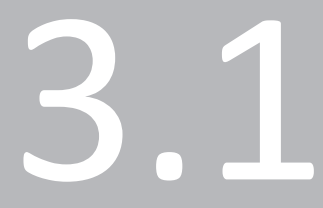

Lifetime vigorous but not light-to-moderate

habitual physical activity impacts favorably on carotid stiffness in young adults

The Amsterdam Growth and Health Longitudinal Study

Roel J. van de Laar, Isabel Ferreira, Willem van Mechelen, Martin H. Prins, Jos W. Twisk, Coen D. Stehouwer Hypertension 2010;55:33-39 


\section{ABSTRACT}

Higher levels of habitual physical activity favorably impact on arterial stiffness. It is not clear, however, whether lifetime habitual physical activities of different intensities carry the same protective effect and to what extent any such effect is mediated by other biological cardiovascular risk factors. We therefore examined longitudinal data on habitual physical activity and cardiovascular risk factors ( 8 repeated measures between the ages of 13 and 36 years) in 373 subjects in whom stiffness estimates of the carotid artery were assessed at age 36 years using non-invasive ultrasonography. The time spent in habitual physical activities (in minutes per week) throughout the longitudinal period was compared between subjects across tertiles of the following stiffness estimates: $\beta$ stiffness index, distensibility and compliance coefficients, and the Young's elastic modulus. After adjustments for sex, body height and other lifestyle variables, subjects in the highest tertile of the beta-stiffness index (i.e. with stiffer arteries) had spent on average, throughout the longitudinal period, less time in vigorous (-26.5 [95\% Cl: $-45.9 ;-7.1])$, but less so in light-to-moderate habitual physical activities $(-11.2[-53.5$; 31.1]) as compared to subjects in the lowest tertile. The difference in time spent in vigorous activities was greatly attenuated when further adjusted for blood lipids, cardiorespiratory fitness, fat distribution, resting heart rate and mean arterial pressure (to $-11.2[95 \% \mathrm{Cl}$ : -29.4 ; 7.0]). Similar results were found for the other stiffness estimates. Promoting vigorous intensity physical activities among the healthy young may, therefore, prevent arterial stiffness and related cardiovascular sequelae later in life, partly through its favorable impact on other biological cardiovascular risk factors. 


\section{INTRODUCTION}

Higher levels of habitual physical activity (HPA) attenuate the increase in arterial stiffness that occurs with ageing. ${ }^{1}$ Given that stiffening of central (i.e. elastic) arteries such as the aorta and carotid arteries increases the risk of cardiovascular disease, ${ }^{2}$ maintaining a physically active lifestyle in the course of life may thus constitute a valuable tool to reduce arterial stiffness-related cardiovascular disease. ${ }^{3}$

The evidence so far underlining the beneficial role of HPA on aortic or carotid stiffness has been derived from both cross-sectional observational studies showing that subjects who are more physically active have less stiff arteries than their sedentary counterparts, ${ }^{4-7}$ and intervention studies showing favorable arterial adaptations after increases in aerobic exercise. ${ }^{6,8,9}$ However, the fact that aerobic exercise has been ineffective in the restoration of arterial distensibility in some clinical populations, for example, in elderly individuals with isolated systolic hypertension, ${ }^{10}$ suggests that increases in HPA are likely more effective when initiated early in life.

Arterial stiffness has its roots early in life. From this perspective, we $e^{11}$ and others $^{12,13}$ have shown previously that higher levels of body fatness and blood pressure in childhood/adolescence are associated with increased arterial stiffness in adulthood. Higher levels of HPA protect against the development of such biological cardiovascular risk factors among the young, ${ }^{14}$ and these effects may, thus, provide a mechanism through which HPA prevents the development of arterial stiffness later in life. However, it is not clear to what extent HPAs of different intensities carry the same protective effect on both arterial stiffness and other cardiovascular risk factors among the young. For instance, some studies have shown that vigorous but not light intensity HPAs were associated with less arterial stiffness. ${ }^{4,15,16}$ From a preventive point of view, addressing these complex interrelationships is of utmost importance to construct targeted interventions with the highest potential for health benefits.

In view of these considerations, we have therefore investigated, in a cohort of healthy young individuals whose HPA levels and cardiovascular risk factors have repeatedly been assessed from ages 13 to 36 and in whom stiffness estimates of the carotid artery could be assessed at age 36: first, whether the mean levels and the developmental patterns, from adolescence up to adulthood, of light-to-moderate and vigorous HPA differed between subjects with stiffer vs. those with less stiff carotid arteries in adulthood; and second, the extent to which any such differences were explained by a favorable impact of HPAs (if any) on other cardiovascular risk factors. 


\section{METHODS}

\section{Subjects and study design}

All of the subjects were participants of the Amsterdam Growth and Health Longitudinal Study. This study started in 1977 with a group of 600 boys and girls from two secondary schools in the Netherlands. Its initial goal was to describe the natural development of growth, health and lifestyle of adolescents and to investigate longitudinal relations between biological and lifestyle variables, as described in detail elsewhere. ${ }^{17}$ The mean age of the subjects at the beginning of the study was 13.1 $( \pm 0.8)$ years. Since then, measurements were obtained 2 to 8 times (i.e. at the ages of $13,14,15,16,21,27,32$ and 36) during a 24-year follow-up period. At each measurement, anthropometrical, biological and lifestyle variables were assessed. In 2000 , when subjects' mean age was $36.5( \pm 0.6)$ years, arterial properties were assessed for the first time in 377 subjects. ${ }^{11,18,19}$ The present study reports on 373 subjects (196 women) in whom complete arterial data were available.

The study was approved by the medical ethical committee of the VU University Medical Center (Amsterdam, the Netherlands). All subjects gave their written informed consent (provided by their parents when subjects were 13 to 16 years old).

\section{Arterial stiffness}

When subjects were 36 years old, arterial properties of the carotid, brachial and femoral arteries were assessed by means of non-invasive ultrasonography according to guidelines for user procedures and with the use of reproducible and valid methods and devices. ${ }^{2,20,21}$ All of the subjects had abstained from smoking and caffeinecontaining beverages on the day the measurements were performed. Measurements took place after subjects had been resting in a supine position for 15 minutes in a quiet, temperature-controlled room. Properties of the right common carotid artery (10 $\mathrm{mm}$ proximal to the beginning of the bulb) were obtained by two trained vascular sonographers with the use of an ultrasound scanner equipped with a 7.5-MHz linear array probe (Pie Medical, Maastricht, The Netherlands). The ultrasound scanner was connected to a personal computer equipped with an acquisition system and a vessel wall movement detector software system (Wall Track System 2, Pie Medical, Maastricht, The Netherlands). This integrated device enabled measurements of arterial diameter (D), distension ( $\Delta D)$, and intima-media thickness (IMT), as described in detail elsewhere. ${ }^{20,21}$

Throughout the entire period of ultrasound imaging, systolic (SP), diastolic (DP) and mean arterial blood pressure were assessed in the left arm at 5-minute intervals with an oscillometric device (Colin Press-Mate, model BP-8800, Komaki-City, Japan). Brachial pulse pressure (PP) was defined as SP-DP, and PP at the level of the common carotid artery was calculated by calibration of the distension waveforms. ${ }^{22}$ The mean carotid IMT, D, $\triangle \mathrm{D}, \mathrm{SP}, \mathrm{DP}$ and local PP of 3 consecutive measurements (each 
including 3 to 7 heartbeats) were used to estimate the beta-stiffness index (SI), distensibility (DC) and compliance (CC) coefficients and the Young's elastic modulus (YEM) as follows: ${ }^{11,12,18,19}$

$$
\begin{aligned}
& \mathrm{SI}=\ln (S P / D P) /(\Delta D / D) \\
& D C=\left(2 \Delta D \cdot D+\Delta D^{2}\right) /\left(P P \cdot D^{2}\right) \\
& C C=\pi \cdot\left(2 D \cdot \Delta D+\Delta D^{2}\right) / 4 P P \\
& Y E M=D /(I M T \cdot D C)
\end{aligned}
$$

\section{Habitual physical activity}

HPA was measured at each measurement occasion (i.e. from age 13 to 36 years) by means of a structured detailed face-to-face interview. At the mean ages of 27 and 32 years, a standard form containing cues was used during the HPA interview, ${ }^{23}$ and, at the mean age of 36, an identical interviewer-administered computer-assisted version was introduced. The interview covered the preceding 3 months, except when subjects were of opinion that their HPA pattern during this period was abnormal (e.g. because of illness or holiday), and was always performed during the same time of the year (i.e. between January and June). The intensity, frequency, and duration of all physical activities (at school, at work, at home, during leisure time, organized and unorganized sports, climbing stairs, and active transportation) with a duration of $\geq 5$ minutes and exceeding an intensity level of 4 times the resting metabolic rate (i.e. $>4$ metabolic equivalents; METs) were retrieved. According to their intensities, activities were then classified into light-to-moderate (4-7 METs, e.g. brisk walking), hard (7-10 METs, e.g. tennis, jogging), and very hard (>10 METs, e.g. squash). Extreme values of HPA at given time points, i.e. those above 3 SD from the time-specific mean level, were excluded from the analyses, and time spent in hard and very hard intensity HPAs were combined into a 'vigorous' intensity category.

\section{Covariates}

Throughout the 24-year study period other lifestyle (i.e. alcohol consumption, smoking behavior and dietary intake), anthropometrical (i.e. body height, body weight, body skinfolds) and biological (i.e. sitting blood pressure, cardiorespiratory fitness, blood lipids and resting heart rate) risk factors were measured as described in detail elsewhere. ${ }^{11,17-19,23,24}$

\section{Statistical analyses}

We used generalized estimating equations to investigate the mean difference in time spent in light-to-moderate and vigorous HPA, throughout the 24-year longitudinal period (i.e. from age 13 up to 36 ), between subjects in the higher sex-specific tertiles 
(i.e. T2 or T3) vs. those in the lowest tertile (T1) of the carotid SI, DC, CC and $\mathrm{E}_{\text {inc }}$ at age 36 years. Before categorization into tertiles, the DC and CC were inversed so that higher values indicate higher stiffness levels in accordance with the SI and theYEM. The longitudinal method of data analyses adopted adjusts for the correlation between repeated observations taken in the same subject and has the advantage of handling repeated data of subjects with varying numbers and unequally time-spaced observations. ${ }^{25}$ The analyses were first adjusted for sex, body height (to account for subjects' growth throughout the longitudinal period) and time (entered in the model as a continuous variable) (model 1 ), and subsequently for other lifestyle risk factors, i.e. smoking and alcohol drinking statuses (yes or no), and total energy intake (in kilocalories per day), all considered as potential confounders (model 2). Next, we further adjusted for other biological cardiovascular risk factors, that is, mean arterial pressure, skinfolds ratio (as a marker of central pattern of fat distribution), ${ }^{11}$ cardiorespiratory fitness, total-to-high density lipoprotein (HDL) cholesterol ratio and resting heart rate, to ascertain the extent to which any differences in HPA between the groups being compared could be explained (i.e. mediated) by the favorable impact of HPA on these risk factors (models $3 \mathrm{~A}$ to $3 \mathrm{E}$ and 4 ). These analyses thus enabled us to ascertain the presence of any such 'mediating effect' by examining the magnitude of the changes in differences in HPA levels between the groups being compared before and after adjustments for these risk factors (in which case these differences would decrease). In these analyses we adjusted for the skinfolds ratio instead of the sum of skinfolds or body mass index, because of its stronger association with HPA and carotid stiffness. ${ }^{11}$

Generalized estimating equations were also used to examine the longitudinal associations between time spent in HPA on the one hand, and biological cardiovascular risk factors on the other. Results of these analyses are expressed as standardized longitudinal regression coefficients to enable comparison of the strength of the associations between HPA and each risk factor. These analyses were adjusted for covariates as mentioned above (models 1 and 2).

Finally, we examined the trajectories of the different intensity HPAs, from age 13 to age 36 years, between the groups being compared, by adding interaction terms between group and time to the models described above, and results hereby obtained were displayed graphically (smoothed line plots). ${ }^{24,25}$

In all generalized estimating equation analyses, an exchangeable correlation structure was used, which was deemed the most appropriate after examination of the inter-period correlation matrixes of HPA and cardiovascular risk factors throughout the 24-year study period. ${ }^{25}$ All results are reported for men and women combined, because no significant interactions with sex were found. All statistical analyses were performed with the use of the STATA software package version 9.2 (STATA Corp, College Station, Texas, USA). 


\section{RESULTS}

Table 3.1.1 shows the general characteristics of the study population throughout the longitudinal period. After adjustment for sex and body height, the total time spent in HPA decreased from age 13 up until age 27 years ( $-77 \mathrm{~min} /$ week [ $95 \% \mathrm{Cl}$ : -143 to -11$]$ ) followed by a considerable increase thereafter up to the age of 36 years (278 min/week [95\% Cl: 225 to 332]). The time spent in light-to-moderate HPA increased by $348 \mathrm{~min} /$ week ( $95 \% \mathrm{Cl}$ : 295 to 401$)$, whereas time spent in vigorous HPA decreased by $148 \mathrm{~min} /$ week $(95 \% \mathrm{Cl}:-169$ to -126$)$ between adolescence and the age of 36.

The mean values ( \pm SD) of SI, DC, CC and YEM across tertiles of each stiffness estimate are presented in Table 3.1.2.

Table 3.1.1 Characteristics of the study population throughout the 24-year longitudinal period.

\begin{tabular}{|c|c|c|c|c|c|c|c|c|}
\hline \multirow[t]{2}{*}{ Variables } & \multicolumn{8}{|c|}{ Calendar age (years) } \\
\hline & 13 & 14 & 15 & 16 & 21 & 27 & 32 & 36 \\
\hline \multicolumn{9}{|l|}{ Habitual physical activity } \\
\hline Total, min/week & $579 \pm 192$ & $548 \pm 197$ & $548 \pm 226$ & $516 \pm 198$ & $513 \pm 299$ & $452 \pm 313$ & $499 \pm 303$ & $745 \pm 455$ \\
\hline $\begin{array}{l}\text { Light-to-moderate, } \\
\mathrm{min} / \text { week }\end{array}$ & $281 \pm 142$ & $310 \pm 159$ & $375 \pm 196$ & $366 \pm 182$ & $427 \pm 269$ & $354 \pm 305$ & $369 \pm 268$ & $628 \pm 449$ \\
\hline Vigorous, min/week & $298 \pm 160$ & $237 \pm 125$ & $172 \pm 103$ & $150 \pm 97$ & $85 \pm 114$ & $98 \pm 94$ & $130 \pm 138$ & $117 \pm 99$ \\
\hline $\begin{array}{l}\text { Other lifestyle risk } \\
\text { factors }\end{array}$ & \multicolumn{7}{|c|}{ Other lifestyle risk } & \\
\hline Alcohol consumption, \% & 13.5 & 15.9 & 33.3 & 48.2 & 69.0 & 72.5 & 80.3 & 82.1 \\
\hline Smoking, \% & 1.6 & 11.0 & 14.0 & 17.9 & 29.9 & 26.2 & 20.2 & 23.5 \\
\hline $\begin{array}{l}\text { Total energy intake, } \\
1000 \mathrm{kcal} / \mathrm{day}\end{array}$ & $2.46 \pm 0.55$ & $2.51 \pm 0.59$ & $2.59 \pm 0.68$ & $2.55 \pm 0.68$ & $2.62 \pm 0.73$ & $2.48 \pm 0.64$ & $2.60 \pm 0.71$ & $2.62 \pm 0.70$ \\
\hline \multicolumn{9}{|l|}{ Biological risk factors } \\
\hline $\begin{array}{l}\text { Systolic blood pressure, } \\
* \mathrm{mmHg}\end{array}$ & $124.7 \pm 9.3$ & $123.3 \pm 9.2$ & $125.2 \pm 9.9$ & $126.0 \pm 10.6$ & $128.8 \pm 11.2$ & $129.5 \pm 11.9$ & $129.6 \pm 12.4$ & $131.2 \pm 14.4$ \\
\hline $\begin{array}{l}\text { Diastolic blood } \\
\text { pressure, }{ }^{*} \mathrm{mmHg}\end{array}$ & $75.5 \pm 7.8$ & $75.9 \pm 7.6$ & $72.5 \pm 8.0$ & $74.6 \pm 8.1$ & $78.7 \pm 8.4$ & $81.1 \pm 8.6$ & $84.6 \pm 8.8$ & $85.4 \pm 10.6$ \\
\hline $\begin{array}{l}\text { Mean arterial pressure, } \\
* \mathrm{mmHg}\end{array}$ & $91.9 \pm 6.9$ & $91.7 \pm 6.6$ & $90.1 \pm 6.6$ & $91.8 \pm 7.2$ & $95.4 \pm 8.0$ & $97.2 \pm 8.4$ & $99.6 \pm 9.0$ & $100.7 \pm 11.0$ \\
\hline Pulse pressure, ${ }^{*} \mathrm{mmHg}$ & $49.2 \pm 9.8$ & $47.4 \pm 10.2$ & $52.7 \pm 11.9$ & $51.4 \pm 11.4$ & $50.1 \pm 10.5$ & $48.4 \pm 10.7$ & $45.0 \pm 9.9$ & $45.8 \pm 9.8$ \\
\hline Body mass index, $\mathrm{kg} / \mathrm{m}^{2}$ & $17.7 \pm 1.8$ & $18.4 \pm 2.0$ & $19.2 \pm 2.1$ & $19.8 \pm 2.1$ & $21.4 \pm 2.2$ & $22.2 \pm 2.3$ & $23.3 \pm 2.9$ & $24.1 \pm 3.1$ \\
\hline $\begin{array}{l}\text { Sum of four skinfolds, } \\
+\mathrm{mm}\end{array}$ & $32.0 \pm 12.0$ & $33.5 \pm 14.0$ & $35.3 \pm 15.0$ & $38.9 \pm 16.6$ & $44.8 \pm 17.2$ & $41.9 \pm 16.1$ & $47.4 \pm 19.2$ & $51.5 \pm 18.2$ \\
\hline Skinfold ratio $¥$ & $0.49 \pm 0.06$ & $0.51 \pm 0.06$ & $0.53 \pm 0.06$ & $0.55 \pm 0.06$ & $0.58 \pm 0.08$ & $0.56 \pm 0.08$ & $0.56 \pm 0.09$ & $0.57 \pm 0.10$ \\
\hline $\mathrm{VO}_{2} \max , \mathrm{mL} / \mathrm{min}^{\prime} \mathrm{kg}^{\mathrm{FFM}}$ & $69.5 \pm 6.5$ & $68.9 \pm 6.3$ & $67.0 \pm 5.7$ & $66.2 \pm 6.5$ & $59.8 \pm 6.2$ & $56.6 \pm 6.4$ & $56.5 \pm 7.4$ & $60.6 \pm 8.4$ \\
\hline $\begin{array}{l}\text { Total-to-HDL } \\
\text { cholesterol ratio }\end{array}$ & $3.2 \pm 0.7$ & $3.2 \pm 0.7$ & $3.4 \pm 0.8$ & $3.2 \pm 0.7$ & $3.8 \pm 0.9$ & $3.8 \pm 1.0$ & $3.7 \pm 1.2$ & $3.8 \pm 1.3$ \\
\hline Resting heart rate, bpm & $83 \pm 14$ & $79 \pm 13$ & $79 \pm 15$ & $76 \pm 14$ & $72 \pm 13$ & $72 \pm 13$ & $75 \pm 14$ & $71 \pm 11$ \\
\hline
\end{tabular}

Data are means \pm SD or percentages. $\mathrm{HDL}$, high-density lipoprotein; FFM, fat-free mass; $\mathrm{VO}_{2}$ max, maximal oxygen uptake as a marker of cardiorespiratory fitness. * Measurements were performed with a sphygmomanometer on the right arm with subjects in the sitting position after $\geq 5 \mathrm{~min}$ of rest. + Data show the sum of the thickness of the following skinfolds: triceps, biceps, subscapular and suprailiac. $¥$ Ratio calculated as: (subscapular + suprailiac)/sum of 4 skinfolds. 
Table 3.1.2 Stiffness levels at the age of 36 years across tertiles of each carotid stiffness estimate.

\begin{tabular}{lccc}
\hline Carotid stiffness estimates & $\begin{array}{c}\text { T1 } \\
\text { (less stiff) }\end{array}$ & $\begin{array}{c}\text { T2 } \\
\text { (intermediate) }\end{array}$ & $\begin{array}{c}\text { T3 } \\
\text { (stiffer) }\end{array}$ \\
\hline SI & $6.0 \pm 0.5$ & $7.2 \pm 0.4$ & $9.0 \pm 1.1$ \\
Distensibility coefficient, $10^{-3} / \mathrm{kPa}$ & $33.4 \pm 4.1$ & $26.2 \pm 1.6$ & $20.3 \pm 2.2$ \\
Compliance coefficient, $\mathrm{mm}^{2} / \mathrm{kPa}$ & $1.28 \pm 0.20$ & $0.97 \pm 0.09$ & $0.72 \pm 0.12$ \\
Young's elastic modulus, $10^{3} \mathrm{kPa}$ & $0.32 \pm 0.05$ & $0.43 \pm 0.03$ & $0.58 \pm 0.09$ \\
\hline
\end{tabular}

Data are means \pm SD. $T 1$, indicates lowest tertile; $T 2$, middle tertile; and T3, highest tertile of each carotid stiffness estimate. All of the stiffness estimates differ significantly across increasing tertiles ( $P$ for trend: $<0.001)$.

\section{Lifetime light-to-moderate and vigorous HPA and arterial stiffness in young adulthood}

Compared to subjects in T1, that is, with a less stiff carotid artery, those in T2 and T3 of the $\mathrm{SI}$, that is, with increasingly higher levels of carotid stiffness at age 36 years, spent on average significantly less time in vigorous HPA (-25.3 min/week [95\% Cl: -45.0 to -5.5 ] and $-31.9 \mathrm{~min} /$ week $[95 \% \mathrm{Cl}$ : -51.6 to -12.1$]$, respectively), throughout the longitudinal period (Table 3.1.3, model 1). In contrast, no significant differences in time spent in light-to-moderate HPA were found between the groups. Similar associations were found for the other stiffness estimates (Figure 3.1.1).

Light-to-moderate HPA
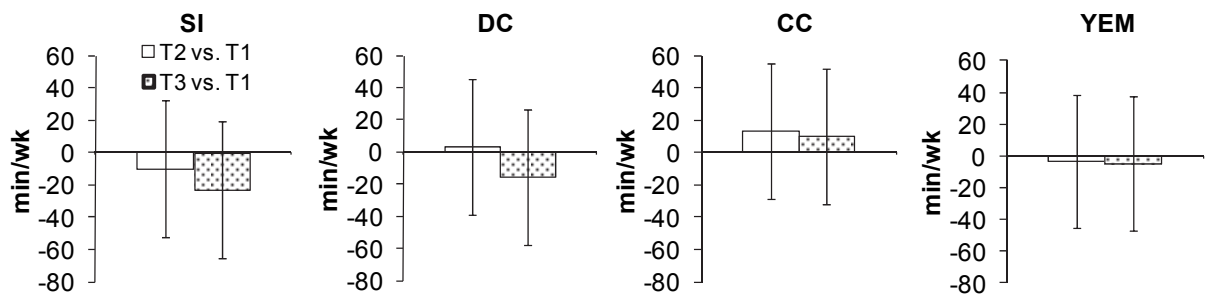

\section{Vigorous HPA}
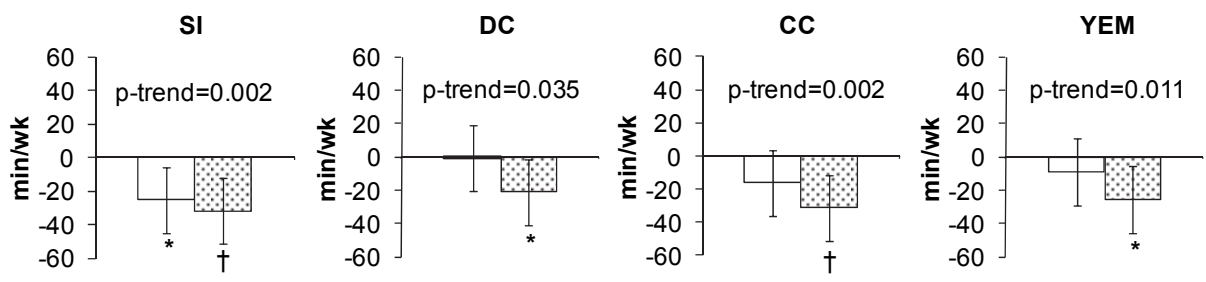

Figure 3.1.3 Average differences in time spent in light-to-moderate-intensity (top) and vigorous-intensity (bottom) HPAs throughout the 24-year longitudinal period between subjects in the middle (T2) and highest (T3) tertiles vs. those in the lowest tertile (T1) of each carotid stiffness estimate (indicated by bars).

Data are adjusted for sex, height and time; error bars indicate the $95 \%$ confidence interval around the average differences. $* P<0.05,+P<0.01$. 
Adjustment for other lifestyle risk factors, that is, potential confounders, attenuated the differences mentioned above in vigorous HPA between T2 and T3 vs. T1 to $-19.5 \mathrm{~min} /$ week $(95 \% \mathrm{Cl}$ : -38.9 to -0.2$)$ and to $-26.5 \mathrm{~min} /$ week $(95 \% \mathrm{Cl}$ : -45.9 to 7.1), respectively (Table 3.1.3, model 2). The difference in time spent in vigorous HPA between subjects with the 'stiffer' arteries (i.e. T3) vs. those with the 'less stiff' arteries (i.e. T1) at age 36 was further attenuated when adjusted for total-to-HDL cholesterol ratio (by 24\%; model 3D), cardiorespiratory fitness (by $23 \%$; model 3C), skinfolds ratio (by 20\%; model $3 \mathrm{~B}$ ), and resting heart rate (by $10 \%$; model $3 \mathrm{E}$ ), but not by mean arterial pressure (model $3 \mathrm{~A}$ ). When adjustments accounted for all these potential mediating risk factors simultaneously, the difference in time spent in vigorous HPAs between subjects in T3 vs. those in T1 was attenuated (i.e. explained) by $58 \%$ and was no longer significant (model 4 ).

Table 3.1.3 Difference in time spent in HPAs throughout the 24-year longitudinal period.

\begin{tabular}{|c|c|c|c|c|c|}
\hline \multirow[t]{3}{*}{ Model } & \multirow[t]{3}{*}{ Adjustment } & \multicolumn{4}{|c|}{ Beta-stiffness index } \\
\hline & & \multicolumn{2}{|c|}{ T2 vs. T1 } & \multicolumn{2}{|c|}{ T3 vs. T1 } \\
\hline & & $\beta$ & $95 \% \mathrm{Cl}$ & $\beta$ & $95 \% \mathrm{Cl}$ \\
\hline \multicolumn{6}{|c|}{ Light-to-moderate HPA } \\
\hline 1 & Sex, height, time & -10.1 & $-52.3 ; 32.1$ & -23.2 & $-65.3 ; 19.0$ \\
\hline 2 & Model $1+$ other lifestyles & -0.3 & $-42.6 ; 41.9$ & -11.2 & $-53.5 ; 31.1$ \\
\hline \multicolumn{6}{|c|}{ Vigorous HPA } \\
\hline 1 & Sex, height, time & -25.3 & $-45.0 ;-5.5^{*}$ & -31.9 & $-51.6 ;-12.1+$ \\
\hline 2 & Model $1+$ other lifestyles & -19.5 & $-38.9 ;-0.2^{*}$ & -26.5 & $-45.9 ;-7.1+$ \\
\hline $3 a$ & Model $2+$ mean arterial pressure & -19.0 & $-38.4 ; 0.3$ & -25.3 & $-44.8 ;-5.9 *$ \\
\hline $3 b$ & Model 2 + skinfolds ratio & -17.5 & $-36.5 ; 1.4$ & -21.1 & $-40.1 ;-2.0^{*}$ \\
\hline $3 c$ & Model $2+$ cardiorespiratory fitness & -14.5 & $-33.0 ; 4.0$ & -20.5 & $-39.1 ;-1.9 *$ \\
\hline $3 d$ & Model $2+$ total-to-HDL cholesterol ratio & -13.0 & $-32.6 ; 6.6$ & -20.1 & $-39.8 ;-0.5^{*}$ \\
\hline $3 e$ & Model $2+$ resting heart rate & -19.3 & $-38.2 ;-0.4^{*}$ & -23.9 & $-42.8 ;-4.9 *$ \\
\hline 4 & Model $2+$ all variables in models $3 a$ to $3 e$ & -9.8 & $-27.8 ; 8.2$ & -11.2 & $-29.4 ; 7.0$ \\
\hline
\end{tabular}

$\beta$ indicates regression coefficient, that is the average difference in time spent in HPAs (in min/wk) throughout the 24-year longitudinal period between subjects in the middle (T2) and highest ( T3) tertiles vs. those in the lowest (T1) tertile of the SI. HDL, high-density lipoprotein. ${ }^{*} P<0.05 ;+P<0.01$.

Similar results as described above were found when the differences in vigorous HPA between subjects in T3 vs. those in T1 of the carotid DC, CC or YEM were adjusted for these potential confounders and mediators; only the attenuation after adjustment for mean arterial pressure was relatively greater than the one observed for the SI (though never exceeding 14\%), because of the greater dependence of those other estimates on mean arterial pressure than the SI (please see Table 3.1.S1 - Appendix 1).

Indeed, more time spent in HPA, particularly of vigorous intensity, was favorably associated with all cardiovascular risk factors examined (Table 3.1.4, model 1), and adjustments for other lifestyle risk factors attenuated these associations only slightly (model 2). 


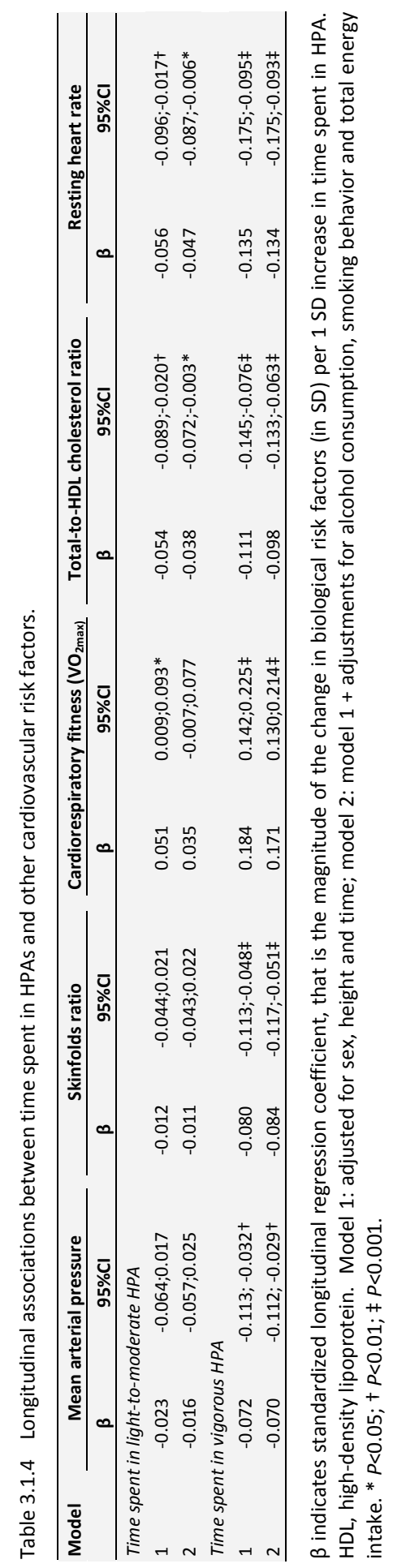




\section{Life-course trajectories of light-to-moderate and vigorous intensity HPA in subjects with stiffer vs. less stiff arteries at the age of 36 years}

All of the groups increased their time spent in light-to-moderate HPAs between adolescence and the age of 36 years, and no marked differences in the patterns of development across groups were observed regarding this type of HPA. Only at the age of 32 years and thereafter did subjects in T1, that is, those with less stiff arteries, tend to spent more time in these type of HPA as compared with those in T2 and T3 of the SI (Figure 3.1.2A). In contrast, time spent in vigorous HPAs decreased substantially between adolescence and young adulthood in all groups. However, subjects in T2 and $\mathrm{T} 3$, that is, those with increasingly higher levels of carotid stiffness, spent less time in these activities than those with less stiff arteries (T1), particularly in late adolescence and thereafter, that is, after the age of 15 years and up to the age of 36 years (Figure 3.1.2B).

Essentially similar patterns of HPAs throughout the course of life were found when subjects were categorized on the basis of levels of DC, CC and YEM (data not shown).
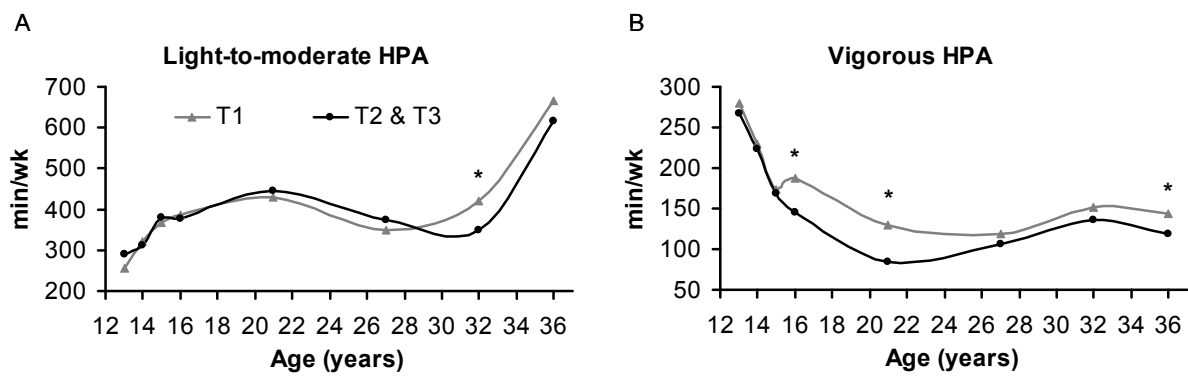

Figure 3.1.2 Time spent in A) light-to-moderate and B) vigorous HPAs throughout the longitudinal period by subjects in the lowest tertile (T1) and those in the middle and highest tertiles (T2 and T3) of the carotid stiffness index at the age of 36 years. Note that the latter two groups were combined because their mean levels of HPAs throughout the longitudinal period were comparable and differed in similar magnitudes from subjects in tertile 1.

Data are adjusted for sex, height and time. ${ }^{*} P<0.05$ (tertiles 2 and 3 vs. tertile 1 ).

\section{DISCUSSION}

The main findings of this study were three-fold. First, subjects with stiffer carotid arteries at the age of 36 years (as assessed by different local stiffness estimates) spent significantly less time in vigorous but not in light-to-moderate intensity HPAs between adolescence and young adulthood, supporting the view of a favorable impact of vigorous HPAs on carotid arterial stiffness. Second, this favorable impact was explained, to a great extent, by the beneficial vigorous HPA-related changes in other cardiovascular disease risk factors. Third, despite considerable decreases in time spent 
in vigorous HPAs during adolescence in the whole study population, compared to subjects with less stiff those with stiffer carotid arteries were characterized by steeper decreases in time spent in vigorous HPAs during late adolescence and consistently less times in these HPAs thereafter, up to the age of 36 years.

The beneficial effects of HPA on aortic or carotid stiffness have been widely reported in cross-sectional and intervention studies. ${ }^{4-9,15,16}$ We have now examined in detail to what extent the beneficial effects of HPA can be attributed to a relatively higher contribution of time spent in HPAs of different intensities throughout the course of life, and identified vigorous intensity HPA as the type of HPA carrying the greatest beneficial impact on carotid arterial stiffness. These findings are in line with others showing that activities of higher intensity were associated with less arterial stiffness. ${ }^{4,15,16}$ By adopting a life-course approach, we found that, with ageing, subjects spent increasingly more time in light-to-moderate and less time in vigorous HPAs. This shift towards less time spent in vigorous activities started already in adolescence. However, maintenance of relatively higher levels of vigorous intensity activities from adolescence up to adulthood were associated with lower levels of arterial stiffness several years later, at the age of 36 . Therefore, our findings emphasize that the promotion of vigorous intensity HPAs in adolescence and young adulthood, in order to counteract its critical decline during this period, ${ }^{26}$ may be a valuable tool to effectively prevent arterial stiffness-related cardiovascular sequelae later in life.

Current physical activity recommendations in both children ${ }^{26}$ and adults $^{27}$ do recognize the added value of increasing vigorous HPA for reducing cardiovascular disease, but do not explicitly focus on these because health benefits are thought to result from increases in either light-to-moderate or vigorous HPAs. Although our findings do not dismiss the value of increasing light-to-moderate HPA, for instance among those children and young adults who are extremely sedentary and usually obese, they emphasize the importance of promoting vigorous HPA, in particular when targeting the common general young population. This is also supported by the observation that higher levels of vigorous, but less so of light-to-moderate, HPA carried a greater beneficial impact on other biological cardiovascular risk factors. In fact, these vigorous HPA-related improvements in the biological cardiovascular risk factors, which are all known determinants of arterial stiffness, ${ }^{2,11-13}$ explained much of the favorable impact of HPA on stiffness levels of the carotid artery. All together, improvements in these cardiovascular risk factors that are intertwined, at least in part, lead to decreased arterial stiffness through mechanisms such as increases in parasympathetic activity, ${ }^{28}$ improvement of endothelial function due to enhanced arterial shear stress, ${ }^{29}$ reduction of low-grade inflammation, ${ }^{30}$ and improvements in insulin sensitivity. ${ }^{31}$

We categorized subjects into tertiles according to the values obtained for each of the carotid stiffness estimate that were assessed at the age of 36 years. This approach allowed us to compare the development of HPA levels from adolescence up to adulthood for subjects with stiffer and those with less stiff carotid arteries in 
adulthood. The differences in, for instance, the carotid DC and CC values between those in the highest vs. those in the lowest tertiles corresponded to values observed in the course of more than one decade of ageing, ${ }^{32}$ which illustrates that the groups being compared translate to physiological relevant differences in mean levels of arterial stiffness.

There are some limitations to our study. First, our findings were confined to subjects attending the follow-up in 2000 in whom complete data on arterial properties could be assessed. However, levels of HPA as well as blood pressure, body fatness, cardiorespiratory fitness and blood lipids in these subjects did not differ, at any earlier time point, from those subjects who dropped-out (data not shown), indicating that selection bias is unlikely to have threatened the validity of our findings. Second, carotid stiffness levels were measured at age 36 only. Therefore, we cannot rule out the possibility that reversed causation may have occurred, i.e. that subjects with stiffer arteries at any earlier time-point may have been less prone to perform (vigorous) HPAs. ${ }^{33}$ Third, in our analyses we did not differentiate between strength and endurance training that could affect arterial stiffness differently. ${ }^{1}$ Indeed, strength exercise has an adverse effect while endurance training has a favorable effect on arterial stiffness. However, the relative contribution of activities carrying a strong component of strength exercise (e.g. bodybuilding, weightlifting, wall climbing, rowing, lifting/carrying heavy-objects) amounted less than $2 \%$ of the total time spent in HPAs, contributed similarly to the time spent in light-to-moderate and vigorous HPAs, and was equally distributed across the groups being compared, and thus did not affect our results. Finally, the assessment of HPA levels by means of questionnaires is subject to recall and misclassification bias. ${ }^{34}$ Most likely these biases were nondifferential, because subjects were unaware of their arterial stiffness levels when they reported their HPAs throughout the study period. Still, some differential biases may have occurred, probably by over-reporting of HPA levels by those with unhealthier lifestyles/risk factor profiles. Either way, the differences in HPA levels between subjects with stiffer vs. those with less stiff arteries as reported herein were probably underestimated. It might also be that over-reporting of HPA occurred more often at older ages when health awareness may have been greater among study participants. This could explain, at least in part, the steep increases in time spent in light-tomoderate intensity HPA observed in this cohort, particularly after the age of 32 years. This somewhat odd trajectory of time spent in light-to-moderate HPA can also be attributed to the change of the interview to a computerized format, which possibly captured more of these HPAs as compared to previous years. However, the increases in HPA, at least in part, may have been real because they were accompanied by an increase in the population's mean cardiorespiratory fitness level from the age of 32 years that was measured objectively by means of maximal oxygen uptake. Importantly, removing HPA data at the age of 36 years from the analyses reported herein did not materially change our findings, however (data not shown). 


\section{PERSPECTIVES}

Our findings show that vigorous but not light-to-moderate HPA, performed and accumulated throughout the course of life, and particularly during young adulthood, have a beneficial impact on carotid arterial stiffness later in life. Promoting increases in HPA among the healthy young as a tool to prevent arterial stiffness and related cardiovascular sequelae should, therefore, target HPAs of vigorous intensity. 


\section{REFERENCES}

1. Seals DR, Desouza CA, Donato AJ, Tanaka H. Habitual exercise and arterial aging. J Appl Physiol. 2008;105:1323-1332.

2. Laurent S, Cockcroft J, Van Bortel L, et al. Expert consensus document on arterial stiffness: methodological issues and clinical applications. Eur Heart J. 2006;27:2588-2605.

3. Ferreira I, Boreham CA, Stehouwer CD. The benefits of exercise for arterial stiffness. Am J Hypertens. 2006;19:1037-1038.

4. Boreham CA, Ferreira I, Twisk JW, Gallagher AM, Savage MJ, Murray L. Cardiorespiratory fitness, physical activity, and arterial stiffness: the Northern Ireland Young Hearts Project. Hypertension. 2004;44:721-726.

5. Schmidt-Trucksass AS, Grathwohl D, Frey I, et al. Relation of leisure-time physical activity to structural and functional arterial properties of the common carotid artery in male subjects. Atherosclerosis. 1999;145:107-114.

6. Tanaka H, Dinenno FA, Monahan KD, Clevenger CM, DeSouza CA, Seals DR. Aging, habitual exercise, and dynamic arterial compliance. Circulation. 2000;102:1270-1275.

7. Kozakova M, Palombo C, Mhamdi L, et al. Habitual physical activity and vascular aging in a young to middle-age population at low cardiovascular risk. Stroke. 2007;38:2549-2555.

8. Cameron JD, Dart AM. Exercise training increases total systemic arterial compliance in humans. Am J Physiol. 1994;266:H693-701.

9. Kakiyama T, Sugawara J, Murakami H, Maeda S, Kuno S, Matsuda M. Effects of short-term endurance training on aortic distensibility in young males. Med Sci Sports Exerc. 2005;37:267-271.

10. Ferrier KE, Waddell TK, Gatzka CD, Cameron JD, Dart AM, Kingwell BA. Aerobic exercise training does not modify large-artery compliance in isolated systolic hypertension. Hypertension. 2001;38:222-226.

11. Ferreira I, Twisk JW, van Mechelen W, Kemper HC, Seidell JC, Stehouwer CD. Current and adolescent body fatness and fat distribution: relationships with carotid intima-media thickness and large artery stiffness at the age of 36 years. J Hypertens. 2004;22:145-155.

12. Juonala M, Jarvisalo MJ, Maki-Torkko N, Kahonen M, Viikari JS, Raitakari OT. Risk factors identified in childhood and decreased carotid artery elasticity in adulthood: the Cardiovascular Risk in Young Finns Study. Circulation. 2005;112:1486-1493.

13. Li S, Chen W, Srinivasan SR, Berenson GS. Childhood blood pressure as a predictor of arterial stiffness in young adults: the bogalusa heart study. Hypertension. 2004;43:541-546.

14. Twisk JW, Ferreira I. Physical activity, physical fitness and cardiovascular health. In: Armstrong N, Van Mechelen W, eds. Paediatric Exercise Science and Medicine. 2nd ed. Oxford: Oxford University Press; 2008:339-352.

15. Schmitz KH, Arnett DK, Bank A, et al. Arterial distensibility and physical activity in the ARIC study. Med Sci Sports Exerc. 2001;33:2065-2071.

16. Sugawara J, Otsuki T, Tanabe T, Hayashi K, Maeda S, Matsuda M. Physical activity duration, intensity, and arterial stiffening in postmenopausal women. Am J Hypertens. 2006;19:1032-1036.

17. Kemper HC. Amsterdam Growth and Health Longitudinal Study (AGAHLS). A 23-Year Follow-Up From Teenager To Adult about Lifestyle and Health. Vol 47. Basel: Karger; 2004.

18. Ferreira I, Henry RM, Twisk JW, van Mechelen W, Kemper HC, Stehouwer CD. The metabolic syndrome, cardiopulmonary fitness, and subcutaneous trunk fat as independent determinants of arterial stiffness: the Amsterdam Growth and Health Longitudinal Study. Arch Intern Med. 2005; 165:875-882.

19. Ferreira I, Twisk JW, Van Mechelen W, Kemper HC, Stehouwer CD. Current and adolescent levels of cardiopulmonary fitness are related to large artery properties at age 36: the Amsterdam Growth and Health Longitudinal Study. Eur J Clin Invest. 2002;32:723-731.

20. Brands PJ, Hoeks AP, Willigers J, Willekes C, Reneman RS. An integrated system for the non-invasive assessment of vessel wall and hemodynamic properties of large arteries by means of ultrasound. Eur $J$ Ultrasound. 1999;9:257-266.

21. Reneman RS, Hoeks AP. Noninvasive vascular ultrasound: an asset in vascular medicine. Cardiovasc Res. 2000;45:27-35. 
22. Van Bortel LM, Balkestein EJ, van der Heijden-Spek JJ, et al. Non-invasive assessment of local arterial pulse pressure: comparison of applanation tonometry and echo-tracking. J Hypertens. 2001;19: 1037-1044.

23. van Mechelen W, Twisk JW, Post GB, Snel J, Kemper HC. Physical activity of young people: the Amsterdam Longitudinal Growth and Health Study. Med Sci Sports Exerc. 2000;32:1610-1616.

24. Ferreira I, Twisk JW, van Mechelen W, Kemper HC, Stehouwer CD. Development of fatness, fitness, and lifestyle from adolescence to the age of 36 years: determinants of the metabolic syndrome in young adults: the amsterdam growth and health longitudinal study. Arch Intern Med. 2005;165:42-48.

25. Twisk JWR. Applied Longitudinal Data Analysis for Epidemiolgy: A Practical Guide. Cambridge: Cambridge University Press; 2003.

26. Strong WB, Malina RM, Blimkie CJ, et al. Evidence based physical activity for school-age youth. J Pediatr. 2005;146:732-737.

27. Haskell WL, Lee IM, Pate RR, et al. Physical activity and public health: updated recommendation for adults from the American College of Sports Medicine and the American Heart Association. Circulation. 2007;116:1081-1093.

28. Shephard RJ, Balady GJ. Exercise as cardiovascular therapy. Circulation. 1999;99:963-972.

29. Laughlin $\mathrm{MH}$, Newcomer SC, Bender SB. Importance of hemodynamic forces as signals for exerciseinduced changes in endothelial cell phenotype. J Appl Physiol. 2008;104:588-600.

30. Abramson JL, Vaccarino V. Relationship between physical activity and inflammation among apparently healthy middle-aged and older US adults. Arch Intern Med. 2002;162:1286-1292.

31. Gill JM, Malkova D. Physical activity, fitness and cardiovascular disease risk in adults: interactions with insulin resistance and obesity. Clin Sci (Lond). 2006;110:409-425.

32. Vermeersch SJ, Rietzschel ER, De Buyzere ML, et al. Age and gender related patterns in carotidfemoral PWV and carotid and femoral stiffness in a large healthy, middle-aged population. J Hypertens. 2008;26:1411-1419.

33. Kingwell BA. Large artery stiffness: implications for exercise capacity and cardiovascular risk. Clin Exp Pharmacol Physiol. 2002;29:214-217.

34. Ferrari $P$, Friedenreich $C$, Matthews $C E$. The role of measurement error in estimating levels of physical activity. Am J Epidemiol. 2007;166:832-840. 


\section{Appendix 3.1}

Supplemental table 
Chapter 3.1 


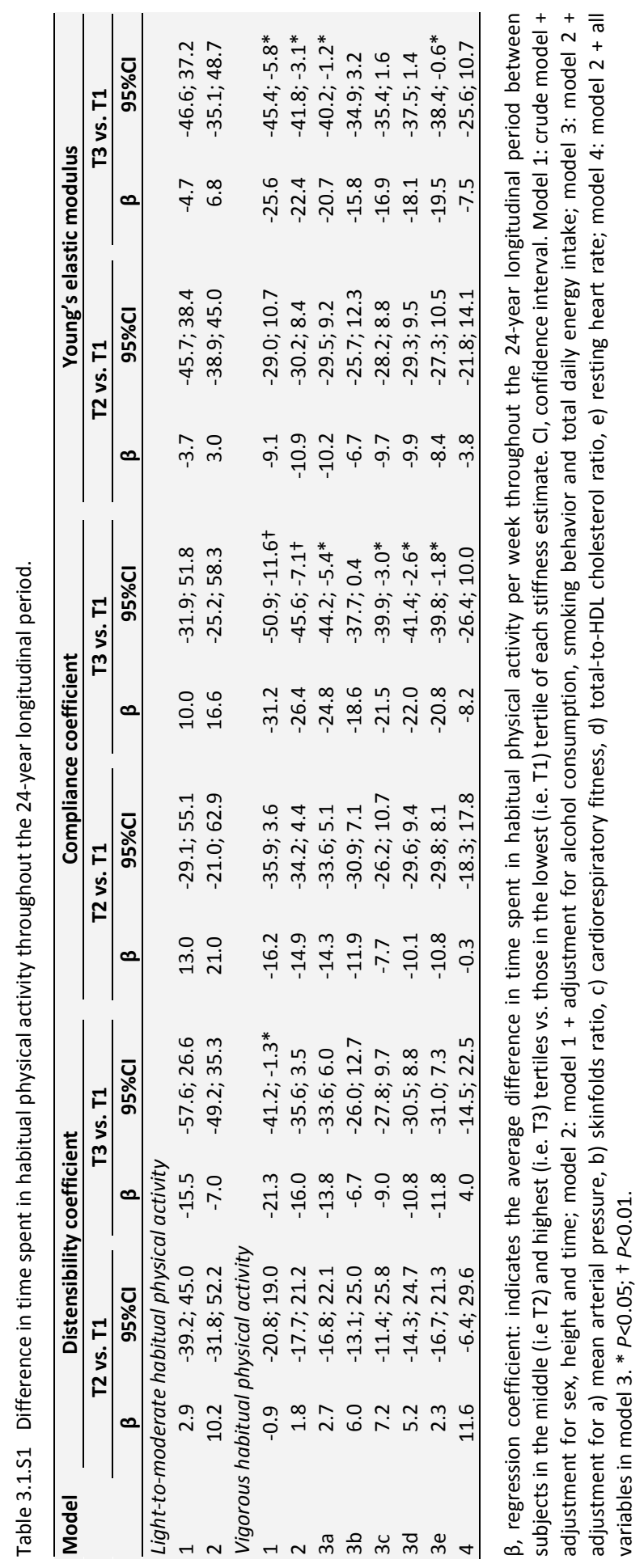




\title{
Chapter
}

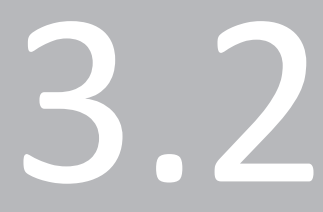

\author{
Habitual physical activity and peripheral \\ arterial compliance in young adults
} The Amsterdam Growth and Health Longitudinal Study

Roel J. van de Laar, Isabel Ferreira, Willem van Mechelen, Martin H. Prins, Jos W. Twisk, Coen D. Stehouwer 


\section{ABSTRACT}

\section{Background}

It remains unclear whether the impact of habitual physical activity (HPA) differs for central vs. peripheral arterial stiffness, both of which are detrimental to cardiovascular health. We investigated the associations of lifetime HPA of different intensities on brachial and femoral stiffness in young adults, and compared these with those previously obtained for the carotid artery in the same study population.

\section{Methods}

Prospectively measured data (eight repeated measures between ages 13 and 36 years) on HPAs, and other lifestyle and biological variables, were retrieved for 373 subjects in whom stiffness of the brachial and femoral, as well as the carotid, arteries was assessed at age 36 . Generalized estimating equations were used to examine the differences in time spent in HPAs (min/week) across sex-specific tertiles of the brachial and femoral distensibility (DC) and compliance (CC) coefficients.

\section{Results}

After adjustment for potential confounders, subjects in the highest (more compliant) vs. those in the lowest tertiles of the brachial and femoral CCs (less compliant) at age 36 years had spent on average )more time in vigorous $(+21.2$ [95\% Cl: $2.0 ; 40.4$ ] and +24.4 [5.0; 43.8], respectively], but not in light-to-moderate HPAs throughout the longitudinal period. These differences were explained by 28 and $62 \%$, respectively, by vigorous-HPA-related favorable impacts on other cardiovascular risk factors. No such associations were observed for the brachial and femoral DCs, however.

\section{Conclusions}

Lifetime vigorous, but not light-to-moderate, HPA is favorably associated with brachial and femoral compliance, but not DC. Altogether, these and our previous findings thus suggest generalized vigorous-HPA-related adaptations, although of different nature, throughout the arterial tree. 


\section{INTRODUCTION}

Arterial stiffness is a major risk factor for the development of cardiovascular disease. ${ }^{1}$ Its predictive value for cardiovascular risk has yet only been established for central (i.e. elastic) arteries, ${ }^{1}$ but higher stiffness levels of peripheral (i.e. muscular) arteries may also be detrimental to cardiovascular health. Indeed, stiffening of the more distal part of the arterial tree may boost the premature return of the reflected pulse wave at the level of the ascending aorta, thereby increasing cardiac afterload during the systolic phase of the cardiac cycle. ${ }^{2}$ In addition, although complications related to arterial stiffness, such as left ventricular hypertrophy, stroke and myocardial infarction, in general occur later in life, the development of arterial stiffening is rooted in childhood/adolescence and is characterized by a pre-clinical and asymptomatic phase that lasts for many decades. ${ }^{3-5}$ Taken all this together, identifying modifiable risk factors among the young that contribute to stiffening of not only the central, but also of the peripheral arteries is, thus, of great importance as it may enable a better understanding of the cross talk between proximal and distal parts of the arterial tree ${ }^{6}$ and may help to construct targeted prevention strategies with the most potential for health benefits later in life.

Higher levels of habitual physical activity (HPA) are favorably associated with arterial stiffness, ${ }^{7}$ which might explain the HPA-related lower risk for incident hypertension among apparently healthy adult men. ${ }^{8}$ However, whether such beneficial associations with arterial stiffness differ between central and peripheral arteries is not clear. The interpretation of the literature with this regard is hampered because most of the studies so far have investigated the association between HPA and stiffness estimates of one artery or arterial segment only, most often the carotid distensibility (DC) or compliance (CC) coefficients or the aortic pulse-wave velocity. ${ }^{9-23}$ The few studies that have investigated associations with stiffness of both types of arteries have shown HPA to be inversely associated with stiffness levels of: 1 ) central arteries only, ${ }^{24}$ arguing in favor of adaptations of mainly the elastic part of the arterial tree; 2) peripheral arteries only, ${ }^{25}$ arguing in favor of a localized adaptation of the arteries irrigating the limbs directly involved with exercise; or 3) both types of arteries, ${ }^{26,27}$ arguing in favor of a 'generalized effect' of HPA.

We have recently shown, in the Amsterdam Growth and Health Longitudinal Study (AGAHLS), that young adults with stiffer vs. those with less stiff carotid arteries had spent less time in vigorous, but not in light-to-moderate, intensity HPA throughout the course of their lives, i.e. from adolescence to adulthood, suggesting a favorable impact of this type of HPA on central arterial stiffness. ${ }^{28}$ This favorable association was explained, into a great extent, by vigorous-HPA-related beneficial associations with traditional cardiovascular risk factors. A major strength of the AGAHLS is that subjects' HPAs and other cardiovascular risk factors were assessed prospectively throughout their lives, which enables the investigation of 'lifetime exposure' to HPAs in relation to subjects' arterial stiffness levels in adulthood. This is in contrast to the previous 
studies mentioned above, which have ascertained subjects' HPA status on the basis of cross-sectional or retrospective examinations. In addition, arterial properties were assessed not only in the carotid, but also the brachial and femoral arteries, which allows us to comprehensively examine whether our previous findings are confined to the central carotid artery or also hold true for the peripheral arteries.

In view of these considerations, we have investigated: 1 ) the extent to which the mean levels of HPAs, of light-to-moderate and/or vigorous intensity, performed from adolescence up to adulthood differed between subjects with stiffer vs. those with less stiff brachial and femoral arteries at the age of 36; and 2) the extent to which any such differences could be explained by the favorable association between lifetime HPAs and other biological cardiovascular risk factors. ${ }^{28}$

\section{METHODS}

\section{Subjects and study design}

All subjects were participants of the AGAHLS. This study started in 1977 with a group of 600 boys and girls from two secondary schools in the Netherlands. ${ }^{29}$ The mean age of the subjects at the beginning of the study was 13.1 (SD 0.8) years. Since then, measurements were obtained 2 to 8 times (i.e. at the ages of $13,14,15,16,21,27,32$ and 36 years) during a 24-year follow-up period. At each measurement, anthropometrical, biological and lifestyle variables were assessed. In 2000, when subjects' mean age was 36.5 (SD 0.6) years, properties of the carotid, brachial and femoral arteries were assessed for the first time in 377 subjects. ${ }^{28,30,31}$ The present study reports on 373 of these subjects (196 women) in whom complete data on all 3 arteries were available.

The study was approved by the medical ethical committee of the VU University Medical Center (Amsterdam, the Netherlands), and all subjects gave their written informed consent (provided by their parents when subjects were 13-16 years old).

\section{Arterial stiffness}

When subjects were 36 years old, properties of three large arteries were assessed by means of non-invasive ultrasonography according to guidelines for user procedures and with the use of reproducible methods and devices. ${ }^{1,32,33}$ All subjects had abstained from smoking and caffeine-containing beverages on the day the measurements were performed. Measurements took place after subjects had been resting in a supine position for 15 minutes in a quiet temperature-controlled room. Properties of the right brachial ( $20 \mathrm{~mm}$ above the antecubital fossa) and the common femoral $(20 \mathrm{~mm}$ proximal to the flow divider) arteries were obtained by two trained vascular sonographers with the use of an ultrasound scanner equipped with a 7.5-MHz linear array probe (Pie medical, Maastricht, The Netherlands). The ultrasound scanner was 
connected to a personal computer equipped with an acquisition system and a vessel wall movement detector software system (Wall Track System 2, Pie Medical, Maastricht, The Netherlands). This integrated device enabled measurements of arterial diameter (D), distension $(\Delta D)$ as described in detail elsewhere.

Throughout the entire period of ultrasound imaging, systolic, diastolic and mean arterial blood pressure were assessed in the left arm at 5-minute intervals with an oscillometric device (Colin Press-Mate, model BP-8800, Komaki-City, Japan). Brachial artery pulse pressure (PP) was defined as systolic - diastolic pressure, and PP at the level of the femoral artery was calculated by calibration of the distension waveforms. $^{34}$ The mean brachial and femoral $D, \Delta D$, and local PP of three consecutive measurements (each including 3-7 heartbeats) were used to estimate the DC and CC coefficients as follows: ${ }^{30,31}$

$$
\begin{array}{ll}
D C=\left(2 \Delta D \cdot D+\Delta D^{2}\right) /\left(P P \cdot D^{2}\right) & \text { in } 10^{-3} / \mathrm{kPa} \\
C C=\pi \cdot\left(2 D \cdot \Delta D+\Delta D^{2}\right) / 4 P P & \text { in } \mathrm{mm}^{2} / \mathrm{kPa}
\end{array}
$$

\section{Habitual physical activity}

HPA was measured at each measurement occasion (i.e. from age 13 to 36 years) by means of a structured detailed face-to-face interview. ${ }^{28}$ At the mean ages of 27 and 32 years, a standard form containing cues was used during the HPA interview, and, at the mean age of 36, an identical interviewer-administered computer-assisted version was introduced. The intensity, frequency, and duration of all physical activities (at school, at work, at home, during leisure time, organized and unorganized sports, climbing stairs, and active transportation) with a duration of at least 5 minutes and exceeding an intensity level of four times the resting metabolic rate (i.e. $>4$ metabolic equivalents) were retrieved. According to their intensities, activities were then classified into light-to-moderate (4-7 metabolic equivalents, e.g. brisk walking), hard (7-10 metabolic equivalents, e.g. tennis, jogging), and very hard (>10 metabolic equivalents, e.g. squash). Extreme values of HPA at given time points, i.e. those above 3 SD from the time-specific mean level, were excluded from the analyses, and time spent in hard and very hard intensity HPAs were combined into a 'vigorous' intensity category. $^{28}$

\section{Covariates}

Throughout the 24-year study period other lifestyle (i.e. alcohol consumption, smoking behavior and dietary intake), anthropometrical (i.e. body height, body weight, body skinfolds and skinfolds ratio) and biological (i.e. sitting blood pressure, cardiorespiratory fitness, blood lipids and resting heart rate) risk factors were measured as described in detail elsewhere. ${ }^{29-31,35}$ 


\section{Statistical analyses}

We used generalized estimating equations to investigate the mean differences in time spent in light-to-moderate and vigorous intensity HPAs throughout the 24-year longitudinal period (i.e. from age 13 to 36 years), between subjects in the middle (T2) and highest (T3) vs. those in the lowest sex-specific tertiles (T1) of the brachial and femoral DC and CC at the age of 36 years. Note that higher levels of both the DC and CC represent lower levels of arterial stiffness. The method of longitudinal data analyses adopted adjusts for the correlation between repeated observations taken in the same subject and has the advantage of handling repeated data of subjects with varying numbers and unequally time-spaced observations. ${ }^{36}$ The analyses were first adjusted for sex, body height and time (model 1), and subsequently for other lifestyle risk factors (i.e. smoking and alcohol drinking statuses [yes/no], and total energy intake [in kilocalories per day]), all considered as potential confounders (model 2). Next, we further adjusted for other biological cardiovascular risk factors (i.e. mean arterial pressure, skinfolds ratio, cardiorespiratory fitness, total-to-HDL cholesterol ratio and resting heart rate), all considered as potential mediators, to ascertain the extent to which any differences in HPAs between the groups being compared could be explained by favorable associations between HPAs and these risk factors (models $3 \mathrm{~A}$ to $3 \mathrm{E}$ and 4$)^{28}$

In addition, we examined the trajectories of the different intensity HPAs, from age 13 to 36 years, between the groups being compared by adding interaction terms between groups and time to model 1 described above. Results hereby obtained were displayed graphically (smoothed line plots). ${ }^{28,35}$

In all generalized estimating equation analyses an exchangeable correlation structure was used, which was deemed the most appropriate after examination of the inter-period correlation matrixes of HPA and cardiovascular risk factors throughout the 24-year study period. All results are reported for men and women combined as no significant interactions with sex were found. All statistical analyses were performed with the use of the STATA software package version 9.2 (STATA Corp, College Station, Texas, USA).

\section{RESULTS}

Table 3.2.1 presents study participants' characteristics at the different ages throughout the longitudinal period. The mean levels of the DC and the CC of the brachial and femoral arteries across tertiles of each stiffness estimate are shown in Table 3.2.2. 
Table 3.2.1 Characteristics of the study population throughout the 24-year longitudinal period.

\begin{tabular}{|c|c|c|c|c|c|c|c|c|}
\hline \multirow[t]{2}{*}{ Variables } & \multicolumn{8}{|c|}{ Calendar age (years) } \\
\hline & 13 & 14 & 15 & 16 & 21 & 27 & 32 & 36 \\
\hline \multicolumn{9}{|l|}{ Habitual physical activity } \\
\hline Total, min/week & $579 \pm 192$ & $548 \pm 197$ & $548 \pm 226$ & $516 \pm 198$ & $513 \pm 299$ & $452 \pm 313$ & $499 \pm 303$ & $745 \pm 455$ \\
\hline $\begin{array}{l}\text { Light-to-moderate, } \\
\mathrm{min} / \text { week }\end{array}$ & $281 \pm 142$ & $310 \pm 159$ & $375 \pm 196$ & $366 \pm 182$ & $427 \pm 269$ & $354 \pm 305$ & $369 \pm 268$ & $628 \pm 449$ \\
\hline Vigorous, min/week & $298 \pm 160$ & $237 \pm 125$ & $172 \pm 103$ & $150 \pm 97$ & $85 \pm 114$ & $98 \pm 94$ & $130 \pm 138$ & $117 \pm 99$ \\
\hline \multicolumn{9}{|l|}{ Other lifestyle risk factors } \\
\hline Alcohol consumption, $\%$ & 13.5 & 15.9 & 33.3 & 48.2 & 69.0 & 72.5 & 80.3 & 82.1 \\
\hline Smoking, \% & 1.6 & 11.0 & 14.0 & 17.9 & 29.9 & 26.2 & 20.2 & 23.5 \\
\hline $\begin{array}{l}\text { Total energy intake, } \\
1000 \mathrm{kcal} / \text { day }\end{array}$ & $2.46 \pm 0.55$ & $2.51 \pm 0.59$ & $2.59 \pm 0.68$ & $2.55 \pm 0.68$ & $2.62 \pm 0.73$ & $2.48 \pm 0.64$ & $2.60 \pm 0.71$ & $2.62 \pm 0.70$ \\
\hline \multicolumn{9}{|l|}{ Biological risk factors } \\
\hline $\begin{array}{l}\text { Mean arterial pressure, } \\
\mathrm{mmHg}\end{array}$ & $91.9 \pm 6.9$ & $91.7 \pm 6.6$ & $90.1 \pm 6.6$ & $91.8 \pm 7.2$ & $95.4 \pm 8.0$ & $97.2 \pm 8.4$ & $99.6 \pm 9.0$ & $100.7 \pm 11.0$ \\
\hline Body mass index, $\mathrm{kg} / \mathrm{m}^{2}$ & $17.7 \pm 1.8$ & $18.4 \pm 2.0$ & $19.2 \pm 2.1$ & $19.8 \pm 2.1$ & $21.4 \pm 2.2$ & $22.2 \pm 2.3$ & $23.3 \pm 2.9$ & $24.1 \pm 3.1$ \\
\hline $\begin{array}{l}\text { Sum of four skinfolds, } \\
{ }^{a} \mathrm{~mm}\end{array}$ & $32.0 \pm 12.0$ & $33.5 \pm 14.0$ & $35.3 \pm 15.0$ & $38.9 \pm 16.6$ & $44.8 \pm 17.2$ & $41.9 \pm 16.1$ & $47.4 \pm 19.2$ & $51.5 \pm 18.2$ \\
\hline Skinfold ratio ${ }^{b}$ & $0.49 \pm 0.06$ & $0.51 \pm 0.06$ & $0.53 \pm 0.06$ & $0.55 \pm 0.06$ & $0.58 \pm 0.08$ & $0.56 \pm 0.08$ & $0.56 \pm 0.09$ & $0.57 \pm 0.10$ \\
\hline $\mathrm{VO}_{2} \mathrm{max}, \mathrm{ml} / \mathrm{min}^{\prime} \mathrm{kg}^{\mathrm{FFM}}$ & $69.5 \pm 6.5$ & $68.9 \pm 6.3$ & $67.0 \pm 5.7$ & $66.2 \pm 6.5$ & $59.8 \pm 6.2$ & $56.6 \pm 6.4$ & $56.5 \pm 7.4$ & $60.6 \pm 8.4$ \\
\hline $\begin{array}{l}\text { Total-to-HDL cholesterol } \\
\text { ratio }\end{array}$ & $3.2 \pm 0.7$ & $3.2 \pm 0.7$ & $3.4 \pm 0.8$ & $3.2 \pm 0.7$ & $3.8 \pm 0.9$ & $3.8 \pm 1.0$ & $3.7 \pm 1.2$ & $3.8 \pm 1.3$ \\
\hline Resting heart rate, bpm & $83 \pm 14$ & $79 \pm 13$ & $79 \pm 15$ & $76 \pm 14$ & $72 \pm 13$ & $72 \pm 13$ & $75 \pm 14$ & $71 \pm 11$ \\
\hline
\end{tabular}

Data are means \pm SD or percentages. Bpm, beats per minute; FFM, fat-free mass; HDL, high-density lipoprotein. ${ }^{a}$ Sum of the thickness of the following skinfolds: triceps, biceps, subscapular and suprailiac. ${ }^{\mathrm{b}}$ Ratio calculated as: (subscapular + suprailiac)/sum of four skinfold.

Table 3.2.2 Mean levels across tertiles of each brachial and femoral stiffness estimate at the age of 36 years.

\begin{tabular}{lccc}
\hline Stiffness estimates & T1 & T2 & T3 \\
\hline Brachial artery & & & \\
Distensibility coefficient, $10^{-3} / \mathrm{kPa}$ & $7.1 \pm 2.1$ & $12.4 \pm 2.5$ & $24.2 \pm 9.4$ \\
Compliance coefficient, $\mathrm{mm}^{2} / \mathrm{kPa}$ & $0.09 \pm 0.03$ & $0.15 \pm 0.03$ & $0.27 \pm 0.08$ \\
Femoral artery & & & \\
Distensibility coefficient, $10^{-3} / \mathrm{kPa}$ & $4.0 \pm 1.1$ & $6.5 \pm 1.2$ & $11.1 \pm 4.0$ \\
Compliance coefficient, $\mathrm{mm}^{2} / \mathrm{kPa}$ & $0.29 \pm 0.06$ & $0.46 \pm 0.05$ & $0.78 \pm 0.20$ \\
\hline
\end{tabular}

Data are means \pm SD. T1, lowest tertile; T2, middle tertile; and T3, highest tertile of each brachial and femoral stiffness estimate.

\section{Lifetime light-to-moderate and vigorous-intensity HPA and brachial and femoral stiffness in young adulthood}

Compared to subjects in T1 (i.e. with stiffer), those in T2 and T3 (i.e. with less stiff arteries) of the brachial CC at age 36 had spent increasingly more time in vigorous $(+14.9 \mathrm{~min} /$ week [ $95 \% \mathrm{Cl}:-4.9$ to 34.6 ] and $+23.4 \mathrm{~min} /$ week [3.7 to 43.2 ], respectively), but not in light-to-moderate HPAs (+20.8 min/week [-20.6 to 62.2$]$ and $-6.9 \mathrm{~min} /$ week 
[-48.3 to 34.5], respectively) throughout the longitudinal period. Similarly, compared to subjects in T1, those in T2 and T3 of the femoral CC at age 36 had spent increasingly more time in vigorous $(+11.8 \mathrm{~min} /$ week [ -8.1 to 31.7$]$ and $+25.3 \mathrm{~min} /$ week [5.2 to 45.3], respectively), but not in light-to-moderate HPAs (-17.2 min/week [-58.8 to 24.3] and $-12.9 \mathrm{~min} /$ week [-54.8 to 29.0 ], respectively) throughout the longitudinal period (Figures 3.2.1A and 3.2.1B; Table 3.2.3, model 1). No such differences were found across the tertiles of the brachial and femoral DC at age 36 (Figures 3.2.1A and 3.2.1B).

Adjustment for the other lifestyle risk factors, i.e. potential confounders, slightly attenuated the differences in time spent in vigorous intensity HPA between T3 and T1 of the brachial and femoral CC (to $+21.2 \mathrm{~min} /$ week [ 2.0 to 40.4] and $+24.4 \mathrm{~min} /$ week [5.0 to 43.8], respectively), which nevertheless remained significant (Table 3.2.3, model 2). These differences decreased after additional adjustment for skinfolds ratio and cardiorespiratory fitness separately (models $3 \mathrm{~B}$ and $3 \mathrm{C}$, respectively), but less so by mean arterial pressure, total-to-HDL cholesterol and resting heart rate (models $3 \mathrm{~A}$, $3 \mathrm{D}$ and $3 \mathrm{E}$, respectively). When adjustments accounted for all these biological risk factors simultaneously, i.e. potential mediators, the differences in time spent in vigorous HPAs between T3 and T1 of the brachial and femoral CCs were attenuated (i.e. explained) by 28 and 62\%, respectively (model 4).

\section{A Light-to-moderate HPA}
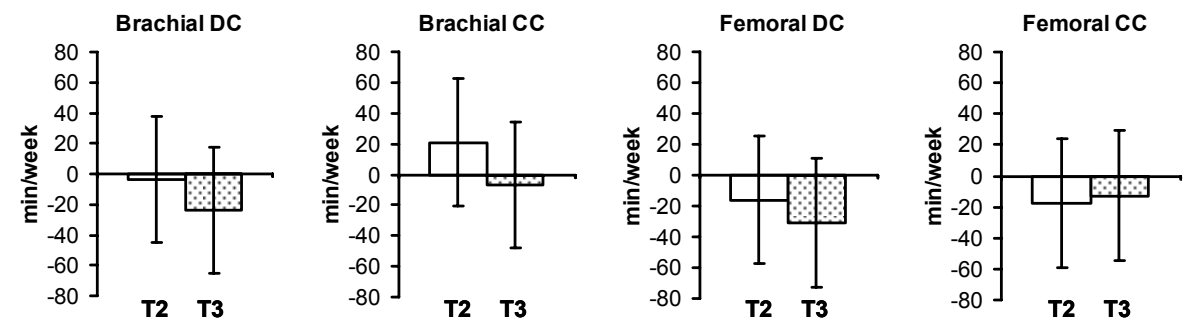

\section{B Vigorous HPA}
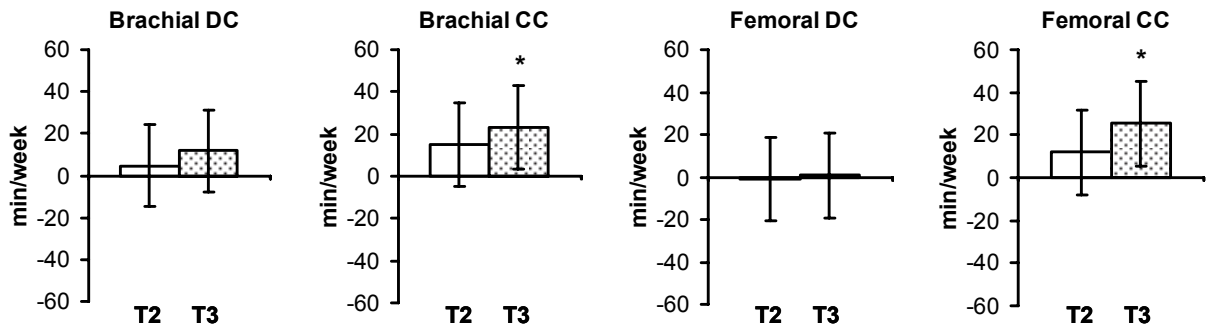

Figure 3.2.1 Mean differences in time spent in A) light-to-moderate and B) vigorous-intensity habitual physical activity throughout the 24-year longitudinal period between subjects with increasing levels (tertiles) of the brachial and femoral distensibility (DC) and compliance (CC) coefficients at the age of 36 years. Data are adjusted for sex, height and time; error bars indicate the $95 \%$ confidence interval; ${ }^{*} P<0.05$ for T3 (highest tertile - less stiff) vs. T1 (lowest tertile - stiffer arteries; reference category). 
Table 3.2.3 Mean differences in time spent in habitual physical activities throughout the longitudinal period across tertiles of the brachial and femoral compliance coefficients at age 36 years.

\begin{tabular}{|c|c|c|c|c|c|c|c|c|c|}
\hline & & \multicolumn{4}{|c|}{ Brachial CC } & \multicolumn{4}{|c|}{ Femoral CC } \\
\hline & & \multicolumn{2}{|c|}{ T2 vs. T1 } & \multicolumn{2}{|c|}{ T3 vs. T1 } & \multicolumn{2}{|c|}{ T2 vs. T1 } & \multicolumn{2}{|c|}{ T3 vs. T1 } \\
\hline & & $\beta$ & $95 \% \mathrm{Cl}$ & $\beta$ & $95 \% \mathrm{Cl}$ & $\beta$ & $95 \% \mathrm{Cl}$ & $\beta$ & $95 \% \mathrm{Cl}$ \\
\hline \multicolumn{10}{|c|}{ Light-moderate HPA } \\
\hline 1 & Sex, height, time & 20.8 & $-20.6 ; 62.2$ & -6.9 & $-48.3 ; 34.5$ & -17.2 & $-58.8 ; 24.3$ & -12.9 & $-54.8 ; 29.0$ \\
\hline 2 & Model $1+$ other lifestyles ${ }^{a}$ & 23.6 & $-17.8 ; 65.0$ & -2.9 & $-44.1 ; 38.2$ & -10.0 & $-51.4 ; 31.4$ & -13.7 & $-55.3 ; 27.9$ \\
\hline \multicolumn{10}{|c|}{ Vigorous intensity HPA } \\
\hline 1 & Sex, height, time & 14.9 & $-4.9 ; 34.6$ & 23.4 & $3.7 ; 43.2^{*}$ & 11.8 & $-8.1 ; 31.7$ & 25.3 & $5.2 ; 45.3^{*}$ \\
\hline 2 & Model $1+$ other lifestyles ${ }^{a}$ & 17.6 & $-1.6 ; 36.9$ & 21.2 & $2.0 ; 40.4^{*}$ & 14.1 & $-5.3 ; 33.4$ & 24.4 & $5.0 ; 43.8^{*}$ \\
\hline $3 a$ & $\begin{array}{l}\text { Model } 2+\text { mean arterial } \\
\text { pressure }\end{array}$ & 16.9 & $-2.4 ; 36.1$ & 20.5 & $1.3 ; 39.7^{*}$ & 13.5 & $-5.8 ; 32.9$ & 23.3 & $3.9 ; 42.8^{*}$ \\
\hline $3 b$ & Model $2+$ skinfolds ratio & 13.6 & $-5.2 ; 32.5$ & 17.1 & $-1.7 ; 35.9$ & 8.4 & $-10.6 ; 27.3$ & 18.1 & $-0.9 ; 37.2$ \\
\hline $3 c$ & $\begin{array}{l}\text { Model } 2+\text { cardiorespiratory } \\
\text { fitness }\end{array}$ & 15.1 & $-3.2 ; 33.4$ & 19.0 & $0.8 ; 37.2^{*}$ & 12.4 & $-6.0 ; 30.9$ & 16.9 & $-1.6 ; 35.4$ \\
\hline $3 d$ & $\begin{array}{l}\text { Model } 2+\text { total-to-HDL } \\
\text { cholesterol }\end{array}$ & 20.1 & $0.8 ; 39.4^{*}$ & 20.1 & $0.9 ; 39.4^{*}$ & 13.0 & $-6.4 ; 32.4$ & 22.2 & $2.8 ; 41.7^{*}$ \\
\hline $3 e$ & Model $2+$ resting heart rate & 17.2 & $-1.5 ; 36.0$ & 20.2 & $1.5 ; 38.8^{*}$ & 11.4 & $-7.5 ; 30.3$ & 21.9 & $2.9 ; 40.9 *$ \\
\hline 4 & $\begin{array}{l}\text { Model } 2+\text { all variables in } \\
\text { models } 3 \text { a to } 3 e\end{array}$ & 13.0 & $-4.7 ; 30.7$ & 15.3 & $-2.3 ; 32.9$ & 4.3 & $-13.6 ; 22.2$ & 9.3 & $-8.6 ; 27.2$ \\
\hline
\end{tabular}

$\beta$, regression coefficient: indicates the average difference in time spent in habitual physical activity (in $\mathrm{min} /$ week) throughout the 24-year longitudinal period between subjects in the middle (T2) and highest (T3) vs. those in the lowest ( $\mathrm{T} 1$; i.e. with stiffer arteries) tertiles of the brachial and femoral compliance coefficients (CC) at age 36 years. $\mathrm{Cl}$, confidence interval; HDL, high-density lipoprotein; HPA, habitual physical activity. a, Lifestyles considered were alcohol consumption, smoking behaviour and total daily energy intake. $* P<0.05$.

\section{Life-course trajectories of vigorous intensity HPA across tertiles of the brachial and femoral CC at the age of 36}

All groups decreased their time spent in vigorous intensity HPAs throughout the longitudinal period. However, those in T3 of the brachial and femoral CCs at the age of 36 spent relatively more time in this intensity of activities, especially from the age of 15 years and thereafter up to the age of 36 years (Figure 3.2.2).
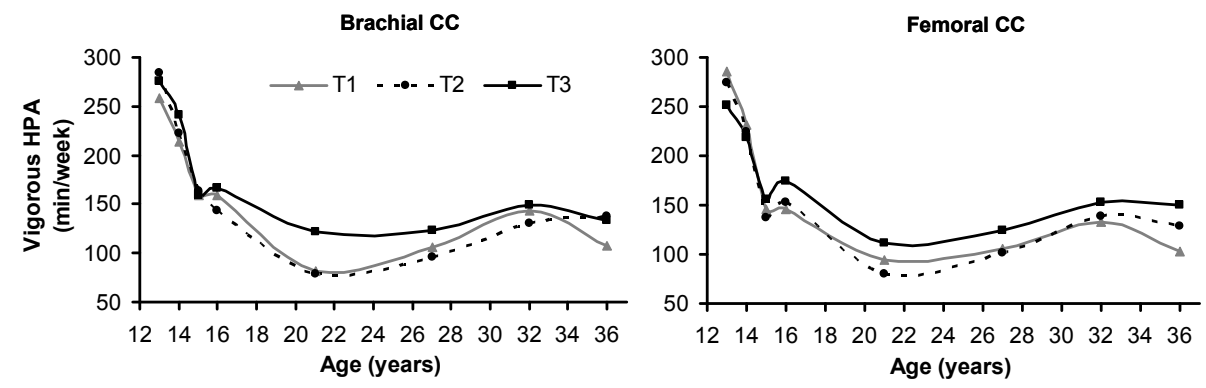

Figure 3.2.2 Trajectories of time spent in vigorous habitual physical activity (HPA) throughout the 24-year longitudinal period by subjects with increasing levels (tertiles) of the brachial and femoral compliance coefficients at the age of 36 years. Data are adjusted for sex, height and time. T1, lowest tertile (stiffer); T2, middle tertile; T3, highest tertile (less stiff arteries). 


\section{Additional analyses}

As we found that lifetime vigorous HPA was associated with mainly the $\mathrm{CC}$, but not the DC, of the brachial and the femoral arteries at age 36 years, whereas before we found that vigorous HPA was associated with both the DC and CC of the carotid artery, ${ }^{28}$ we performed additional analyses to investigate the vigorous intensity HPArelated differences in driving forces (i.e. $D, \Delta D$ or local PP) behind these stiffness estimates in all three arteries (Figure 3.2.3). These analyses unveiled a different pattern of associations between lifetime vigorous-intensity HPAs and arterial properties of each artery, such that: in the femoral artery associations were stronger with the arterial diameter (Figure 3.2.3B), whereas in the carotid artery associations were stronger with the distension (Figure 3.2.3C); strengths of associations with brachial diameter and distension were comparable (Figure 3.2.3A). Given that $D$ is positively associated with the $\mathrm{CC}$, but inversely associated with the $\mathrm{DC}$, the above thus explains the differences found between the central carotid and the peripheral femoral arteries.

In addition, and because time spent in light-to-moderate intensity HPAs is inversely associated with time spent in vigorous-intensity HPAs, we have repeated all analyses that were reported herein with further mutual adjustments for the two types of HPAs. Results of these analyses did not materially differ from the ones reported, however (data not shown).
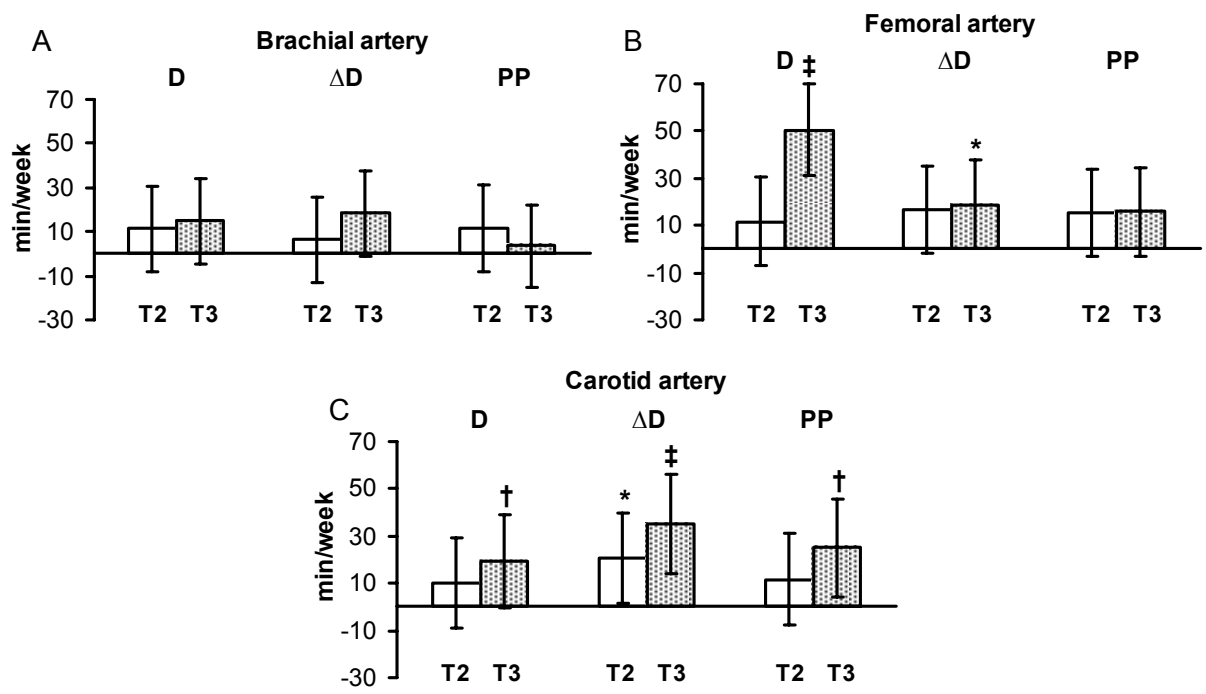

Figure 3.2.3 Mean differences in time spent in vigorous habitual physical activity throughout the 24-year longitudinal period between subjects with increasing levels (tertiles) of the diameter (D), distension $(\Delta D)$, and local pulse pressure (PP) of the A) brachial, B) femoral, and C) carotid arteries at the age of 36 years. Data are adjusted for sex, height, time, other lifestyle risk factors, mean arterial pressure and the other arterial properties as appropriate. Error bars indicate the $95 \%$ confidence interval. ${ }^{*} P<0.05 ;+P<0.01 ; \ddagger P<0.001$ for T2 or T3 (higher tertiles) vs. T1 (lowest tertiles; reference category). 


\section{DISCUSSION}

The main findings of this study are threefold: 1) subjects with more compliant, but not distensible, brachial and femoral arteries at age 36 years were characterized by higher levels of vigorous, but not light-to-moderate, intensity HPA between adolescence and adulthood; 2) this favorable association between vigorous-intensity HPA and brachial and femoral arterial compliance was explained to a great extent by concomitant beneficial associations of this type of HPA with other traditional biological risk factors; and 3) although all groups decreased their time spent in vigorous intensity HPA throughout the longitudinal period, subjects with more vs. those with less compliant brachial and femoral arteries tended to spent relatively more time in this type of HPA from late adolescence and persisted to do so thereafter, up to the age of 36 years.

We recently reported that higher levels of vigorous intensity HPA performed from adolescence up to adulthood are favorably associated with stiffness levels of the 'central' carotid artery in young adulthood ${ }^{28}$ and now extended these findings by showing favorable lifetime vigorous-HPA-related arterial adaptations in the 'peripheral' brachial and femoral arteries. These latter observations are in agreement with previous cross-sectional studies showing that subjects who are more physically active have less stiff arteries in the upper and/or lower limb, ${ }^{14,24-27,37}$ and intervention studies showing that increases in exercise levels led to decreases in stiffness estimates, in the 'long term', in the $\mathrm{arm}^{38}$ and leg $^{39}$ arteries. Inconclusive findings in other studies may have been due to lack of power given the low number of study participants $^{40-42}$, the low intensity of physical activities performed, ${ }^{43}$ and the participants' advanced stage of cardiovascular disease. ${ }^{41}$

Cardiovascular risk factors may impact differently on arterial stiffness at different localizations throughout the arterial tree. ${ }^{2}$ This might be attributed to the marked difference in architecture of the central vs. peripheral arteries. Indeed, although central arteries contain mainly elastin fibers, and relatively less collagen, this ratio is reversed in the peripheral muscular arteries, where collagen predominates. ${ }^{2}$ Although we found favorable associations of vigorous-intensity HPA with stiffness estimates of all arteries investigated, supporting the view of a generalized effect of exercise throughout the arterial tree, ${ }^{44}$ this seemed to be rooted on different adaptations in the carotid vs. the brachial and femoral arteries. Lifetime vigorous-intensity HPA was associated with greater brachial and femoral CC only, while in the carotid artery it was associated with greater DC and CC, as well as with lower beta-stiffness index and Young's elastic modulus. ${ }^{28}$ The $\mathrm{CC}$ reflects the buffering capacity of an artery, and depends more strongly on arterial diameter than on distension. In fact, we found vigorous-HPA-related adaptations towards greater arterial diameter in the femoral artery mainly, which may reflect a relatively greater involvement of leg musculature in the vigorous HPAs reported. Indeed, blood flow to the peripheral tissues increases during HPA to support the increased metabolic need in the active muscle tissues ${ }^{45}$ and yields arterial remodeling (i.e. larger vessel diameter) in order to restore basal shear 
stress, a phenomenon that was shown to be endothelium-dependent. ${ }^{46}$ Interestingly, our data suggest that vigorous-HPA-related higher levels of the carotid DC and CC were driven by comparatively stronger associations with distension than with diameter, and these occurred despite the also positive association with local PP. We can only speculate that this positive association with PP is due to an increased stroke volume in subjects who spent more time in this type of activity, ${ }^{47}$ rather than an increase in early return of wave reflections, deemed not likely especially in young and apparently healthy subjects as examined herein. Measures of these two factors were not obtained, however. The role of vigorous-intensity HPA on stiffness levels of the central and of the peripheral part of the arterial tree throughout life, the latter of which seems to be comparatively less affected by ageing, 48,49 needs to be further elucidated in future studies.

By adopting a life-course approach, we were able to identify late adolescence as the period in life during which performance of specifically vigorous-intensity HPA was critical for the peripheral, as well as the central, ${ }^{28}$ arterial stiffness phenotype several years later in young adulthood. These data are in line with previous studies showing that biological risk factors, such as body fatness, high blood pressure and dyslipidemia, $^{4,50-52}$ at younger ages are associated with arterial stiffness levels in adulthood. In fact, a great extent of the favorable association of lifetime vigorous HPAs with brachial and femoral compliance, as well as with carotid stiffness levels, ${ }^{28}$ could be explained (i.e. mediated) by concomitant beneficial associations between vigorous HPA and such biological risk factors.

Importantly, the average differences in time spent in vigorous intensity HPA throughout the longitudinal period between subjects with more vs. those with less compliant peripheral arteries, as well as those with stiffer vs. those with less stiff carotid arteries, ${ }^{28}$ were relatively small, amounting approximately $20-25 \mathrm{~min} /$ week (or 3-4 min/day). This thus suggests that even modest increases in this type of HPA, in particular when performed from adolescence onwards may yield beneficial arterial adaptations in young adulthood. Although we do not dismiss the value of light-tomoderate HPA, especially in those subjects who are extremely sedentary and usually overweight, our findings further emphasize the importance of promoting vigorous intensity HPA, rather than simply any HPA, among the healthy young in order to prevent the development of arterial stiffness-related cardiovascular sequelae later in life.

Some study limitations need to be mentioned. First, the analyses were confined to subjects with complete arterial data at the age of 36 years. However, their levels of HPA as well as of other traditional biological cardiovascular risk factors did not differ, at any earlier time point, with those of subjects who dropped out (data not shown), indicating that our findings were not threatened by selection bias. Second, arterial properties were measured at age 36 years only and, therefore, we cannot rule out that reverse causation may have occurred. Nevertheless, we think this is unlikely because of the pre-clinical and asymptomatic nature of arterial stiffness, especially in 
this young cohort. Third, our findings are confined to local arterial stiffness estimates. No measures on regional stiffness (e.g. aortic or limbs pulse wave velocity) or wave reflection (e.g. augmentation index) were available in this cohort. Fourth, the assessment of brachial and femoral arterial properties using ultrasonography is accompanied with greater measurement error, as compared to that of the carotid artery. ${ }^{31}$ Therefore, misclassification might have occurred into a greater extent when categorizing subjects according to tertiles of stiffness estimates of these arteries. Nevertheless, if present, such misclassification, would thus have led to an underestimation of the differences in vigorous-intensity HPA levels across tertiles of the brachial and femoral stiffness estimates as reported herein. Fifth, HPAs were grouped according to their intensity levels, but not as aerobic vs. resistance exercises, which are known to affect arterial stiffness differently. ${ }^{7}$ However, the relative time spent in the latter category amounted $<2 \%$ of the total time spent in HPAs and contributed equally to both intensity types of activities and could not have affected our results. Finally, the assessment of HPA by questionnaires is subject to recall and misclassification bias. ${ }^{53}$ We think that this was non-differential because, throughout the study period, participants were not aware of their arterial stiffness levels in adulthood. However, some differential misclassification might have occurred, most probably by over-reporting of vigorous HPAs by those with unhealthier lifestyles/risk factor profiles. Either way, the differences in time spent in vigorous-intensity HPA between the groups being compared are likely to be underestimated.

This study enabled us to investigate, comprehensively, the associations of lifetime HPAs with the stiffness levels of peripheral (i.e. brachial and femoral) vs. central (i.e. carotid) arteries in young adulthood. We found favorable associations between vigorous but not light-to-moderate HPAs and compliance, but not distensibility, of peripheral arteries, whereas previously we have shown that these associations also extend to those estimates reflecting the intrinsic elastic properties of the carotid arterial wall. Thus, though generalized, vigorous HPA-related adaptations in arterial properties differ in nature across the arterial tree. Altogether, our findings suggest that even modest increases in vigorous intensity HPA from adolescence up to adulthood may prevent arterial stiffness in young adulthood. This emphasizes the importance of promoting this type of activity in particular as a tool to prevent arterial stiffness-related cardiovascular sequelae later in life. 


\section{REFERENCES}

1. Laurent S, Cockcroft J, Van Bortel L, et al. Expert consensus document on arterial stiffness: methodological issues and clinical applications. Eur Heart J. 2006;27:2588-2605.

2. Safar ME, O'Rourke MF. Arterial Stiffness in Hypertension. Vol 23. Amsterdam: Elsevier; 2006.

3. Ferreira I, Twisk JW, van Mechelen W, Kemper HC, Seidell JC, Stehouwer CD. Current and adolescent body fatness and fat distribution: relationships with carotid intima-media thickness and large artery stiffness at the age of 36 years. J Hypertens. 2004;22:145-155.

4. Juonala M, Jarvisalo MJ, Maki-Torkko N, Kahonen M, Viikari JS, Raitakari OT. Risk factors identified in childhood and decreased carotid artery elasticity in adulthood: the Cardiovascular Risk in Young Finns Study. Circulation. 2005;112:1486-1493.

5. Li S, Chen W, Srinivasan SR, et al. Childhood cardiovascular risk factors and carotid vascular changes in adulthood: the Bogalusa Heart Study. JAMA. 2003;290:2271-2276.

6. Safar ME, Levy BI, Struijker-Boudier H. Current perspectives on arterial stiffness and pulse pressure in hypertension and cardiovascular diseases. Circulation. 2003;107:2864-2869.

7. Seals DR, Desouza CA, Donato AJ, Tanaka H. Habitual exercise and arterial aging. J Appl Physiol. 2008;105:1323-1332.

8. Chase NL, Sui X, Lee DC, Blair SN. The association of cardiorespiratory fitness and physical activity with incidence of hypertension in men. Am J Hypertens. 2009;22:417-424.

9. Vaitkevicius PV, Fleg JL, Engel JH, et al. Effects of age and aerobic capacity on arterial stiffness in healthy adults. Circulation. 1993;88:1456-1462.

10. Tanaka H, DeSouza CA, Seals DR. Absence of age-related increase in central arterial stiffness in physically active women. Arterioscler Thromb Vasc Biol. 1998;18:127-132.

11. Cameron JD, Rajkumar C, Kingwell BA, Jennings GL, Dart AM. Higher systemic arterial compliance is associated with greater exercise time and lower blood pressure in a young older population. $J \mathrm{Am}$ Geriatr Soc. 1999;47:653-656.

12. Schmidt-Trucksass AS, Grathwohl D, Frey I, et al. Relation of leisure-time physical activity to structural and functional arterial properties of the common carotid artery in male subjects. Atherosclerosis. 1999;145:107-114.

13. Tanaka H, Dinenno FA, Monahan KD, Clevenger CM, DeSouza CA, Seals DR. Aging, habitual exercise, and dynamic arterial compliance. Circulation. 2000;102:1270-1275.

14. Giannattasio C, Failla M, Grappiolo A, et al. Effects of physical training of the dominant arm on ipsilateral radial artery distensibility and structure. J Hypertens. 2001;19:71-77.

15. Mason NJ, Jenkins AJ, Best JD, Rowley KG. Exercise frequency and arterial compliance in non-diabetic and type 1 diabetic individuals. Eur J Cardiovasc Prev Rehabil. 2006;13:598-603.

16. Kozakova M, Palombo C, Mhamdi L, et al. Habitual physical activity and vascular aging in a young to middle-age population at low cardiovascular risk. Stroke. 2007;38:2549-2555.

17. Sakuragi S, Abhayaratna K, Gravenmaker KJ, et al. Influence of adiposity and physical activity on arterial stiffness in healthy children: the lifestyle of our kids study. Hypertension. 2009;53:611-616.

18. Schmitz KH, Arnett DK, Bank A, et al. Arterial distensibility and physical activity in the ARIC study. Med Sci Sports Exerc. 2001;33:2065-2071.

19. Monahan KD, Tanaka H, Dinenno FA, Seals DR. Central arterial compliance is associated with age- and habitual exercise-related differences in cardiovagal baroreflex sensitivity. Circulation. 2001;104: 1627-1632.

20. Erol MK, Yilmaz M, Oztasyonar Y, Sevimli S, Senocak H. Aortic distensibility is increasing in elite athletes. Am J Cardiol. 2002;89:1002-1004.

21. Gates PE, Tanaka H, Graves J, Seals DR. Left ventricular structure and diastolic function with human ageing. Relation to habitual exercise and arterial stiffness. Eur Heart J. 2003;24:2213-2220.

22. Sugawara J, Otsuki T, Tanabe T, Hayashi K, Maeda S, Matsuda M. Physical activity duration, intensity, and arterial stiffening in postmenopausal women. Am J Hypertens. 2006;19:1032-1036.

23. Kasikcioglu E, Kayserilioglu A, Oflaz H, Akhan H. Aortic distensibility and left ventricular diastolic functions in endurance athletes. Int J Sports Med. 2005;26:165-170.

24. Heffernan KS, Jae SY, Tomayko E, Ishaque MR, Fernhall B, Wilund KR. Influence of arterial wave reflection on carotid blood pressure and intima-media thickness in older endurance trained men and women with pre-hypertension. Clin Physiol Funct Imaging. 2009;29:193-200. 
25. Boreham CA, Ferreira I, Twisk JW, Gallagher AM, Savage MJ, Murray L. Cardiorespiratory fitness, physical activity, and arterial stiffness: the Northern Ireland Young Hearts Project. Hypertension. 2004;44:721-726.

26. Schmidt-Trucksass A, Schmid A, Brunner C, et al. Arterial properties of the carotid and femoral artery in endurance-trained and paraplegic subjects. J Appl Physiol. 2000;89:1956-1963.

27. Schack-Nielsen L, Molgaard C, Larsen D, Martyn C, Michaelsen KF. Arterial stiffness in 10-year-old children: current and early determinants. Br J Nutr. 2005;94:1004-1011.

28. van de Laar RJ, Ferreira I, van Mechelen W, Prins MH, Twisk JW, Stehouwer CD. Lifetime vigorous but not light-to-moderate habitual physical activity impacts favorably on carotid stiffness in young adults: the amsterdam growth and health longitudinal study. Hypertension. 2010;55:33-39.

29. Kemper HC. Amsterdam Growth and Health Longitudinal Study (AGAHLS). A 23-Year Follow-Up From Teenager To Adult about Lifestyle and Health. Vol 47. Basel: Karger; 2004.

30. Ferreira I, Henry RM, Twisk JW, van Mechelen W, Kemper HC, Stehouwer CD. The metabolic syndrome, cardiopulmonary fitness, and subcutaneous trunk fat as independent determinants of arterial stiffness: the Amsterdam Growth and Health Longitudinal Study. Arch Intern Med. 2005; 165:875-882.

31. Ferreira I, Twisk JW, Van Mechelen W, Kemper HC, Stehouwer CD. Current and adolescent levels of cardiopulmonary fitness are related to large artery properties at age 36: the Amsterdam Growth and Health Longitudinal Study. Eur J Clin Invest. 2002;32:723-731.

32. Brands PJ, Hoeks AP, Willigers J, Willekes C, Reneman RS. An integrated system for the non-invasive assessment of vessel wall and hemodynamic properties of large arteries by means of ultrasound. Eur J Ultrasound. 1999;9:257-266.

33. Reneman RS, Hoeks AP. Noninvasive vascular ultrasound: an asset in vascular medicine. Cardiovasc Res. 2000;45:27-35.

34. Van Bortel LM, Balkestein EJ, van der Heijden-Spek JJ, et al. Non-invasive assessment of local arterial pulse pressure: comparison of applanation tonometry and echo-tracking. J Hypertens. 2001;19: 1037-1044.

35. Ferreira I, Twisk JW, van Mechelen W, Kemper HC, Stehouwer CD. Development of fatness, fitness, and lifestyle from adolescence to the age of 36 years: determinants of the metabolic syndrome in young adults: the amsterdam growth and health longitudinal study. Arch Intern Med. 2005;165:42-48.

36. Twisk JWR. Applied Longitudinal Data Analysis for Epidemiolgy: A Practical Guide. Cambridge: Cambridge University Press; 2003.

37. Wijnen JA, Kuipers $\mathrm{H}$, Kool MJ, et al. Vessel wall properties of large arteries in trained and sedentary subjects. Basic Res Cardiol. 1991;86 Suppl 1:25-29.

38. Madden KM, Lockhart C, Cuff D, Potter TF, Meneilly GS. Short-term Aerobic Exercise Reduces Arterial Stiffness in Older Adults with Type 2 Diabetes, Hypertension and Hypercholesterolemia. Diabetes Care. 2009;32:1531-1535.

39. Yokoyama H, Emoto M, Fujiwara S, et al. Short-term aerobic exercise improves arterial stiffness in type 2 diabetes. Diabetes Res Clin Pract. 2004;65:85-93.

40. Hayashi K, Sugawara J, Komine H, Maeda S, Yokoi T. Effects of aerobic exercise training on the stiffness of central and peripheral arteries in middle-aged sedentary men. Jpn J Physiol. 2005;55: 235-239.

41. Parnell MM, Holst DP, Kaye DM. Exercise training increases arterial compliance in patients with congestive heart failure. Clin Sci (Lond). 2002;102:1-7.

42. Wijnen JA, Kool MJ, Kooman JP, et al. Vessel wall properties of large arteries and endurance training. $J$ Hypertens Suppl. 1993;11:S88-89.

43. Seals DR, Tanaka $\mathrm{H}$, Clevenger $\mathrm{CM}$, et al. Blood pressure reductions with exercise and sodium restriction in postmenopausal women with elevated systolic pressure: role of arterial stiffness. J Am Coll Cardiol. 2001;38:506-513.

44. Green DJ, Maiorana AJ, Cable NT. Point: exercise training does induce vascular adaptations beyond the active muscle beds. J Appl Physiol. 2008;105:1002-1004; discussion 1007.

45. Prior BM, Lloyd PG, Yang HT, Terjung RL. Exercise-induced vascular remodeling. Exerc Sport Sci Rev. 2003;31:26-33.

46. Niebauer J, Cooke JP. Cardiovascular effects of exercise: role of endothelial shear stress. J Am Coll Cardiol. 1996;28:1652-1660. 
47. Ferguson S, Gledhill N, Jamnik VK, Wiebe C, Payne N. Cardiac performance in endurance-trained and moderately active young women. Med Sci Sports Exerc. 2001;33:1114-1119.

48. Vermeersch SJ, Rietzschel ER, De Buyzere ML, et al. Age and gender related patterns in carotidfemoral PWV and carotid and femoral stiffness in a large healthy, middle-aged population. J Hypertens. 2008;26:1411-1419.

49. van der Heijden-Spek JJ, Staessen JA, Fagard RH, Hoeks AP, Boudier HA, van Bortel LM. Effect of age on brachial artery wall properties differs from the aorta and is gender dependent: a population study. Hypertension. 2000;35:637-642.

50. Juonala M, Viikari JS, Ronnemaa $\mathrm{T}$, et al. Associations of dyslipidemias from childhood to adulthood with carotid intima-media thickness, elasticity, and brachial flow-mediated dilatation in adulthood: the Cardiovascular Risk in Young Finns Study. Arterioscler Thromb Vasc Biol. 2008;28:1012-1017.

51. Li S, Chen W, Srinivasan SR, Berenson GS. Childhood blood pressure as a predictor of arterial stiffness in young adults: the bogalusa heart study. Hypertension. 2004;43:541-546.

52. Raitakari OT, Juonala M, Viikari JS. Obesity in childhood and vascular changes in adulthood: insights into the Cardiovascular Risk in Young Finns Study. Int J Obes (Lond). 2005;29 Suppl 2:S101-104.

53. Ferrari P, Friedenreich C, Matthews CE. The role of measurement error in estimating levels of physical activity. Am J Epidemiol. 2007;166:832-840. 


\section{Chapter}

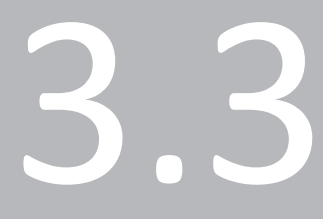

Time spent watching television is

associated with higher arterial stiffness in

young adults

The Amsterdam Growth and Health Longitudinal Study

Roel J.J. van de Laar, Coen D.A. Stehouwer, Martin H. Prins, Willem van Mechelen, Jos W.R. Twisk, Isabel Ferreira

Submitted 


\section{ABSTRACT}

\section{Objectives}

To investigate whether time spent watching television (a marker of sedentary behaviour) is associated with arterial stiffness, a major determinant of cardiovascular disease, and whether any such association is explained by related deleterious levels of habitual physical activity (HPA) and/or other lifestyle and biological risk factors.

\section{Methods}

Prospective measures (ages 32 and 36 years) of television time and concomitant risk factors were retrieved in 373 subjects (196 women) in whom stiffness of the carotid, brachial and femoral arteries was assessed by means of ultrasonography at age 36 years. Analyses were performed with the use of generalised estimating equations.

\section{Results}

As compared to subjects with less stiff (i.e. in lowest tertiles), those with the stiffest carotid arteries (i.e. in the highest tertiles of the reversed distensibility and compliance coefficients, and the Young's elastic modulus) had spent on average more time (in min/day) watching television during the 4 preceding years: +22.4 ( $95 \% \mathrm{Cl}: 8.7$ to 36.1$),+18.4$ (4.2 to 32.5$)$ and +19.7 (6.0 to 33.4), respectively. These differences were independent of potential confounders, such as vigorous intensity HPA and other lifestyle variables, and could only in part (i.e. up to $31 \%$ ) be explained by the adverse associations of television time with traditional biological risk factors. Qualitatively similar results were found for femoral, but not brachial, stiffness estimates.

\section{Conclusions}

Given the independent associations of time spent watching television and vigorous intensity HPA with arterial stiffness, our data suggest that not only promotion of physical activity, but also discouragement of sedentary behaviours should be targeted in young adults in order to prevent accelerated arterial stiffening. 


\section{INTRODUCTION}

Arterial stiffness is a major determinant of cardiovascular disease and mortality through its contribution to systolic hypertension, left ventricular hypertrophy and impaired coronary perfusion. ${ }^{1}$ The complications of arterial stiffness occur generally after the fifth decade of age, but its developmental process is characterized by a long pre-clinical phase that starts at younger ages due to exposure to several risk factors. ${ }^{2-6}$ Although the predictive value of stiffer arteries in young adulthood has yet to be established, it is of interest to identify (modifiable) risk factors that impact on arterial stiffness among young adults. This may enable a better understanding of the aetiology of arterial stiffening and, from a primary prevention point of view, the construction of targeted interventions with the most potential for health benefits in the long-term.

Excessive time spent in common sedentary behaviours involving sitting may constitute such a risk factor. ${ }^{7}$ Indeed, several studies have shown that time spent watching television (hereafter referred to as television time), a common sedentary behaviour, is adversely associated with body fatness, ${ }^{8-11}$ blood pressure, ${ }^{9,11}$ blood lipids, ${ }^{8,9,11}$ type 2 diabetes mellitus, ${ }^{10}$ and the metabolic syndrome, ${ }^{12}$ all of which are determinants of arterial stiffness, ${ }^{1}$ as well as cardiovascular mortality. ${ }^{13}$ Importantly, most of these adverse associations with television time were shown to be independent of concomitant levels of physical activity. ${ }^{8-13}$ The adverse effects of sedentary behaviour were confirmed in a recent systematic review of prospective studies, which also emphasized its independent association with incident cardiovascular and all-cause mortality. ${ }^{14}$

Such observations have led to a rethinking of traditional views that placed sedentary and physically active behaviours on a single continuum; instead, these are two distinct behaviours that may actually coexist, and have different determinants and affect metabolic and cardiovascular health through different pathobiological mechanisms. $^{7,15}$ We have previously shown habitual physical activity (HPA), in particular of vigorous intensity, performed throughout the course of young life (i.e. from adolescence up to young adulthood) to be beneficially associated with arterial stiffness in young adults. ${ }^{16,17}$ However, whether excessive television time adversely affects arterial stiffness and whether any such association is explained by related lack of HPA (the 'continuum' hypothesis) or, instead, is independent of individuals' HPA levels (the 'coexistence' hypothesis) is not known. Likewise, whether television time is associated with arterial stiffness through or independently of adverse associations with traditional cardiovascular risk factors previously shown to mediate the beneficial associations of (vigorous intensity) HPA with arterial stiffness is not known.

We have, therefore, investigated in a cohort of young adults in whom television time was measured prospectively at the ages of 32 and 36 years, and stiffness of three large arteries were assessed at age 36 years: first, whether the mean levels of television time in young adulthood differed between subjects with stiffer vs. those with less stiff carotid, brachial and femoral arteries at age 36; second, whether any 
such differences were independent of other lifestyle risk factors, most notably time spent in vigorous intensity HPA; and third, the extent to which any such differences could be explained by adverse associations of television time with other cardiovascular risk factors.

\section{MATERIALS AND METHODS}

\section{Subjects and study design}

All subjects were participants of the Amsterdam Growth and Health Longitudinal Study. This study started in 1976-77 with a group of approximately 60013 -year-old children from two secondary schools in the Netherlands. Since then, repeated measurements of anthropometrical, biological and lifestyle variables have been obtained two to eight times during a 24-year follow-up period. ${ }^{3,16-18}$ In the $8^{\text {th }}$ measurement round (in the year 2000), when's subjects mean age was $36 \pm 0.6$, measurements of the properties of three large arteries were introduced in the study and assessed in 377 subjects out of the 378 who attended this measurement round. The present study reports on 373 (196 women) subjects who had complete arterial data at the mean age of 36 . From these, television time was retrieved for the first time in 342 who attended the $7^{\text {th }}$ measurement round (in 1996/97, subjects' mean age $32 \pm 0.9,348$ attendees) and in 370 who attended the $8^{\text {th }}$ measurement round. In detail, television time data was available in 339 of the study subjects at the ages 32 and 36, in 3 at the age of 32 only, and in 31 at the age of 36 only (Figure 3.3.1). General characteristics and arterial properties of subjects with two television time measures $(n=339)$ did not differ from the 373 considered in the present study (i.e. including the 34 subjects with only one television time measure (see Tables 3.3.S1 and 3.3.S2 [Appendix 3.3.1] vs. Tables 3.3.1 and 3.3.2 below).

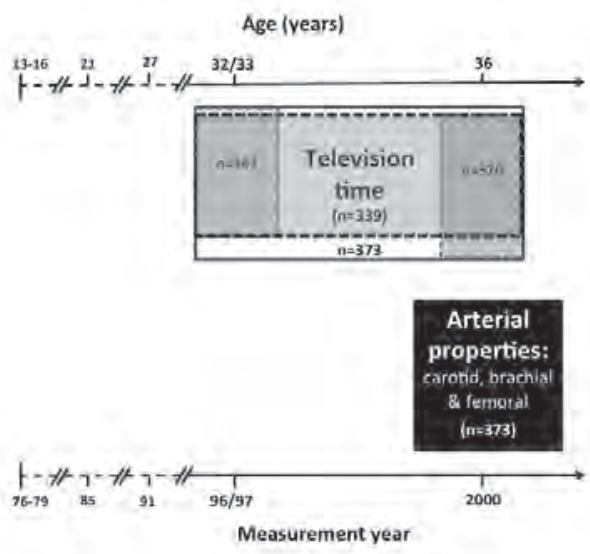

Figure 3.3.1 Subjects and study design. 
Table 3.3.1 General characteristics of the study population.

\begin{tabular}{|c|c|c|c|c|}
\hline \multirow[t]{2}{*}{ Variable } & \multicolumn{2}{|r|}{ Age 32} & \multicolumn{2}{|r|}{ Age 36} \\
\hline & $\mathbf{n}$ & Descriptive statistic & $\mathbf{n}$ & Descriptive statistic \\
\hline Sex (men/women), $n$ & $348^{a}$ & $161 / 187$ & $373^{a}$ & $177 / 196$ \\
\hline \multicolumn{5}{|l|}{ Lifestyle risk factors } \\
\hline Television time, $\mathrm{min} / \mathrm{day}$ & 342 & $117 \pm 62$ & 370 & $124 \pm 64$ \\
\hline \multicolumn{5}{|l|}{ Time spent in HPA, min/week } \\
\hline Total & 348 & $437[292-658]$ & 372 & 657 [408-1022] \\
\hline Light-to-moderate & 348 & 305 [176-507] & 372 & $515[313-890]$ \\
\hline Vigorous & 348 & 92 [42-169] & 372 & $94[47-154]$ \\
\hline Alcohol consumption, \% & 346 & 80.3 & 368 & 82.1 \\
\hline Smoking, \% & 341 & 20.2 & 371 & 23.5 \\
\hline Total energy intake, $1000 \mathrm{kcal} / \mathrm{day}$ & 346 & $2.60 \pm 0.71$ & 368 & $2.62 \pm 0.70$ \\
\hline \multicolumn{5}{|l|}{ Biological risk factors } \\
\hline Systolic blood pressure, $\mathrm{mmHg}$ & 347 & $129.6 \pm 12.4$ & 373 & $131.2 \pm 14.4$ \\
\hline Diastolic blood pressure, $\mathrm{mmHg}$ & 347 & $84.6 \pm 8.8$ & 373 & $85.4 \pm 10.6$ \\
\hline Mean arterial pressure, $\mathrm{mmHg}$ & 347 & $99.6 \pm 9.0$ & 373 & $100.7 \pm 11.0$ \\
\hline Body mass index, $\mathrm{kg} / \mathrm{m}^{2}$ & 347 & $23.3 \pm 2.9$ & 373 & $24.1 \pm 3.1$ \\
\hline Sum of 4 skinfolds, $\mathrm{mm}$ & 346 & $47.4 \pm 19.2$ & 373 & $51.5 \pm 18.2$ \\
\hline Skinfolds ratio & 346 & $0.56 \pm 0.09$ & 373 & $0.57 \pm 0.10$ \\
\hline VO2max, $\mathrm{mL} / \mathrm{min} / \mathrm{kgFFM}$ & 339 & $56.4 \pm 7.4$ & 359 & $60.6 \pm 8.4$ \\
\hline Total cholesterol, mmol/l & 347 & $4.92 \pm 0.86$ & 371 & $5.00 \pm 0.93$ \\
\hline HDL-cholesterol, mmol/l & 347 & $1.42 \pm 0.37$ & 371 & $1.41 \pm 0.37$ \\
\hline Total-to-HDL cholesterol ratio & 347 & $3.7 \pm 1.2$ & 371 & $3.8 \pm 1.3$ \\
\hline Triglycerides, mmol/l & 347 & $0.94[0.70-1.26]$ & 371 & $1.00[0.80-1.50]$ \\
\hline Resting heart rate, bpm & 344 & $75 \pm 14$ & 372 & $71 \pm 11$ \\
\hline
\end{tabular}

Data are means $\pm S D$, medians [inter-quartile ranges] or percentages. HPA, habitual physical activity; HDL, high-density lipoprotein; $\mathrm{VO}_{2}$ max, maximal oxygen uptake; FFM, free fat mass. ${ }^{a}$ Differences in $\mathrm{n}$ are due to the fact that some participants who were measured and had complete arterial data the age of 36 did not attend the previous measurement round when aged 32. Note that within each measurement round the exact $n$ of each study variable differs slightly from 348 (age 32) or 373 (age 36) due to occasional missing assessments (e.g. questionnaire not completed or test not performed).

Table 3.3.2 Arterial stiffness levels at the age of 36 years across sex-specific tertiles ${ }^{\mathrm{a}}$ of each stiffness estimate.

\begin{tabular}{|c|c|c|c|}
\hline Stiffness estimates & $\begin{array}{c}\text { T1 - Less stiff } \\
(n=124)\end{array}$ & $\begin{array}{c}\text { T2 - Intermediate } \\
(n=125)\end{array}$ & $\begin{array}{c}\text { T3 - Stiffest } \\
(n=124)\end{array}$ \\
\hline \multicolumn{4}{|l|}{ Common carotid artery } \\
\hline Distensibility coefficient, ${ }^{a} 10^{-3} \cdot \mathrm{kPa}^{-1}$ & $33.4 \pm 4.1$ & $26.2 \pm 1.6$ & $20.3 \pm 2.2$ \\
\hline Compliance coefficient, ${ }^{\mathrm{a}} \mathrm{mm}^{2} \cdot \mathrm{kPa}^{-1}$ & $1.28 \pm 0.20$ & $0.97 \pm 0.09$ & $0.72 \pm 0.12$ \\
\hline Young's elastic modulus, $10^{3} \cdot \mathrm{kPa}$ & $0.32 \pm 0.05$ & $0.43 \pm 0.03$ & $0.58 \pm 0.09$ \\
\hline \multicolumn{4}{|l|}{ Brachial artery } \\
\hline Distensibility coefficient, ${ }^{\mathrm{a}} 10^{-3} \cdot \mathrm{kPa}^{-1}$ & $24.2 \pm 9.4$ & $12.4 \pm 2.5$ & $7.1 \pm 2.1$ \\
\hline Compliance coefficient, ${ }^{a} \mathrm{~mm}^{2} \cdot \mathrm{kPa}^{-1}$ & $0.27 \pm 0.08$ & $0.15 \pm 0.03$ & $0.09 \pm 0.03$ \\
\hline \multicolumn{4}{|l|}{ Common femoral artery } \\
\hline Distensibility coefficient, ${ }^{\mathrm{a}} 10^{-3} \cdot \mathrm{kPa}^{-1}$ & $11.1 \pm 4.0$ & $6.5 \pm 1.2$ & $4.0 \pm 1.1$ \\
\hline Compliance coefficient, ${ }^{\mathrm{a}} \mathrm{mm}^{2} \cdot \mathrm{kPa}^{-1}$ & $0.78 \pm 0.20$ & $0.46 \pm 0.05$ & $0.29 \pm 0.06$ \\
\hline
\end{tabular}

Data are means \pm SD. $P$-values for comparisons in stiffness estimates between all 3 groups were all $<0.001$. ${ }^{a}$ Note that distensibility and compliance coefficients values were reversed (i.e. multiplied by -1 ) prior to categorization into tertiles so that higher values indicate greater stiffness (in agreement with the carotid Young's elastic modulus). 
The study was approved by the medical ethical committee of the VU University Medical Center (Amsterdam, the Netherlands), and all subjects gave their written informed consent.

\section{Arterial stiffness}

Arterial properties were assessed by means of ultrasonography according to guidelines for user procedures and with the use of reproducible methods and devices. ${ }^{1,19,20}$ All subjects had abstained from smoking and caffeine-containing beverages on the day the measurements were performed. Measurements took place after subjects had been resting in a supine position for $15 \mathrm{~min}$ in a quiet temperaturecontrolled room. Properties of the right common carotid $(10 \mathrm{~mm}$ proximal to the beginning of the bulb), brachial (20 $\mathrm{mm}$ above the antecubital fossa), and common femoral ( $20 \mathrm{~mm}$ proximal to the flow divider) arteries were obtained by two trained vascular sonographers with an ultrasound scanner equipped with a 7.5- $\mathrm{MHz}$ linear array probe (Pie medical, Maastricht, The Netherlands). The ultrasound scanner was connected to a personal computer equipped with an acquisition system and a vessel wall movement detector software system (Wall Track System 2, Pie Medical, Maastricht, The Netherlands). This integrated device enabled measurements of arterial diameter (D), distension ( $\Delta \mathrm{D})$, and intima-media thickness (IMT) as described in detail elsewhere. ${ }^{19,20}$

Throughout the entire period of ultrasound imaging, blood pressure was assessed in the left arm at 5-minute intervals with an oscillometric device (Colin Press-Mate, model BP-8800, Komaki-City, Japan). Brachial pulse pressure (PP) was defined as systolic - diastolic pressure, and PP at the level of the common carotid and the common femoral arteries was calculated by calibration of the distension waveforms. ${ }^{21}$ The mean $D, \Delta D$, and local PP of three consecutive measurements were used to estimate the distensibility (DC) and compliance (CC) coefficients of each artery as follows: ${ }^{16,17,22}$

$$
\begin{array}{ll}
D C=\left(2 \Delta D \cdot D+\Delta D^{2}\right) /\left(P P \cdot D^{2}\right) & \text { in } 10^{-3} / \mathrm{kPa} \\
C C=\pi \cdot\left(2 D \cdot \Delta D+\Delta D^{2}\right) / 4 P P & \text { in } \mathrm{mm}^{2} / \mathrm{kPa}
\end{array}
$$

Distensibility reflects the elastic properties, whereas the compliance reflects the buffering capacity of the artery. From carotid D, DC and IMT, the Young's elastic modulus (YEM), an estimate of the intrinsic elastic properties of the vessel wall, was calculated as follows:

$$
\mathrm{YEM}=\mathrm{D} /(\mathrm{IMT} \cdot \mathrm{DC}) \quad \text { in } 10^{3} \cdot \mathrm{kPa}
$$




\section{Television time}

At ages 32 and 36 years, a questionnaire was used to retrieve subjects' average time spent watching television or videos during weekdays and weekends in the preceding three months, unless the participants were of opinion that their television viewing behaviour was unusual in this time period (e.g., because of illness or holiday). At both time-points, television time was assessed during the same time of the year (i.e. between January and June). Television time during weekdays and weekends were combined for analyses, and expressed in min/day.

\section{Covariates}

Other lifestyle and biological variables were measured at ages 32 and 36 years as described in detail elsewhere ${ }^{16,18,22}$ and briefly below.

HPA was assessed by means of a structured detailed face-to-face interview. ${ }^{16-18}$ The intensity, frequency and duration of all physical activities (at work, at home, during leisure time, in organized and unorganized sports, climbing stairs and active transportation) with duration of $\geq 5$ minutes and intensity exceeding 4 times the resting metabolic rate (i.e. $\geq 4$ metabolic equivalents; METs) were retrieved. Time spent in light-to-moderate (4-7 METs) and vigorous (>7 METs) intensity HPAs (in $\mathrm{min} /$ week) were used in the analyses. ${ }^{16-18}$ Total daily energy intake (in kcal/day), alcohol consumption and smoking behaviour (yes/no) were assessed by means of interviews and questionnaires. ${ }^{18}$

Systolic and diastolic blood pressure (using a sphygmomanometer) and heart rate (using a telemeter) were measured after subjects had rested in a sitting position for at least 5 min. ${ }^{18,22}$ Mean arterial pressure (MAP) was calculated as [(2·diastolic pressure) + systolic pressure]/3. Body mass index (BMI, in $\left.\mathrm{kg} / \mathrm{m}^{2}\right)$ and the sum of the biceps, triceps, subscapular and suprailiac skinfolds $(\Sigma 4 \mathrm{SKF}$, in $\mathrm{mm}$ ) were used as measures of total body fatness, and the ratio between the subscapular+suprailiac/ $\Sigma 4$ SKF was used as a measure of central fatness. ${ }^{3,18,22}$ Total and high-density lipoprotein (HDL) cholesterol and triglycerides were measured in non-fasting blood samples with the use of enzymatic techniques (Roche Diagnostics, Mannheim, Germany). ${ }^{18,22}$ Cardiorespiratory fitness was measured with a maximal running test on a treadmill and with direct measurements of maximal oxygen uptake $\left(\mathrm{VO}_{2} \mathrm{max}\right.$; in $\left.\mathrm{ml} / \mathrm{min} / \mathrm{kg}^{\mathrm{FFM}}\right){ }^{16,18,22}$

\section{Statistical analyses}

We used generalised estimating equations (GEE) to estimate: 1 ) the mean differences in television time during a 4-year period (ages 32-36) between subjects with different levels of arterial stiffness at age 36; and 2) the longitudinal associations between television time on the one hand and (light-to-moderate and vigorous) HPA and traditional biological risk factors on the other, during the same 4-y period. Adopting GEE as method of longitudinal data analyses has the advantage of handling all data 
available in subjects with varying number of observations (instead of confining analyses to complete cases), renders imputation of missing values unnecessary when missing are not selective, ${ }^{23}$ and enables proper adjustment for the correlation between the repeated observations of television time and covariates taken in the same subject over time. ${ }^{24}$

In detail, we compared mean levels of television time at ages 32-36 years between subjects in the higher sex-specific tertiles (T2 or T3) vs. those in the lowest tertile (T1) of the carotid, brachial and femoral stiffness estimates at age 36 years. Before categorization into tertiles, the DCs and CCs were reversed (i.e. multiplied by -1 ) so that higher values indicate higher arterial stiffness in accordance with the carotid YEM. The reference group (i.e. T1) thus refers to those individuals with 'less stiff' arteries on the basis of such (reversed) estimates graphically., 6,17 These analyses were first adjusted for sex, body height and time of measurement (model 1), and subsequently for the values of, at both the age of 32 and 36 (and thus the changes during follow-up in), vigorous intensity HPA (model 2), and smoking behaviour, alcohol consumption and total daily energy intake (model 3), all considered as potential confounders. We adjusted for vigorous intensity HPA specifically, because these HPAs, but not those of light-to-moderate intensity, were associated with lower arterial stiffness in this population. ${ }^{16,17}$ Next, we additionally adjusted for the longitudinal values of several biological risk factors (i.e. BMI or $\sum 4$ SKF or the skinfolds ratio, MAP, $\mathrm{VO}_{2}$ max, total-to-HDL cholesterol ratio, triglycerides and resting heart rate) separately (models $4 \mathrm{~A}-\mathrm{F}$ ) and in combination (models 5 ) to ascertain the extent to which associations between television time and arterial stiffness could be explained by (any of) these risk factors. ${ }^{6}$ This was appreciated by the extent of attenuation in the television time differences between the stiffness groups being compared, before and after adjustment for these biological risk factors (i.e. models 4 and 5 vs. model 3 ).

We also investigated whether the development of television time between the ages of 32 and 36 years differed between groups of subjects with different arterial stiffness levels at age 36; these were obtained by adding interaction terms between stiffness tertiles and time to model 3 described above, ${ }^{24}$ and results hereby obtained were displayed graphically. ${ }^{6,16,17}$

All statistical analyses were performed with the use of the STATA software package version 11.2 (STATA Corp, College Station, Texas, USA). Triglycerides, which were positively skewed, were $\log _{e}$-transformed prior to analyses. Statistical significance was set at $P<0.05$ (two-sided).

\section{RESULTS}

Table 3.3.1 presents study participants' characteristics at ages 32 and 36 years and levels of participants' arterial stiffness estimates at the age of 36 are shown in Table 3.3.2. 


\section{Television time in young adulthood and arterial stiffness at age 36}

Compared with subjects in with less stiff (i.e. in T1), those with the stiffest carotid arteries (i.e. in T3) at the age of 36 had spent on average more time watching television during the 4 preceding years (Table 3.3.3). For example, these differences amounted to $+19.9 \mathrm{~min} /$ day (6.1 to 34.1) for comparisons on the basis of the carotid DC (model 1). Further adjustment for vigorous HPA (model 2) and other lifestyle variables (model 3; i.e. potential confounders) slightly strengthened these differences, to $+22.4 \mathrm{~min} /$ day (8.7 to 36.1 ). Television time did not differ significantly between subjects in T2 (i.e. with intermediate stiffness) vs. those in T1, however.

Despite the unfavourable longitudinal associations between television time and $\mathrm{VO}_{2} \max , \mathrm{BMI}, \sum 4 \mathrm{SKF}$ (but less so skinfolds ratio), triglycerides, MAP, total-to-HDL cholesterol ratio, and, to a lesser extent, resting heart rate (Table 3.3.4), additional adjustment for each of these risk factors separately (i.e. potential mediators) only slightly attenuated the differences in television time between subjects in T3 vs. those in T1 of each carotid stiffness estimates (Table 3.3.3, models 4A-F). Altogether, the biological risk factors explained these differences up to a maximum of $31 \%$ (e.g., decreases from $22.4 \mathrm{~min} /$ day to $+15.4 \mathrm{~min} /$ day on the basis of subjects' levels of the carotid DC), which nevertheless remained overall statistically significant (models 5 ).

Qualitatively similar results were obtained for the femoral (Table 3.3.5), but not brachial stiffness estimates (data not shown).

The mean levels of television time increased over the course of the 4 years in the whole study population by $7.3 \mathrm{~min} /$ day ( $95 \% \mathrm{Cl}: 1.1$ to 13.6 ), but such increases did not differ significantly between groups with increasing levels of arterial stiffness $(P$ values for interactions between tertiles of each stiffness estimate and time all >0.239). Albeit not significant, the 4-year increases in television time tended to be greater in individuals with the stiffest vs. less stiff arteries (e.g. $+9.1 \mathrm{~min} /$ day [-6.0 to 24.2] and +9.3 min/day [-6.0 to 24.5] for T3 vs. T1 of the carotid and femoral DCs, respectively, adjusted for sex, height and other lifestyle variables), leading to differences in television time between these groups that were wider at the age of 36 than 32 years (Figure 3.3.2A and 3.3.2B, respectively; for details see Table 3.3.S3 - Appendix 3.3.1). In fact, these trajectory analyses show that subjects with the stiffest arteries at the age of 36 were those who significantly spent more time watching television during the 4 preceding years, i.e. consistently so above $2 \mathrm{~h} /$ day at both the ages of 32 and 36 years. Indeed, television time was strongly correlated between the two ages (partial $r=0.6, P<0.001)$ and individuals who spent $>2 \mathrm{~h} /$ day on this behaviour at the age of 32 were considerably more likely to remain doing so at the age of 36 (OR=6.4 [3.8 to 10.8]). 


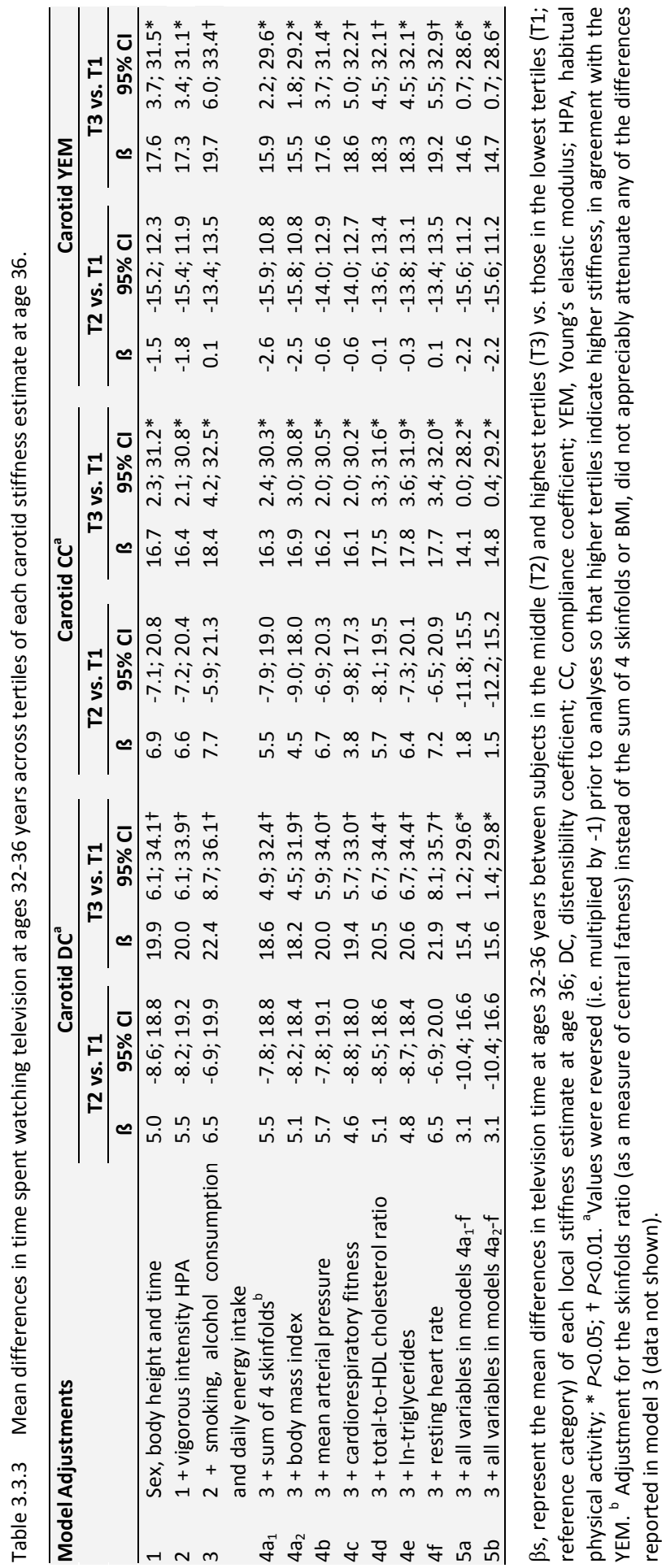


Table 3.3.4 Longitudinal associations between television time and biological cardiovascular risk factors.

\begin{tabular}{|c|c|c|c|c|c|c|}
\hline \multirow[t]{2}{*}{ Risk factor } & \multicolumn{2}{|c|}{ Model 1} & \multicolumn{2}{|r|}{ Model 2} & \multicolumn{2}{|c|}{ Model 3} \\
\hline & 及 & $95 \% \mathrm{Cl}$ & B & $95 \% \mathrm{Cl}$ & B & $95 \% \mathrm{Cl}$ \\
\hline Mean arterial pressure & 0.068 & $0.000 ; 0.136^{*}$ & 0.067 & $-0.002 ; 0.136$ & 0.078 & $0.007 ; 0.148^{*}$ \\
\hline Body mass index & 0.076 & $0.030 ; 0.123+$ & 0.077 & $0.030 ; 0.125+$ & 0.078 & $0.029 ; 0.127+$ \\
\hline Sum of 4 skinfolds & 0.065 & $0.010 ; 0.119 *$ & 0.064 & $0.009 ; 0.118^{*}$ & 0.067 & $0.013 ; 0.122 *$ \\
\hline Skinfolds ratio & 0.034 & $-0.013 ; 0.081$ & 0.032 & $-0.016 ; 0.079$ & 0.033 & $-0.015 ; 0.081$ \\
\hline $\begin{array}{l}\text { Cardiorespiratory fitness } \\
\left(\mathrm{VO}_{2} \max \right)\end{array}$ & -0.188 & $-0.258 ;-0.118 \ddagger$ & -0.177 & $-0.245 ;-0.108 \ddagger$ & -0.168 & $-0.237 ;-0.099 \ddagger$ \\
\hline $\begin{array}{l}\text { Total-to-HDL cholesterol } \\
\text { ratio }\end{array}$ & 0.068 & $0.012 ; 0.125^{*}$ & 0.063 & $0.007 ; 0.119 *$ & 0.066 & $0.007 ; 0.125^{*}$ \\
\hline Ln-triglycerides & 0.080 & $0.012 ; 0.149 *$ & 0.074 & $0.006 ; 0.142 *$ & 0.078 & $0.008 ; 0.148 *$ \\
\hline Resting heart rate & 0.058 & $-0.017 ; 0.132$ & 0.049 & $-0.026 ; 0.123$ & 0.053 & $-0.024 ; 0.129$ \\
\hline
\end{tabular}

ßs, standardized longitudinal regression coefficients: indicates the difference in biological risk factors (in SD) per 1 SD increase in television time. ${ }^{*} P<0.05 ;+P<0.01 ; \ddagger P<0.001$. Model 1 : Adjusted for sex, body height and time; Model 2: model $1+$ adjustment for vigorous intensity HPA; Model 3: model $2+$ adjustment for smoking, alcohol consumption and daily energy intake.

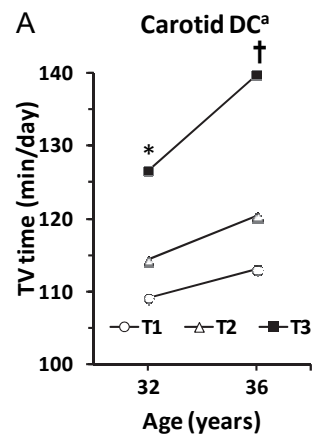

B Femoral DC

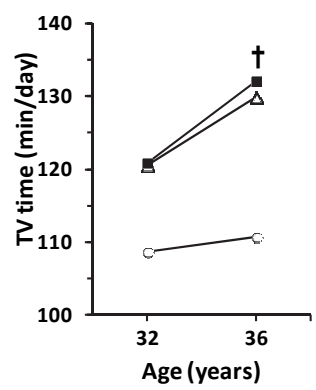

Carotid CCa

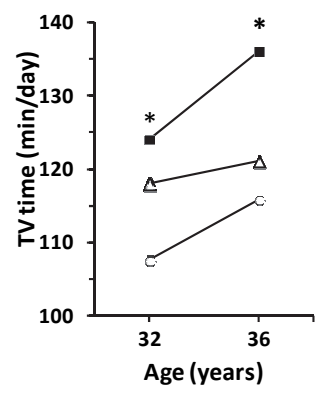

Femoral CC $^{\mathrm{a}}$

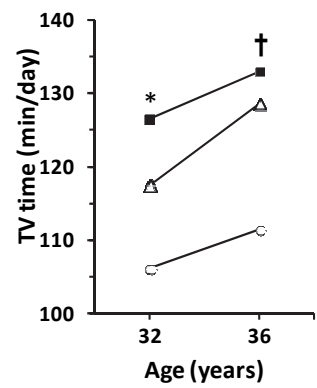

Carotid YEM

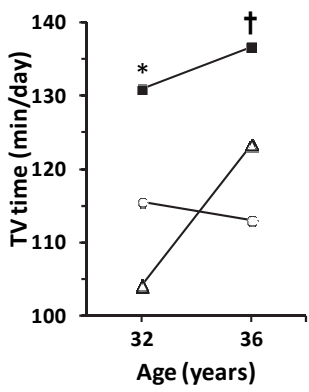

Figure 3.3.2 Levels of television time at the ages of 32 and 36 years in subjects with different levels (tertiles) of A) carotid and B) femoral stiffness estimates, as estimated by means of generalized estimating equations. All data are adjusted for sex, body height, time, vigorous intensity habitual physical activity, smoking, alcohol consumption and daily energy intake. DC, distensibility coefficient; CC, compliance coefficient; YEM, Young's elastic modulus. ${ }^{*} P<0.05$ and $+P<0.01$ for differences between T3 (i.e. stiffest) vs. T1 (i.e. less stiff artery) on the basis of each stiffness estimate; ${ }^{a}$ Note that values of DCs and CCs were reversed (i.e. multiplied by -1) prior to analyses so that higher tertiles indicate higher stiffness, in agreement with the carotid YEM. 


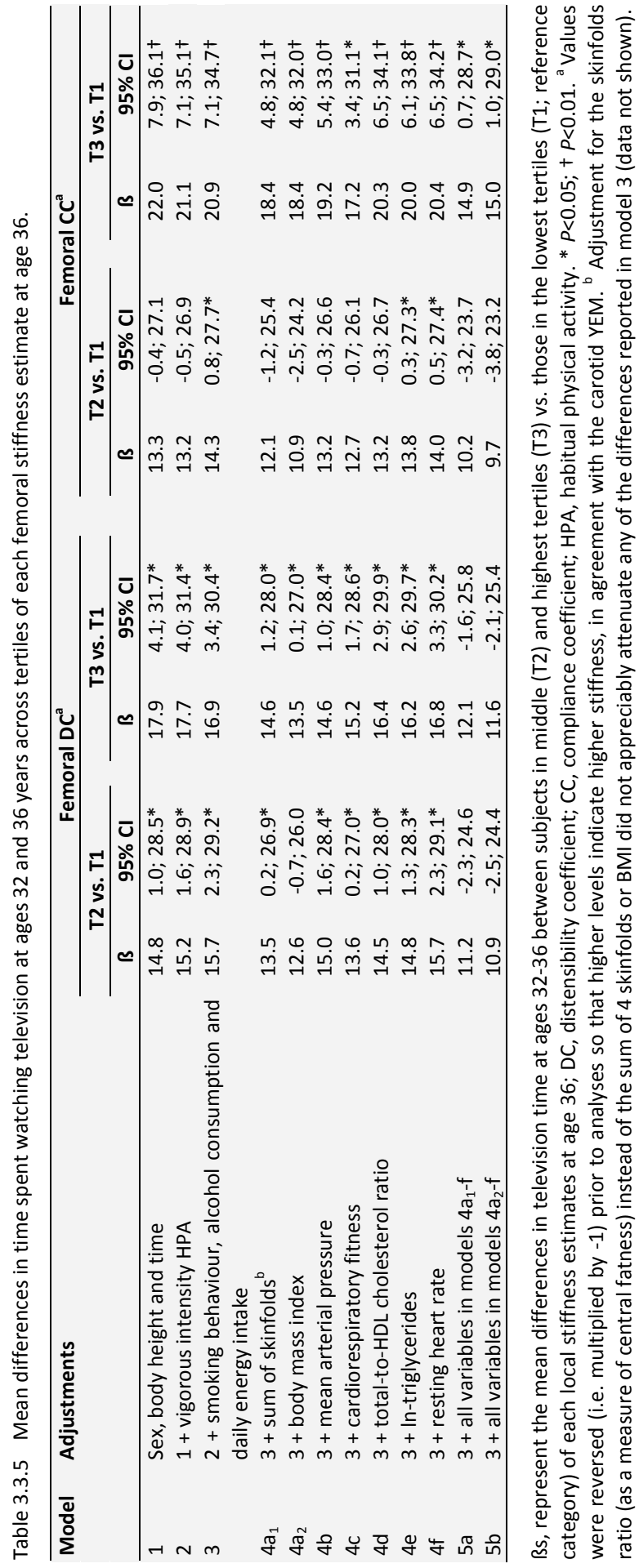




\section{Television time, HPA and arterial stiffness}

Vigorous, but not light-to-moderate, intensity HPA (per min/day increase) was inversely, though weakly, associated with television time $(\beta=-0.24 \mathrm{~min} /$ day $[-0.45$ to $0.04]$ and $\beta=-0.01 \mathrm{~min} /$ day [ -0.07 to 0.06$]$, respectively, in analyses adjusted for sex, body height, time and other lifestyle variables). Replacing the adjustment for vigorous intensity HPA by that for light-to-moderate HPA, thus, did not materially change the differences in television time across the tertiles of stiffness estimates as presented in model 2 of Tables 3.3.3 and 3.3.5 (data not shown). Furthermore, no effect modification by vigorous intensity HPA was found in the comparisons of television time across tertiles of arterial stiffness estimates as described above ( $P$-values for interaction terms with vigorous intensity HPA all >0.2).

Additional analyses. All results shown above were estimated by means of GEE analyses of all television time (and covariates) data available in the selected study population. Confining of our analyses to the 339 (185 women) subjects with television time data at both the age of 32 and 36 years did not appreciably affect the results reported, however (see Tables 3.3.S4 to 3.3.S6 and Figure 3.3.S1- Appendix 3.3.1).

\section{DISCUSSION}

The major findings of this study are: 1) that subjects with stiffer carotid and femoral arteries, as defined on the basis of local arterial stiffness estimates measured at age 36 years, were those who had spent more time watching television during the four preceding years, indicating an unfavourable association of this sedentary behaviour with arterial stiffness; 2 ) that these associations were independent of other lifestyle risk factors, most notably time spent in vigorous intensity HPA; and 3) that these associations were in part explained by, but remained to a large extent independent of the adverse associations between television time and other cardiovascular risk factors, such as cardiorespiratory fitness, body fatness, mean arterial pressure, blood lipids and, to a lesser extent, resting heart rate.

To the best of our knowledge, this is the first study that has investigated and shown adverse associations between television time and arterial stiffness, at the levels of both the carotid and femoral arteries, and this in young and apparently healthy adults. Arterial stiffness could thus be one of the pathobiological mechanisms explaining the increased cardiovascular risk associated with television time. ${ }^{13}$ Indeed, stiffness of mainly elastic arteries, such as the carotid and aorta, predicts incident cardiovascular disease and mortality, notably also in the general population. ${ }^{1,25-27}$ Changes in elastic properties of peripheral arteries, such as the femoral artery, have not been directly linked to incident cardiovascular outcome, ${ }^{1}$ but these may contribute to an earlier arrival of the reflected pulse wave at the left ventricle during late systole, thereby increasing cardiovascular risk. ${ }^{28}$ Although an association between arterial stiffness in individuals as young as $40-50$ years with cardiovascular mortality 
has been demonstrated ${ }^{26,27}$ it still remains to be established whether stiffness levels observed in younger adults also have the same predictive value. Nevertheless, in the course of ageing, young adults with stiffer arteries are not likely to have these reversed unless changes towards healthier behaviours or other interventions are adopted.

Given that the process of arterial stiffening starts already at younger ages, ${ }^{2-6}$ we have previously investigated whether lifetime (i.e. from adolescence up to young adulthood) HPA of different intensities was associated with arterial stiffness in young adults, and the extent to which such associations differed throughout the arterial tree (i.e. central [or elastic] vs. peripheral [or muscular] arteries). ${ }^{16,17}$ We have now investigated television time, as a determinant of elastic or muscular arterial stiffness, but confined these analyses to the young adulthood period because, in this cohort, this sedentary behaviour was ascertained at the ages of 32 and 36 years only. We also specifically investigated whether any such associations were independent of individuals' levels of HPA in line with recent views suggesting that these two behaviours are not merely two measures of a single continuum, but two distinct behaviours that may coexist. ${ }^{7,15}$ In support of this hypothesis, we observed that the adverse associations of television time with arterial stiffness and also other cardiovascular risk factors were independent of subjects' vigorous-intensity HPA levels, which we have previously shown to be favourably associated with carotid stiffness $^{16}$ and brachial and femoral compliance. ${ }^{17}$ These observations are in agreement with previous studies that investigated the associations of television time and HPA on the one hand and body fatness, ${ }^{10,11}$ blood lipids, ${ }^{11}$ blood pressure, ${ }^{11}$ type 2 diabetes mellitus ${ }^{10}$ and the metabolic syndrome ${ }^{12}$ on the other. In addition, we found weak correlations between the two behaviours and no evidence for any effect modification by vigorous intensity HPA in the associations between television time and arterial stiffness suggesting that the adverse association of television time could not be nullified by increasing the levels of vigorous intensity HPA. Furthermore, in the present cohort, a similar proportion of individuals with high and low levels of television time had high levels of vigorous HPA at the ages of 32 and 36 years, suggesting that these phenotypes indeed often co-occur (see Figure 3.3.S2 Appendix 3.3.1).

Our data also suggest that only a modest part (i.e. approximately $25-30 \%$ ) of the higher carotid and femoral stiffness related to higher television time could be explained by the adverse associations of television time with traditional biological cardiovascular risk factors. In contrast, we have previously shown that the beneficial associations between vigorous HPA and carotid stiffness were explained to a greater extent (i.e. up to $\sim 70 \%$ ) by concomitant vigorous HPA-related favourable associations with the same risk factors. ${ }^{16}$ These observations suggest that sedentary behaviours are likely to have specific, though largely unknown, cellular and molecular processes explaining their deleterious associations with arterial stiffness. In this line, it has been proposed that sedentariness and physical activity may affect metabolic and 
cardiovascular health through common pathways, such as low-grade inflammation, endothelial dysfunction and insulin sensitivity, ${ }^{16,29,30}$ but that the regulation of these might be qualitatively different in response to the two behaviours. ${ }^{7}$ Further investigation is thus necessary to unravel the specific mechanisms that link sedentary behaviour to arterial stiffness.

From a public health point of view it is important to notice that differences in television time found between subjects with higher vs. lower carotid and femoral stiffness were relatively small and amounted to approximately $20 \mathrm{~min} /$ day. The categorization of subjects in with the stiffest vs. the less stiff arteries was based on tertiles of the measured values of the local stiffness estimates assessed at age 36 . The differences in, for instance, the mean carotid DC and CC of subjects in the highest vs. the lowest tertiles correspond to those observed in the course of one decade of ageing, $^{31}$ indicating that the groups being compared translate to physiologically relevant differences in arterial stiffness. Furthermore, together with our earlier observations ${ }^{16,17}$ the present findings strongly suggest that both lack of (vigorous) HPA activity, as well as excessive time spent in sedentary behaviours, need to be targeted to prevent arterial stiffening in young adults. Guidelines directed to young adults and targeting sedentary behaviours in particular, as already available for children, ${ }^{32}$ and complementary to those available for exercise physical activities, ${ }^{33}$ are thus needed. In this line, we observed that subjects with the stiffest arteries were those who consistently spent more than $2 \mathrm{~h}$ /day on television viewing in the 4-year study period (Figure 3.3.2), which is the maximum total media time advised for children. ${ }^{32}$ Television time at the age of 32 was strongly correlated with that at the age of 36 and individuals who spent $>2 \mathrm{~h} /$ day on this behaviour at the age of 32 were considerably more likely to remain doing so at the age of 36 , indicating high tracking in sedentariness. ${ }^{34}$ Whether decreases in television time, and promotion of such upper limits are, indeed, effective among young adults in order to decrease arterial stiffness needs to be further investigated, however.

Strengths of our study are that data on television time, and several other lifestyle and biological risk factors, were measured prospectively during young adulthood in subjects for whom arterial stiffness was assessed at both central (i.e. carotid artery) and peripheral (i.e. brachial and femoral arteries) arterial sites at the age of 36 years. This extensive phenotyping of study participants allowed a comprehensive assessment of the associations of these risk factors, and their interrelations, with arterial stiffness in young adulthood. Some limitations need to be addressed, however. First, we only investigated television time as a measure of sedentary behaviour. Television viewing, however, is the most common and time consuming activity during individuals' leisure time in the Netherlands, ${ }^{35}$ as well as in Australia, the United States and United Kingdom. ${ }^{13,36,37}$ In addition, assessment of television time with questionnaires similar to the ones used in the present study showed reasonable reliability and validity of this measure as a marker for overall sedentary behaviour. ${ }^{38}$ Although we can argue that such a simple and easy to assess measure was robust to 
identify subjects with higher arterial stiffness, more extensive instruments may be needed for a more comprehensive assessment of a wider range of sedentary behaviours (e.g. passive transportation, sitting and talking, listening to music, computer use) and understanding of their specific effects on metabolic and cardiovascular health. ${ }^{15}$ In addition, investigation of the physical and psychosocial determinants of sedentary behaviours is needed in order to design preventive measures tailored to individuals' realities and thus more likely to be effective. ${ }^{39}$ Second, the use of questionnaires to assess television time is subject to recall and misclassification bias. Although we think that most was non-differential, because subjects were unaware of their arterial stiffness levels at the time of assessment, we cannot exclude the possibility that some differential misclassification has occurred. Either way, this may have led to an underestimation of the differences in television time estimated in this study, as unhealthier behaviours are more likely to be underreported by those with unhealthier risk profiles ${ }^{40}$ and who are thus more likely to have stiffer arteries. Third, the present study was confined to the 373 subjects from the original cohort who had complete arterial data at the age of 36 years, but their general characteristics did not differ from those not included in the analyses at any of the earlier time points extending back to the start of the cohort in 1976-7 (data not shown). The study population is therefore representative of the original cohort, and selection bias did not threaten our results. Also, the 34 subjects (out of 373 examined herein) with only one measure of television time at the age of 32 or 36 did not differ from the remaining 339 who had television data at both ages; this justified the use of all data available on risk exposure in the selected study population enabled by the method of statistical analyses adopted (GEE), instead of restricting analyses to complete cases. Finally, arterial stiffness was only measured at the age of 36 , which did not enable investigation of the impact of changes in television time on changes in arterial stiffness. We could thus only establish that individuals with the stiffest arteries at the age of 36 were those with the highest levels of television time (as a measure of risk exposure) in the 4-preceding years. Still, given the pre-clinical and asymptomatic character of arterial stiffness in young adults we deem reverse causality unlikely.

In conclusion, we show that television time, an important and modifiable sedentary behaviour, is unfavourably associated with arterial stiffness in young adults. This association was independent of other lifestyle risk factors, such as (vigorous) physical activity, and could only in part be explained by television-time-related deleterious associations with traditional biological risk factors. Although the mechanisms explaining these associations are yet not fully understood, these seem to differ, to a great extent, from those linking physical activity to arterial stiffness. Therefore, not only promotion of vigorous habitual physical activity, but also measures targeting sedentary behaviour in particular should be encouraged in order to prevent the development of arterial stiffness in young adults. 


\section{REFERENCES}

1. Laurent S, Cockcroft J, Van Bortel L, et al. Expert consensus document on arterial stiffness: methodological issues and clinical applications. Eur Heart J. 2006;27:2588-2605.

2. Aggoun Y, Szezepanski I, Bonnet D. Noninvasive assessment of arterial stiffness and risk of atherosclerotic events in children. Pediatr Res. 2005;58:173-178.

3. Ferreira I, Twisk JW, van Mechelen W, Kemper HC, Seidell JC, Stehouwer CD. Current and adolescent body fatness and fat distribution: relationships with carotid intima-media thickness and large artery stiffness at the age of 36 years. J Hypertens. 2004;22:145-155.

4. Juonala M, Jarvisalo MJ, Maki-Torkko N, Kahonen M, Viikari JS, Raitakari OT. Risk factors identified in childhood and decreased carotid artery elasticity in adulthood: the Cardiovascular Risk in Young Finns Study. Circulation. 2005;112:1486-1493.

5. Li S, Chen W, Srinivasan SR, Berenson GS. Childhood blood pressure as a predictor of arterial stiffness in young adults: the Bogalusa Heart Study. Hypertension. 2004;43:541-546.

6. Ferreira I, van de Laar RJ, Prins MH, Twisk JW, Stehouwer CD. Carotid stiffness in young adults: a lifecourse analysis of its early determinants: the Amsterdam Growth and Health Longitudinal Study. Hypertension. 2012;59:54-61.

7. Hamilton MT, Hamilton DG, Zderic TW. Role of low energy expenditure and sitting in obesity, metabolic syndrome, type 2 diabetes, and cardiovascular disease. Diabetes. 2007;56:2655-2667.

8. Hancox RJ, Milne BJ, Poulton R. Association between child and adolescent television viewing and adult health: a longitudinal birth cohort study. Lancet. 2004;364:257-262.

9. Healy GN, Dunstan DW, Salmon J, Shaw JE, Zimmet PZ, Owen N. Television time and continuous metabolic risk in physically active adults. Med Sci Sports Exerc. 2008;40:639-645.

10. Hu FB, Li TY, Colditz GA, Willett WC, Manson JE. Television watching and other sedentary behaviors in relation to risk of obesity and type 2 diabetes mellitus in women. JAMA. 2003;289:1785-1791.

11. Jakes RW, Day NE, Khaw KT, et al. Television viewing and low participation in vigorous recreation are independently associated with obesity and markers of cardiovascular disease risk: EPIC-Norfolk population-based study. Eur J Clin Nutr. 2003;57:1089-1096.

12. Dunstan DW, Salmon J, Owen N, et al. Associations of TV viewing and physical activity with the metabolic syndrome in Australian adults. Diabetologia. 2005;48:2254-2261.

13. Dunstan DW, Barr EL, Healy GN, et al. Television viewing time and mortality: the Australian Diabetes, Obesity and Lifestyle Study (AusDiab). Circulation. 2010;121:384-391.

14. Thorp AA, Owen N, Neuhaus M, Dunstan DW. Sedentary behaviors and subsequent health outcomes in adults a systematic review of longitudinal studies, 1996-2011. Am J Prev Med. 2011;41:207-215.

15. Biddle SJ. Sedentary behavior. Am J Prev Med. 2007;33:502-504.

16. van de Laar RJ, Ferreira I, van Mechelen W, Prins MH, Twisk JW, Stehouwer CD. Lifetime vigorous but not light-to-moderate habitual physical activity impacts favorably on carotid stiffness in young adults: the Amsterdam Growth and Health Longitudinal Study. Hypertension. 2010;55:33-39.

17. van de Laar RJ, Ferreira I, van Mechelen W, Prins MH, Twisk JW, Stehouwer CD. Habitual physical activity and peripheral arterial compliance in young adults: the Amsterdam Growth and Health Longitudinal Study. Am J Hypertens. 2011;24:200-208.

18. Ferreira I, Twisk JW, van Mechelen W, Kemper HC, Stehouwer CD. Development of fatness, fitness, and lifestyle from adolescence to the age of 36 years: determinants of the metabolic syndrome in young adults: the Amsterdam Growth and Health Longitudinal Study. Arch Intern Med. 2005;165: 42-48.

19. Brands PJ, Hoeks AP, Willigers J, Willekes C, Reneman RS. An integrated system for the non-invasive assessment of vessel wall and hemodynamic properties of large arteries by means of ultrasound. Eur J Ultrasound. 1999;9:257-266

20. Reneman RS, Hoeks AP. Noninvasive vascular ultrasound: an asset in vascular medicine. Cardiovasc Res. 2000;45:27-35.

21. Van Bortel LM, Balkestein EJ, van der Heijden-Spek JJ, et al. Non-invasive assessment of local arterial pulse pressure: comparison of applanation tonometry and echo-tracking. J Hypertens. 2001;19:10371044. 
22. Ferreira I, Henry RM, Twisk JW, van Mechelen W, Kemper HC, Stehouwer CD. The metabolic syndrome, cardiopulmonary fitness, and subcutaneous trunk fat as independent determinants of arterial stiffness: the Amsterdam Growth and Health Longitudinal Study. Arch Intern Med. 2005; 165:875-882.

23. Twisk J, de Vente W. Attrition in longitudinal studies. How to deal with missing data. J Clin Epidemiol. 2002;55:329-337.

24. Twisk JWR. Applied Longitudinal Data Analysis for Epidemiolgy: A Practical Guide. Cambridge: Cambridge University Press; 2003.

25. Vlachopoulos C, Aznaouridis K, Stefanadis C. Prediction of cardiovascular events and all-cause mortality with arterial stiffness: a systematic review and meta-analysis. J Am Coll Cardiol. 2010;55: 1318-1327.

26. Willum-Hansen T, Staessen JA, Torp-Pedersen C, et al. Prognostic value of aortic pulse wave velocity as index of arterial stiffness in the general population. Circulation. 2006;113:664-670.

27. Yang EY, Chambless L, Sharrett AR, et al. Carotid arterial wall characteristics are associated with incident ischemic stroke but not coronary heart disease in the Atherosclerosis Risk in Communities (ARIC) Study. Stroke. 2012;43:103-108.

28. Safar ME, Levy BI, Struijker-Boudier H. Current perspectives on arterial stiffness and pulse pressure in hypertension and cardiovascular diseases. Circulation. 2003;107:2864-2869.

29. Pavy-Le Traon A, Heer M, Narici MV, Rittweger J, Vernikos J. From space to Earth: advances in human physiology from 20 years of bed rest studies (1986-2006). Eur J Appl Physiol. 2007;101:143-194.

30. Shephard RJ, Balady GJ. Exercise as cardiovascular therapy. Circulation. 1999;99:963-972.

31. Vermeersch SJ, Rietzschel ER, De Buyzere ML, et al. Age and gender related patterns in carotidfemoral PWV and carotid and femoral stiffness in a large healthy, middle-aged population. $J$ Hypertens. 2008;26:1411-1419.

32. American Academy of Pediatrics. Policy statement: Children, adolescents, and television. Pediatrics. 2001;107:423-426.

33. Haskell WL, Lee IM, Pate RR, et al. Physical activity and public health: updated recommendation for adults from the American College of Sports Medicine and the American Heart Association. Circulation. 2007;116:1081-1093.

34. Gordon-Larsen P, Nelson MC, Popkin BM. Longitudinal physical activity and sedentary behavior trends: adolescence to adulthood. Am J Prev Med. 2004;27:277-283.

35. Sociaal en Cultureel planbureau. Tijdsbestedingsonderzoek 2005. www.tijdsbesteding.nl. Accessed 27 December, 2011.

36. Bureau of Labor Statistics. American Time Use Survey - 2010 Results. www.bls.gov/tus/. Accessed 27 december, 2011.

37. Office for National Statistics. The Time Use Survey, 2005. http://www.ons.gov.uk/ons/index.html. Accessed 27 December, 2011.

38. Clark BK, Sugiyama T, Healy GN, Salmon J, Dunstan DW, Owen N. Validity and reliability of measures of television viewing time and other non-occupational sedentary behaviour of adults: a review. Obes Rev. 2009;10:7-16

39. Brug J, Oenema A, Ferreira I. Theory, evidence and Intervention Mapping to improve behavior nutrition and physical activity interventions. Int J Behav Nutr Phys Act. 2005;2:2.

40. Macdiarmid J, Blundell J. Assessing dietary intake: Who, what and why of under-reporting. Nutr Res Rev. 1998;11:231-253. 


\section{Appendix 3.3.1}

Supplemental tables and figures 
Chapter 3.3 
Table 3.3.S1 General characteristics of the study population ( $n=339,185$ women - complete cases analyses).

\begin{tabular}{|c|c|c|}
\hline Variable & Age 32 & Age 36 \\
\hline \multicolumn{3}{|l|}{ Lifestyle risk factors } \\
\hline Television time, $\mathrm{min} /$ day & $117 \pm 63$ & $124 \pm 64$ \\
\hline \multicolumn{3}{|l|}{ Time spent in HPA, min/week } \\
\hline Total & $434[290-646]$ & $657[408-1026]$ \\
\hline Light-to-moderate & 305 [176-499] & $515[313-865]$ \\
\hline Vigorous & $92[43-165]$ & 93 [47-152] \\
\hline Alcohol consumption, \% & 80.1 & 81.7 \\
\hline Smoking, \% & 20.4 & 22.4 \\
\hline Total energy intake, $1000 \mathrm{kcal} / \mathrm{day}$ & $2.59 \pm 0.71$ & $2.63 \pm 0.70$ \\
\hline \multicolumn{3}{|l|}{ Biological risk factors } \\
\hline Systolic blood pressure, $\mathrm{mmHg}$ & $129.4 \pm 12.4$ & $130.4 \pm 13.4$ \\
\hline Diastolic blood pressure, $\mathrm{mmHg}$ & $84.5 \pm 8.8$ & $84.7 \pm 10.1$ \\
\hline Mean arterial pressure, $\mathrm{mmHg}$ & $99.4 \pm 9.0$ & $100.0 \pm 10.4$ \\
\hline Body mass index, $\mathrm{kg} / \mathrm{m}^{2}$ & $23.3 \pm 3.0$ & $23.9 \pm 3.1$ \\
\hline Sum of four skinfolds, $\mathrm{mm}$ & $47.4 \pm 19.3$ & $51.5 \pm 17.9$ \\
\hline Skinfolds ratio & $0.56 \pm 0.09$ & $0.57 \pm 0.10$ \\
\hline $\mathrm{VO}_{2} \mathrm{max}, \mathrm{ml} / \mathrm{min}^{\prime} \mathrm{kg}^{\mathrm{FFM}}$ & $56.5 \pm 7.3$ & $60.6 \pm 8.3$ \\
\hline Total cholesterol, mmol/l & $4.93 \pm 0.86$ & $4.98 \pm 0.88$ \\
\hline HDL cholesterol, mmol/l & $1.42 \pm 0.37$ & $1.42 \pm 0.37$ \\
\hline Total-to-HDL cholesterol ratio & $3.7 \pm 1.2$ & $3.8 \pm 1.3$ \\
\hline Triglycerides, mmol/l & $0.94[0.70-1.26]$ & $1.00[0.70-1.50]$ \\
\hline Resting heart rate, bpm & $75 \pm 14$ & $71 \pm 11$ \\
\hline
\end{tabular}

Data are means $\pm S D$, medians [inter-quartile ranges], or percentages. HPA, habitual HPA, habitual physical activity; $\mathrm{HDL}$, high-density lipoprotein; $\mathrm{VO}_{2} \max$, maximal oxygen uptake; FFM, free fat mass.

Table 3.3.S2 Arterial stiffness levels at the age of 36 years across sex-specific tertiles ${ }^{\mathrm{a}}$ of each stiffness estimate 36 ( $n=339,185$ women - complete cases analyses).

\begin{tabular}{|c|c|c|c|}
\hline Stiffness estimates & $\begin{array}{c}\text { T1 } \\
\text { Less stiff }\end{array}$ & $\begin{array}{c}\mathrm{T} 2 \\
\text { Intermediate }\end{array}$ & $\begin{array}{c}\text { T3 } \\
\text { Stiffest }\end{array}$ \\
\hline \multicolumn{4}{|l|}{ Common carotid artery } \\
\hline Distensibility coefficient, ${ }^{\mathrm{a}} 10^{-3} \cdot \mathrm{kPa}^{-1}$ & $33.5 \pm 4.0$ & $26.2 \pm 1.7$ & $20.4 \pm 2.2$ \\
\hline Compliance coefficient, ${ }^{\mathrm{a}} \mathrm{mm}^{2} \cdot \mathrm{kPa}^{-1}$ & $1.29 \pm 0.21$ & $0.97 \pm 0.09$ & $0.73 \pm 0.12$ \\
\hline Young's elastic modulus, $10^{3} \cdot \mathrm{kPa}$ & $0.32 \pm 0.05$ & $0.43 \pm 0.03$ & $0.58 \pm 0.09$ \\
\hline \multicolumn{4}{|l|}{ Brachial artery } \\
\hline Distensibility coefficient, ${ }^{\mathrm{a}} 10^{-3} \cdot \mathrm{kPa}^{-1}$ & $24.2 \pm 9.2$ & $12.5 \pm 2.4$ & $7.2 \pm 2.1$ \\
\hline Compliance coefficient, ${ }^{\mathrm{a}} \mathrm{mm}^{2} \cdot \mathrm{kPa}^{-1}$ & $0.27 \pm 0.08$ & $0.15 \pm 0.03$ & $0.09 \pm 0.03$ \\
\hline \multicolumn{4}{|l|}{ Common femoral artery } \\
\hline Distensibility coefficient, ${ }^{\mathrm{a}} 10^{-3} \cdot \mathrm{kPa}^{-1}$ & $11.1 \pm 4.0$ & $6.5 \pm 1.2$ & $4.1 \pm 1.1$ \\
\hline Compliance coefficient, ${ }^{\mathrm{a}} \mathrm{mm}^{2} \cdot \mathrm{kPa}^{-1}$ & $0.78 \pm 0.20$ & $0.46 \pm 0.05$ & $0.29 \pm 0.06$ \\
\hline
\end{tabular}

Data are means \pm SD. $P$-values for comparisons in stiffness estimates between all 3 groups were all $<0.001$. ${ }^{a}$ Note that distensibility and compliance coefficients values were reversed (i.e. multiplied by -1 ) prior to categorization into tertiles so that higher values indicate greater stiffness (in agreement with the carotid Young's elastic modulus. 


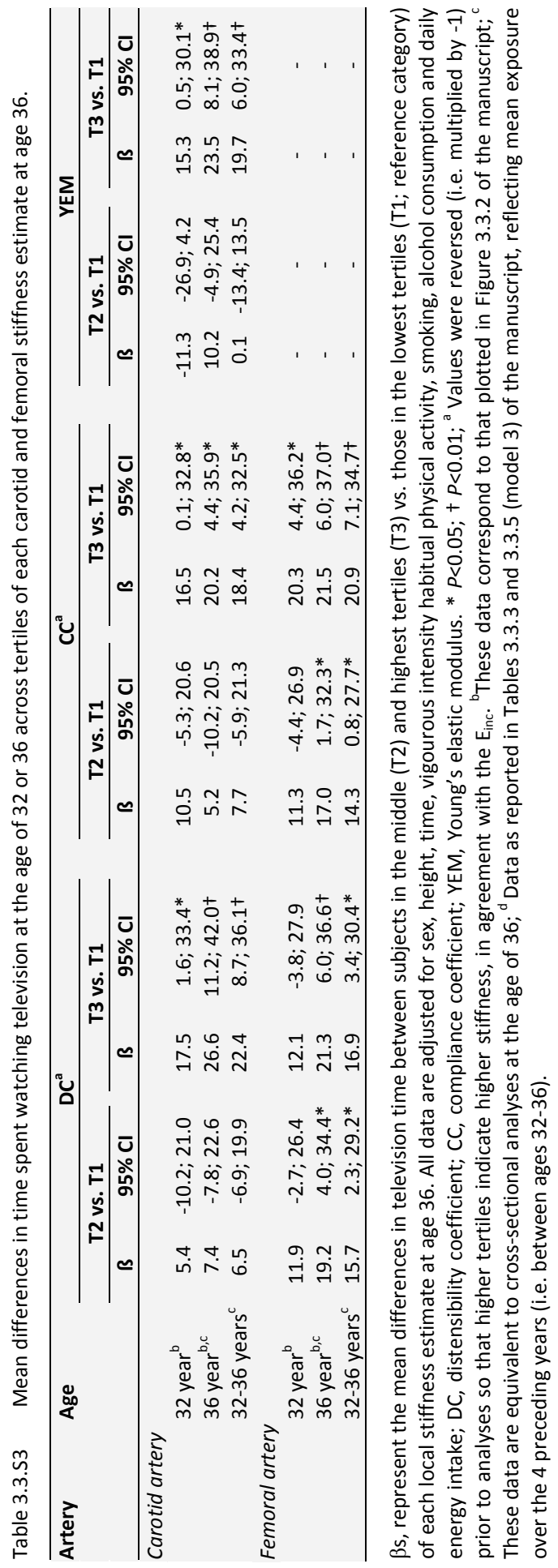




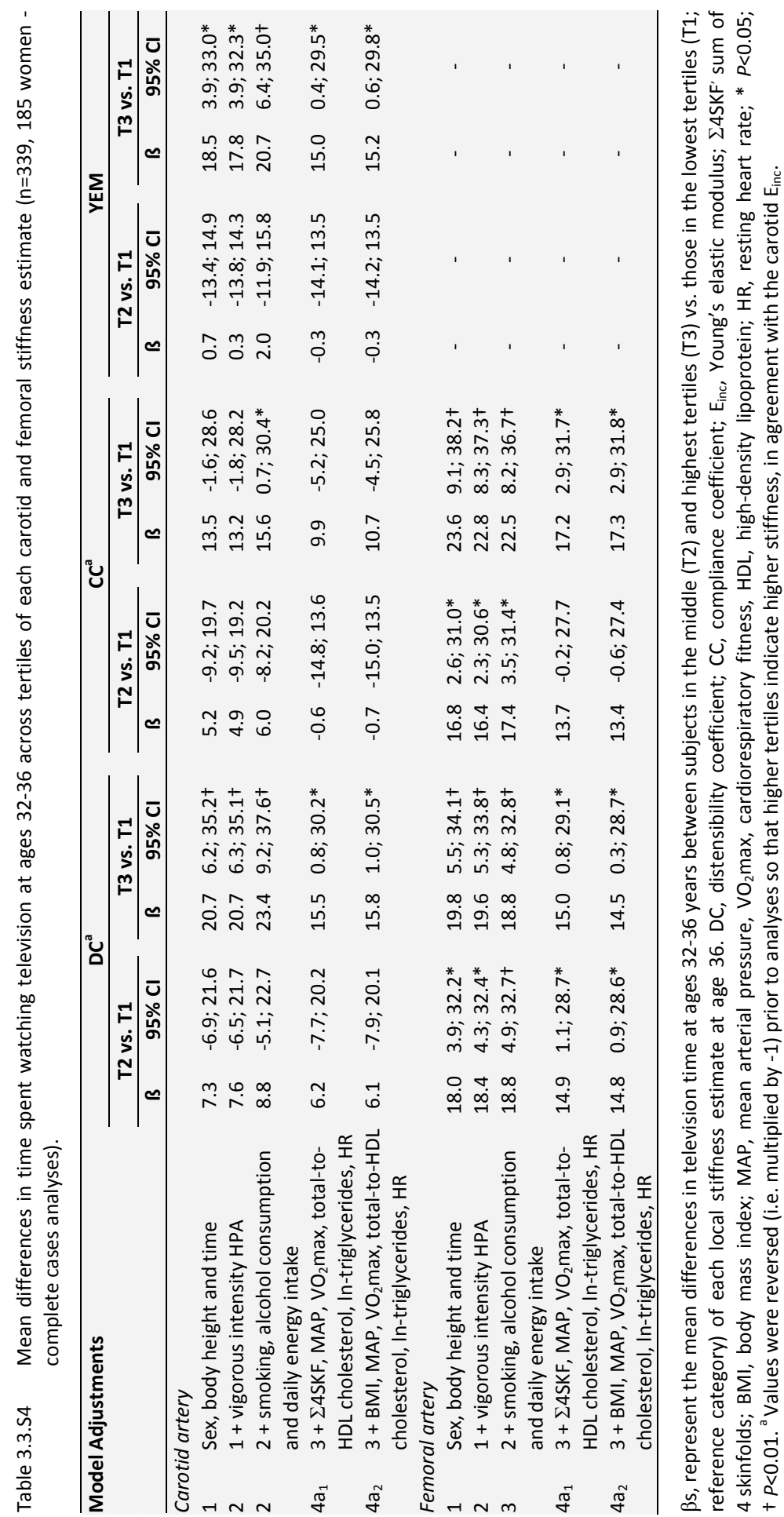




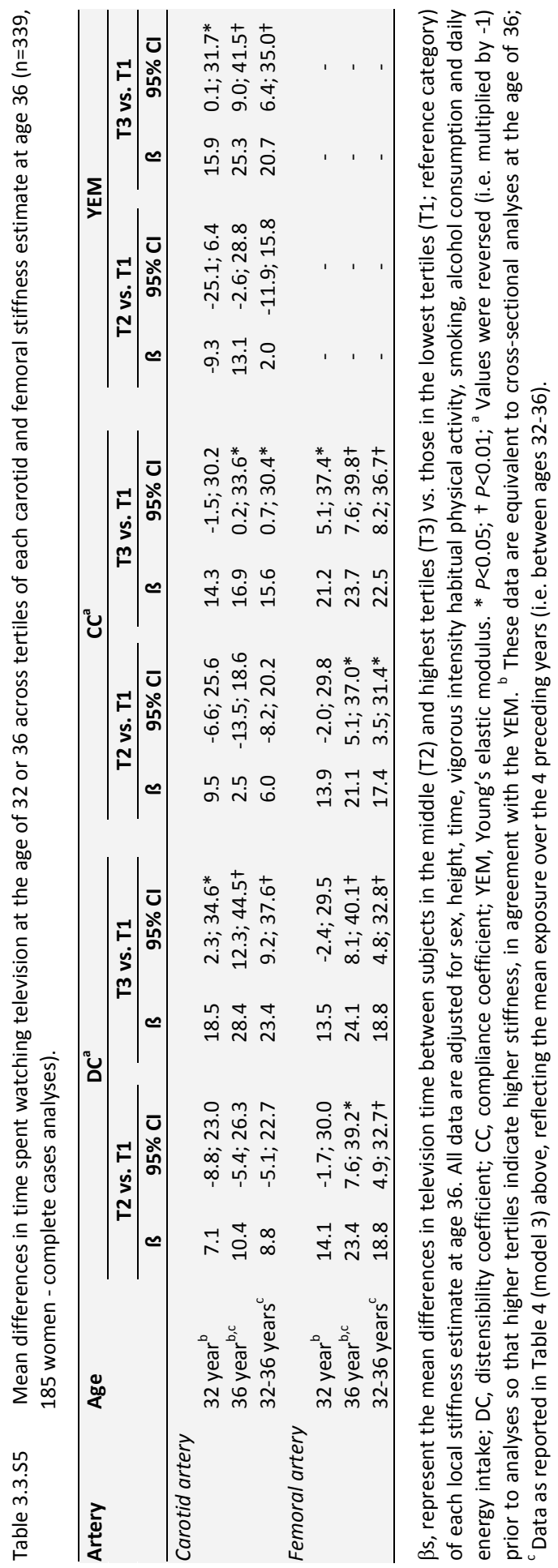


Table 3.3.S6 Longitudinal associations between television time and biological cardiovascular risk factors ( $\mathrm{n}=339,185$ women - complete cases analyses).

\begin{tabular}{|c|c|c|c|c|c|c|}
\hline \multirow[t]{2}{*}{ Risk factor } & \multicolumn{2}{|r|}{ Model 1} & \multicolumn{2}{|c|}{ Model 2} & \multicolumn{2}{|r|}{ Model 3} \\
\hline & B & $95 \% \mathrm{Cl}$ & B & $95 \% \mathrm{Cl}$ & B & $95 \% \mathrm{Cl}$ \\
\hline Mean arterial pressure & 0.067 & $0.000 ; 0.134^{*}$ & 0.066 & $-0.002 ; 0.134$ & 0.081 & $0.012 ; 0.150^{*}$ \\
\hline Body mass index & 0.065 & $0.022 ; 0.107+$ & 0.065 & $0.022 ; 0.109+$ & 0.066 & $0.021 ; 0.110+$ \\
\hline Sum of skinfolds & 0.059 & $0.005 ; 0.113^{*}$ & 0.057 & $0.003 ; 0.112^{*}$ & 0.063 & $0.008 ; 0.118^{*}$ \\
\hline Skinfolds ratio & 0.042 & $-0.008 ; 0.092$ & 0.040 & $-0.010 ; 0.089$ & 0.041 & $-0.009 ; 0.091$ \\
\hline $\mathrm{VO}_{2} \max$ & -0.172 & $-0.243 ;-0.111 \ddagger$ & -0.160 & $-0.230 ;-0.090$ & -0.153 & $-0.224 ;-0.083 \ddagger$ \\
\hline Total-to-HDL cholesterol & 0.070 & $0.017 ; 0.123+$ & 0.064 & $0.012 ; 0.116^{*}$ & 0.068 & $0.012 ; 0.123^{*}$ \\
\hline Ln-triglycerides & 0.082 & $0.012 ; 0.152^{*}$ & 0.075 & $0.005 ; 0.145^{*}$ & 0.077 & $0.006 ; 0.150^{*}$ \\
\hline Resting heart rate & 0.060 & $-0.018 ; 0.138$ & 0.051 & $-0.027 ; 0.129$ & 0.056 & $-0.023 ; 0.136$ \\
\hline
\end{tabular}

ßs, standardized longitudinal regression coefficients: indicates the difference in biological risk factors (in SD) per 1 SD increase in television time. ${ }^{*} P<0.05 ;+P<0.01 ; \ddagger P<0.001$. Model 1 : Adjusted for sex, body height and time; Model 2: model $1+$ adjustment for vigorous intensity HPA; Model 3: model $2+$ adjustment for smoking.

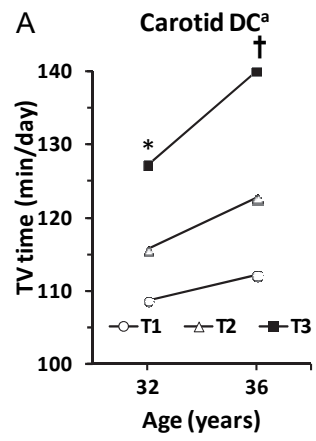

B

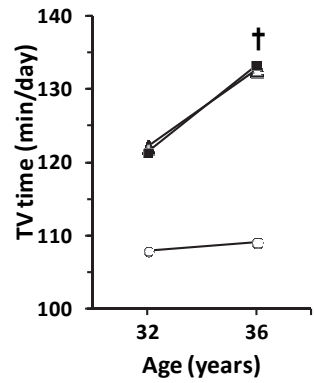

Carotid CC $^{\mathbf{a}}$

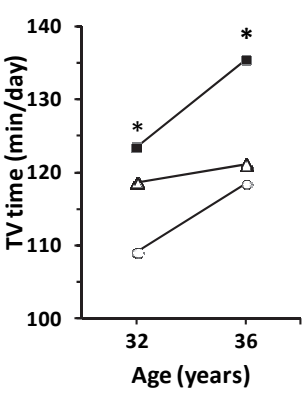

Femoral CCa

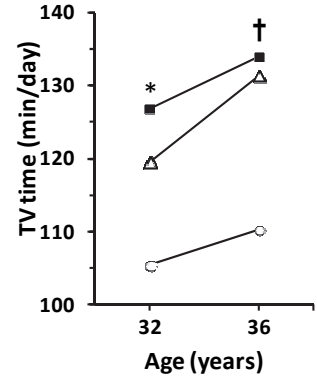

\section{Carotid YEM}

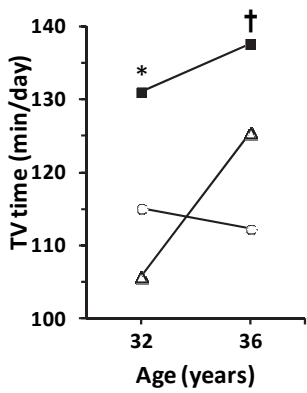

Figure 3.3.S1 Levels of television time at the ages of 32 and 36 years in subjects with different levels (tertiles) of A) carotid and B) femoral stiffness estimates, as estimated by means of generalized estimating equations. All data are adjusted for sex, body height, time, vigorous intensity habitual physical activity, smoking, alcohol consumption and daily energy intake and are confined to complete cases ( $n=339,185$ women). DC, distensibility coefficient; CC, compliance coefficient; YEM, Young's elastic modulus. ${ }^{*} p<0.05$ and $+p<0.01$ for differences between T3 (i.e., stiffest) vs. T1 (i.e., less stiff artery) on the basis of each stiffness estimate. ${ }^{a}$ Note that values of DCs and CCs were reversed (i.e. multiplied by -1 ) prior to analyses so that higher tertiles indicate higher stiffness, in agreement with the carotid YEM. 


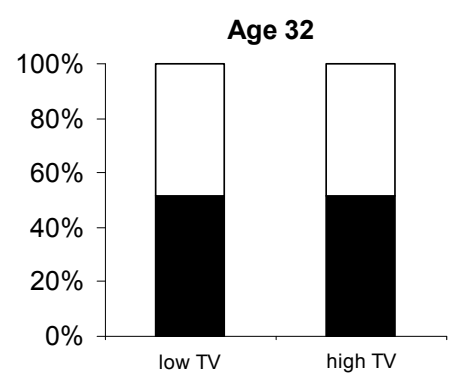

- low vigorous HPA $\square$ high vigorous HPA

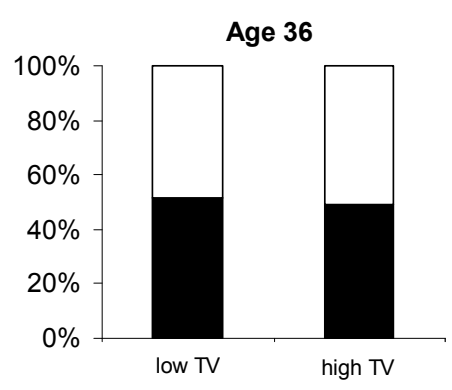

— low vigorous HPA $\square$ high vigorous HPA

Figure 3.3.S2 Percentage of participants in 'low' and 'high' vigorous HPA groups within 'low' and 'high' television time strata at ages 32 ( $n=170$ and $n=172$, respectively) and 36 years $(n=169$ and $\mathrm{n}=200$, respectively).

Categories were defined on the basis of age-specific medians of television time (i.e. 120 $\mathrm{min} /$ day at ages 32 and 36 years) and vigorous intensity HPA (i.e. 93 and $94 \mathrm{~min} /$ week at ages 32 and 36 years, respectively). 
Dietary habits

.

\section{Chapter 4}




\section{Chapter 4.1}

Lower lifetime dietary fiber intake is associated with carotid artery stiffness The Amsterdam Growth and Health Longitudinal Study

Roel J.J. van de Laar, Coen D.A. Stehouwer, Bas C.T. van Bussel, Saskia J. te Velde, Martin H. Prins, Jos W.R. Twisk, Isabel Ferreira Am J Clin Nutr. 2012;96:14-23 


\section{ABSTRACT}

\section{Background}

Fiber intake is associated with lower cardiovascular risk. Whether arterial stiffness is influenced by lifetime fiber intake, is not known. Any such association could explain, at least in part, the cardio-protective effects attributed to fiber intake.

\section{Objective}

The objective was to investigate whether a lower intake of fiber (and fiber rich foods) throughout the course of young life (i.e. from adolescence to adulthood) is associated with arterial stiffness in adulthood.

\section{Design}

This was a longitudinal cohort study among 373 participants in whom dietary intake was assessed between the ages of 13-36 y (2-8 repeated measures, mean of 5), and arterial stiffness estimates of 3 large arteries (ultrasonography) were ascertained at age $36 \mathrm{y}$.

\section{Results}

After adjustment for sex, height, total energy intake and other lifestyle variables, subjects with 'stiffer' carotid arteries consumed less fiber (in g/d) during the 24-y study than did those with less stiff arteries, as defined on the basis of the highest vs. lowest sex-specific tertiles of the distensibility and compliance coefficients (reversed) and Young's elastic modulus: $-1.9(95 \% \mathrm{Cl}$ : $-3.1 ;-0.7),-2.3(-3.5 ;-1.1)$, and $-1.3(-2.5 ;-0.0)$, respectively. Furthermore, subjects with 'stiffer' carotid arteries were characterized by a lower lifetime consumption of fruits, vegetables and whole grains - deleterious associations that could be explained, to a great extent, by related low fiber intake.

\section{Conclusions}

Lower lifetime intake of fiber during the course of young age is associated with carotid artery stiffness in adulthood. Promoting consumption of fiber-rich foods among the young may offer a means to prevent accelerated arterial stiffening in adulthood and related cardiovascular sequelae. 


\section{INTRODUCTION}

Arterial stiffness may cause cardiovascular disease (CVD) by contributing to increased systolic blood pressure, increased cardiac afterload and diminished cardiac perfusion. ${ }^{1}$ Arterial stiffness-related complications, such as coronary heart disease (CHD), stroke, heart failure and mortality, generally occur after the fifth decade of life, ${ }^{2,3}$ but the process of arterial stiffening starts much earlier due to exposure to risk factors (RFs) during a preclinical phase that may last for decades. Indeed, adverse levels of cardiovascular RFs in childhood/adolescence, such as low vigorous habitual physical activity and elevated (central) body fatness and blood pressure, have been shown to be associated with arterial stiffness in adulthood. ${ }^{4-8}$ Given that lifelong engagement in unhealthy lifestyles may be established in childhood, ${ }^{9}$ it is important to identify already at a young age modifiable RFs that may impact on arterial stiffness later in life.

Low dietary fiber intake may be one such RF. Several observational studies have shown fiber to be inversely associated with risk of incident CHD and stroke, ${ }^{10-12}$ and all-cause and cardiovascular mortality. ${ }^{13}$ Current recommendations thus suggest increasing fiber intake through higher consumption of fruits, vegetables and whole grains in order to reduce cardiovascular risk in the general population. ${ }^{14}$ Higher fiber intake may prevent arterial stiffening, as suggested by a recent study showing that individuals with the highest consumption of fruits and vegetables during childhoodadolescence and adulthood had lower levels of aortic pulse wave velocity (PWV) in adulthood. ${ }^{15}$ Whether these associations can be attributed to the fiber-content of these foods and may thus hold also for other foods rich in fiber, such as whole grain products, is not known.

In view of these considerations, we investigated, in a cohort of young individuals in whom dietary intake was repeatedly assessed from adolescence up to adulthood, and stiffness estimates of three larger arteries was ascertained at the age of 36 years: 1 ) whether the lifetime intake of fiber differed between subjects with increasing levels of arterial stiffness at age 36 years; and 2) whether these differences could be attributed to the consumption of foods high in fiber content, such as fruits, vegetables and whole grain products. Individuals' levels of arterial stiffness were defined on the basis of local estimates obtained at the central (elastic) carotid, and peripheral (muscular) brachial and femoral arteries, ${ }^{4-6}$ to ascertain the extent to which associations of fiber intake with arterial stiffness differed along the arterial tree. This distinction is important not only from an aetiological point of view, but also because stiffness levels of central arteries, such as the carotid ${ }^{2}$ and aorta, ${ }^{3}$ but not of peripheral arteries, may be stronger predictors of cardiovascular outcome. ${ }^{1}$ 


\section{SUBJECTS AND METHODS}

All subjects were participants of the Amsterdam Growth And Health Longitudinal Study, an observational study that started in 1976-77 with a group of 600 children aged 13 years from two secondary schools in the Netherlands. Since then, repeated measurements of dietary intake, anthropometrical, biological and other lifestyle variables have been obtained two to eight times (i.e. at ages 13, 14, 15, 16, 21, 27, 32 and 36 years; average of 5 repeated measures per individual) during a 24-year followup period, as described in detail elsewhere. ${ }^{16}$ In 2000, when mean ( \pm SD) age of study participants was $36.5 \pm 0.5$ years, arterial properties of three large arteries were ascertained in 373 participants (196 women). ${ }^{4-6}$ The current study was confined to these participants, but their levels of dietary (fiber, fiber-rich foods) intake, as well as of other lifestyle and biological RFs, did not differ from those not included in the analyses at any of the earlier time-points (data not shown). The study population is therefore representative of the original cohort and selection bias did not threaten our results.

The study was approved by the medical ethical committee of the VU University Medical Center (Amsterdam, the Netherlands), and all subjects gave their written informed consent (provided by their parents when participants were 13 to 16 years of age).

\section{Arterial stiffness}

Arterial properties were assessed by means of ultrasonography according to guidelines for user procedures and with the use of reproducible methods and devices, ${ }^{1,17,18}$ as described in detail elsewhere ${ }^{4-6}$ and briefly below.

All subjects abstained from smoking and alcohol and caffeine-containing beverages on the day the measurements were performed. Measurements in different individuals were distributed throughout the day and started after subjects had been resting in a supine position for 15 minutes in a quiet temperature-controlled room. Properties of the right common carotid $(10 \mathrm{~mm}$ proximal to the beginning of the bulb), brachial (20 $\mathrm{mm}$ above the antecubital fossa) and common femoral (20 mm proximal to the flow divider) arteries were obtained with an ultrasound scanner equipped with a 7.5-MHz linear array probe (Pie medical, Maastricht, The Netherlands). The ultrasound scanner was connected to a personal computer equipped with an acquisition system and a vessel wall movement detector software system (Wall Track System 2, Pie Medical, Maastricht, The Netherlands) that enabled measurement of the arterial diameter $(D)$, distension $(\Delta D)$, and intima-media thickness (IMT) as described in detail elsewhere. ${ }^{17,18}$

Throughout the entire period of ultrasound imaging blood pressure was assessed in the left arm at 5-minute intervals with an oscillometric device (Colin Press-Mate, model BP-8800, Komaki-City, Japan). Brachial pulse pressure (PP) was defined as systolic - diastolic pressure, and PP at the level of the common carotid and femoral 
arteries was calculated by calibration of the distension waveforms. ${ }^{19}$ The mean $D, \Delta D$, and local PP of three consecutive measurements were used to estimate the distensibility coefficient (DC) and compliance coefficient (CC) of each artery as follows: ${ }^{17,18}$

$$
\begin{aligned}
& D C=\left(2 \Delta D \cdot D+\Delta D^{2}\right) /\left(P P \cdot D^{2}\right) \\
& C C=\pi \cdot\left(2 D \cdot \Delta D+\Delta D^{2}\right) / 4 P P
\end{aligned}
$$

$$
\begin{aligned}
& \text { in } 10^{-3} / \mathrm{kPa} \\
& \text { in } \mathrm{mm}^{2} / \mathrm{kPa}
\end{aligned}
$$

The DC reflects the elastic properties, whereas the CC reflects the buffering capacity of the artery at given operating local pressures. From carotid D, DC and IMT, the Young's elastic modulus (YEM), an estimate of the intrinsic elastic properties of the vessel wall, was calculated as follows:

$$
\mathrm{YEM}=\mathrm{D} /(\mathrm{IMT} \cdot \mathrm{DC}) \quad \text { in } 10^{3} \cdot \mathrm{kPa}
$$

In contrast with the DC and CC, higher YEM values indicate greater arterial stiffness. Therefore, the DCs and CCs were reversed (multiplied by -1 ) so that higher values represent greater stiffness in agreement with the carotid YEM. Subsequently, we categorized subjects on the basis of the sex-specific tertiles of each stiffness estimate into those with 'less stiff' (i.e. lowest tertiles; T1), 'intermediate' (i.e. middle tertiles; T2), and 'stiffer' (i.e. highest tertiles; T3) arteries.

\section{Dietary assessment}

From the age of 13 through 36 years, usual food intake was repeatedly measured using a previously validated cross-check dietary history (face-to-face) interview based on the method developed by $\mathrm{Beal}^{20}$ and $\mathrm{Marr}^{21}$ and adapted to the Amsterdam Growth And Health Longitudinal Study, as described in detail elsewhere. ${ }^{16,22-24}$ In brief, participants were asked to recall their usual food intake during the previous month by reporting the frequency, amount, and method of preparation of the foods and drinks (including alcoholic beverages) consumed. The interviews took, on average, 1 hour to complete. The amounts were reported in household measures or grams and models were used to illustrate portion sizes. During the 2000 measurement, a newly developed interviewer-administered computer-assisted cross-check dietary history method was introduced. ${ }^{23}$ Computer questions and interview structure were based on the original face-to-face interview. The two methods of dietary assessment showed high comparability, though introduction of the computer-assisted method likely caused a reduction of interviewer bias. ${ }^{23}$

The mean fiber (in $\mathrm{g} / \mathrm{d}$ ) and total energy (in $\mathrm{kcal} / \mathrm{d}$ ) intakes, as well as fruits, vegetables and whole grain products (all in $\mathrm{g} / \mathrm{d}$ ) were calculated using the 1996 Dutch Food Composition Table. ${ }^{25}$ Fruits included fresh (citrus and noncitrus), dried and 
canned fruit, and fruit juices. Potatoes and legumes were included in the vegetable consumption.

\section{Covariates}

Throughout the 24-year study period, other lifestyle (i.e. habitual physical activity and smoking behavior), anthropometric (i.e. body height, weight, and skinfolds), and biological RFs (i.e. mean arterial pressure, total and HDL cholesterol) were measured as described in detail elsewhere. ${ }^{4-6,16,26}$

\section{Statistical analyses}

We used generalized estimating equations (GEEs) to estimate the mean differences in fiber intake during the 24-year study period between subjects in the highest compared with those in the lowest sex-specific tertiles of each stiffness estimate at age 36 years, or, in other words, between subjects with stiffer vs. less stiff carotid, brachial and femoral arteries. ${ }^{4-6}$ GEEs take into account the correlation between repeated observations within the same subject, and have the advantage of handling data of subjects with varying number of and unequally time-spaced observations. ${ }^{27}$ All analyses were adjusted for sex, height, and time (model 1). We have also added interaction terms between time and groups to this model to ascertain whether the strength of the differences differed at any specific age (critical period) throughout the course of the longitudinal study. Results hereby obtained were displayed graphically and reflect the life-course trajectories of fiber intake, from adolescence to adulthood, by levels of arterial stiffness at the age of 36 years. ${ }^{4,5}$ The mean differences in lifetime fiber intake between groups with increasing levels of arterial stiffness were further adjusted for potential confounders, i.e. total energy intake ( $\mathrm{kcal} / \mathrm{d}$ ), habitual physical activity (metabolic equivalents/wk), smoking behavior (yes or no) and alcohol intake (g/wk), as measured throughout the whole longitudinal period (model 2). Adjustment for time of the day at which arterial measures were obtained did materially affect the effect estimates, reason why we not included this variable in our models. We additionally adjusted for potential mediators, that is, mean arterial pressure, skinfolds ratio (as a measure of central body fatness), and/or total-to-HDL cholesterol ratio, to ascertain the extent to which any differences in levels of lifetime fiber intake between the groups could be explained by these variables (in which case the differences as obtained in models 2 would be appreciably attenuated - mediation analyses).

GEE models similar to those described above were also used to estimate the mean differences in fruits, vegetables and whole grain products consumption throughout the longitudinal period between subjects with stiffer vs. less stiff arteries at age 36 . Further adjustments for lifetime fiber intake allowed us to ascertain the extent to which any difference in the lifetime consumption of these foods could be explained by their fiber content and/or the other RFs (see also mediation analyses). 
All GEE analyses were carried out with the use of the STATA software package version 9.2 (STATA Corp, College Station, Texas, USA). In all analyses an exchangeable correlation structure and robust estimation of standard errors were used; statistical significance was set at $P<0.05$ (two-sided).

Mediation analyses. We used the $a b$ product-coefficient method to investigate the magnitude of the attenuations in mean levels of fiber or fibre-rich foods after adjustment for potential mediators (see details of calculations provided in footnotes to Supplemental Tables 4.1.S1 and 4.1.S2 - Appendix 4.1.1). ${ }^{28}$ The significance of these attenuations were ascertained by the respective confidence intervals $(\mathrm{Cl})$, which were estimated with the use of the RMediation package written for use in R statistical software program (version 2.13.0, The R Foundation for Statistical Computing 2011). ${ }^{29}$

\section{RESULTS}

Characteristics of the study population throughout the 24-year study period are presented in Table 4.1.1. The mean intake of fiber decreased by $-1.6 \mathrm{~g} / \mathrm{d}(95 \% \mathrm{Cl}:-2.8$ to -0.4$)$ between the ages of 13 and 27 years, and increased thereafter by $5.4 \mathrm{~g} / \mathrm{d}(4.3$ to 6.6) up to the age of 36 years. The mean levels of each local stiffness estimate across the tertiles are shown in Table 4.1.2.

\section{Lifetime fiber intake by levels of arterial stiffness at age 36 years}

After adjustment for sex, height and time, and as compared with subjects with less stiff arteries (i.e. in T1), those with stiffer carotid arteries (i.e. in T3 of the DC, CC, both reversed, and the YEM) took less fiber during the 24-year study period: on average $-2.6 \mathrm{~g} / \mathrm{d}(-4.0$ to -1.1$),-3.0 \mathrm{~g} / \mathrm{d}(-4.4$ to -1.6$)$, and $-2.1 \mathrm{~g} / \mathrm{d}(-3.5$ to -0.7$)$, respectively (Table 4.1.3, model 1). Trajectory analyses revealed that these differences were already present in adolescence and remained fairly stable over time (Figure 4.1.1). Adjustments for potential confounders (i.e. total energy intake and other lifestyle variables) attenuated the differences mentioned above to $-1.9 \mathrm{~g} / \mathrm{d}(-3.1$ to -0.7$)$, $-2.3 \mathrm{~g} / \mathrm{d}(-3.5$ to -1.1$)$ and $-1.3 \mathrm{~g} / \mathrm{d}(-2.5$ to -0.0$)$, respectively, which nevertheless remained statistically significant (model 2). Further adjustment for mean arterial pressure, skinfolds ratio, and/or total-to-HDL cholesterol ratio (model 3), did not materially explain these differences, given their weak longitudinal associations with fiber intake (Table 4.1.4). Indeed, after adjustment for these RFs, differences in lifetime fiber intake were only slightly attenuated $(\leq 8 \%)$, and the magnitude of these attenuations was not statistically significant (Table 4.1.S1, simple and multiple mediation analyses). Qualitatively similar differences in lifetime fiber intake, though of lower magnitude and only statistically significant for the CC, were observed across the tertiles of the femoral (Table 4.1.3 \& Table 4.1.S1), but not brachial stiffness estimates (data not shown). 


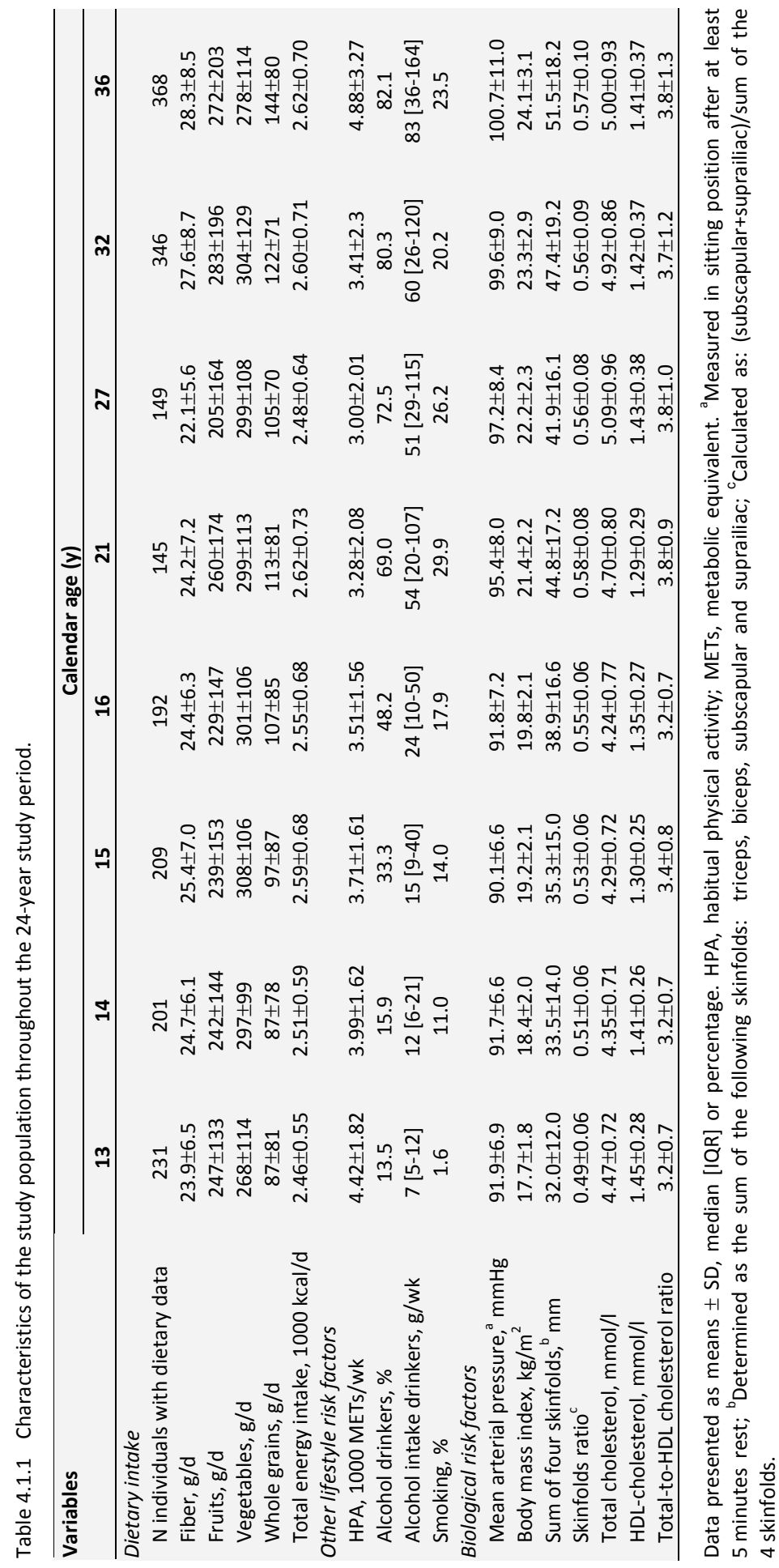


Table 4.1.2 Arterial stiffness levels at the age of $36 \mathrm{y}$ according to sex-specific tertiles of each stiffness estimate.

\begin{tabular}{|c|c|c|c|c|}
\hline Stiffness estimates & Sex & $\begin{array}{c}\text { Tertile } 1 \\
\text { (Less stiff) } \\
\end{array}$ & $\begin{array}{c}\text { Tertile } 2 \\
\text { (Intermediate) }\end{array}$ & $\begin{array}{l}\text { Tertile } 3 \\
\text { (Stiffer) } \\
\end{array}$ \\
\hline Sex, n M/F & & $59 / 65$ & $59 / 66$ & $59 / 65$ \\
\hline \multicolumn{5}{|l|}{ Common carotid artery } \\
\hline \multirow[t]{2}{*}{ Distensibility coefficient, ${ }^{a} 10^{-3 / \mathrm{kPa}}$} & M & $32.0 \pm 3.4$ & $25.8 \pm 1.4$ & $20.7 \pm 2.1$ \\
\hline & $\mathrm{F}$ & $34.7 \pm 4.3$ & $26.5 \pm 1.7$ & $19.9 \pm 2.3$ \\
\hline \multirow[t]{2}{*}{ Compliance coefficient, ${ }^{a} \mathrm{~mm}^{2} / \mathrm{kPa}$} & M & $1.35 \pm 0.20$ & $1.04 \pm 0.05$ & $0.80 \pm 0.01$ \\
\hline & $\mathrm{F}$ & $1.22 \pm 0.18$ & $0.91 \pm 0.06$ & $0.65 \pm 0.09$ \\
\hline \multirow[t]{2}{*}{ Young's elastic modulus, $10^{3} \cdot \mathrm{kPa}$} & M & $0.35 \pm 0.04$ & $0.45 \pm 0.02$ & $0.60 \pm 0.09$ \\
\hline & $\mathrm{F}$ & $0.30 \pm 0.04$ & $0.41 \pm 0.03$ & $0.56 \pm 0.08$ \\
\hline \multicolumn{5}{|l|}{ Brachial artery } \\
\hline \multirow[t]{2}{*}{ Distensibility coefficient, ${ }^{a} 10^{-3} / \mathrm{kPa}$} & $\mathrm{M}$ & $22.0 \pm 10.5$ & $10.5 \pm 1.5$ & $6.2 \pm 1.6$ \\
\hline & $\mathrm{F}$ & $26.2 \pm 7.9$ & $14.1 \pm 1.9$ & $7.9 \pm 2.3$ \\
\hline \multirow[t]{2}{*}{ Compliance coefficient, ${ }^{a} \mathrm{~mm}^{2} / \mathrm{kPa}$} & M & $0.30 \pm 0.10$ & $0.17 \pm 0.02$ & $0.10 \pm 0.03$ \\
\hline & $\mathrm{F}$ & $0.24 \pm 0.05$ & $0.14 \pm 0.02$ & $0.07 \pm 0.2$ \\
\hline \multicolumn{5}{|l|}{ Common femoral artery } \\
\hline \multirow[t]{2}{*}{ Distensibility coefficient, ${ }^{a} 10^{-3} / \mathrm{kPa}$} & M & $9.0 \pm 3.1$ & $5.5 \pm 0.5$ & $3.3 \pm 0.8$ \\
\hline & $\mathrm{F}$ & $12.9 \pm 3.8$ & $7.4 \pm 0.9$ & $4.7 \pm 0.9$ \\
\hline \multirow[t]{2}{*}{ Compliance coefficient, ${ }^{a} \mathrm{~mm}^{2} / \mathrm{kPa}$} & $\mathrm{M}$ & $0.78 \pm 0.22$ & $0.48 \pm 0.05$ & $0.29 \pm 0.06$ \\
\hline & $\mathrm{F}$ & $0.78 \pm 0.19$ & $0.45 \pm 0.05$ & $0.29 \pm 0.06$ \\
\hline
\end{tabular}

Data are means \pm SD. ${ }^{a}$ Distensibility and compliance coefficients were reversed (i.e. multiplied by -1 ) prior to categorization into tertiles, so that higher tertiles indicate higher arterial stiffness in agreement with the Young's elastic modulus.
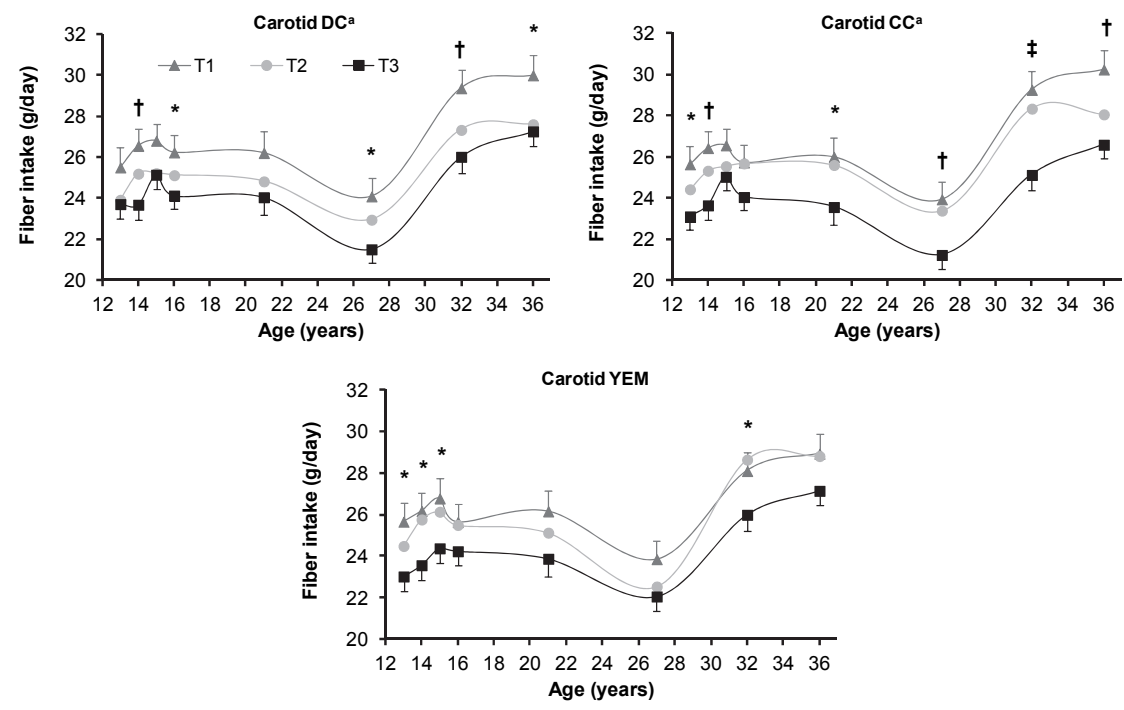

Figure 4.1.1 Lifetime trajectories of fiber intake throughout the 24-year study period across groups of subjects with increasing carotid stiffness at the age of 36 years (defined on the basis of sexspecific tertiles for each stiffness estimates); data were estimated with the use of generalized estimating equations and were adjusted for sex, height, and time; $\mathrm{n}=373$. ${ }^{*} P<0.05,+P<0.01$ and $¥ P<0.001$ for comparisons between subjects in the highest (T3) vs. those in the lowest (T1) tertiles of the carotid distensibility (DC) and compliance (CC) coefficients (both reversed ${ }^{\mathrm{a}}$ ), and the Young's elastic modulus (YEM). Error bars indicate standard error of the mean. 


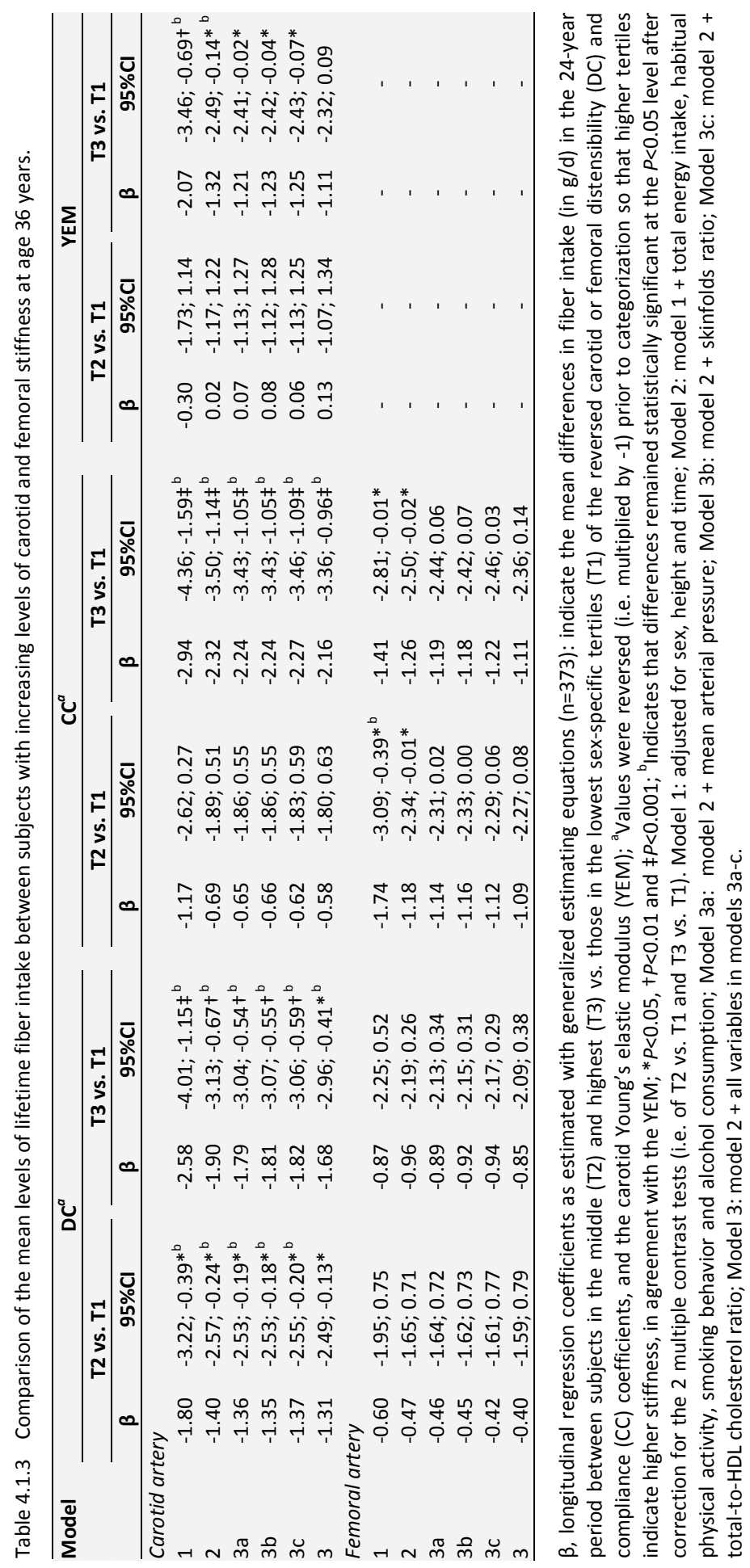




\section{Lifetime consumption of fiber-rich foods by levels of arterial stiffness at age 36 years}

After adjustment for sex, height, time, and potential confounders (i.e. total energy intake and other lifestyle variables), subjects with stiffer arteries consumed less fiberrich foods in the 24-y study period than those with less stiff arteries: e.g. $-32.6 \mathrm{~g} / \mathrm{d}$ of fruits $(-61.9$ to -3.4$),-22.9 \mathrm{~g} / \mathrm{d}$ of vegetables $(-42.6$ to -3.2$)$ and $-18.6 \mathrm{~g} / \mathrm{d}$ of whole grain products (-33.4 to -3.8$)$, when classified on the basis of the carotid DC (Table 4.1.5, models 2). These differences were explained to a great extent when additionally adjusted for fiber intake (models 3 vs. 2) but less so, if at all, when adjusted for the biological RFs (models 4 compared with 2). These biological RFs only appreciably attenuated the differences in vegetable consumption, given their stronger association with this food group (Table 4.1.4).

Table 4.1.4 Longitudinal associations of fiber and fiber-rich foods intake with biological risk factors.

\begin{tabular}{|c|c|c|c|c|c|c|}
\hline \multirow[t]{2}{*}{ Model } & \multicolumn{2}{|c|}{ Mean arterial pressure } & \multicolumn{2}{|c|}{ Skinfold ratio } & \multicolumn{2}{|c|}{ Total-to-HDL cholesterol } \\
\hline & $\boldsymbol{\beta}$ & $95 \% \mathrm{Cl}$ & $\beta$ & $95 \% \mathrm{Cl}$ & $\beta$ & $95 \% \mathrm{Cl}$ \\
\hline \multicolumn{7}{|l|}{ Fiber } \\
\hline 1 & -0.066 & $-0.117 ;-0.015^{*}$ & -0.061 & $-0.104 ;-0.018 \dagger$ & -0.092 & $-0.144 ;-0.039+$ \\
\hline 2 & -0.045 & $-0.103 ; 0.012$ & -0.034 & $-0.085 ; 0.016$ & -0.047 & $-0.105 ; 0.011$ \\
\hline \multicolumn{7}{|l|}{ Fruits } \\
\hline 1 & 0.006 & $-0.042 ; 0.054$ & -0.010 & $-0.045 ; 0.026$ & 0.041 & $0.001 ; 0.081^{*}$ \\
\hline 2 & 0.014 & $-0.034 ; 0.061$ & 0.002 & $-0.034 ; 0.037$ & 0.054 & $0.014 ; 0.094 \dagger$ \\
\hline \multicolumn{7}{|c|}{ Vegetables } \\
\hline 1 & -0.055 & $-0.095 ;-0.016+$ & -0.061 & $-0.099 ;-0.023+$ & -0.080 & $-0.128 ;-0.031+$ \\
\hline 2 & -0.050 & $-0.090 ;-0.009 *$ & -0.050 & $-0.088 ;-0.012 \dagger$ & -0.063 & $-0.110 ;-0.016+$ \\
\hline \multicolumn{7}{|c|}{ Whole grain products } \\
\hline 1 & -0.027 & $-0.079 ; 0.024$ & -0.005 & $-0.044 ; 0.033$ & -0.046 & $-0.098 ; 0.007$ \\
\hline 2 & -0.020 & $-0.073 ; 0.033$ & 0.010 & $-0.029 ; 0.048$ & -0.025 & $-0.075 ; 0.025$ \\
\hline
\end{tabular}

$\beta$, standardized longitudinal regression coefficients as estimated with the use of generalized estimating equations ( $n=373$ ): indicate the change in biological risk factors (in SD) per 1 SD increase in dietary fiber, fruits, vegetables or whole grains; ${ }^{*} P<0.05$ and $+P<0.001$. Model 1 : adjusted for sex, height and time; Model 2: model 1 + total energy intake, habitual physical activity, smoking behavior and alcohol consumption.

Indeed, mediation analyses revealed that the differences in lifetime consumption of fiber-rich foods were significantly explained by fiber intake; for example, adjustments for fiber attenuated the differences in fruits by 65\% $(-21.1 \mathrm{~g} / \mathrm{d}[-35.0$ to $-8.0])$, in vegetables by $\sim 78 \%(-17.8 \mathrm{~g} / \mathrm{d}$ [-29.1 to -6.8$])$ and in whole grain products by $\sim 67 \%$ (-12.4 g/d [-20.2 to -4.8$]$ ), for comparison between subjects with stiffer vs. less stiff arteries as defined on the basis of their carotid DC levels, and essentially similar results were obtained on the basis of CC and YEM (Table 4.1.S2, simple mediation). Likewise, adjustment for each of the biological RFs significantly attenuated the differences in vegetable consumption, but not fruits nor whole grain products. In models adjusting for all the potential mediators simultaneously, only the mediating effects of fiber intake remained largely unaffected and statistically significant (Table 4.1.S2, multiple mediation). 


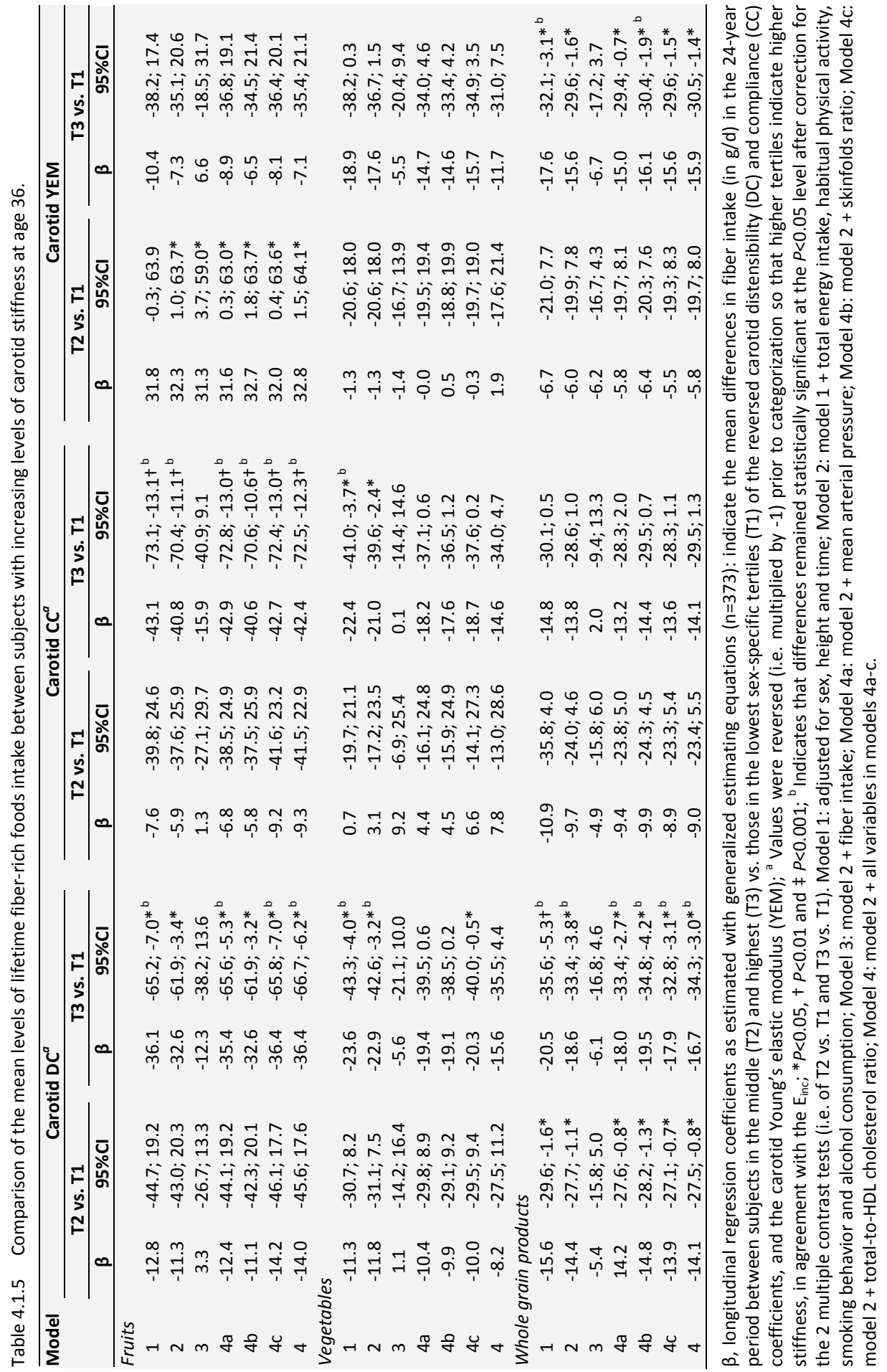


Subjects with stiffer compared with those with less stiff femoral arteries also tended to consume less fruits, vegetables and whole grain products in the 24-year study (Table 4.1.S3). However, these differences were not always statistically significant and their magnitude was appreciably lower than those observed for the carotid artery.

\section{Additional analyses}

Additional adjustment for fatty fish intake, a major source of omega-3 (n-3) fatty acids that has been shown to lower arterial stiffness, ${ }^{30}$ did not materially affect any of the associations reported herein (data not shown). Replacing in our models the adjustment for mean arterial pressure by systolic pressure, or the adjustment for total-to-HDL cholesterol by total or LDL cholesterol (the latter available from the ages of 21 to 36 years only), also did not change our results (data not shown).

\section{DISCUSSION}

The major findings of this study are that: 1) adults with higher levels of arterial stiffness, mainly of the carotid artery, took consistently less fiber during the preceding 24-year covering the period from adolescence up to the age of $36 \mathrm{y}$, suggesting a favorable association between lifetime fiber intake and arterial stiffness in adulthood; and 2) lower lifetime consumption of fruits, vegetables and whole grain products was similarly associated with carotid stiffness in adulthood, which could be explained, to a great extent, by the fiber-portion of these foods.

A recent systematic review of intervention studies investigating the impact of changes in specific foods and/or nutrients intake on arterial stiffness concluded that omega-3 and soy isoflavone supplementation might reduce arterial stiffness. ${ }^{30}$ However, this evidence derived from small studies, none of which investigating the role of fiber or its major dietary sources, and almost all were confined to older and clinical populations. Observational studies suggesting a beneficial influence of fiber on arterial stiffness are scarce too, and because these findings derived from associations with fiber-rich foods, disentangling the specific role of fiber therein is not straightforward. For instance, a dietary pattern high in meat and alcohol, and low in fruits, sweetening products and dairy products was associated with greater aortic PWV 7.5 years later in healthy middle-aged individuals. ${ }^{31}$ In addition, consistently high vs. low consumption of fruits and vegetables at both young and adult age was associated with lower aortic PWV in adulthood. ${ }^{15}$ In line with these findings, and the cardiovascular protective effects attributed to fiber, ${ }^{32,33}$ we now show that fiber intake throughout the course of young life is inversely associated with carotid stiffness in adulthood, and that the fiber-content of fruits, vegetables and whole grain products explained, to a great extent, their similar beneficial associations with arterial stiffness. 
The elastic properties of conduit arteries vary along the arterial tree due to heterogeneity in the molecular, cellular and histological structure of the arterial wall. ${ }^{1}$ Indeed, although central arteries contain mainly elastic fibers and relatively less collagen, this ratio is reversed in the peripheral muscular arteries where collagens predominates, ${ }^{1,34}$ which explains why elastic and muscular arteries may respond differently to ageing, drugs and other factors. We have therefore used ultrasonography to assess stiffness levels at different sites of the arterial tree to obtain a better understanding of the etiology of changes in arterial stiffness related to RF exposure. In this line, the present study suggests that the beneficial effects of fiber intake may act preferentially on the elastic carotid than the muscular femoral or brachial arteries. The associations with carotid stiffness estimates were not confined to the DC and CC but were also observed with the YEM, which suggests a higher intrinsic elasticity of the carotid artery wall among individuals who consumed more fiber. These observations also emphasize the potential clinical relevance of this study, because greater stiffness of central elastic arterial sites or segments, such as the carotid artery and the aorta, ${ }^{2,3,35-37}$ but not of peripheral arteries, have been shown to predict incident CVD. The link between arterial stiffness and incident CVD has been more often investigated and clearly established when stiffness levels of the aorta are measured by means of aortic PWV. ${ }^{1,3}$ Although, conceptually, local and regional stiffness estimates are closely related, mismatches between carotid and aortic PWV have been reported, particularly in the presence of hypertension and/or diabetes. ${ }^{38}$ In this line, prospective studies linking carotid stiffness to incident CVD have not always led to consistent findings. ${ }^{2,38}$ However, a recent report from the ARIC Study, unique by its larger population size ( $\mathrm{n}>10.000$, all free from CVD at baseline), better power with regard to incident cases, and longer duration of follow-up (>13 years) than any other such study before, showed that greater carotid stiffness estimates, as used in the present study, were significantly associated with incident stroke, but not CHD. ${ }^{2}$ Carotid stiffness may thus more closely reflect arterial damage in the cerebrovascular territories and thereby predispose to cerebrovascular disease in particular. Low fiber intake has not only been associated with higher incident $\mathrm{CHD}^{10,12}$ but also stroke. ${ }^{11}$ Our present findings thus suggest that increasing fiber consumption may reduce the incidence of stoke, due to, at least in part, its beneficial effects on carotid stiffness.

Although cross-sectional ${ }^{39}$ and prospective $^{40}$ studies have shown fiber to be favorably associated with blood pressure, body fatness and blood lipids, in the present study the longitudinal associations between fiber intake and these RFs were not independent of the confounding effect of other lifestyle variables. Therefore, we did not find evidence for a mediating role by any of these RFs in the fiber-arterial stiffness relationships. This may be due to the relatively young and healthy study population examined herein. Indeed, a meta-analysis showed that increases in fiber intake yield only modest decreases in blood pressure, which occurred mainly above the age of 40 years. ${ }^{41}$ Other fiber-related pathobiological mechanisms such as improved glucose metabolism, $^{32}$ inflammation $^{42}$ and endothelial dysfunction, ${ }^{43}$ all of which are 
determinants of arterial stiffness, ${ }^{1,44}$ may thus explain the observed associations. Longitudinal measures of these variables were not obtained in the present study, however.

Our findings may have important implications for public health. The life-course approach used to study risk exposure revealed that differences in fiber intake between individuals with stiffer vs. less stiff arteries were already present during adolescence. This emphasizes the view that increases in fiber intake should be pursued already among young children, as recommended by current guidelines. ${ }^{32}$ Implementation of comprehensive school-based programs promoting consumption of fiber-rich foods, and a healthy diet in general, integrating also major determinants for success, such as parental involvement, and availability/accessibility of healthy foods, ${ }^{45-47}$ may be an effective tool to raise children's awareness and empower them for a lifelong engagement with healthy dietary habits. In addition, our data suggest that, at the population level, relatively small increases in fiber intake throughout the course of life - equivalent to the daily consumption of about one apple or banana, or half a portion of broccoli or muesli - might translate to physiologically relevant differences in arterial stiffness in adulthood. Indeed, the absolute differences in levels of the carotid stiffness estimates between subjects grouped into the highest vs. the lowest tertiles correspond to those found for more than one decade of ageing. ${ }^{48}$ Finally, although fiber, but not other biological RFs, explained a great part of the beneficial associations of fruits, vegetables and whole grain products intake with arterial stiffness, other components of these foods, such as vitamins (i.e. $C$ and $E$, and $\beta$ carotene), unsaturated fatty acids, minerals, lignans and other phytochemicals, may favorably influence arterial stiffness and/or general cardiovascular healh. ${ }^{49,50}$ In this line, the beneficial associations, observed throughout the whole longitudinal period, between vegetable intake and blood pressure, central fatness and blood lipids should be emphasized, despite the lack of an independent mediating effect by these RFs. All of these are established cardiovascular RFs and, therefore, promoting vegetable intake in particular may translate to cardiovascular health benefits beyond decreases in arterial stiffness. On the other hand, fruit intake was adversely associated with total-to-HDL cholesterol ratio, but this was abolished when fruit juices (often sugar sweetened and possibly with higher glycemic-indexes ${ }^{51}$ ) were removed from the fruit category (standardized longitudinal regression coefficient: 0.009 [-0.033 to 0.052]). Noteworthy, the associations with arterial stiffness remained qualitatively unchanged (data not shown). All together, our findings thus suggest that primary prevention efforts focusing on increases in fresh/low-glycemic index fruits, vegetables and whole grain products consumption may translate to beneficial arterial and CV health in general.

Some limitations of our study need to be addressed. First, measurement of dietary habits with the use of questionnaires is subject to recall and misclassification bias. ${ }^{52}$ Likely, any such bias was largely non-differential as, throughout the study period, participants were unaware of their stiffness levels at age 36 years. However, if any 
differential misclassification has occurred, this most likely derived from over-reporting of healthier dietary habits by those with unhealthier lifestyles. ${ }^{52}$ Either way, effect sizes may have been underestimated. Second, although in our analyses ascertainment of the 'cause' (i.e. dietary intake from adolescence to adult age) preceded that of the 'consequence' (i.e. arterial stiffness), definite conclusions with regard to causality cannot be inferred given the observational study design. Third, although very unlikely, we cannot exclude the possibility of reverse causation as arterial stiffness was measured at the age of 36 years only. Fourth, we were not able to distinguish between soluble and insoluble fibers; further (experimental) studies may be needed to clarify any potential differential associations of these on arterial stiffness. Last, our findings were obtained in a young, healthy and generally Caucasian cohort and should thus be interpreted with caution when extrapolated to elderly, high-risk populations and other ethnicities.

In conclusion, we showed that lower intake of dietary fiber throughout the course of young life (i.e. from adolescence up to adulthood) is associated with higher carotid stiffness in adulthood. Promoting the consumption of fiber-rich foods starting already at young age may offer an important means to prevent accelerated arterial stiffening and related sequelae later in life. 


\section{REFERENCES}

1. Laurent S, Cockcroft J, Van Bortel L, et al. Expert consensus document on arterial stiffness: methodological issues and clinical applications. Eur Heart J. 2006;27:2588-2605.

2. Yang EY, Chambless L, Sharrett AR, et al. Carotid Arterial Wall Characteristics Are Associated With Incident Ischemic Stroke But Not Coronary Heart Disease in the Atherosclerosis Risk in Communities (ARIC) Study. Stroke. 2012;43:103-108.

3. Vlachopoulos C, Aznaouridis K, Stefanadis C. Prediction of cardiovascular events and all-cause mortality with arterial stiffness: a systematic review and meta-analysis. J Am Coll Cardiol. 2010; 55:1318-1327.

4. Ferreira I, van de Laar RJ, Prins MH, Twisk JW, Stehouwer CD. Carotid stiffness in young adults: a lifecourse analysis of its early determinants: the Amsterdam Growth and Health Longitudinal Study. Hypertension. 2012;59:54-61.

5. van de Laar RJ, Ferreira I, van Mechelen W, Prins MH, Twisk JW, Stehouwer CD. Lifetime vigorous but not light-to-moderate habitual physical activity impacts favorably on carotid stiffness in young adults: the amsterdam growth and health longitudinal study. Hypertension. 2010;55:33-39.

6. van de Laar RJ, Ferreira I, van Mechelen W, Prins MH, Twisk JW, Stehouwer CD. Habitual physical activity and peripheral arterial compliance in young adults: the amsterdam growth and health longitudinal study. Am J Hypertens. 2011;24:200-208.

7. Juonala M, Jarvisalo MJ, Maki-Torkko N, Kahonen M, Viikari JS, Raitakari OT. Risk factors identified in childhood and decreased carotid artery elasticity in adulthood: the Cardiovascular Risk in Young Finns Study. Circulation. 2005;112:1486-1493.

8. Li S, Chen W, Srinivasan SR, Berenson GS. Childhood blood pressure as a predictor of arterial stiffness in young adults: the bogalusa heart study. Hypertension. 2004;43:541-546.

9. Kelder SH, Perry CL, Klepp KI, Lytle LL. Longitudinal tracking of adolescent smoking, physical activity, and food choice behaviors. Am J Public Health. 1994;84:1121-1126.

10. Bazzano LA, He J, Ogden LG, Loria CM, Whelton PK. Dietary fiber intake and reduced risk of coronary heart disease in US men and women: the National Health and Nutrition Examination Survey I Epidemiologic Follow-up Study. Arch Intern Med. 2003;163:1897-1904.

11. Mozaffarian D, Kumanyika SK, Lemaitre RN, Olson JL, Burke GL, Siscovick DS. Cereal, fruit, and vegetable fiber intake and the risk of cardiovascular disease in elderly individuals. JAMA. 2003;289:1659-1666.

12. Pereira MA, O'Reilly E, Augustsson K, et al. Dietary fiber and risk of coronary heart disease: a pooled analysis of cohort studies. Arch Intern Med. 2004;164:370-376.

13. Park Y, Subar AF, Hollenbeck A, Schatzkin A. Dietary fiber intake and mortality in the NIH-AARP diet and health study. Arch Intern Med. 2011;171:1061-1068.

14. Lichtenstein $A H$, Appel $\amalg$, Brands $M$, et al. Diet and lifestyle recommendations revision 2006: a scientific statement from the American Heart Association Nutrition Committee. Circulation. 2006;114:82-96.

15. Aatola $\mathrm{H}$, Koivistoinen $\mathrm{T}$, Hutri-Kahonen $\mathrm{N}$, et al. Lifetime fruit and vegetable consumption and arterial pulse wave velocity in adulthood: the Cardiovascular Risk in Young Finns Study. Circulation. 2010; 122:2521-2528.

16. Kemper HC. Amsterdam Growth and Health Longitudinal Study (AGAHLS). A 23-Year Follow-Up From Teenager To Adult about Lifestyle and Health. Vol 47. Basel: Karger; 2004.

17. Brands PJ, Hoeks AP, Willigers J, Willekes C, Reneman RS. An integrated system for the non-invasive assessment of vessel wall and hemodynamic properties of large arteries by means of ultrasound. Eur $J$ Ultrasound. 1999;9:257-266.

18. Reneman RS, Hoeks AP. Noninvasive vascular ultrasound: an asset in vascular medicine. Cardiovasc Res. 2000;45:27-35.

19. Van Bortel LM, Balkestein EJ, van der Heijden-Spek JJ, et al. Non-invasive assessment of local arterial pulse pressure: comparison of applanation tonometry and echo-tracking. J Hypertens. 2001;19: 1037-1044.

20. Beal VA. The nutritional history in longitudinal research. J Am Diet Assoc. 1967;51:426-432.

21. Marr JW. Individual dietary surveys: purposes and methods. World Rev Nutr Diet. 1971;13:105-164. 
22. te Velde SJ, Twisk JW, Brug J. Tracking of fruit and vegetable consumption from adolescence into adulthood and its longitudinal association with overweight. Br J Nutr. 2007;98:431-438.

23. Bakker I, Twisk JW, van Mechelen W, Mensink GB, Kemper HC. Computerization of a dietary history interview in a running cohort; evaluation within the Amsterdam Growth and Health Longitudinal Study. Eur J Clin Nutr. 2003;57:394-404.

24. Bertheke Post G, de Vente W, Kemper HC, Twisk JW. Longitudinal trends in and tracking of energy and nutrient intake over 20 years in a Dutch cohort of men and women between 13 and 33 years of age: The Amsterdam growth and health longitudinal study. Br J Nutr. 2001;85:375-385.

25. NEVO Tabel 1996 (Dutch Food Composition Table 1996). The Hague: Voorlichtingsbureau voor de voeding; 1996.

26. Ferreira I, Twisk JW, van Mechelen W, Kemper HC, Stehouwer CD. Development of fatness, fitness, and lifestyle from adolescence to the age of 36 years: determinants of the metabolic syndrome in young adults: the amsterdam growth and health longitudinal study. Arch Intern Med. 2005;165:42-48.

27. Twisk JWR. Applied Longitudinal Data Analysis for Epidemiolgy: A Practical Guide. Cambridge: Cambridge University Press; 2003.

28. Lockwood CM, DeFrancesco CA, Elliot DL, Beresford SA, Toobert DJ. Mediation analyses: applications in nutrition research and reading the literature. J Am Diet Assoc. 2010;110:753-762.

29. Tofighi D, Mackinnon DP. RMediation: An R package for mediation analysis confidence intervals. Behav Res Methods. 2011;43:692-700.

30. Pase MP, Grima NA, Sarris J. The effects of dietary and nutrient interventions on arterial stiffness: a systematic review. Am J Clin Nutr. 2011;93:446-454.

31. Kesse-Guyot E, Vergnaud AC, Fezeu L, et al. Associations between dietary patterns and arterial stiffness, carotid artery intima-media thickness and atherosclerosis. Eur J Cardiovasc Prev Rehabil. 2010;17:718-724.

32. Slavin JL. Position of the American Dietetic Association: health implications of dietary fiber. J Am Diet Assoc. 2008;108:1716-1731.

33. Anderson JW, Baird P, Davis RH, Jr., et al. Health benefits of dietary fiber. Nutr Rev. 2009;67:188-205.

34. Safar ME, Levy BI, Struijker-Boudier H. Current perspectives on arterial stiffness and pulse pressure in hypertension and cardiovascular diseases. Circulation. 2003;107:2864-2869.

35. Barenbrock M, Kosch M, Joster E, Kisters K, Rahn KH, Hausberg M. Reduced arterial distensibility is a predictor of cardiovascular disease in patients after renal transplantation. J Hypertens. 2002;20:79-84.

36. Blacher J, Guerin AP, Pannier B, Marchais SJ, London GM. Arterial calcifications, arterial stiffness, and cardiovascular risk in end-stage renal disease. Hypertension. 2001;38:938-942.

37. Dijk JM, Algra A, van der Graaf Y, Grobbee DE, Bots ML. Carotid stiffness and the risk of new vascular events in patients with manifest cardiovascular disease. The SMART study. Eur Heart J. 2005;26: 1213-1220.

38. Paini A, Boutouyrie P, Calvet D, Tropeano Al, Laloux B, Laurent S. Carotid and aortic stiffness: determinants of discrepancies. Hypertension. 2006;47:371-376.

39. Lairon D, Arnault N, Bertrais S, et al. Dietary fiber intake and risk factors for cardiovascular disease in French adults. Am J Clin Nutr. 2005;82:1185-1194.

40. Ludwig DS, Pereira MA, Kroenke $\mathrm{CH}$, et al. Dietary fiber, weight gain, and cardiovascular disease risk factors in young adults. JAMA. 1999;282:1539-1546.

41. Streppel MT, Arends LR, van 't Veer P, Grobbee DE, Geleijnse JM. Dietary fiber and blood pressure: a meta-analysis of randomized placebo-controlled trials. Arch Intern Med. 2005;165:150-156.

42. King DE, Egan BM, Woolson RF, Mainous AG, 3rd, Al-Solaiman Y, Jesri A. Effect of a high-fiber diet vs a fiber-supplemented diet on C-reactive protein level. Arch Intern Med. 2007;167:502-506.

43. Brock DW, Davis CK, Irving BA, et al. A high-carbohydrate, high-fiber meal improves endothelial function in adults with the metabolic syndrome. Diabetes Care. 2006;29:2313-2315.

44. Stehouwer CD, Henry RM, Ferreira I. Arterial stiffness in diabetes and the metabolic syndrome: a pathway to cardiovascular disease. Diabetologia. 2008;51:527-539.

45. Briggs M, Mueller CG, Fleischhacker S. Position of the American Dietetic Association, School Nutrition Association, and Society for Nutrition Education: comprehensive school nutrition services. J Am Diet Assoc. 2011;110:1738-1749.

46. Knai C, Pomerleau J, Lock K, McKee M. Getting children to eat more fruit and vegetables: a systematic review. Prev Med. 2006;42:85-95. 
47. O'Dea JA. Why do kids eat healthful food? Perceived benefits of and barriers to healthful eating and physical activity among children and adolescents. J Am Diet Assoc. 2003;103:497-501.

48. Vermeersch SJ, Rietzschel ER, De Buyzere ML, et al. Age and gender related patterns in carotidfemoral PWV and carotid and femoral stiffness in a large healthy, middle-aged population. $J$ Hypertens. 2008;26:1411-1419.

49. Ness AR, Powles JW. Fruit and vegetables, and cardiovascular disease: a review. Int J Epidemiol. 1997; 26:1-13.

50. Slavin J. Whole grains and human health. Nutr Res Rev. 2004;17:99-110.

51. Jenkins DJ, Srichaikul K, Kendall CW, et al. The relation of low glycaemic index fruit consumption to glycaemic control and risk factors for coronary heart disease in type 2 diabetes. Diabetologia. 2011; 54:271-279.

52. Macdiarmid J, Blundell J. Assessing dietary intake: Who, what and why of under-reporting. Nutr Res Rev. 1998;11:231-253. 
Chapter 4.1 


\section{Appendix 4.1.1}

Supplemental tables 
Chapter 4.1 


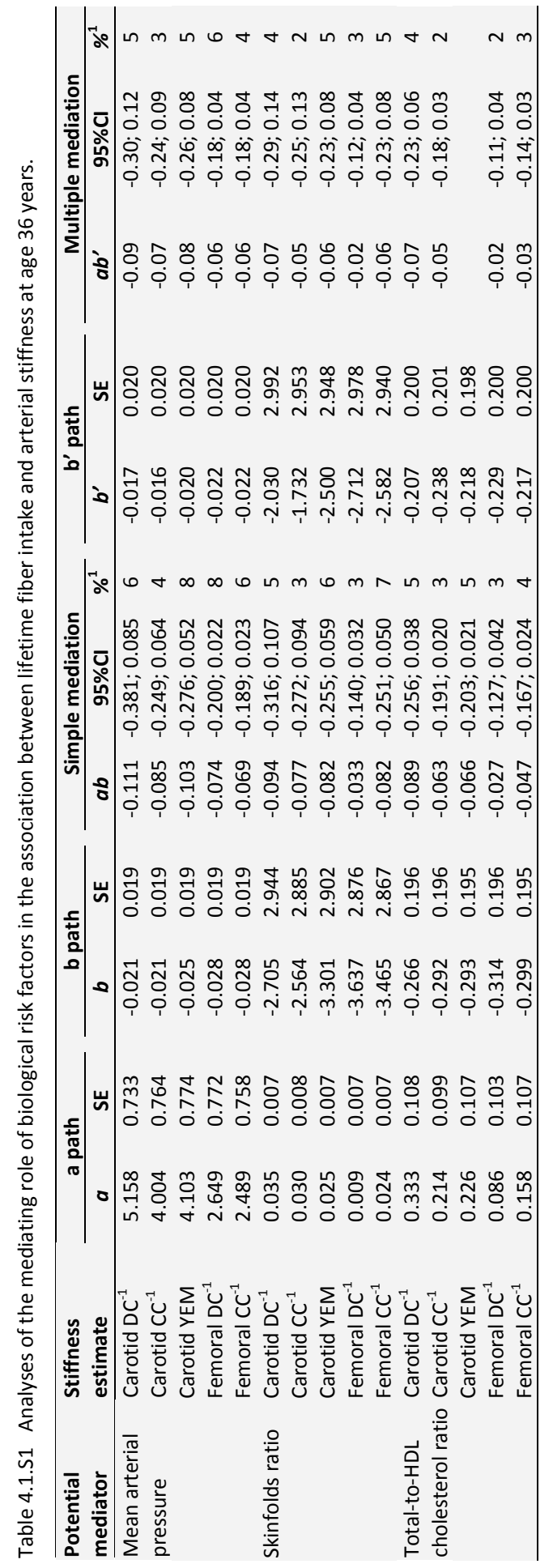

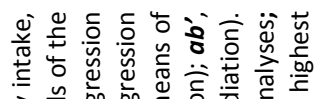

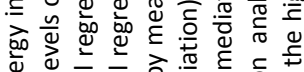

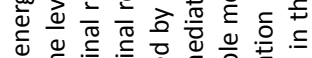

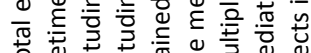

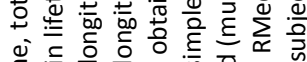

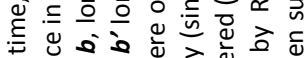

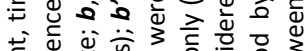

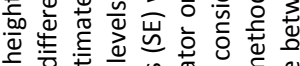

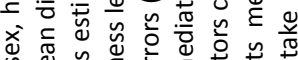
बै.

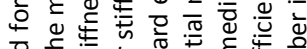

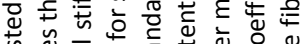

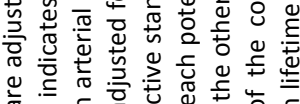
To

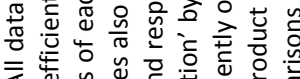

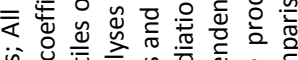

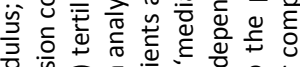
일

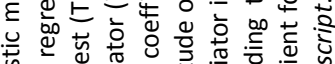

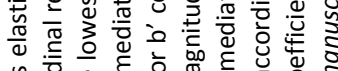

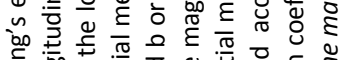

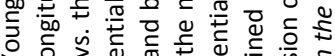

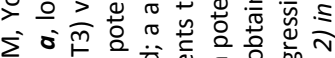

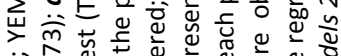

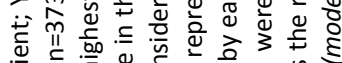

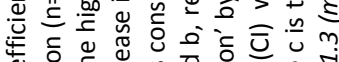
峞

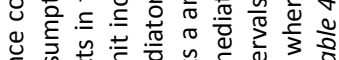

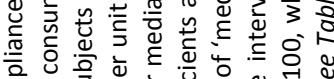

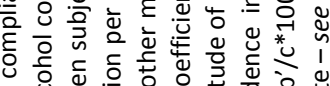
。

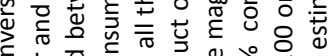

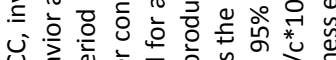

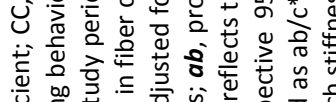

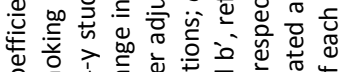

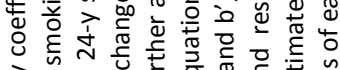

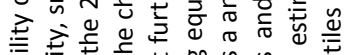

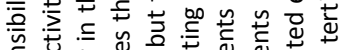
芴

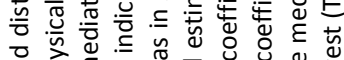

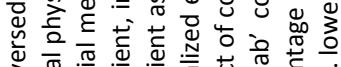

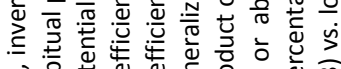

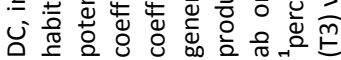




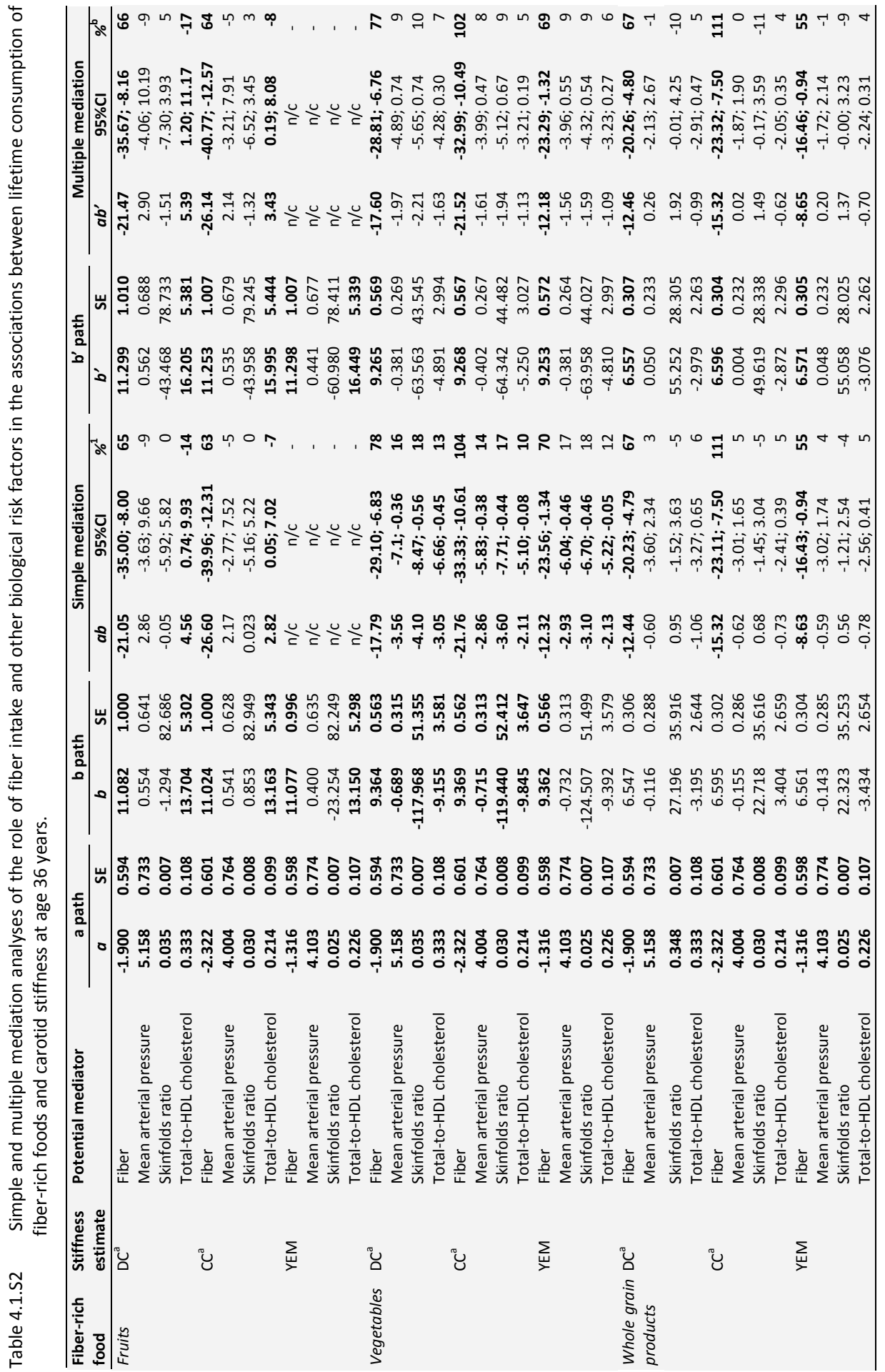




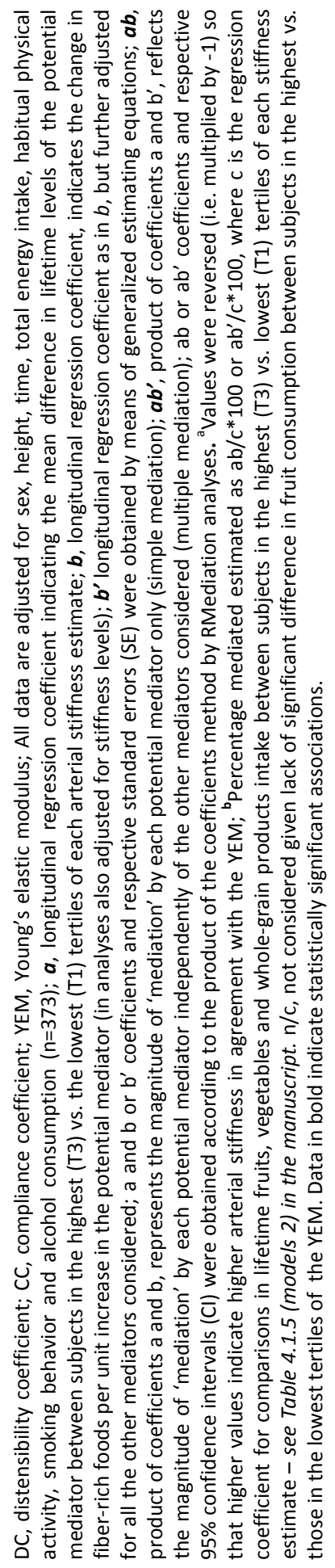


Table 4.1.S3 Comparison of the mean levels of lifetime intake of fiber-rich foods between subjects with increasing levels of femoral stiffness at age 36 years.

\begin{tabular}{|c|c|c|c|c|c|c|c|c|}
\hline \multirow[t]{3}{*}{ Model } & \multicolumn{4}{|c|}{ Femoral $D^{a}{ }^{a}$} & \multicolumn{4}{|c|}{ Femoral $\mathrm{CC}^{\mathrm{a}}$} \\
\hline & \multicolumn{2}{|c|}{ T2 vs. T1 } & \multicolumn{2}{|c|}{ T3 vs. T1 } & \multicolumn{2}{|c|}{ T2 vs. T1 } & \multicolumn{2}{|c|}{ T3 vs. T1 } \\
\hline & $\beta$ & $95 \% \mathrm{Cl}$ & $\beta$ & $95 \% \mathrm{Cl}$ & $\beta$ & $95 \% \mathrm{Cl}$ & $\beta$ & $95 \% \mathrm{Cl}$ \\
\hline \multicolumn{9}{|l|}{ Fruits } \\
\hline 1 & -15.7 & $-46.7 ; 15.4$ & -17.5 & $-50.2 ; 15.2$ & -15.7 & $-47.1 ; 15.6$ & -33.5 & $-65.2 ;-1.9^{*}$ \\
\hline 2 & -14.2 & $-45.1 ; 16.7$ & -17.8 & $-50.2 ; 14.7$ & -12.6 & $-43.9 ; 18.6$ & -31.3 & $-62.7 ; 0.1$ \\
\hline 3 & -9.4 & $-36.3 ; 17.5$ & -7.6 & $-35.1 ; 20.0$ & -0.8 & $-27.9 ; 26.4$ & -18.1 & $-45.0 ; 8.8$ \\
\hline $4 a$ & -14.4 & $-45.3 ; 16.6$ & -18.8 & $-51.0 ; 13.5$ & -13.1 & $-44.4 ; 18.1$ & -32.3 & $-63.8 ;-0.8^{*}$ \\
\hline $4 b$ & -14.1 & $-45.1 ; 16.9$ & -17.4 & $-49.9 ; 15.2$ & -12.6 & $-43.8 ; 18.6$ & -30.9 & $-62.6 ; 0.7$ \\
\hline $4 c$ & -16.0 & $-47.3 ; 15.2$ & -17.2 & $-49.7 ; 15.4$ & -13.5 & $-45.0 ; 18.0$ & -31.7 & $-63.1 ;-0.4^{*}$ \\
\hline 4 & -15.9 & $-47.0 ; 15.3$ & -16.9 & $-49.3 ; 15.5$ & -13.8 & $-45.2 ; 17.6$ & -30.9 & $-62.6 ; 0.9$ \\
\hline \multicolumn{9}{|c|}{ Vegetables } \\
\hline 1 & 5.5 & $-13.2 ; 24.3$ & -5.8 & $-25.4 ; 13.9$ & -1.6 & $-20.4 ; 17.2$ & -13.2 & $-33.1 ; 6.6$ \\
\hline 2 & 5.8 & $-12.9 ; 24.5$ & -6.5 & $-26.4 ; 13.4$ & 2.0 & $-16.6 ; 20.7$ & -11.0 & $-31.0 ; 9.1$ \\
\hline 3 & 10.3 & $-4.6 ; 25.3$ & 2.4 & $-13.4 ; 18.2$ & 12.8 & $-2.2 ; 27.7$ & 0.7 & $-15.1 ; 16.4$ \\
\hline $4 a$ & 6.1 & $-12.6 ; 24.8$ & -4.5 & $-24.5 ; 15.4$ & 2.9 & $-15.7 ; 21.5$ & -9.2 & $-29.3 ; 11.0$ \\
\hline $4 b$ & 6.6 & $-11.9 ; 25.1$ & -5.2 & $-25.0 ; 14.7$ & 2.3 & $-16.2 ; 20.7$ & -8.3 & $-28.3 ; 11.7$ \\
\hline $4 c$ & 7.4 & $-11.4 ; 26.3$ & -5.6 & $-25.7 ; 14.4$ & 3.6 & $-15.2 ; 22.5$ & -9.6 & $-29.7 ; 10.5$ \\
\hline 4 & 7.8 & $-11.0 ; 26.5$ & -3.4 & $-23.3 ; 16.6$ & 4.1 & $-14.6 ; 22.8$ & -6.7 & $-26.7 ; 13.4$ \\
\hline \multicolumn{9}{|c|}{ Whole grain products } \\
\hline 1 & -9.7 & $-23.4 ; 4.0$ & -11.0 & $-25.8 ; 3.7$ & -22.1 & $-36.1 ;-8.2 \dagger$ & -15.4 & $-30.2 ;-0.5^{*}$ \\
\hline 2 & -9.7 & $-23.1 ; 3.7$ & -11.4 & $-25.9 ; 3.1$ & -19.6 & $-33.2 ;-6.0+$ & -14.1 & $-28.8 ; 0.6$ \\
\hline 3 & -6.6 & $-16.6 ; 3.4$ & -5.4 & $-16.5 ; 5.6$ & -11.9 & $-22.2 ;-1.6^{*}$ & -6.0 & $-17.0 ; 4.9$ \\
\hline $4 a$ & -9.6 & $-23.0 ; 3.8$ & -10.9 & $-25.6 ; 3.8$ & -19.4 & $-32.9 ;-5.8+$ & -13.7 & $-28.4 ; 1.1$ \\
\hline $4 b$ & -9.8 & $-23.3 ; 3.6$ & -11.5 & $-26.1 ; 3.1$ & -19.6 & $-33.2 ;-6.0+$ & -14.4 & $-29.3 ; 0.4$ \\
\hline $4 c$ & -9.6 & $-23.0 ; 3.8$ & -12.1 & $-26.6 ; 2.4$ & -19.2 & $-32.8 ;-5.7+$ & -13.9 & $-28.7 ; 0.8$ \\
\hline 4 & -9.7 & $-23.0 ; 3.7$ & -12.0 & $-26.7 ; 2.7$ & -19.0 & $-32.5 ;-5.5+$ & -14.2 & $-29.1 ; 0.7$ \\
\hline
\end{tabular}

$\beta$, longitudinal regression coefficients as estimated by generalized estimating equations $(n=373)$ : indicate the mean differences in consumption of the food groups (in g/day) in the 24-year longitudinal period between subjects in the middle (T2) and highest (T3) vs. those in the lowest sex-specific tertiles (T1) of the reversed femoral distensibility (DC) and compliance (CC) coefficients; ${ }^{a}$ Values were reversed (i.e. multiplied by -1 ) so that higher values indicate higher arterial stiffness in agreement with the Young's elastic modulus; * $P<0.05$ and $+P<0.01$. Model 1: adjusted for sex, height and time; Model 2: model $1+$ total energy intake, habitual physical activity, smoking behavior and alcohol consumption; Model 3: model $2+$ fiber intake; Model 4a: model $2+$ mean arterial pressure; Model 4b: model $2+$ skinfolds ratio; Model 4c: model $2+$ total-to-HDL cholesterol ratio; Model 4: model $2+$ all variables in models $4 a-c$. 


\section{Chapter 4.2}

Adherence to a Mediterranean dietary

pattern in early life is associated with

lower arterial stiffness in adulthood

The Amsterdam Growth and Health Longitudinal Study

Roel J.J. van de Laar, Coen D.A. Stehouwer, Bas C.T. van Bussel, Martin H. Prins, Jos W.R. Twisk, Isabel Ferreira J Intern Med. 2013;273:79-93 


\section{ABSTRACT}

\section{Objectives}

To investigate whether adherence to a Mediterranean dietary pattern during adolescence and early adulthood affects arterial stiffness in adulthood, and the extent to which any such association may be attributed to a beneficial impact of this diet on cardiovascular disease risk factors such as blood pressure, central fatness and dyslipidaemia.

\section{Setting}

The Amsterdam Growth and Health Longitudinal Study.

\section{Design and subjects}

We compared longitudinal levels of adherence to a Mediterranean dietary pattern (aMED score with range 0-9) during adolescence and adulthood (two to eight repeated measures obtained between the ages of 13 and 36 years) between individuals with different levels of arterial stiffness in adulthood. The study population included 373 (196 women) apparently healthy adults in whom properties of the carotid, brachial and femoral arteries were assessed using ultrasonography at 36 years of age.

\section{Results}

After adjustments for potential confounders, individuals with stiffer carotid arteries (defined on the basis of the most adverse tertile of, for instance, the distensibility coefficient) had lower aMED scores $(-0.32,95 \% \mathrm{Cl}-0.60 ;-0.06)$ and were less likely to have adhered to this dietary pattern (aMED score $\geq 5$, odds ratio $0.69,95 \% \mathrm{Cl} 0.50 ;-0.94$ ) during the preceding 24 years compared with those with less stiff arteries. Differences in aMED scores were already present in adolescence and were only in part explained by the favourable associations between the Mediterranean dietary pattern and other cardiovascular disease risk factors (up to 26\%), particularly mean blood pressure (up to $19 \%$ ).

\section{Conclusions}

Promoting the Mediterranean diet in adolescence and early adulthood may constitute an important means of preventing arterial stiffness in adulthood. 


\section{INTRODUCTION}

There is much evidence to support a protective effect of a Mediterranean dietary pattern, which is characterized by high intake of plant foods and olive oil, moderately high intake of fish, low-to-moderate intake of meat and poultry, and regular but moderate consumption of alcohol, ${ }^{1}$ on cardiovascular disease (CVD). ${ }^{2-10}$ Indeed, greater adherence to a Mediterranean dietary pattern correlates favourably with several CVD risk factors (RFs), such as elevated blood pressure (BP), ${ }^{2-4}$ total body fatness and central fat distribution, ${ }^{4,5}$ lipid profile, ${ }^{3,4}$ and insulin resistance..$^{3,4}$ and with lower incidence of CVD and cardiovascular and all-cause mortality. ${ }^{6-10}$

The evidence supporting the protective effects of a Mediterranean dietary pattern on incident CVD has been derived mainly from studies conducted among middle-aged and older individuals. However, the pathophysiological processes underlying the development of CVD start much earlier. ${ }^{11}$ In this line, we ${ }^{12-15}$ as others ${ }^{16,17}$ have shown that the presence of RFs such as elevated BP and central fatness at a young age is associated with adult levels of arterial stiffness (i.e. the loss of the elastic properties and cushioning function of large arteries), which may lead to poorer cardiovascular outcome. ${ }^{18,19}$ With ageing, arterial stiffening leads to an increase in systolic BP (SBP) ${ }^{20}$ because higher end-systolic pressures must be generated for the same net stroke volume. This leads to increased decay of arterial pressure and volume during systole, causing a reduced arterial volume at the onset of diastole, which in turn causes a greater decrease in diastolic BP (DBP). As such, arterial stiffness may lead to an increased risk of stroke, the development of left ventricular hypertrophy and a decrease in coronary perfusion and heart failure. ${ }^{19}$ Indeed, it has been shown that stiffness levels of mainly central (i.e. elastic) arteries, such as the aorta ${ }^{21}$ and the carotid arteries, ${ }^{22-25}$ predict incident CVD and mortality across different populations.

A recent systematic review of dietary and nutrient interventions demonstrated that omega-3 and soy isoflavone supplementation reduced arterial stiffness, thus supporting a role of diet in the prevention of arterial stiffening and its related sequelae. However, this evidence was derived from small studies, which were mainly focused on individual foods or nutrients and confined to clinical populations. ${ }^{26}$ The extent to which (better adherence to) a Mediterranean dietary pattern throughout the course of adolescence/young adulthood impacts favourably on levels of arterial stiffness later in life is unknown. From a primary prevention point of view, this may be of particular relevance because lifelong adherence to a (un)healthy diet may start at a young age. ${ }^{27}$ In addition, the complex interplay between different foods and nutrients may result in synergistic effects on health, ${ }^{28}$ and therefore evaluation of dietary patterns, such as the Mediterranean diet, rather than the individual dietary components, may better reflect individuals' dietary habits and capture its impact on cardiovascular health. ${ }^{29}$

From an aetiological point of view, the question arises as to whether any beneficial impact of a Mediterranean dietary pattern on arterial stiffness may be due to (i.e. 
mediated by) or independent of the protective effects of this diet on traditional CVD RFs, some of which (e.g. BP and central fatness) are known determinants of arterial stiffness. ${ }^{15}$ In an effort to answer this question, we used mediation analysis ${ }^{30,31}$ to quantify the extent and significance of mediation by these RFs in the association between adherence to a Mediterranean diet and arterial stiffness.

We have therefore investigated these issues in a longitudinal cohort of individuals whose usual dietary intake and CVD RFs were repeatedly assessed from adolescence to adulthood, and levels of arterial stiffness were determined at 36 years of age.

\section{SUBJECTS AND METHODS}

All subjects participated in the Amsterdam Growth and Health Longitudinal Study (AGAHLS), an observational study that started in 1976-1977 with a group of approximately 600 boys and girls from two secondary schools in the area of Amsterdam, the Netherlands. This cohort was established to enable the investigation of growth, lifestyle and health of adolescents, and the longitudinal relationships between lifestyle and biological RFs extending into adulthood, as described in detail elsewhere. ${ }^{32}$ Briefly, the mean age of the subjects at the beginning of the study was $13.1 \pm 0.8$ years. Since then, repeated measurements of lifestyle (including dietary, physical activity and smoking habits), anthropometric (height, weight and skinfold measurements) and biological (BP and blood lipid levels) RFs were obtained according to standard procedures two to eight times up to the age of 36 years, over a total follow-up period of 24 years. ${ }^{13,32-34}$ In the year 2000, when the mean age of participants was $36.5 \pm 0.5$ years, biophysical properties of three large arteries were evaluated for the first time in 373 participants (196 women); ${ }^{12,13,15,35}$ these subjects comprise the sample of the present study.

The medical ethical committee of the VU University Medical Center (Amsterdam, the Netherlands) approved the study, and all subjects gave their written informed consent (provided by parents when participants were 13-16 years old).

\section{Arterial stiffness}

Biophysical properties of the large arteries were measured according to guidelines and using reproducible methods, ${ }^{18,36,37}$ as described in detail elsewhere. ${ }^{12,13,15,35}$ Briefly, all subjects had abstained from smoking and consumption of caffeinecontaining beverages on the day of the measurements, which took place after subjects had been resting in a supine position for $15 \mathrm{~min}$ in a quiet temperaturecontrolled room. Properties of the right common carotid (10 $\mathrm{mm}$ proximal to the beginning of the carotid bulb) and the brachial (20 $\mathrm{mm}$ above the antecubital fossa) and common femoral (20 $\mathrm{mm}$ proximal to the flow divider) arteries were obtained with the use of an ultrasound scanner equipped with a 7.5- $\mathrm{MHz}$ linear array probe (Pie 
Medical, Maastricht, the Netherlands). The ultrasound scanner was connected to a personal computer equipped with an acquisition system and a vessel wall movement detector software system (Wall Track System 2, Pie Medical). This integrated device enabled measurement of arterial diameter $(D)$, distension $(\Delta D)$ and intima-media thickness (IMT) as described in detail previously. ${ }^{36,37}$ SBP, DBP and mean BP (MBP) were assessed in the left arm at 5-min intervals throughout the period of ultrasound imaging using an oscillometric device (Colin Press-Mate, model BP-8800, Komaki-City, Japan). Brachial pulse pressure (PP) was defined as SBP-DBP, and PP at the level of the carotid and femoral arteries was calculated by calibration of the distension waveforms. $^{38}$ The mean values of $D, \Delta D$ and local PP from three consecutive measurements were used to estimate the distensibility (DC) and compliance (CC) coefficients of each artery as follows:

$$
\begin{array}{ll}
D C=\left(2 \Delta D \cdot D+\Delta D^{2}\right) /\left(P P \cdot D^{2}\right) & \text { in } 10^{-3} / \mathrm{kPa} \\
C C=\pi \cdot\left(2 D \cdot \Delta D+\Delta D^{2}\right) / 4 P P & \text { in } \mathrm{mm}^{2} / \mathrm{kPa}
\end{array}
$$

The DC reflects the elastic properties, whereas the CC reflects the buffering capacity of the artery at given operating local pressures. From D, DC and IMT, the carotid Young's elastic modulus $\left(E_{\text {inc }}\right)$, an estimate of the intrinsic elastic properties of the vessel wall, was calculated as follows:

$$
\mathrm{YEM}=\mathrm{D} /(\mathrm{IMT} \cdot \mathrm{DC}) \quad \text { in } 10^{3} \cdot \mathrm{kPa}
$$

Degree of stiffness. In contrast to the $\mathrm{E}_{\mathrm{inc}}$, higher values of the DC and CC indicate lower arterial stiffness. Therefore, DC and CC values were multiplied by -1 (i.e. reversed) prior to categorizing subjects into three groups on the basis of the sexspecific tertiles $(T)$ of the stiffness estimate: less stiff (T1), intermediate (T2) and stiffer arteries $(\mathrm{T} 3)^{13,15,35}$

\section{Dietary assessment}

From 13 to 36 years of age, usual dietary intake was measured using a cross-check dietary history (face-to-face) interview, as described previously. ${ }^{39,40}$ In brief, participants were asked to recall their usual food intake during the previous month by reporting frequency, amount and method of preparation of foods and drinks (including alcoholic beverages) consumed. Amounts were reported in household measures or grams, and models were used to illustrate portion sizes. During the measurements in 2000, a newly developed interviewer-administered, computerassisted, cross-check dietary history method was introduced. ${ }^{40}$ The questions and interview structure were based on the original face-to-face interview. The two methods of dietary assessment showed a high level of comparability, though it is likely that introduction of the computer-assisted method caused a reduction in interviewer bias. ${ }^{40}$ Total energy intake was calculated using the 1996 Dutch Food Composition Table. $^{41}$ 
Mediterranean diet score. For each subject, and for each measurement round, we calculated the alternate Mediterranean diet score (aMED), ${ }^{6,10,42}$ which is an adapted version of the original score developed by Trichopoulou et al. ${ }^{8}$ and contains the following nine dietary components: vegetables (excluding potatoes), fruits, whole grains, nuts, legumes, fish, red and processed meats, ratio of monounsaturated to saturated fat and alcohol. Subjects scored one point whenever the intake of each component was above the sex-specific median, except in the case of red and processed meat, for which one point was attributed if the intake was below the sexspecific median, and alcohol intake, for which one point was scored if participants abstained from drinking during adolescence (ages 13-16 years) or if the level of consumption was 5 to $25 \mathrm{~g}$ /day during adulthood (ages 21-36 years). ${ }^{10}$ This distinction seemed to be appropriate because underage drinking may outweigh any beneficial effects of (moderate) alcohol consumption. The aMED score thus ranged from 0 to 9 with higher values indicating a higher degree of adherence to a Mediterranean dietary pattern.

\section{Statistical analyses}

We used generalized estimating equations (GEEs) to investigate the mean differences in the aMED score throughout the 24-year longitudinal period between subjects with different levels of arterial stiffness at the age of 36 years. ${ }^{13,15,35}$ GEEs properly take into account the correlation between repeated observations within the same individual, and have the advantage of being able to analyse varying numbers of and unequally time-spaced observations. ${ }^{43}$ All analyses were adjusted for sex, height and time (model 1). Interaction terms between stiffness groups and time were added to this model to ascertain whether the magnitude of the differences in the aMED score emerged at any specific age during the course of young life. Results were displayed graphically and reflect the life-course trajectories of the aMED score by levels of arterial stiffness at age $36 . .^{13,15,35,43}$ The mean differences in the aMED score between groups with different levels of arterial stiffness were further adjusted for potential confounders such as total energy intake (kcal), habitual physical activity (metabolic equivalents per week) and smoking (yes/no) (model 2).

GEE analyses were also used to ascertain longitudinal associations between the aMED score and CVD RFs (i.e. BP, body fatness and blood lipid levels) throughout the 24-year period; results were expressed by standardized longitudinal regression coefficients to allow direct comparison of the strength of the associations between the score and each RF.

An exchangeable correlation structure was used in all analyses, and statistical significance was set at $P<0.05$ (two sided). GEE analyses were carried out using STATA software version 9.2 (STATA Corp, College Station, TX, USA).

Mediation analyses. The mediating role of a variable (mediator) hypothesized to be involved in the pathway between a given determinant (Mediterranean diet) and a given outcome (arterial stiffness) is ascertained by quantitative evaluation (i.e. extent 
and significance) of the attenuation in the strength of the association between determinant and outcome after adjustment for the potential mediator. ${ }^{30,31}$ We hypothesized that RFs such as MBP, central fatness and/or dyslipidaemia, all of which were previously shown to be associated with arterial stiffness in this study population, ${ }^{12,15}$ could play a mediating role in the association between Mediterranean diet and arterial stiffness. Therefore, we additionally adjusted the differences in the levels of lifetime aMED score between subjects with stiffer versus less stiff arteries (as obtained in model 2 described above) for these potential mediators, both one at a time (models $3 \mathrm{~A}-\mathrm{C}$ ) and simultaneously (model 4). We used the ab product-coefficient method to quantify the magnitude of the attenuations due to these adjustments and the respective $95 \%$ confidence intervals $(\mathrm{Cls})$; the latter enable appreciation of whether mediation by any of the RFs investigated was significant (if so, the $95 \% \mathrm{Cl}$ around the magnitude of attenuation would not include 0). ${ }^{30,31}$ These analyses were conducted with the RMediation package written for use in the R statistical program (version 2.13.0, The R Foundation for Statistical Computing 2011). ${ }^{44}$

\section{RESULTS}

Characteristics of the study population and dietary consumption throughout the 24year period are shown in Tables 4.2.1 and 4.2.2, respectively. Levels of arterial stiffness across tertiles of the stiffness are presented in Table 4.2.3; these data are shown for men and women separately because sex-specific cut-off values were used in the analyses. All subsequent data are shown for men and women together as there was no evidence for sex-interactions.

\section{Lifetime adherence to a Mediterranean dietary pattern and arterial stiffness at age 36 years}

After adjustment for sex, height and time, subjects with stiffer carotid arteries at the age of 36 years had significantly lower mean aMED scores during the 24-year study period, compared with subjects with less stiff arteries: $-0.36(95 \% \mathrm{Cl}-0.62 ;-0.10)$, $-0.56(95 \% \mathrm{Cl}-0.83 ;-0.29)$ and $-0.31(95 \% \mathrm{Cl}-0.58 ;-0.04)$ when stiffness levels were determined on the basis of the DC, CC and YEM, respectively (Table 4.2.4, model 1). Of note, such differences were already present during adolescence and remained fairly stable throughout the study period, particularly for comparisons based on the carotid DC and CC (Figure 4.2.1). After adjustment for potential confounders (i.e. total energy intake and other lifestyle variables), the mean differences in the aMED scores were attenuated to $-0.32(95 \% \mathrm{Cl}-0.58 ;-0.06),-0.52(95 \% \mathrm{Cl}-0.79 ;-0.25)$ and -0.27 $(95 \% \mathrm{Cl}-0.54 ;-0.01)$, respectively, but remained statistically significant (model 2 ). 


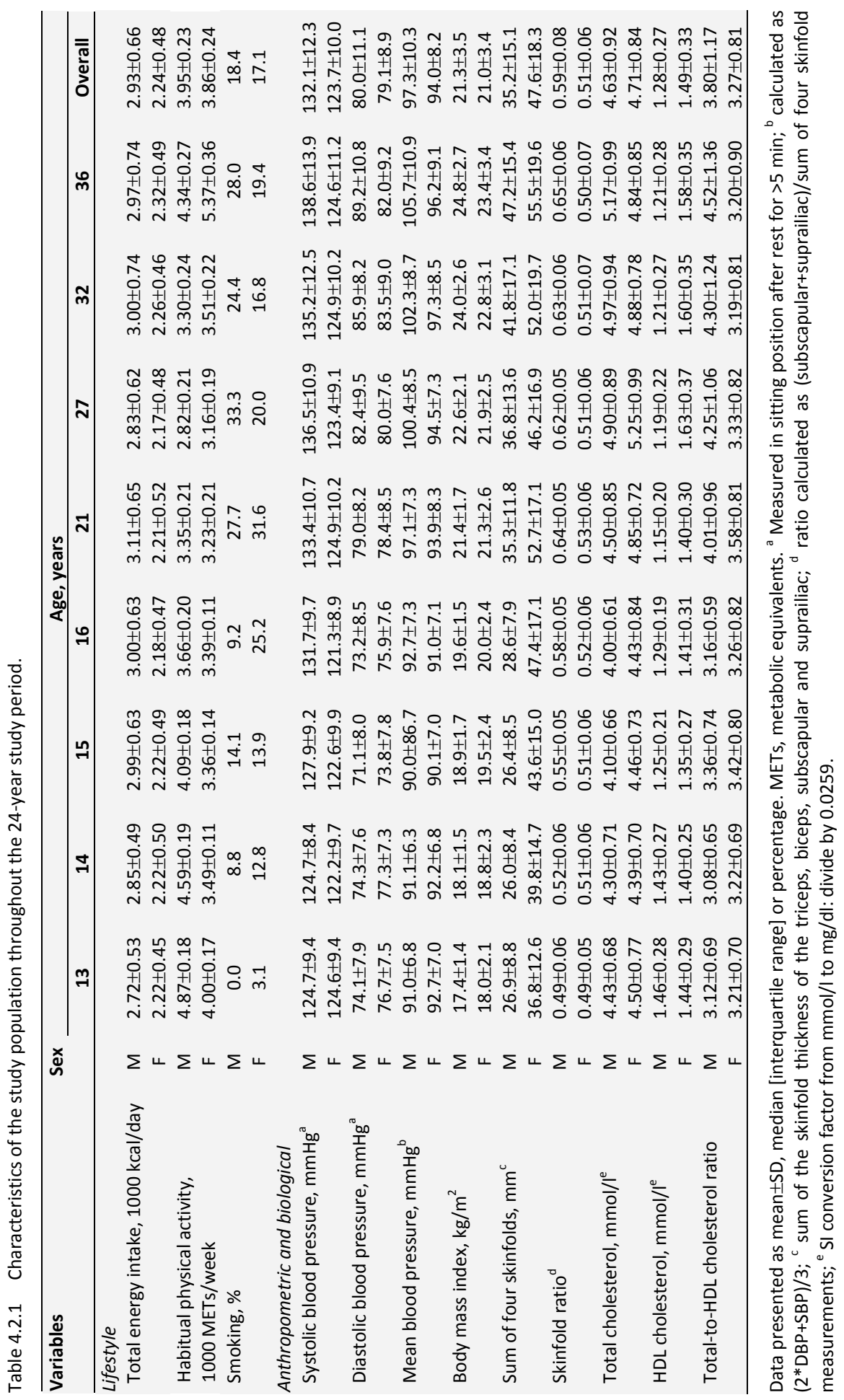




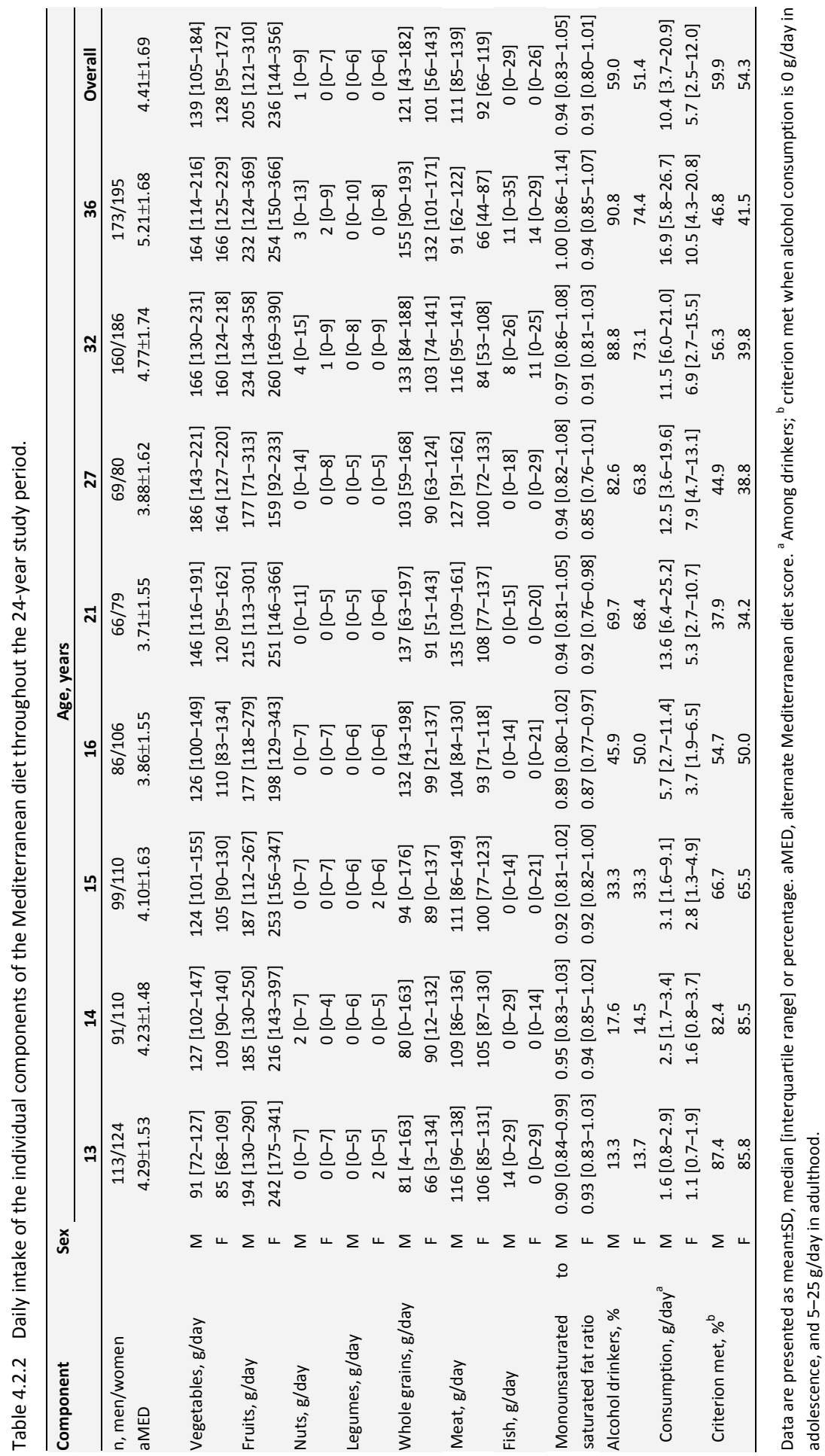


Table 4.2.3 Arterial stiffness levels at the age of 36 years according to sex-specific tertiles of each stiffness estimate.

\begin{tabular}{|c|c|c|c|c|}
\hline Stiffness estimates & Sex & $\begin{array}{c}\text { Tertile } 1 \\
\text { (Less stiff) }\end{array}$ & $\begin{array}{c}\text { Tertile } 2 \\
\text { (Intermediate) }\end{array}$ & $\begin{array}{l}\text { Tertile } 3 \\
\text { (Stiffer) }\end{array}$ \\
\hline Men/women, $\mathrm{n}$ & & $59 / 65$ & $59 / 66$ & $59 / 65$ \\
\hline \multicolumn{5}{|l|}{ Common carotid artery } \\
\hline \multirow[t]{2}{*}{ Distensibility coefficient, ${ }^{\mathrm{a}} 10^{-3} \cdot \mathrm{kPa}^{-1}$} & M & $32.0 \pm 3.4$ & $25.8 \pm 1.4$ & $20.7 \pm 2.1$ \\
\hline & $\mathrm{F}$ & $34.7 \pm 4.3$ & $26.5 \pm 1.7$ & $19.9 \pm 2.3$ \\
\hline \multirow[t]{2}{*}{ Compliance coefficient, ${ }^{\mathrm{a}} \mathrm{mm}^{2} \cdot \mathrm{kPa}^{-1}$} & M & $1.35 \pm 0.20$ & $1.04 \pm 0.05$ & $0.80 \pm 0.01$ \\
\hline & $\mathrm{F}$ & $1.22 \pm 0.18$ & $0.91 \pm 0.06$ & $0.65 \pm 0.09$ \\
\hline \multirow[t]{2}{*}{ Young's elastic modulus, $10^{3} \cdot \mathrm{kPa}$} & M & $0.35 \pm 0.04$ & $0.45 \pm 0.02$ & $0.60 \pm 0.09$ \\
\hline & $\mathrm{F}$ & $0.30 \pm 0.04$ & $0.41 \pm 0.03$ & $0.56 \pm 0.08$ \\
\hline \multicolumn{5}{|l|}{ Brachial artery } \\
\hline \multirow[t]{2}{*}{ Distensibility coefficient, ${ }^{\mathrm{a}} 10^{-3} \cdot \mathrm{kPa}^{-1}$} & M & $22.0 \pm 10.5$ & $10.5 \pm 1.5$ & $6.2 \pm 1.6$ \\
\hline & $\mathrm{F}$ & $26.2 \pm 7.9$ & $14.1 \pm 1.9$ & $7.9 \pm 2.3$ \\
\hline \multirow[t]{2}{*}{ Compliance coefficient, ${ }^{a} \mathrm{~mm}^{2} \cdot \mathrm{kPa}^{-1}$} & M & $0.30 \pm 0.10$ & $0.17 \pm 0.02$ & $0.10 \pm 0.03$ \\
\hline & $\mathrm{F}$ & $0.24 \pm 0.05$ & $0.14 \pm 0.02$ & $0.07 \pm 0.2$ \\
\hline \multicolumn{5}{|l|}{ Common femoral artery } \\
\hline \multirow[t]{2}{*}{ Distensibility coefficient, ${ }^{\mathrm{a}} 10^{-3} \cdot \mathrm{kPa}^{-1}$} & M & $9.0 \pm 3.1$ & $5.5 \pm 0.5$ & $3.3 \pm 0.8$ \\
\hline & $\mathrm{F}$ & $12.9 \pm 3.8$ & $7.4 \pm 0.9$ & $4.7 \pm 0.9$ \\
\hline \multirow[t]{2}{*}{ Compliance coefficient, ${ }^{a} \mathrm{~mm}^{2} \cdot \mathrm{kPa}^{-1}$} & $M$ & $0.78 \pm 0.22$ & $0.48 \pm 0.05$ & $0.29 \pm 0.06$ \\
\hline & $\mathrm{F}$ & $0.78 \pm 0.19$ & $0.45 \pm 0.05$ & $0.29 \pm 0.06$ \\
\hline
\end{tabular}

Data are means $\pm S D .{ }^{a}$ Distensibility and compliance coefficients were multiplied by -1 (i.e. reversed) prior to categorization into tertiles, so that, in agreement with the carotid Young's elastic modulus, higher tertiles indicate higher arterial stiffness.
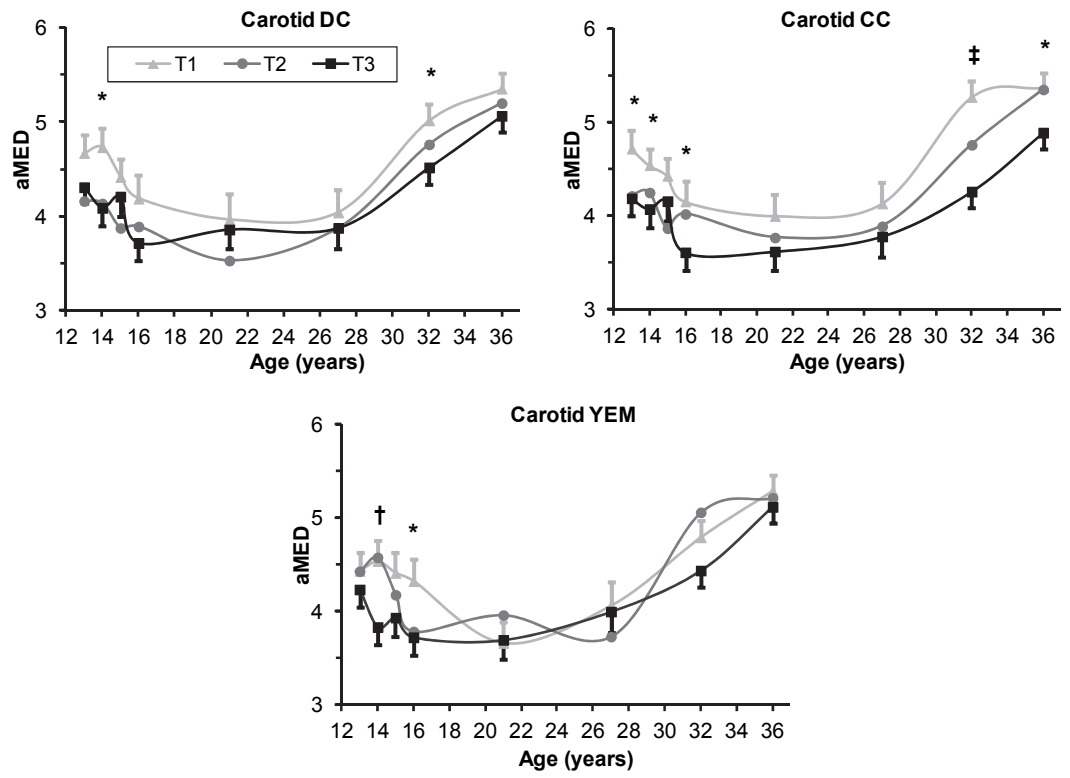

Figure 4.2.1 The alternate Mediterranean diet score (aMED) throughout the study period by tertile (T) of the carotid distensibility (DC) and compliance (CC) coefficients and Young's elastic modulus (YEM) at age 36 years. Data are adjusted for sex, height and time. Error bars indicate standard errors of the means. ${ }^{*} P<0.05 ;+P<0.01 ; \ddagger P<0.001$ for T3 (stiffer) versus T1 (less stiff arteries). 


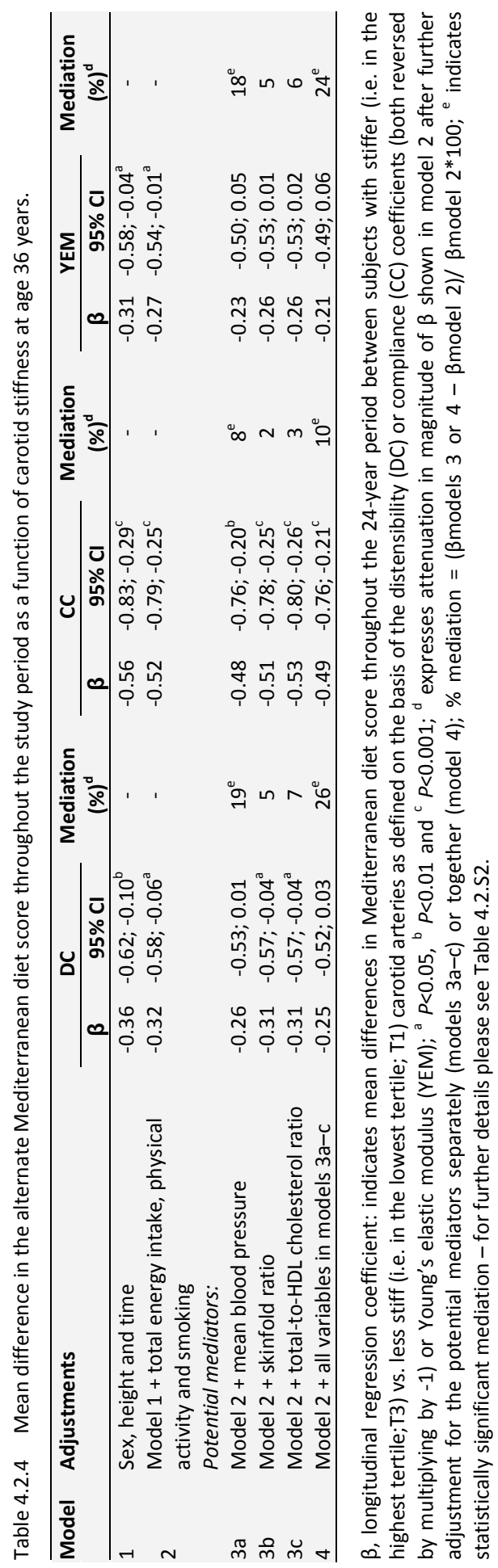


When adherence to a Mediterranean dietary pattern was defined by aMED score $\geq 5$ (i.e. the median value in this population), subjects with stiffer carotid arteries were less likely to have adhered to this diet throughout the 24-year study period than their counterparts with less stiff arteries: odds ratio (OR) 0.69 (95\% Cl $0.50 ; 0.94), 0.64$ $(95 \% \mathrm{Cl} 0.46 ; 0.87)$ and $0.68(95 \% \mathrm{Cl} 0.50 ; 0.93)$ for comparisons based on the DC, CC and YEM, respectively (Figure 4.2.2). Similar trends, albeit mostly non-significant, were observed for each of the components comprising the aMED score, except nuts, legumes and the monounsaturated-to-saturated fatty acids ratio. Clustering of the components in the aMED score thus seemed to better capture the favourable associations with carotid arterial stiffness than each component separately.

Qualitatively similar differences in lifetime aMED score and likelihood of adherence, albeit of lower magnitude, were observed for comparisons based on the estimated level of brachial and femoral stiffness at 36 years (supplemental Table 4.2.S1).
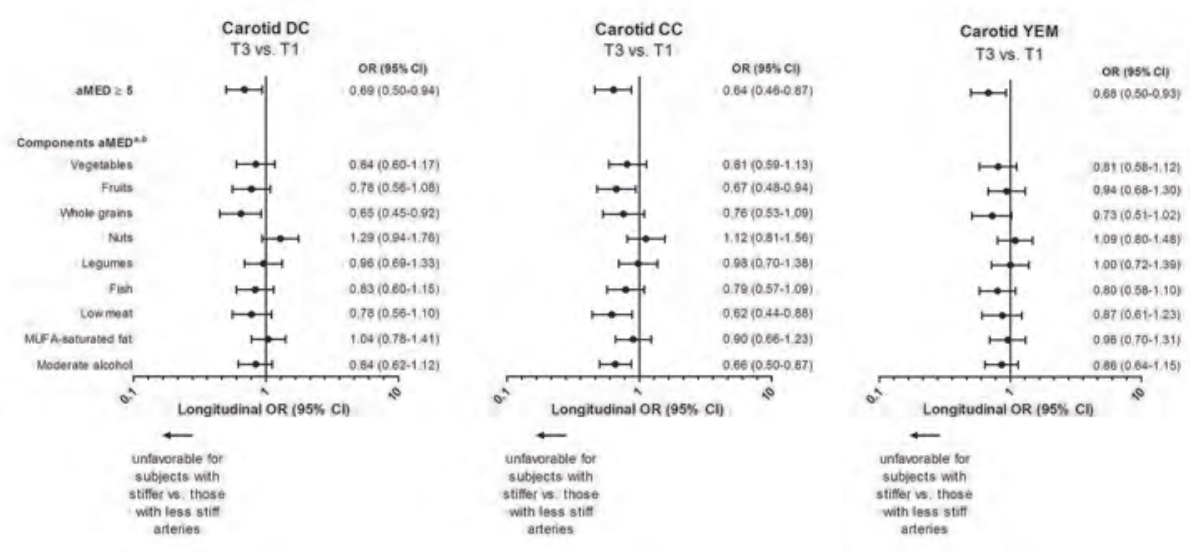

Figure 4.2.2 Longitudinal odd ratio (OR) of adherence to the alternate Mediterranean diet (aMED; score $\geq 5$ ) and favourable intake of each of its components throughout the 24-year study period for subjects with stiffer (in the highest tertile; T3) vs. less stiff (in the lowest tertile;T1, i.e. the reference category) carotid arteries; stiffness levels were defined on the basis of the distensibility (DC) or compliance (CC) coefficients (both reversed by multiplication by -1 ), or the Young's elastic modulus (YEM) at age 36 years. Whiskers indicate the $95 \%$ confidence intervals. Data are adjusted for sex, height, time, total daily energy intake, habitual physical activity and smoking. ${ }^{a}$ Favourable intake of each of the aMED components defined as consumption above the sex-specific median, except for meat intake (defined as consumption below the sex-specific median) and alcohol consumption (defined as abstinence during adolescence, and 5-25 g/day during adulthood). ${ }^{\mathrm{b}}$ Analyses with different components of the aMED were mutually adjusted for each other. 


\section{Longitudinal associations between the aMED score and other CVD RFs}

Higher levels of the aMED score were significantly associated with lower levels of BP (SBP, DBP and MBP) and total cholesterol throughout the longitudinal period. Inverse but weaker associations were also found with anthropometric measures of total and central fatness, and with HDL and total-to-HDL cholesterol ratio (Figure 4.2.3).

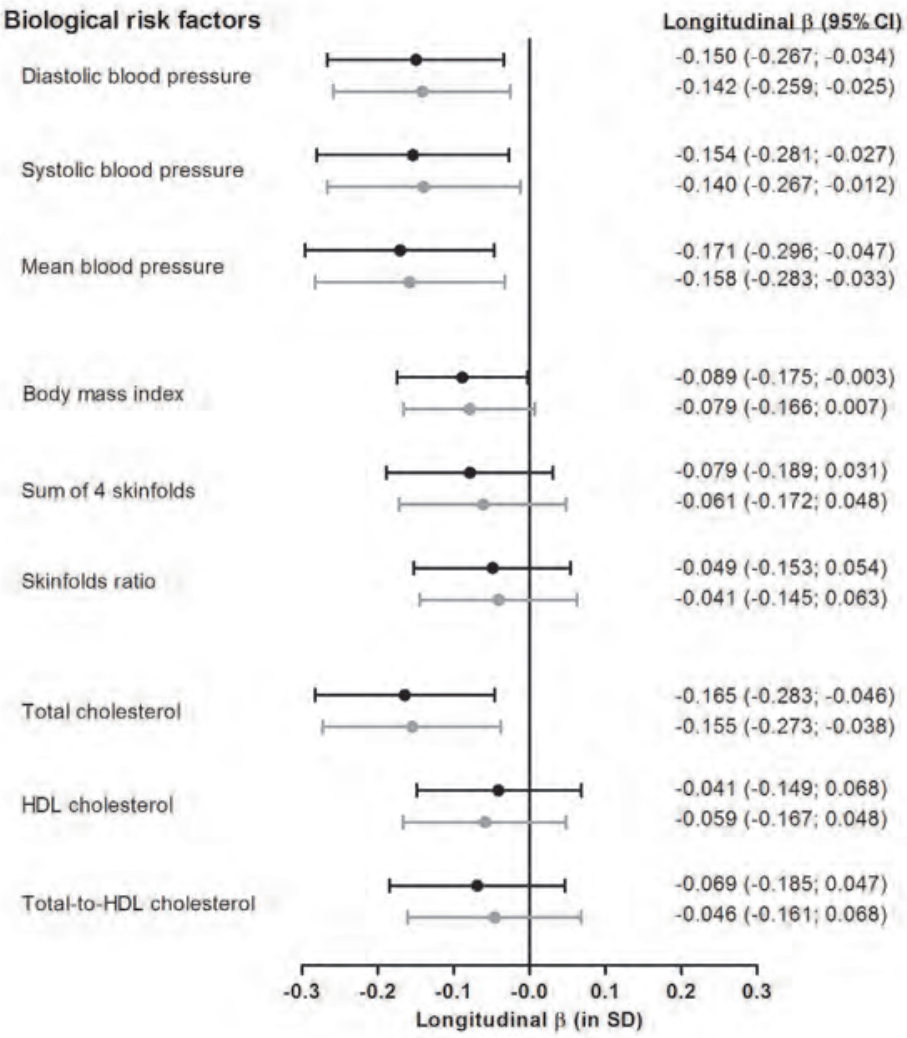

Figure 4.2.3 Longitudinal associations between the alternate Mediterranean diet (aMED) score and cardiovascular disease risk factors. Point estimates indicate change in risk factor (in SD) per two-point increase in the aMED score; whiskers indicate the $95 \%$ confidence intervals. Data were first adjusted for sex, height and time (model 1, black lines) and then additionally for potential confounders (i.e. total daily energy intake, habitual physical activity and smoking; model 2, grey lines). 


\section{Lifetime adherence to a Mediterranean dietary pattern and arterial stiffness at age 36: mediation role of CVD RFs}

The mean differences in aMED between subjects with stiffer compared with those with less stiff carotid arteries (Table 4.2.4, model 2) were significantly attenuated after further adjustment for MBP (models 2 vs. 3A), but less so after adjustment for the skinfold ratio (reflecting a central body fat distribution; models 2 vs. $3 \mathrm{~B}$ ) or the total-to-HDL cholesterol ratio (models 2 vs. $3 C$ ), using simple mediation analyses. When analyses included adjustment for MBP, the skinfold ratio and total-to-HDL cholesterol ratio simultaneously (i.e. multiple mediation model), the differences between subjects with stiffer vs. less stiff carotid arteries as estimated on the basis of the DC, CC or YEM were attenuated by $26 \%$ (i.e. from -0.32 to -0.25 ), $10 \%$ (i.e. from 0.52 to -0.49 ) and $24 \%$ (i.e. from -0.27 to -0.21 ), respectively (models 2 vs. 4). Furthermore, in these multiple mediation analyses, MBP accounted for the greatest portion of the attenuations (i.e., $19 \%, 8 \%$ and $17 \%$, respectively) and was the only mediator that attenuated the lifelong differences in aMED score between subjects with stiffer vs. less stiff carotid arteries to a significant extent (for further details regarding mediation analyses, see Table 4.2.S2 - Appendix 4.2.1).

Replacing adjustment for the skinfold ratio by body mass index (BMI) or sum of the skinfold measurements, and for total-to-HDL cholesterol ratio by total cholesterol did not essentially affect the results of these analyses (data not shown).

\section{DISCUSSION}

The first main finding of this study was that subjects with stiffer carotid arteries, and to a lesser extent brachial and femoral arteries, at the age of 36 years had adhered to a lesser extent to a Mediterranean dietary pattern during the preceding 24 years, suggesting a favourable association between a Mediterranean diet throughout adolescence and early adulthood and arterial stiffness in adulthood. Second, greater adherence to a Mediterranean dietary pattern was associated with lower levels of BP, total cholesterol and BMI throughout the study period. Third, the beneficial association with MBP explained in part (up to 19\%) the favourable association between the Mediterranean dietary pattern and arterial stiffness, which remained largely independent of the other CVD RFs.

To the best of our knowledge, this is the first study to investigate the associations between intake of a Mediterranean diet throughout adolescence and early adulthood and arterial stiffness in adulthood. Our findings are in line with those of previous studies showing that high intake of fruits and vegetables in adolescence and young adulthood was associated with lower aortic stiffness in adulthood, ${ }^{45}$ and that a dietary pattern low in fruits, sweetening and dairy products, and high in meat and alcohol (identified by principal component analyses) was associated with higher aortic stiffness 7.5 years later in middle-aged individuals. ${ }^{46}$ In contrast to the latter study, we 
investigated adherence to a dietary pattern defined a priori (Mediterranean diet) instead of individual foods or dietary patterns defined a posteriori by means of exploratory data analyses techniques. ${ }^{29}$ Investigating a dietary pattern may capture better synergistic health effects, and reduce confounding bias by separate foods or nutrients, which are more prone to show associations due to chance. ${ }^{28,29}$ In addition, we obtained repeated dietary data throughout a period of 24 years, from adolescence to young adulthood. This enabled a more robust assessment of risk exposure, ${ }^{47}$ appreciation of its changes over time, and identification of potential critical periods early in life when exposure could be related to arterial stiffness in adulthood.

Indeed, trajectory analyses revealed that adherence to a Mediterranean dietary pattern, as depicted by the calculated aMED score, declined from adolescence into young adulthood in all individuals, and differed already during adolescence and throughout follow-up between individuals with different levels of arterial stiffness at 36 years. In addition, greater adherence to a Mediterranean dietary pattern was associated with lower levels of other CVD RFs, such as BP, total cholesterol and BMI, all of which have been shown to track from young to older age. ${ }^{34,48}$ Despite the fact that the aMED score was inversely (but not significantly) associated with HDL cholesterol, these data emphasize a potential preventive role of adherence to a Mediterranean diet starting at a young age. Preventive strategies targeting children and their parents may, given the shared environment and parents' primary responsibility for their children's dietary intake, ${ }^{49}$ thus be more beneficial as a means to engage in long-term healthy dietary habits. ${ }^{27}$ In addition, targeting the time of transition between adolescence and young adulthood, when individuals become increasingly more independent and responsible for their own dietary choices, may be particularly important given the decline in dietary quality observed during this period.

The protective association between lifelong adherence to a Mediterranean dietary pattern and arterial stiffness found in the present study applied to both the elastic carotid and the muscular brachial and femoral arteries, suggesting a favourable impact throughout the arterial tree. The effect estimates were relatively smaller for the muscular arteries, however, which may reflect underestimation given the larger measurement error with which properties of these arteries (mainly distension) were measured. $^{12}$ Alternatively, structural differences between elastic and muscular arteries may account for these findings. ${ }^{35}$ Nevertheless, the observation of significant associations between adherence to a Mediterranean dietary pattern and stiffness estimates of mainly the carotid artery may be clinically most relevant as stiffness levels of elastic arteries in particular (e.g. the carotid and the aorta) have been shown to predict incident CVD. ${ }^{21-25}$ In addition, differences in stiffness levels between the groups being compared (i.e. T3 vs. T1 of the carotid stiffness estimates) correspond to those previously observed over one decade of ageing, ${ }^{50}$ suggesting that physiologically meaningful differences in arterial stiffness levels at age 36 were studied. Our findings thus suggest that lower arterial stiffness may in part explain the beneficial impact of a Mediterranean diet on CVD and related mortality. ${ }^{6-10}$ 
We have previously shown that the life-course levels of MBP and central (i.e. skinfold ratio) rather than total (i.e. BMI or the sum of skinfolds) fatness were the main independent biological RFs associated with arterial stiffness in adulthood. ${ }^{15}$ In line with these earlier observations, we have now shown that the beneficial association between the Mediterranean diet and MBP constituted a significant biological pathway through which this dietary pattern could affect arterial stiffness. However, the mediating role of MBP accounted for only a small part (up to 19\%) of the associations between the Mediterranean diet and carotid stiffness, and all RFs considered up to $26 \%$, thus suggesting that other factors may also play a role. Such factors may include less low-grade inflammation, reduced endothelial dysfunction, ${ }^{3,42}$ reduced oxidative stress ${ }^{51}$ and/or improved insulin sensitivity ${ }^{3}$ and thus need to be further investigated as potential mechanisms linking a Mediterranean dietary pattern to arterial stiffness. However, longitudinal measures of these factors were not available in this cohort.

The aMED score calculated in the present and other studies ${ }^{6,10,42}$ differs from the traditional $^{2,8}$ and modified $^{9}$ Mediterranean diet scores originally proposed by Trichopoulou et al. by separating fruits from nuts, excluding dairy products, using whole grains instead of total cereals, and applying the same criterion for moderate alcohol consumption in both sexes. The modified Mediterranean diet also takes into account polyunsaturated fat intake. We chose to use the aMED score because recent evidence indicates that quality of carbohydrates is an important determinant of cardiovascular health. ${ }^{52}$ Nevertheless, additional analyses showed high correlations between the three scores (standardized longitudinal regression coefficients all $>0.7$, $P<0.001)$, and repeating analyses using the two other scores instead yielded essentially the same results as those reported herein (data not shown).

Some limitations of this study should be considered. First, our study was confined to participants in the AGAHLS attending the follow-up measurement round in 2000 in whom complete data on arterial properties could be assessed. These subjects did not significantly differ those who dropped outs at any of the earlier time points with regard to the RFs considered and the consumption of foods comprising the aMED score, except for lower alcohol consumption at the mean ages of 14, 15 and 21 years. It is thus unlikely that selection bias has affected the validity of our findings. Second, longitudinal data on dietary intake were collected prospectively but were selfreported, which might be subject to misclassification and recall bias. ${ }^{53}$ Given that throughout the study period individuals were unaware of their arterial stiffness levels at the age of 36 years, it is likely that any such bias was non-differential. Moreover, if differential bias has occurred, it most probably resulted from over-reporting of healthy dietary habits by those with unhealthier lifestyles. ${ }^{53}$ In both cases, the effect sizes as reported in the present study may have been underestimated. Third, the aMED score is a relative measure that depends on the distribution of food intake in the study population as it is calculated on the basis of the median values of each of its components (except for alcohol consumption for which predefined cut-off levels were 
used). Though valid from an aetiological point of view, this does not enable direct extrapolation of our findings to other cohorts with other distributions. Similarly, we investigated a young, apparently healthy Caucasian population, and thus extrapolation of the present findings to older, high-risk populations and/or those of other ethnicities should be done with caution. Finally, given the observational design of the study and that arterial stiffness was only ascertained at the age of 36 years, our findings do not enable causality to be inferred.

In conclusion, we showed that adherence to a Mediterranean dietary pattern throughout the course of adolescence and early adulthood was associated with lower arterial stiffness in young adulthood, as well as with lower BP, BMI and total cholesterol during the 24-year study period. Promoting a Mediterranean dietary pattern among children, and throughout the course of adolescence and young adulthood, may constitute an important means of preventing adverse levels of CVD RFs and accelerated arterial stiffening in adulthood. 


\section{REFERENCES}

1. Willett WC, Sacks F, Trichopoulou A, et al. Mediterranean diet pyramid: a cultural model for healthy eating. Am J Clin Nutr. 1995;61:1402S-1406S.

2. Psaltopoulou T, Naska A, Orfanos P, Trichopoulos D, Mountokalakis T, Trichopoulou A. Olive oil, the Mediterranean diet, and arterial blood pressure: the Greek European Prospective Investigation into Cancer and Nutrition (EPIC) study. Am J Clin Nutr. 2004;80:1012-1018.

3. Estruch R, Martinez-Gonzalez MA, Corella D, et al. Effects of a Mediterranean-style diet on cardiovascular risk factors: a randomized trial. Ann Intern Med. 2006;145:1-11.

4. Nordmann AJ, Suter-Zimmermann K, Bucher HC, et al. Meta-analysis comparing mediterranean to low-fat diets for modification of cardiovascular risk factors. Am J Med. 2011;124:841-851 e842.

5. Romaguera D, Norat T, Vergnaud AC, et al. Mediterranean dietary patterns and prospective weight change in participants of the EPIC-PANACEA project. Am J Clin Nutr. 2010;92:912-921.

6. Fung TT, Rexrode KM, Mantzoros CS, Manson JE, Willett WC, Hu FB. Mediterranean diet and incidence of and mortality from coronary heart disease and stroke in women. Circulation. 2009;119:1093-1100.

7. Knoops KT, de Groot LC, Kromhout D, et al. Mediterranean diet, lifestyle factors, and 10-year mortality in elderly European men and women: the HALE project. JAMA. 2004;292:1433-1439.

8. Trichopoulou A, Costacou T, Bamia C, Trichopoulos D. Adherence to a Mediterranean diet and survival in a Greek population. N Engl J Med. 2003;348:2599-2608.

9. Trichopoulou A, Orfanos P, Norat T, et al. Modified Mediterranean diet and survival: EPIC-elderly prospective cohort study. BMJ. 2005;330:991.

10. van den Brandt PA. The impact of a Mediterranean diet and healthy lifestyle on premature mortality in men and women. Am J Clin Nutr. 2011;94:913-920.

11. McGill HC, Jr., McMahan CA, Herderick EE, Malcom GT, Tracy RE, Strong JP. Origin of atherosclerosis in childhood and adolescence. Am J Clin Nutr. 2000;72:1307S-1315S.

12. Ferreira I, Twisk JW, van Mechelen W, Kemper HC, Seidell JC, Stehouwer CD. Current and adolescent body fatness and fat distribution: relationships with carotid intima-media thickness and large artery stiffness at the age of 36 years. J Hypertens. 2004;22:145-155.

13. van de Laar RJ, Ferreira I, van Mechelen W, Prins MH, Twisk JW, Stehouwer CD. Lifetime vigorous but not light-to-moderate habitual physical activity impacts favorably on carotid stiffness in young adults: the Amsterdam Growth and Health Longitudinal Study. Hypertension. 2010;55:33-39.

14. van de Laar RJ, Stehouwer CD, Boreham CA, et al. Continuing smoking between adolescence and young adulthood is associated with higher arterial stiffness in young adults: the Northern Ireland Young Hearts Project. J Hypertens. 2011;29:2201-2209.

15. Ferreira I, van de Laar RJ, Prins MH, Twisk JW, Stehouwer CD. Carotid stiffness in young adults: a lifecourse analysis of its early determinants: the Amsterdam Growth and Health Longitudinal Study. Hypertension. 2012;59:54-61.

16. Juonala M, Jarvisalo MJ, Maki-Torkko N, Kahonen M, Viikari JS, Raitakari OT. Risk factors identified in childhood and decreased carotid artery elasticity in adulthood: the Cardiovascular Risk in Young Finns Study. Circulation. 2005;112:1486-1493.

17. Li S, Chen W, Srinivasan SR, Berenson GS. Childhood blood pressure as a predictor of arterial stiffness in young adults: the bogalusa heart study. Hypertension. 2004;43:541-546.

18. Laurent S, Cockcroft J, Van Bortel L, et al. Expert consensus document on arterial stiffness: methodological issues and clinical applications. Eur Heart J. 2006;27:2588-2605.

19. Stehouwer CD, Henry RM, Ferreira I. Arterial stiffness in diabetes and the metabolic syndrome: a pathway to cardiovascular disease. Diabetologia. 2008;51:527-539.

20. Izzo JL, Jr. Arterial stiffness and the systolic hypertension syndrome. Curr Opin Cardiol. 2004;19: 341-352.

21. Vlachopoulos C, Aznaouridis K, Stefanadis C. Prediction of cardiovascular events and all-cause mortality with arterial stiffness: a systematic review and meta-analysis. I Am Coll Cardiol. 2010;55:1318-1327.

22. Barenbrock M, Kosch M, Joster E, Kisters K, Rahn KH, Hausberg M. Reduced arterial distensibility is a predictor of cardiovascular disease in patients after renal transplantation. J Hypertens. 2002;20:79-84. 
23. Blacher J, Guerin AP, Pannier B, Marchais SJ, London GM. Arterial calcifications, arterial stiffness, and cardiovascular risk in end-stage renal disease. Hypertension. 2001;38:938-942.

24. Stork S, van den Beld AW, von Schacky C, et al. Carotid artery plaque burden, stiffness, and mortality risk in elderly men: a prospective, population-based cohort study. Circulation. 2004;110:344-348.

25. Yang EY, Chambless L, Sharrett AR, et al. Carotid arterial wall characteristics are associated with incident ischemic stroke but not coronary heart disease in the Atherosclerosis Risk in Communities (ARIC) study. Stroke. 2012;43:103-108.

26. Pase MP, Grima NA, Sarris J. The effects of dietary and nutrient interventions on arterial stiffness: a systematic review. Am J Clin Nutr. 2011;93:446-454.

27. Lake AA, Adamson AJ, Craigie AM, Rugg-Gunn AJ, Mathers JC. Tracking of dietary intake and factors associated with dietary change from early adolescence to adulthood: the ASH30 study. Obes Facts. 2009;2:157-165.

28. Jacobs DR, Jr., Steffen LM. Nutrients, foods, and dietary patterns as exposures in research: a framework for food synergy. Am J Clin Nutr. 2003;78:508S-513S.

29. Hu FB. Dietary pattern analysis: a new direction in nutritional epidemiology. Curr Opin Lipidol. 2002;13:3-9.

30. Lockwood CM, DeFrancesco CA, Elliot DL, Beresford SA, Toobert DJ. Mediation analyses: applications in nutrition research and reading the literature. J Am Diet Assoc. 2010;110:753-762.

31. MacKinnon DP. Introduction to Statistical Mediation Analysis. New York: Taylor \& Francis Group; 2008.

32. Wijnstok NJ, Hoekstra T, van Mechelen W, Kemper HC, Twisk JW. Cohort profile: The Amsterdam Growth and Health Longitudinal Study. Int J Epidemiol. In press.

33. Ferreira I, Twisk JW, van Mechelen W, Kemper HC, Stehouwer CD. Development of fatness, fitness, and lifestyle from adolescence to the age of 36 years: determinants of the metabolic syndrome in young adults: The Amsterdam Growth and Health Longitudinal Study. Arch Intern Med. 2005;165: $42-48$.

34. Twisk JW, Kemper HC, van Mechelen W, Post GB. Tracking of risk factors for coronary heart disease over a 14-year period: a comparison between lifestyle and biologic risk factors with data from the Amsterdam Growth and Health Study. Am J Epidemiol. 1997;145:888-898.

35. van de Laar RJ, Ferreira I, van Mechelen W, Prins MH, Twisk JW, Stehouwer CD. Habitual physical activity and peripheral arterial compliance in young adults: the Amsterdam Growth and Health Longitudinal Study. Am J Hypertens. 2011;24:200-208.

36. Brands PJ, Hoeks AP, Willigers J, Willekes C, Reneman RS. An integrated system for the non-invasive assessment of vessel wall and hemodynamic properties of large arteries by means of ultrasound. Eur $\mathrm{J}$ Ultrasound. 1999;9:257-266.

37. Reneman RS, Hoeks AP. Noninvasive vascular ultrasound: an asset in vascular medicine. Cardiovasc Res. 2000;45:27-35.

38. Van Bortel LM, Balkestein EJ, van der Heijden-Spek JJ, et al. Non-invasive assessment of local arterial pulse pressure: comparison of applanation tonometry and echo-tracking. J Hypertens. 2001;19: 1037-1044.

39. te Velde SJ, Twisk JW, Brug J. Tracking of fruit and vegetable consumption from adolescence into adulthood and its longitudinal association with overweight. Br J Nutr. 2007;98:431-438.

40. Bakker I, Twisk JW, van Mechelen W, Mensink GB, Kemper HC. Computerization of a dietary history interview in a running cohort; evaluation within the Amsterdam Growth and Health Longitudinal Study. Eur J Clin Nutr. 2003;57:394-404.

41. NEVO Tabel 1996 (Dutch Food Composition Table 1996). The Hague: Voorlichtingsbureau voor de voeding; 1996.

42. Fung TT, McCullough ML, Newby PK, et al. Diet-quality scores and plasma concentrations of markers of inflammation and endothelial dysfunction. Am J Clin Nutr. 2005;82:163-173.

43. Twisk JWR. Applied Longitudinal Data Analysis for Epidemiolgy: A Practical Guide. Cambridge: Cambridge University Press; 2003.

44. Tofighi D, Mackinnon DP. RMediation: An R package for mediation analysis confidence intervals. Behav Res Methods. 2011;43:692-700. 
45. Aatola $\mathrm{H}$, Koivistoinen $\mathrm{T}$, Hutri-Kahonen $\mathrm{N}$, et al. Lifetime fruit and vegetable consumption and arterial pulse wave velocity in adulthood: the Cardiovascular Risk in Young Finns Study. Circulation. 2010;122:2521-2528.

46. Kesse-Guyot E, Vergnaud AC, Fezeu L, et al. Associations between dietary patterns and arterial stiffness, carotid artery intima-media thickness and atherosclerosis. Eur J Cardiovasc Prev Rehabil. 2010;17:718-724.

47. White E, Hunt JR, Casso D. Exposure measurement in cohort studies: the challenges of prospective data collection. Epidemiol Rev. 1998;20:43-56.

48. Chen X, Wang Y. Tracking of blood pressure from childhood to adulthood: a systematic review and meta-regression analysis. Circulation. 2008;117:3171-3180.

49. Briggs M, Mueller CG, Fleischhacker S. Position of the American Dietetic Association, School Nutrition Association, and Society for Nutrition Education: comprehensive school nutrition services. J Am Diet Assoc. 2011;110:1738-1749.

50. Vermeersch SJ, Rietzschel ER, De Buyzere ML, et al. Age and gender related patterns in carotidfemoral PWV and carotid and femoral stiffness in a large healthy, middle-aged population. J Hypertens. 2008;26:1411-1419.

51. Dai J, Jones DP, Goldberg J, et al. Association between adherence to the Mediterranean diet and oxidative stress. Am J Clin Nutr. 2008;88:1364-1370.

52. Ludwig DS. The glycemic index: physiological mechanisms relating to obesity, diabetes, and cardiovascular disease. JAMA. 2002;287:2414-2423.

53. Macdiarmid J, Blundell J. Assessing dietary intake: Who, what and why of under-reporting. Nutr Res Rev. 1998;11:231-253. 


\section{Appendix 4.2.1}

Supplemental tables 
Chapter 4.2 
Table 4.2.S1 Mean differences in the alternate Mediterranean diet score and odds ratios for lifetime adherence to the alternate Mediterranean diet throughout the longitudinal period as function of brachial and femoral stiffness at age 36 .

\begin{tabular}{|c|c|c|c|c|c|c|c|c|}
\hline \multirow[t]{2}{*}{ Model } & \multicolumn{4}{|c|}{ DC } & \multicolumn{4}{|c|}{$\mathrm{CC}$} \\
\hline & $\beta$ & $95 \% \mathrm{Cl}$ & OR & $95 \% \mathrm{Cl}$ & $\beta$ & $95 \% \mathrm{Cl}$ & OR & $95 \% \mathrm{Cl}$ \\
\hline \multicolumn{9}{|c|}{ Brachial artery } \\
\hline 1 & -0.11 & $-0.39 ; 0.16$ & 0.81 & $0.59 ; 1.10$ & -0.28 & $-0.54 ;-0.02^{a}$ & 0.72 & $0.53 ; 0.97^{\mathrm{a}}$ \\
\hline 2 & -0.12 & $-0.39 ; 0.15$ & 0.80 & $0.58 ; 1.09$ & -0.28 & $-0.55 ;-0.02^{a}$ & 0.72 & $0.53 ; 0.97^{a}$ \\
\hline \multicolumn{9}{|c|}{ Femoral artery } \\
\hline 1 & -0.14 & $-0.40 ; 0.13$ & 0.77 & $0.56 ; 1.06$ & -0.26 & $-0.52 ; 0.00$ & 0.74 & $0.54 ; 1.00$ \\
\hline 2 & -0.15 & $-0.41 ; 0.12$ & 0.77 & $0.56 ; 1.06$ & -0.25 & $-0.51 ; 0.01$ & 0.75 & $0.55 ; 1.02$ \\
\hline
\end{tabular}

$\beta$, longitudinal regression coefficients; OR, odds ratio; these indicate the mean differences in Mediterranean diet score or the odds of adherence to a Mediterranean dietary pattern (i.e., score $\geq 5$ ) throughout the 24-year period between subjects with stiffer (i.e. in the highest tertile -T3) vs. less stiff (i.e. in the lowest tertile - T1) carotid arteries as defined on the basis of this artery's distensibility (DC) or compliance (CC) coefficients (both reversed); ${ }^{a} P<0.05$. Model 1 : crude + adjustment for sex, body height and time; Model 2: model $1+$ adjustment for total energy intake, habitual physical activity and smoking behaviour. 


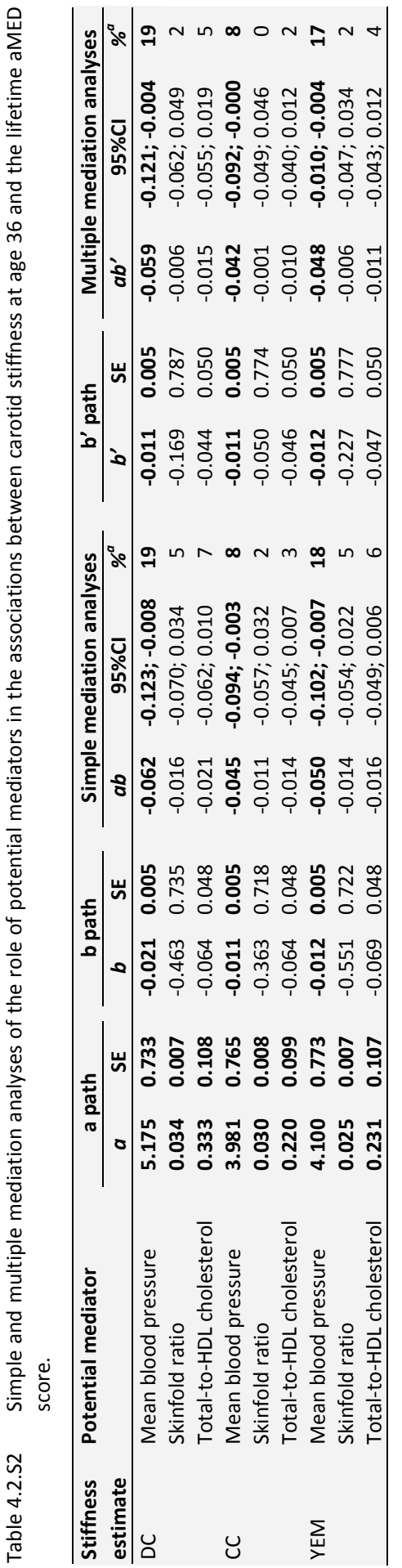

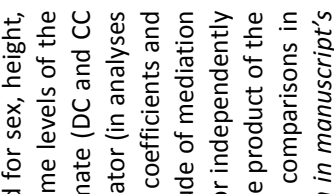

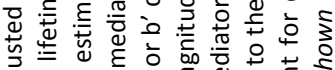
盯.

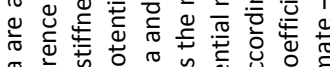

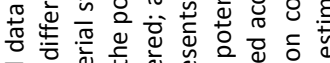

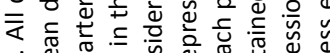

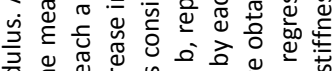

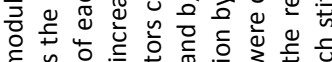

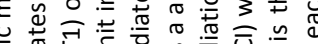

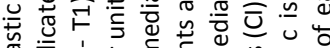

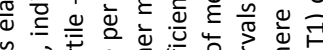

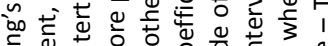

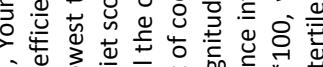

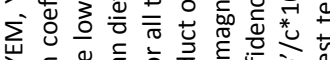
崩 ᄃ

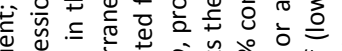

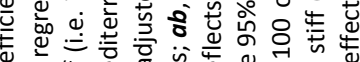

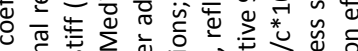

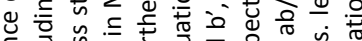

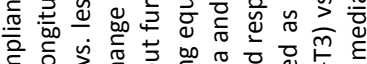

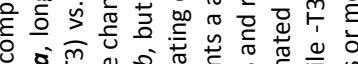
Uั

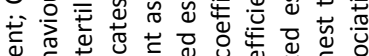

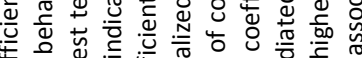
ठํ.

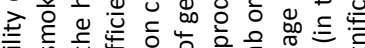

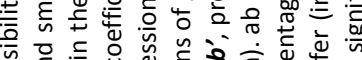

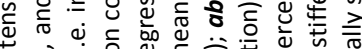

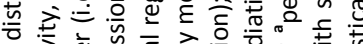

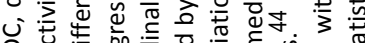

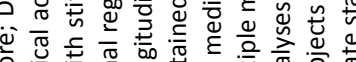

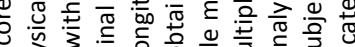

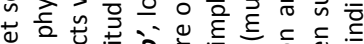

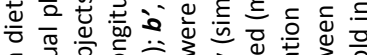

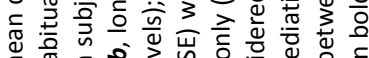
ก

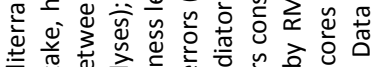

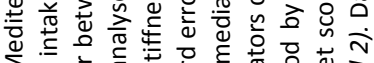

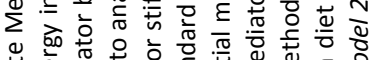

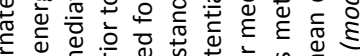

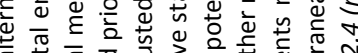

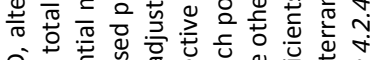

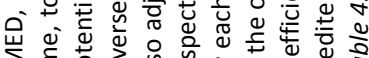

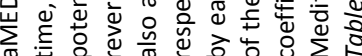




\section{Chapter 5

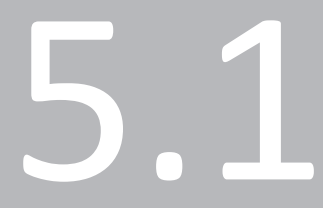

Continuing smoking between adolescence and young adulthood is associated with higher arterial stiffness in young adults The Northern Ireland Young Hearts Project

Roel J.J. van de Laar, Coen D.A. Stehouwer, Colin A. Boreham, Liam M. Murray, Casper G. Schalkwijk, Martin H. Prins, Jos W.R. Twisk, Isabel Ferreira 


\section{ABSTRACT}

\section{Objectives}

To investigate the associations between smoking in adolescence and adulthood, and changes in smoking behaviour between these age periods, with arterial stiffness in young adults; and whether any such associations could be explained by concomitant smoking-related levels of inflammation and endothelial dysfunction.

\section{Methods}

We studied 424 subjects ( 216 females) in whom smoking status was assessed in adolescence (age 15 years) and again in young adulthood (mean age of $22.6 \pm 1.6$ years), along with aortoiliac, aorto-radial, and aorto-dorsalis pedis pulse wave velocity (PWV), and markers of inflammation (i.e. C-reactive protein and fibrinogen) and endothelial dysfunction (i.e. von Willebrand factor and tissue-plasminogen activator antigen) in young adulthood only.

\section{Results}

Smoking in adolescence was associated with higher aorto-iliac PWV, as well as with inflammation and endothelial dysfunction levels (expressed as two scores), independently of other adolescent and adult lifestyles. Compared with never smokers, continuing smokers, but not starters nor quitters, showed higher aorto-iliac PWV, independent of changes in other lifestyle variables: $+0.157 \mathrm{~m} / \mathrm{s}(95 \% \mathrm{Cl}: 0.026$ to 0.288$)$. This difference was attenuated to $0.124 \mathrm{~m} / \mathrm{s}(-0.009$ to 0.257$)$ after adjustment for changes in traditional biological risk factors, but was not materially affected when adjusted for the inflammation and endothelial dysfunction scores, despite the continuing smoking-related higher levels of inflammation and endothelial dysfunction. Smoking was not associated with aorto-radial and aorto-dorsalis pedis PWV.

\section{Conclusions}

Starting to smoke in adolescence and continuing to do so up to young adulthood is adversely associated with aortic stiffness. The continuing smoking-related aortic stiffness was not explained by concomitant higher inflammation and endothelial dysfunction. Prevention of smoking should target the young to prevent arterial stiffness in young adults. 


\section{INTRODUCTION}

Arterial stiffness is a major risk factor for cardiovascular disease and mortality. ${ }^{1}$ Although its complications, such as stroke, left ventricular hypertrophy, and heart failure, usually do not occur before middle or older age, ${ }^{2,3}$ the process of arterial stiffening starts much earlier and is characterized by a preclinical period that may last for many decades. Indeed, changes in the arterial wall structure and function associated with classical cardiovascular risk factors have been observed already in children. ${ }^{4}$ In addition, we, and others, found body fatness, blood pressure and blood lipids in childhood/adolescence to be adversely associated with arterial stiffness in adulthood. ${ }^{5,6}$ These findings emphasize the importance of identifying at a young age lifestyle risk factors associated with arterial stiffness to enable use of more efficient health measures in the early stages of cardiovascular disease development.

Smoking may be one such risk factor, but thus far the studies linking this lifestyle to arterial stiffness have yielded inconsistent findings. ${ }^{7}$ Acute increases in arterial stiffness after smoking one cigarette have been well established in experimental settings. ${ }^{8-10}$ In contrast, although several studies showed regular smoking to be associated with higher arterial stiffness ${ }^{9,11-13}$ and its progression, ${ }^{14}$ others found no differences in carotid, brachial and femoral distensibility, ${ }^{15,16}$ brachial-ankle pulse wave velocity (PWV), ${ }^{17}$ carotid-femoral $\mathrm{PWV}^{18}$ and large artery compliance ${ }^{19}$ between smokers and non-smokers. Some of these inconsistencies might be attributable to the cross-sectional and/or retrospective assessment of smoking behaviour adopted in all these studies. Furthermore, the relative impact on arterial stiffness of starting to smoke in adolescence - a critical period with respect to lifelong smoking addiction ${ }^{20}$ or changing smoking behaviour between adolescence and young adulthood, has not been investigated.

The pathophysiological mechanisms linking smoking to arterial stiffness are not fully elucidated. Low-grade inflammation and endothelial dysfunction ${ }^{21,22}$ may play a role through their impact on the extracellular matrix of the arterial wall, ${ }^{23}$ but the few studies on the interrelations between smoking, arterial stiffness and these potential explanatory factors have yielded contradictory results. ${ }^{13,14,17,18}$ It thus remains unclear whether, and if so, to what extent, these two mechanisms lie in the causal pathway between (changes in) smoking behaviour and arterial stiffness in young adults.

In view of these considerations, we investigated: whether smoking in adolescence and in young adulthood is associated with arterial stiffness, as well as inflammation and endothelial dysfunction, in young adulthood; whether changes in smoking behaviour between adolescence and young adulthood are associated with arterial stiffness in young adulthood; and to what extent any such associations could be explained (i.e. mediated) by smoking-related higher levels of inflammation and/or endothelial dysfunction in young adulthood. 


\section{METHODS}

\section{Subjects and study design}

The Northern Ireland Young Hearts (YH) Project started in 1989/1990 by sampling a 2\% representative group of school children from Northern Ireland aged 12 and 15 years old ( $n=1015$; YH1). ${ }^{24,25}$ In 1992/1993, the original cohort of 12-year-old children was re-examined at the age of 15 years under identical conditions, with complete data on 445 children (YH2). Between 1997 and 1999, all participants, then aged between 20 and 25 years (mean age $22.6 \pm 1.6$ years), were invited to participate in the third phase ( $\mathrm{YH} 3$ ); 489 persons participated (48\% of the original $\mathrm{YH} 1$ population). Compared with drop-outs, these participants were characterized at $\mathrm{YH} 1$ by lower systolic blood pressure and body fatness, and more often belonged to a higher socio-economic class. $^{26}$

Biological and lifestyle variables were ascertained at all three measurement rounds. Arterial stiffness estimates, as well as markers of inflammation and endothelial dysfunction, were assessed during YH3 only. For the present study we used the data from 424 participants ( 216 girls/women) with complete data on arterial stiffness and smoking behaviour, the latter as obtained during $\mathrm{YH} 1$ or $\mathrm{YH} 2$ when participants were 15 years old (i.e. adolescence) and again during YH3 (i.e. young adulthood; Figure 5.1.1). Measurements were performed by trained nurses and research assistants with the use of similar methods throughout the study period, ${ }^{24,25}$ unless otherwise specified. Each participant (or their parents at $\mathrm{YH} 1 / 2$ ) provided written informed consent, and the study was approved by the Research Ethics Committee of Queen's University, Belfast.

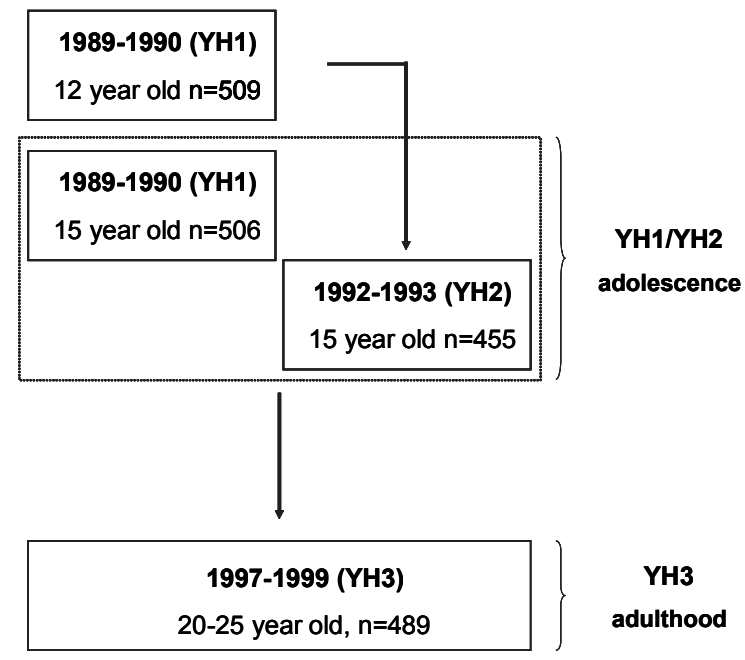

Figure 5.1.1 Study design of the Northern Ireland Young Hearts Project (YH). 


\section{Smoking behaviour}

In adolescence, smoking status and the weekly number of cigarettes smoked were ascertained by means of a confidential 7-day recall questionnaire. In adulthood, a more extensive questionnaire on current and past smoking behaviour was forwarded to participants in advance and was checked for completeness at the research center at the day of their appointment. The number of cigarettes smoked per week was extracted. In both adolescence and adulthood, those who admitted smoking at least one cigarette per week were characterized as being smokers. For the purpose of the present study, we further categorized participants according to their changes in smoking behaviour between the two time-points into four groups: never smokers, starters, quitters, and continuing smokers.

\section{Arterial stiffness}

All participants had refrained from smoking and drinking caffeine-containing beverages on the day the measurements were performed. After participants had been resting in a supine position for 15 minutes in a quiet, temperature-controlled room, a single trained investigator obtained measurements of PWV in three arterial segments (all on the left side of the body) with the use of a non-invasive optical method. ${ }^{25,27,28}$ This method determines the transit time that the wave of dilation takes to arrive at a distal site over a known distance. The transit time measurements (in ms) were performed with a photoplethysmographic probe and were triggered by the R-wave of the electrocardiogram. ${ }^{29}$ This method yields measures of pulse wave transit times closely related to those obtained by Doppler ultrasonography and intra-arterial measurements. ${ }^{29}$ The distances between the sternal notch to the femoral, the radial and the dorsalis pedis arteries were measured with a flexible non-elastic tape measure (to the nearest $0.1 \mathrm{~cm}$ ) and divided by the transit time the pulse wave took to arrive at each of these arterial sites, to determine PWV (in $\mathrm{m} / \mathrm{s}$ ) of the aorto-iliac, aorto-radial and aorto-dorsalis pedis segments, respectively.

In some participants it was not possible to obtain PWV measurements of adequate quality (due to attenuation of the optical signal by subcutaneous fat or difficulty in assessing the artery position); according to the protocol's quality control criteria, measures based on fewer than 10 cycles or those in which the coefficient of variation was greater than $20 \%$ were rejected (specifically, in 31, 25, and 29 out of 489 participants regarding the aorto-iliac, aorto-radial and aorto-dorsalis pedis segments, respectively).

\section{Biomarkers of low-grade inflammation and endothelial dysfunction}

Fasting blood samples were drawn from the antecubital vein. The samples used were citrated plasma stored at $-70^{\circ} \mathrm{C}$ until analyses. Fibrinogen was measured using an automated Clauss assay and C-reactive protein (CRP) by an immunoturbidometric assay (Randox Laboratories Ltd.) on a Cobas Fara analyzer. ${ }^{28}$ Enzyme linked 
immunosorbent assays (ELISAs) were used for measurement of von Willeband factor (vWF; Dako, Copenhagen) ${ }^{30}$ and tissue plasminogen activator antigen (tPA; Biopool). ${ }^{31}$ Levels of CRP under the lower detection limit (i.e. $0.5 \mathrm{mg} / \mathrm{l} ; \mathrm{n}=63$ ) were recoded into $0.25 \mathrm{mg} / \mathrm{l}$. The inter-assay coefficients of variations of control samples for all biomarkers were less than $10 \%$.

Prior to the analyses, inflammation and endothelial dysfunction scores were calculated by averaging the z-scores (i.e. [subjects' values - sample's mean] / sample's standard deviation) of CRP ( $\log _{\mathrm{e}}$-transformed) and fibrinogen, and VWF and TPA, respectively. Complete information on all four markers was obtained in 417 of the YH3 participants, 397 of whom had also complete data on smoking status in both $\mathrm{YH} 1 / 2$ and $\mathrm{YH} 3$.

\section{Covariates}

Other lifestyle (i.e. total energy intake, alcohol consumption and habitual physical activity) and biological (i.e. body height and weight, sitting blood pressure, resting heart rate [YH3 only], blood lipids, cardiorespiratory fitness $\left[\mathrm{VO}_{2} \mathrm{max}\right]$, and insulin resistance [YH3 only; estimated with the use of the homeostasis model assessment HOMA2-IR]) risk factors were measured in adolescence and adulthood as described in detail elsewhere. ${ }^{24,25,27,28,32-34}$ Social class (i.e. manual/non-manual) in adolescence (of the mother) and in adulthood was determined using the 'Standard Occupational Classification'. ${ }^{35}$

\section{Statistical analyses}

All analyses were performed using the Statistical Package of Social Sciences, version 15.0 for Windows (SPSS Inc., Chicago, Illinois, USA). Statistical significance was set at $P$ less than 0.05 .

Linear regression analyses were used to investigate differences in adult PWV, inflammation and endothelial dysfunction scores between smokers and non-smokers in adolescence. These analyses were adjusted for sex and adult age, and also for adult mean arterial pressure (MAP), and body height in analyses with PWV as dependent variable. We additionally adjusted for adolescent and adult, and thus changes in, other lifestyle variables (i.e. alcohol consumption, energy intake, and habitual physical activity) and adolescent social class. Similar analyses were performed for smokers vs. non-smokers in adulthood. Adjustments in these analyses were restricted to adult lifestyles and social class.

Linear regression analyses were also used to investigate differences in adult PWV, inflammation and endothelial dysfunction scores between categories of changes in smoking behaviour, that is, starters, quitters, and continuing smokers (entered into the model as dummy variables) vs. never smokers (reference category). 
Table 5.1.1 Characteristics of 424 study participants in adolescence and young adulthood ${ }^{\mathrm{a}}$.

\begin{tabular}{|c|c|c|}
\hline Variables & Adolescence & Adulthood \\
\hline Sex, male / female & - & $208 / 216(49 / 51)$ \\
\hline Social class, manual / non-manual ${ }^{b}$ & $119 / 190(38.5 / 61.5)$ & $132 / 257(33.9 / 66.1)$ \\
\hline \multicolumn{3}{|l|}{ Lifestyle } \\
\hline Smoking, yes & $74(17.5)$ & 148 (34.9) \\
\hline \multicolumn{3}{|l|}{ Changes in smoking behaviour } \\
\hline Never smokers & - & $261(61.6)$ \\
\hline Starters & - & $89(21.0)$ \\
\hline Quitters & - & $15(3.5)$ \\
\hline Continuing smokers & - & 59 (13.9) \\
\hline Alcohol consumption, yes & $125(29.5)$ & $340(80.2)$ \\
\hline Among drinkers, g/day & $5.5[2.6-11.3]$ & 27.0 [12.3-49.0] \\
\hline Total daily energy intake, $10^{3} \mathrm{kcal}$ & $2.72 \pm 0.85$ & $2.53 \pm 0.91$ \\
\hline Physical activity ${ }^{c}$ & $22.7 \pm 13.8$ & $7.7 \pm 1.3$ \\
\hline \multicolumn{3}{|l|}{ Biological } \\
\hline Weight, kg & $58.1 \pm 9.2$ & $70.0 \pm 13.2$ \\
\hline Height, m & $1.66 \pm 0.08$ & $1.71 \pm 0.09$ \\
\hline Body mass index, $\mathrm{kg} / \mathrm{m}^{2}$ & $22.1 \pm 5.0$ & $23.8 \pm 3.7$ \\
\hline Mean arterial blood pressure, $\mathrm{mmHg}$ & $84.7 \pm 8.9$ & $86.7 \pm 9.5$ \\
\hline Total cholesterol, mmol/l & $4.21 \pm 0.78$ & $4.64 \pm 0.89$ \\
\hline HDL cholesterol, mmol/l & $1.30 \pm 0.28$ & $1.36 \pm 0.36$ \\
\hline Total-to-HDL cholesterol ratio & $3.4 \pm 0.9$ & $3.6 \pm 1.1$ \\
\hline $\mathrm{VO}_{2} \mathrm{max}, \mathrm{mL} / \mathrm{min} / \mathrm{kg}^{\mathrm{FFMd}}$ & $59.4 \pm 6.0$ & $41.6 \pm 9.0$ \\
\hline Resting heart rate, bpm & - & $73.1 \pm 11.5$ \\
\hline HOMA2-IR, arbitrary units & - & $1.3[1.0-1.8]$ \\
\hline \multicolumn{3}{|l|}{ Pulse wave velocity, $\mathrm{m} / \mathrm{s}$} \\
\hline Aorto-iliac segment & - & $3.1 \pm 0.5$ \\
\hline Aorto-radial segment & - & $4.2 \pm 0.5$ \\
\hline Aorto-dorsalis pedis segment & - & $5.0 \pm 0.6$ \\
\hline \multicolumn{3}{|l|}{ Biomarkers $^{e}$} \\
\hline C-reactive protein, $\mathrm{mg} / \mathrm{l}$ & - & $0.9[0.5-2.1]$ \\
\hline Fibrinogen, g/l & - & $2.69 \pm 0.65$ \\
\hline Von Willebrand factor, IU/dl & - & $91.6 \pm 29.7$ \\
\hline Tissue Plasminogen Activator-antigen, $\mathrm{ng} / \mathrm{ml}$ & - & $5.73 \pm 2.31$ \\
\hline
\end{tabular}

Data are presented as mean \pm standard deviation, median [interquartile range], or number (percentage) as appropriate. $\mathrm{HDL}$, high density lipoprotein; $\mathrm{VO}_{2} \mathrm{max}$, maximal oxygen uptake; HOMA2-IR, homeostasis model assessment of insulin resistance. ${ }^{a}$ Number of participants with available data on each of the covariates might differ; ${ }^{b}$ social class of the mother in adolescence; ' scores ranging from 3-15 in adolescence

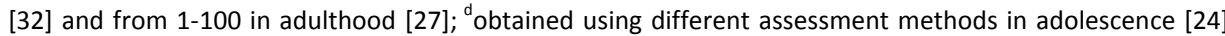
and adulthood [25]; e presented for 397 participants with complete data on smoking behaviour and biomarkers.

These analyses were first adjusted for sex and adult age, and also for adult MAP and body height in analyses with PWV as dependent variable (model 1), and subsequently for the adolescent and adult lifestyle variables and adult social class (model 2). The analyses with PWV as dependent variable were then further adjusted for (changes in) traditional biological risk factors (i.e. MAP, body mass index, total-to$\mathrm{HDL}$ cholesterol ratio, $\mathrm{VO}_{2} \max$, heart rate and HOMA2-IR; model 3), adult levels of inflammation and/or endothelial dysfunction (model $4 A-C$ ), and all of the above (model 5) to ascertain whether these variables could explain any of the differences in 
PWV found between the groups. Any such 'mediating effect' was appraised by comparing the change (in percentage) in the magnitude of the differences in PWV between the smoking categories before and after adjustment for these variables (models 3-5 vs. model 2).

\section{RESULTS}

Characteristics of the study population in adolescence and young adulthood are presented in Table 5.1.1. In adolescence, 74 participants (18\%) smoked, and this proportion increased to 148 participants (35\%) in young adulthood. Fifty-nine participants were categorized as continuing smokers; these represented $14 \%$ of the whole study population and $80 \%$ of those who started to smoke during adolescence.

\section{Adolescent and adult smoking and arterial stiffness, inflammation and endothelial dysfunction}

As compared to non-smokers, and after adjustment for sex and adult age, MAP and body height, adolescent smokers showed higher aorto-iliac PWV in young adulthood: $0.185 \mathrm{~m} / \mathrm{s}(95 \% \mathrm{Cl}: 0.078$ to 0.293$)$. This difference decreased, but remained statistically significant, after further adjustment for changes in other lifestyle variables and social class (to $0.135 \mathrm{~m} / \mathrm{s}$ [0.020 to 0.249]; Figure 5.1.2A, left panel). No such significant differences were found for the aorto-radial and aorto-dorsalis pedis segments, however (Figures 5.1.2B and C). Adolescent smokers also had higher inflammation and endothelial dysfunction scores as compared to non-smokers (Figures 5.1.2D and E).

After adjustment for sex and adult age, MAP, body height, other lifestyle variables and social class, levels of aorto-iliac, aorto-radial and aorto-dorsalis pedis PWV did not differ between adult smokers and non-smokers (Figures 5.1.2A-C, right panels); levels of the inflammation and endothelial dysfunction scores were higher among smokers than non-smokers, however (Figures 5.1.2D and E).

\section{Changes in smoking behaviour, and inflammation, endothelial dysfunction and arterial stiffness}

Continuing smokers, but not starters nor quitters, had higher aorto-iliac PWV than never smokers: $0.213 \mathrm{~m} / \mathrm{s}$ (0.092 to 0.334$)$, adjusted for sex, and adult age, MAP and body height (Table 5.1.2, model 1). This difference decreased to $0.157 \mathrm{~m} / \mathrm{s}(0.026$ to 0.288 ) but remained significant after additional adjustment for changes in other lifestyle variables and adult social class (model 2, Figure 5.1.3A). Levels of aorto-radial and aorto-dorsalis pedis PWV did not differ between the categories of change in smoking behavior (data not shown). 


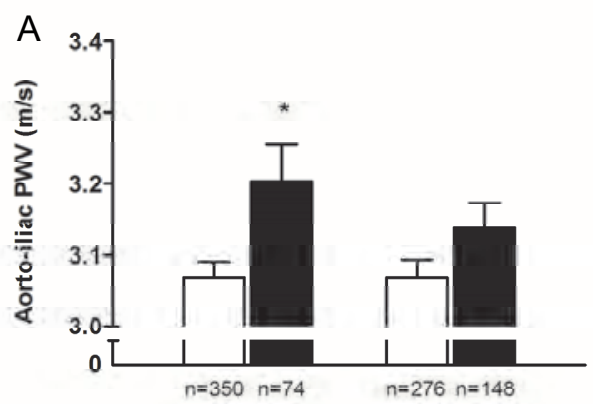

Adolescence Adulthood

\section{B}

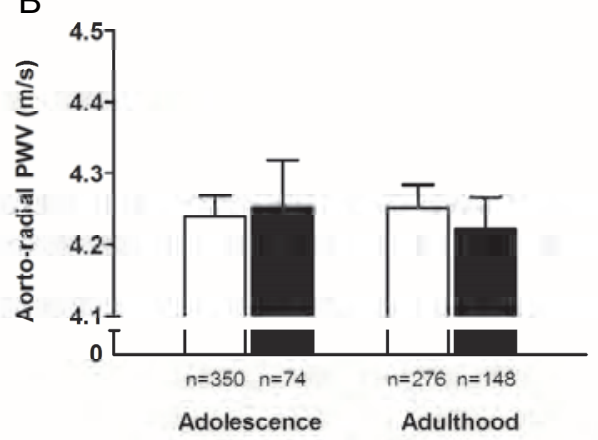

C

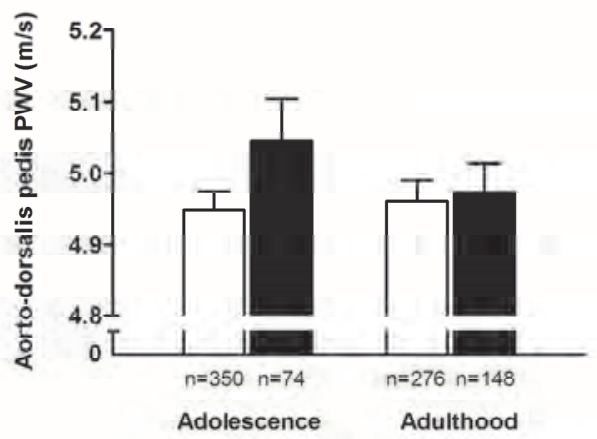

D

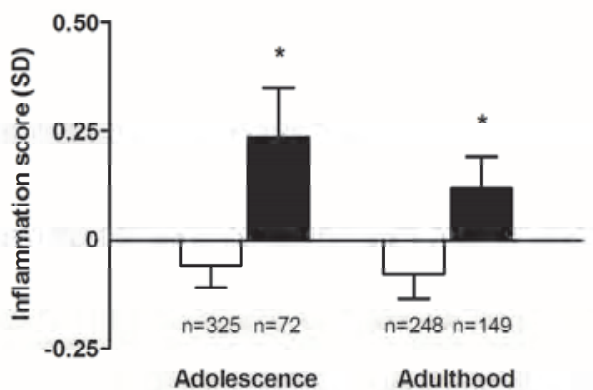

E

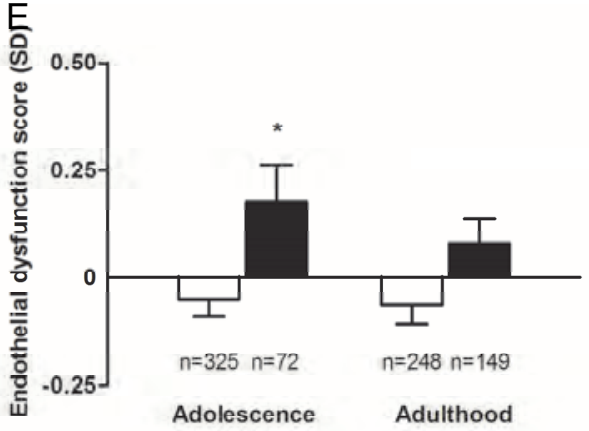

Figure 5.1.2 Mean adult levels of A) aorto-iliac, B) aorto-radial and C) aorto-dorsalis pedis pulse wave velocity $(P W V)^{a}$ and $\left.D\right)$ inflammation and $E$ ) endothelial dysfunction scores ${ }^{b}$ among nonsmokers (white bars) and smokers (black bars) in adolescence and in young adulthood. Data are adjusted for sex, adult age and (changes in) other lifestyle variables (i.e. alcohol consumption, energy intake and habitual physical activity) and social class, and also for adult body height and mean arterial pressure in analyses with PWV as dependent variable. Error bars indicate the standard errors of the means. ${ }^{*} P<0.05$ for comparison with non-smokers. ${ }^{a}$ Analyses in parts A), B) and C) included 424 participants with complete data on smoking and arterial stiffness. ${ }^{b}$ Analyses in parts D) and E) included 397 participants with complete data on smoking and biomarkers. 
Table 5.1.2 Aorto-iliac pulse wave velocity in young adulthood as a function of changes in smoking behaviour between adolescence and young adulthood.

\begin{tabular}{|c|c|c|c|c|c|c|c|}
\hline \multirow[t]{3}{*}{ Model } & \multirow[t]{3}{*}{ Adjustments } & \multicolumn{6}{|c|}{ Smoking categories } \\
\hline & & \multicolumn{2}{|c|}{$\begin{array}{l}\text { Starters } \\
(n=89)\end{array}$} & \multicolumn{2}{|r|}{$\begin{array}{l}\text { Quitters } \\
(n=15)\end{array}$} & \multicolumn{2}{|c|}{$\begin{array}{l}\text { Continuing smokers } \\
\qquad(n=59)\end{array}$} \\
\hline & & $\beta$ & $95 \% \mathrm{Cl}$ & $\beta$ & $95 \% \mathrm{Cl}$ & $\beta$ & $95 \% \mathrm{Cl}$ \\
\hline 1 & $\begin{array}{l}\text { Sex, and adult age, body } \\
\text { height, and MAP }\end{array}$ & 0.000 & $-0.103 ; 0.104$ & 0.076 & $-0.147 ; 0.299$ & 0.213 & $0.092 ; 0.334 \dagger$ \\
\hline 2 & $\begin{array}{l}1+\text { adolescent and adult } \\
\text { lifestyle variables }{ }^{a} \text { and } \\
\text { adult social class }\end{array}$ & -0.024 & $-0.131 ; 0.083$ & 0.025 & $-0.198 ; 0.249$ & 0.157 & $0.026 ; 0.288^{*}$ \\
\hline 3 & $\begin{array}{l}2+\text { adolescent and/or } \\
\text { adult biological variables }\end{array}$ & -0.054 & $-0.160 ; 0.051$ & 0.040 & $-0.181 ; 0.262$ & 0.124 & $-0.009 ; 0.257$ \\
\hline $4 a$ & $2+$ inflammation score & -0.024 & $-0.131 ; 0.084$ & 0.026 & $-0.199 ; 0.250$ & 0.157 & $0.024 ; 0.289 *$ \\
\hline $4 b$ & $\begin{array}{l}2+\text { endothelial } \\
\text { dysfunction score }\end{array}$ & -0.026 & $-0.133 ; 0.081$ & 0.024 & $-0.200 ; 0.248$ & 0.150 & $0.018 ; 0.282^{*}$ \\
\hline $4 c$ & $\begin{array}{l}2+\text { inflammation and } \\
\text { endothelial dysfunction } \\
\text { scores }\end{array}$ & -0.025 & $-0.132 ; 0.083$ & 0.026 & $-0.199 ; 0.251$ & 0.151 & $0.018 ; 0.284^{*}$ \\
\hline 5 & $\begin{array}{l}2+\text { all variables models } 3 \\
\text { and } 4\end{array}$ & -0.058 & $-0.164 ; 0.047$ & 0.040 & $-0.182 ; 0.262$ & 0.113 & $-0.021 ; 0.247$ \\
\hline
\end{tabular}

$\beta$, regression coefficient: indicates the difference in pulse wave velocity in young adulthood (in $\mathrm{m} / \mathrm{s}$ ) between starters, quitters and continuing smokers vs. never smokers (i.e. reference category; $n=261$ ). $M A P$, mean arterial pressure. ${ }^{a}$ Alcohol consumption, energy intake and habitual physical activity; ${ }^{b}$ body mass index, total-to- $\mathrm{HDL}$ cholesterol ratio, $\mathrm{VO}_{2} \mathrm{max}$, (adolescent) MAP, and (adult) resting heart rate and $\mathrm{HOMA2}$ IR. * $\mathrm{P}<0.05$ and $+\mathrm{P}<0.01$.

The difference in aorto-iliac PWV between continuing and never smokers was attenuated by $21 \%$ (i.e. to $0.124 \mathrm{~m} / \mathrm{s}$ [-0.009 to 0.257$]$ ) after further adjustment for (changes in) biological risk factors (model 3), and this was mainly driven by adjustment for changes in cardiorespiratory fitness and adult resting heart rate (i.e. difference was then attenuated to $0.132 \mathrm{~m} / \mathrm{s}$ [0.000 to 0.263 ] and $0.135 \mathrm{~m} / \mathrm{s}$ [0.003 to 0.267], respectively). The difference in aorto-iliac PWV did not materially change after additional adjustment for the inflammation and endothelial dysfunction scores (model 4), despite the higher inflammation and endothelial dysfunction scores in continuing vs. never smokers (Figures 5.1.3B and C, respectively). Adjustment for all the variables simultaneously explained $28 \%$ of the difference in aorto-iliac PWV between continuing smokers vs. never smokers (i.e. from $0.157 \mathrm{~m} / \mathrm{s}$ to $0.113 \mathrm{~m} / \mathrm{s}$; Table 5.1.2, model 5). 

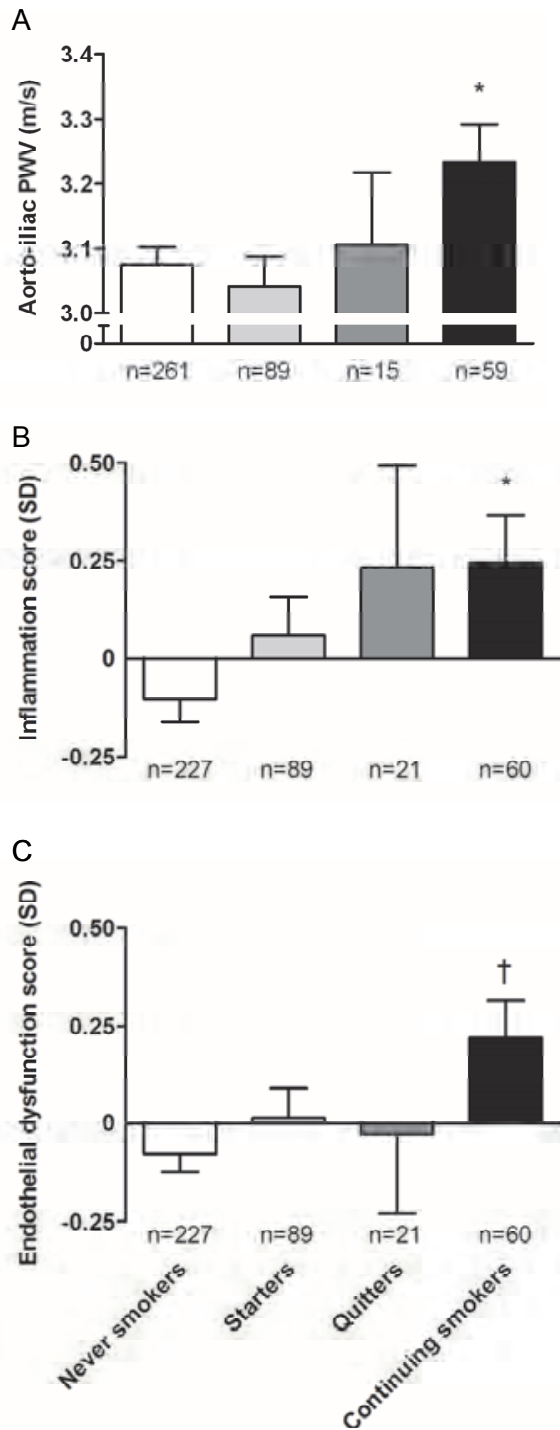

Figure 5.1.3 Mean adult levels of A) aorto-iliac pulse wave velocity (PWV) ${ }^{a}, B$ ) inflammation score ${ }^{b}$ and C) endothelial dysfunction score ${ }^{b}$ of never smokers, starters, quitters and continuing smokers. Data are adjusted for sex, adult age and social class, and changes in other lifestyle variables (i.e. alcohol consumption, energy intake and habitual physical activity), and also for adult body height and mean arterial pressure in analyses with PWV as dependent variable. Error bars indicate the standard errors of the means. ${ }^{*} P<0.05$ and ${ }^{\dagger} P<0.01$ for comparison with never smokers. ${ }^{a}$ Analyses in part A) included 424 participants with complete data on smoking and arterial stiffness. ${ }^{\text {b }}$ Analyses in parts B) and C) included 397 participants with complete data on smoking and biomarkers. 


\section{DISCUSSION}

The main findings of this study are: that smoking in adolescence is associated with greater aorto-iliac PWV, but not aorto-radial or aorto-doralis pedis PWV, as well as with low-grade inflammation and endothelial dysfunction approximately 7 years later in young adulthood; that notably, subjects who started to smoke in adolescence and persisted doing so into young adulthood, but not those who started to smoke in adulthood only, showed greater aorto-iliac PWV in young adulthood; and that the continuing smoking-associated aortic stiffness could, in part, be explained by concomitant continuing smoking-associated adverse (changes in) traditional biological risk factors, in particular by cardiorespiratory fitness and resting heart rate, but not by low-grade inflammation and endothelial dysfunction in young adulthood.

Smoking has previously been shown to be associated with greater levels of arterial stiffness ${ }^{9,11-13}$ and its progression, ${ }^{14}$ but this could not be confirmed by all studies conducted thus far. ${ }^{15-19}$ The small number of participants in some of the negative studies, ${ }^{15,17}$ the variety of stiffness measures assessed, and the cross-sectional and/or retrospective assessment of smoking behaviour may explain these discrepancies. The latter is supported by our current findings showing the lack of a cross-sectional association between smoking and stiffness of the three arterial segments investigated in young adulthood, but unveiling a pattern of greater aortic stiffness particularly in individuals who had started smoking and continued doing so between adolescence and young adulthood. Obtaining prospective and repeated measures of smoking behaviour as adopted in the present study probably yields a more robust characterization of smoking exposure over time. In this line, prospectively obtained pack-years have indeed been shown to be a more accurate measure of lifelong tobacco consumption than pack-years assessed retrospectively. ${ }^{36}$

With this prospective approach we have identified adolescence as a potential critical period in early life during which smoking may lay the foundation for adverse cardiovascular health. Indeed, adolescents who smoked had higher aortic stiffness and inflammation and endothelial dysfunction levels in young adulthood independently of other adolescent and adult lifestyle behaviours. However, since most adolescents who smoked persisted doing so in adulthood (80\%), our findings may have simply reflected the 'effects' of longer smoking duration (captured also by the most adverse profile of the continuing smokers group), rather than the 'effects' of the age at which this behaviour was initiated per se. In other words, it is thus possible that individuals who only started to smoke in young adulthood will also manifest adverse arterial outcomes in the future if they persist smoking. Whether duration of smoking affects arterial stiffness regardless of the starting age and/or starting age per se may have an additional deleterious effect to that of smoking duration needs to be further investigated in studies with lifelong prospective data on both smoking behaviour and arterial stiffness. Nevertheless, this discussion does not diminish the public health implications of our findings, which emphasize the importance of 
smoking prevention measures among the young. The observation that adolescents who smoke are likely to remain doing so in adulthood (vide supra) in fact emphasizes this. This is further supported by previous studies suggesting that adolescents' developing brains are particularly susceptible to nicotine addiction through effects on number of nicotine receptors. ${ }^{20}$ Furthermore, although we observed that among quitters, the levels of aortic stiffness and endothelial dysfunction seemed to have been 'normalized', their levels of inflammation remained elevated and comparable to those of continuing smokers. These latter findings need to be interpreted with caution given the small number of quitters in the present study (explaining the wider confidence intervals around estimates). Yet, they are supported by previous prospective studies among individuals with coronary heart disease showing reductions in all-cause mortality and non-fatal re-infarction relatively soon after smoking cessation, ${ }^{37}$ while CRP and fibrinogen remained significantly elevated 10 to 19 years thereafter. ${ }^{21}$ From a public health point of view, it is therefore of the utmost importance to prevent smoking among the young, as this may be the most effective and efficient strategy for beneficial, long-term health outcomes.

In the present study, smoking-associated greater stiffness was found for the elastic aorta, but not for the predominantly muscular limb arteries. Most studies to date have investigated the impact of smoking on one arterial site or segment only, which thus limits appreciation of whether it could have differential associations along the arterial tree. Our findings, however, are in agreement with the greater aortic and carotid, but not brachial arterial stiffness, as assessed with magnetic resonance imaging, previously reported in otherwise healthy smokers. ${ }^{13}$ Together, these observations suggest that cigarette smoke may exert its detrimental effect mainly on elastin, which is the predominant component in the medial layer of the thoracic aorta. ${ }^{38}$ In addition, these findings might be of clinical relevance as the aorta is what the heart 'sees' during each cardiac contraction, and stiffness of mainly central arteries is predictive of incident cardiovascular disease and mortality among the general population. ${ }^{1-3}$ Although one of these latter studies included apparently healthy adults of 40 years of age, ${ }^{3}$ it still needs to be established whether greater aortic stiffness in even younger adults, such as those of the present study, is similarly associated with cardiovascular risk later in life. Nevertheless, in the course of ageing, young adults with stiffer arteries are not likely to have this reversed unless changes towards healthier behaviours or other interventions are adopted.

The underlying pathobiological mechanisms explaining smoking-related arterial stiffening are complex and remain unclear. Cigarette smoke contains many vasoactive substances of which nicotine and free radicals, but seemingly less so carbon monoxide, are associated with vascular dysfunction; ${ }^{39}$ their impact on the vasculature is thought to occur in part through 'downstream' pathways that were of particular interest in our study, i.e. inflammation and endothelial dysfunction. Indeed, nicotine decreases the bioavailability of nitric oxide, downregulates endothelial nitric oxide synthase, decreases endothelium-dependent vasodilation, and stimulates both 
adhesion of leukocytes in the endothelial layer and the release of catecholamine. ${ }^{40}$ Free-radical-mediated oxidative stress may also explain, to a large extent, smokingrelated endothelial dysfunction, inflammation, increased platelet reactivity and reduced fibrinolysis. ${ }^{39}$ In this study, we could ascertain that a modest part ( $21 \%$ ) of the continuing-smoking-related higher aortic stiffness could be explained by concomitant (changes in) traditional cardiovascular risk factors, most notably cardiorespiratory fitness and resting heart rate, both of which are known determinants of arterial stiffness. ${ }^{27,41}$ In contrast, the continuing smoking-associated greater levels of inflammation and endothelial dysfunction did not materially affect the differences in aortic stiffness as described herein. Similarly, a previous study found that smoking was associated with higher aortic and carotid stiffness, as well as lower brachial flow-mediated dilation (FMD - a functional marker of endothelial dysfunction), whereas no interrelation between stiffness and FMD was observed. ${ }^{13}$ Findings from other studies that also investigated the associations of smoking with measures of both arterial stiffness as well as inflammation or endothelial dysfunction illustrate a mismatch too; for instance, smoking was found to be associated with neither brachial-ankle PWV nor CRP; ${ }^{18}$ adversely associated with brachial FMD, but not with brachial-ankle PWV; ${ }^{17}$ and associated with brachial-ankle PWV progression, but not with increases in CRP. ${ }^{14}$ Altogether, in as much as the markers used in the present and other studies reflect the two mechanisms of interest, we found no evidence for a causal link between smoking-related inflammation and endothelial dysfunction and smoking-related arterial stiffness; instead, these processes seem to co-occur in this young population. Other biomarkers of these and other mechanisms, such as sympathetic activation, ${ }^{42}$ oxidative stress, and production of oxidized LDL $^{39}$ need to be further explored as potential links explaining the smoking-arterial stiffness relationship.

Some limitations of the present study need to be discussed. Firstly, smoking was assessed at two points in time using self-reported data. Although confidential questionnaires were used, this might have led to miss-classification, potentially mainly in adolescence due to 'desirable' denial of smoking behaviour. Indeed, the proportion of adolescents smoking in the current study (i.e. 17.5\%) was lower than the contemporary prevalence previously found among Northern Irish teenagers (i.e. approximately $30 \%) .^{43}$ In addition, individuals' 'true' smoking status between the two measurements, as well as the exact time from starting and quitting smoking in adulthood, was unknown. This may have led to miss-classification when categorizing subjects according to their changes in smoking behaviour, in which case the differences in arterial stiffness between continuing vs. never smokers we have reported were, most likely, underestimated. Secondly, analyses were confined to participants with complete data on smoking on the one hand and arterial stiffness or biomarkers on the other. These individuals tended to be older, have lower daily energy intake, lower habitual physical activity levels in adolescence and lower alcohol intake in adulthood, but their smoking status at both time-points did not significantly 
differ from those excluded from the analyses (data not shown). In addition, sensitivity analyses in a subgroup of participants with complete data on smoking, arterial stiffness and the biomarkers did not affect the results of this study, indicating that our conclusions remain justified. Thirdly, arterial stiffness and biomarkers were measured in adulthood only and thus we could not examine associations between changes in smoking behaviour and concomitant changes in these variables. Nevertheless, we do not think that reverse causation has affected our results, since it is not reasonable to expect that greater levels of theses variables would trigger smoking behaviour. Still, definite conclusions with regard to causality need to be made with caution. Finally, this study was performed in a cohort from Northern Ireland, a region with high mortality from cardiovascular disease, ${ }^{25}$ which might limit extrapolation of our findings to other populations.

In conclusion, we showed that smoking in adolescence and continuing to do so into young adulthood are associated with higher aortic stiffness, low-grade inflammation and endothelial dysfunction in young adulthood. This continuing smoking-related aortic stiffness could not be explained by the higher levels of lowgrade inflammation and endothelial dysfunction, however. Our findings emphasize the importance of targeting smoking among the young in order to prevent the development of arterial stiffness in young adults. 


\section{REFERENCES}

1. Laurent S, Cockcroft J, Van Bortel L, et al. Expert consensus document on arterial stiffness: methodological issues and clinical applications. Eur Heart J. 2006;27:2588-2605.

2. Mattace-Raso FU, van der Cammen TJ, Hofman A, et al. Arterial stiffness and risk of coronary heart disease and stroke: the Rotterdam Study. Circulation. 2006;113:657-663.

3. Willum-Hansen T, Staessen JA, Torp-Pedersen C, et al. Prognostic value of aortic pulse wave velocity as index of arterial stiffness in the general population. Circulation. 2006;113:664-670.

4. Aggoun Y, Szezepanski I, Bonnet D. Noninvasive assessment of arterial stiffness and risk of atherosclerotic events in children. Pediatr Res. 2005;58:173-178.

5. Ferreira I, Twisk JW, van Mechelen W, Kemper HC, Seidell JC, Stehouwer CD. Current and adolescent body fatness and fat distribution: relationships with carotid intima-media thickness and large artery stiffness at the age of 36 years. J Hypertens. 2004;22:145-155.

6. Juonala M, Jarvisalo MJ, Maki-Torkko N, Kahonen M, Viikari JS, Raitakari OT. Risk factors identified in childhood and decreased carotid artery elasticity in adulthood: the Cardiovascular Risk in Young Finns Study. Circulation. 2005;112:1486-1493.

7. Doonan RJ, Hausvater A, Scallan C, Mikhailidis DP, Pilote L, Daskalopoulou SS. The effect of smoking on arterial stiffness. Hypertens Res. 2010;33:398-410.

8. Stefanadis C, Tsiamis E, Vlachopoulos C, et al. Unfavorable effect of smoking on the elastic properties of the human aorta. Circulation. 1997;95:31-38.

9. Mahmud A, Feely J. Effect of smoking on arterial stiffness and pulse pressure amplification. Hypertension. 2003;41:183-187.

10. Failla M, Grappiolo A, Carugo S, Calchera I, Giannattasio C, Mancia G. Effects of cigarette smoking on carotid and radial artery distensibility. J Hypertens. 1997;15:1659-1664.

11. Jatoi NA, Jerrard-Dunne P, Feely J, Mahmud A. Impact of smoking and smoking cessation on arterial stiffness and aortic wave reflection in hypertension. Hypertension. 2007;49:981-985.

12. Liang YL, Shiel LM, Teede H, et al. Effects of Blood Pressure, Smoking, and Their Interaction on Carotid Artery Structure and Function. Hypertension. 2001;37:6-11.

13. Wiesmann F, Petersen SE, Leeson PM, et al. Global impairment of brachial, carotid, and aortic vascular function in young smokers: direct quantification by high-resolution magnetic resonance imaging. J Am Coll Cardiol. 2004;44:2056-2064.

14. Tomiyama $\mathrm{H}$, Hashimoto $\mathrm{H}$, Tanaka $\mathrm{H}$, et al. Continuous smoking and progression of arterial stiffening: a prospective study. J Am Coll Cardiol. 2010;55:1979-1987.

15. Kool MJ, Hoeks AP, Struijker Boudier HA, Reneman RS, Van Bortel LM. Short- and long-term effects of smoking on arterial wall properties in habitual smokers. J Am Coll Cardiol. 1993;22:1881-1886.

16. van der Berkmortel FW, Wollersheim $\mathrm{H}$, van Langam $\mathrm{H}$, de Boo $\mathrm{T}$, Thien $\mathrm{T}$. Dynamic vessel wall properties of large conduit arteries in habitual cigarette smokers. European Journal of Internal Medicine. 1999;10:159-165.

17. Yufu K, Takahashi N, Hara M, Saikawa T, Yoshimatsu H. Measurement of the brachial-ankle pulse wave velocity and flow-mediated dilatation in young, healthy smokers. Hypertens Res. 2007;30: 607-612.

18. Rehill N, Beck CR, Yeo KR, Yeo WW. The effect of chronic tobacco smoking on arterial stiffness. Br J Clin Pharmacol. 2006;61:767-773.

19. Li H, Srinivasan SR, Berenson GS. Comparison of the measures of pulsatile arterial function between asymptomatic younger adult smokers and former smokers: the Bogalusa Heart Study. Am J Hypertens. 2006;19:897-901.

20. Britton J, Edwards R. Tobacco smoking, harm reduction, and nicotine product regulation. Lancet. 2008;371:441-445.

21. Wannamethee SG, Lowe GD, Shaper AG, Rumley A, Lennon L, Whincup PH. Associations between cigarette smoking, pipe/cigar smoking, and smoking cessation, and haemostatic and inflammatory markers for cardiovascular disease. Eur Heart J. 2005;26:1765-1773.

22. Celermajer DS, Sorensen KE, Georgakopoulos D, et al. Cigarette smoking is associated with doserelated and potentially reversible impairment of endothelium-dependent dilation in healthy young adults. Circulation. 1993;88:2149-2155. 
23. Stehouwer CD, Henry RM, Ferreira I. Arterial stiffness in diabetes and the metabolic syndrome: a pathway to cardiovascular disease. Diabetologia. 2008;51:527-539.

24. Boreham C, Savage JM, Primrose D, Cran G, Strain J. Coronary risk factors in schoolchildren. Arch Dis Child. 1993;68:182-186.

25. Gallagher AM, Savage JM, Murray LJ, et al. A longitudinal study through adolescence to adulthood: the Young Hearts Project, Northern Ireland. Public Health. 2002;116:332-340.

26. van Lenthe FJ, Boreham CA, Twisk JW, Savage MJ, Murray L, Smith GD. What determines drop out in prospective studies of coronary heart disease risk factors between youth and young adulthood: the Young Hearts Study. J Epidemiol Community Health. 2001;55:681-682.

27. Boreham CA, Ferreira I, Twisk JW, Gallagher AM, Savage MJ, Murray LJ. Cardiorespiratory fitness, physical activity, and arterial stiffness: the Northern Ireland Young Hearts Project. Hypertension. 2004;44:721-726.

28. Ferreira I, Boreham CA, Twisk JW, et al. Clustering of metabolic syndrome risk factors and arterial stiffness in young adults: the Northern Ireland Young Hearts Project. J Hypertens. 2007;25:1009-1020.

29. Loukogeorgakis S, Dawson R, Phillips N, Martyn CN, Greenwald SE. Validation of a device to measure arterial pulse wave velocity by a photoplethysmographic method. Physiol Meas. 2002;23:581-596.

30. Rumley A, Lowe GD, Sweetnam PM, Yarnell JW, Ford RP. Factor VIII, von Willebrand factor and the risk of major ischaemic heart disease in the Caerphilly Heart Study. Br J Haematol. 1999;105:110-116.

31. Yarnell JW, Sweetnam PM, Rumley A, Lowe GD. Lifestyle and hemostatic risk factors for ischemic heart disease : the Caerphilly Study. Arterioscler Thromb Vasc Biol. 2000;20:271-279.

32. Boreham C, Twisk J, Neville C, Savage M, Murray L, Gallagher A. Associations between physical fitness and activity patterns during adolescence and cardiovascular risk factors in young adulthood: the Northern Ireland Young Hearts Project. Int J Sports Med. 2002;23 Suppl 1:S22-26.

33. Durnin JV, Rahaman MM. The assessment of the amount of fat in the human body from measurements of skinfold thickness. Br J Nutr. 1967;21:681-689.

34. Wallace TM, Levy JC, Matthews DR. Use and abuse of HOMA modeling. Diabetes Care. 2004;27: 1487-1495.

35. Standard Occupational Classification. London: Office of Population Censuses and Surveys; 1990.

36. Bernaards CM, Twisk JW, Snel J, Van Mechelen W, Kemper HC. Is calculating pack-years retrospectively a valid method to estimate life-time tobacco smoking? A comparison between prospectively calculated pack-years and retrospectively calculated pack-years. Addiction. 2001;96:1653-1661.

37. Critchley JA, Capewell S. Mortality risk reduction associated with smoking cessation in patients with coronary heart disease: a systematic review. Jama. 2003;290:86-97.

38. Safar ME, Levy BI, Struijker-Boudier H. Current perspectives on arterial stiffness and pulse pressure in hypertension and cardiovascular diseases. Circulation. 2003;107:2864-2869.

39. Ambrose JA, Barua RS. The pathophysiology of cigarette smoking and cardiovascular disease: an update. J Am Coll Cardiol. 2004;43:1731-1737.

40. Balakumar P, Kaur J. Is nicotine a key player or spectator in the induction and progression of cardiovascular disorders? Pharmacol Res. 2009;60:361-368.

41. McEniery CM, Spratt M, Munnery M, et al. An analysis of prospective risk factors for aortic stiffness in men: 20-year follow-up from the Caerphilly prospective study. Hypertension. 2010;56:36-43.

42. Narkiewicz K, van de Borne PJ, Hausberg M, et al. Cigarette smoking increases sympathetic outflow in humans. Circulation. 1998;98:528-534.

43. Miller PM, Plant M. Drinking, smoking, and illicit drug use among 15 and 16 year olds in the United Kingdom. BMJ. 1996;313:394-397. 


\section{Chapter 6}

General discussion 
Chapter 6 


\section{GENERAL DISCUSSION}

The general aim of this thesis was to investigate the extent to which exposure to lifestyle risk factors in the course of early life, specifically from adolescence to adulthood, may affect arterial stiffness, a determinant of cardiovascular disease, ${ }^{1}$ at young adult age. In addition, we aimed at gaining more insight into the pathobiological mechanisms that may explain the associations of each lifestyle risk factor investigated with arterial stiffness.

In this final chapter we will firstly summarize the main findings of the studies comprised in this thesis. Secondly, we will discuss methodological issues related to the epidemiological studies performed. Thirdly, the potential Public Health implications will be addressed, and finally some directions for future research will be proposed.

\section{MAIN FINDINGS}

\section{Biological risk factors and arterial stiffness}

In Chapter 2 we sought to investigate the life-course trajectories and the cumulative burden of biological risk factors measured from the age of 13 to 36 years, specifically, blood pressure, body fatness and fat distribution, blood lipids, cardiorespiratory fitness, and resting heart rate, in relation to stiffness levels of the carotid artery at the age of 36 years. In brief, as compared to individuals with less stiff arteries, those with stiffer arteries at the age of 36 years were characterized by on average poorer (i.e. unfavourable) levels of each of these risk factors throughout the 24-year study period and this independently of lifestyle behaviours, such as total energy intake, physical activity, smoking behaviour and alcohol consumption. In particular, we showed that the differences in blood pressure and a central pattern of body fat distribution (as reflected by the body skinfolds ratio) were: first, present already in adolescence; second, increased from adolescence into adulthood; and third, preceded and remained independent of the differences observed in the other biological risk factors considered (i.e. blood lipids, cardiorespiratory fitness and resting heart rate). Adding to the evidence available thus far linking these biological risk considered to arterial stiffness, ${ }^{2-7}$ our longitudinal approach to risk factor exposure enabled us to pinpoint adolescence as the period in life during which increases in blood pressure and a central pattern of body fat distribution in particular may determine stiffness levels at adult age. In fact, our findings suggest that increases in blood pressure and central body fatness triggered the development of the other biological risk factors investigated, thereby contributing to arterial stiffness at later age. These findings may have important Public Health implications in the sense that detection of adolescents with higher blood pressure and central fatness and also those who display greater increases in these variables during the period of transition into adulthood, may help 
to identify those at greatest risk of developing cardiovascular disease in the long term and likely to benefit from preventive measures.

Because these key risk factors may be consequences of adverse lifestyle habits and be amenable to lifestyle changes, we carried out the subsequent studies where we investigated, specifically, the extent to which lifelong exposure to physical activity and/or sedentary behaviour, dietary habits and smoking habits could be associated with adult arterial stiffness, at least in part via these biological risk factors. The biological risk factors were, therefore, regarded as potential intermediate factors explaining such associations (Chapters 3-5). ${ }^{8}$

\section{Physical activity of different intensities, sedentary behaviour and arterial stiffness}

Chapter 3 addressed the potential impact of time spent on physical activities of different intensity categories and sedentary behaviour on arterial stiffness. We first investigated the potential associations between, on the one hand, the time spent in light-to-moderate or the time spent in vigorous intensity habitual physical activities (HPAs) performed during adolescence up to adulthood, and, on the other hand, adult levels of stiffness in the central carotid artery (Chapter 3.1) and the peripheral brachial and femoral arteries (Chapter 3.2). In brief, and in line with previous studies (Chapter 1), $7,9-13$ our data suggest that HPA from adolescence up to adulthood may lead to favourable arterial adaptations throughout the arterial tree, and that these could be attributed to vigorous-intensity HPAs in particular. Indeed, as compared to individuals with less stiff carotid arteries, those with stiffer carotid arteries at the age of 36 years had spent on average significantly less time in vigorous-intensity HPAs (i.e. approximately 20-30 minutes per week), independently of the other lifestyle risk factors considered (i.e. total energy intake, smoking behaviour and alcohol consumption). Notably, we were now able to show that these differences were present already in late adolescence (i.e. at age of 15 years), persisted into adulthood (i.e. up to the age of 36 years), and were mediated to a great extent by the vigorousintensity HPA-related longitudinal associations with the traditional biological risk factors investigated in Chapter 2. Qualitatively similar results were obtained for the peripheral brachial and femoral arteries, although the 'favourable' associations were confined to estimates reflecting the arteries' buffering capacity (i.e. compliance) rather than their intrinsic elastic properties (Chapter 3.2).

There is emerging evidence, however, that, in contrast to (vigorous intensity) HPA (e.g. jogging, cycling, aerobics and competitive tennis), sedentary behaviours may form independent determinants of adverse cardiovascular health (Chapter 1). ${ }^{14}$ It must be emphasized that the term sedentary behaviour in this context does not reflect a lack of 'exercise' physical activities, as often mentioned in literature. Instead, it defines those (in)activities that usually involve prolonged sitting and yield low energy expenditure. ${ }^{14,15}$ In Chapter 3.3, we thus specifically sought to investigate to what extent television viewing, a prominent sedentary behaviour in our society, surely 
during the period when computer use was not so widespread as that covered by the Amsterdam Growth and Health Longitudinal Study (AGAHLS), was associated with arterial stiffness among young adults. In addition, we also investigated and whether any such association was qualitatively different (i.e. mediated by different biological risk factors) from those found for (vigorous-intensity) HPA (Chapters 3.1 \& 3.2). Inevitably, this study was confined to adulthood only as, within the framework of the AGAHLS, the daily time spent watching television was assessed at the ages of 32 and 36 years (years 1996 and 2000, respectively) only. In brief, we found that, as compared to individuals with less stiff arteries, those with stiffer carotid and femoral arteries at the age of $\mathbf{3 6}$ years had spent more time watching television at the ages of 32 and 36 years, indicating an unfavourable association between this sedentary behaviour and arterial stiffness. Notably, the associations observed were independent of the concomitant time spent in (vigorous intensity) HPA and the other lifestyle risk factors and seemed to be mediated only slightly, but remained to a great extent independent of, television viewing-related adverse associations with the biological risk factors during the 4-year study period examined. Our findings are in line with an emerging body of evidence showing increased cardiovascular risk attributed to this type of physical (in)activity. ${ }^{14,16-19}$ In addition, these findings support the notion that sedentary behaviour on the one hand, and (vigorous intensity) HPA on the other, are not merely two behaviours on the opposite ends of a single continuum, but rather two types of behaviours that may co-exist, each of which may have opposite effects on arterial stiffness in particular, and cardiovascular health in general, ${ }^{14,20}$ with specific cellular and molecular mechanism explaining their effects. ${ }^{14}$

Of note, in our and many other studies, the time spent in low-intensity physical activities, which include the usual daily activities that are characterized by intensities of $<3$ metabolic equivalents (METs), was not assessed. This might be of particular interest as the time spent in these activities, as compared to vigorous-intensity physical activity, account to a far greater extent for the variation in total daily energy expenditure. Especially in today's modern world, in which there is less need to be physically active, the non-exercise physical activities may increasingly be replaced by sedentary behaviours, thereby forming a great and potentially further growing health burden. In support of this notion a previous study showed that sedentary behaviours were strongly associated with light-intensity activities (i.e. <3 METs), but less so with moderate-vigorous-intensity activities (i.e. $\geq 3 \mathrm{METs}$ ), all ascertained by means of accelerometry. ${ }^{21}$ Whether associations between television time and arterial stiffness are indeed explained by less time spent in such low-intensity physical activities needs to be further investigated.

Altogether these findings may thus have important implications from a primary prevention point of view in the sense that that not only a lack of vigorous-intensity HPA, but also an excess of sedentary behaviours, may form important targets in the prevention of arterial stiffness and cardiovascular health in general. 


\section{Dietary habits and arterial stiffness}

In Chapter 4 we addressed the associations between dietary habits in the period from adolescence up to adulthood and arterial stiffness at adult age. In Chapter 4.1 we showed that, as compared to individuals with less stiff arteries, those with stiffer carotid and, to a lesser extent, femoral arteries at the age of 36 years took consistently less fibre from adolescence up to adulthood, suggesting a favourable influence of fibre intake from adolescence up to young adulthood on arterial stiffness at adult ages. These differences were independent of other lifestyle behaviours, and were corroborated by qualitatively similar differences in the intake of fibre-rich foods (i.e. fruits, vegetables, and whole grains products). Indeed, the magnitude of the difference in fibre intake between stiffness groups was, albeit likely underestimated, rather small (approximately 2 to $3 \mathrm{~g} /$ day, equivalent to the consumption of one apple or banana or half-portion of broccoli or muesli), emphasizing the potential for primary prevention by means of promotion of intake of these foods starting already at young age. Our findings are thus in line with the cardiovascular protective effects attributed to fibre ${ }^{22,23}$ and propose the reduction of arterial stiffening as a potential explanation for some of those. In line with ours, a previous study showed that adults with lower aortic pulse wave velocity were characterized by consistent higher consumption of fruits and vegetables in childhood/adolescence and adulthood. ${ }^{24}$ The trajectory analyses in our study revealed that differences in fibre intake between the stiffness groups were present already at the age of 13 years and remained fairly stable over time, suggesting that prevention strategies should target children at even younger ages. The mediation analyses showed that the favourable associations between lifetime fibre-rich food consumption and adults levels of arterial stiffness could be significantly explained by the fibre portions of these foods. No evidence for a mediating role of the biological risk factors considered (i.e. mean arterial pressure, [central] body fatness, and total-to-HDL cholesterol ratio) were observed, however, given their rather weak associations with fibre intake throughout the longitudinal period. This might, at least in part, be explained by the relatively young and healthy study population examined herein.

In Chapter 4.2, we showed, for the first time, favourable associations between adherence to a Mediterranean dietary pattern, from adolescence to adulthood, and adult arterial stiffness. Specifically, compared to individuals with less stiff arteries, those with stiffer carotid and, though to a lesser extent, brachial and femoral arteries in adulthood were characterized by lower adherence to this type of diet throughout the ages of 13 up to 36 years. Again, the differences between the groups being compared were independent of other lifestyle behaviours and were present already at the age of 13 years. In addition, we also observed that the Mediterranean dietary pattern was associated with favourable levels of the traditional biological risk factors throughout the longitudinal period, mainly blood pressure which was shown to be a significant mediator in the Mediterranean diet-arterial stiffness association. Our findings are in line with previous studies that have shown favourable associations 
between a Mediterranean dietary pattern and blood pressure, ${ }^{25-27}$ body fatness, ${ }^{27,28}$ dyslipidaemia, ${ }^{26,27}$ and insulin resistance, ${ }^{26,27}$ as well as incident cardiovascular disease and mortality, ${ }^{29-33}$ although most of these studies were conducted among middleaged or older populations. We have thus extended these findings to younger ages, which may be critical for the establishment of lifelong dietary habits, hereby emphasizing the role of promotion of a Mediterranean diet in cardiovascular primary prevention.

\section{Smoking and arterial stiffness}

Studies investigating the effects of smoking on arterial stiffness have thus far yielded inconsistent findings. ${ }^{34}$ Inconsistencies from observational studies investigating smoking's long-term or chronic 'effects' could, at least in part, be attributable to the cross-sectional and/or retrospective assessment of smoking behaviour adopted in all these. In addition, to what extent smoking at young age may be linked to higher stiffness levels in adulthood, and whether any such effects may be explained by lowgrade inflammation and/or endothelial dysfunction, ${ }^{35-38}$ remains unclear. In Chapter 5 we therefore investigated the associations of smoking in adolescence and in adulthood, and changes in smoking behaviour between the two time points with arterial stiffness as assessed by regional measures of arterial stiffness (i.e. pulse wave velocity; PWV), and to what extent any such association could be explained by concomitant associations between smoking and biomarkers of inflammation and/or endothelial dysfunction. In brief, we found that smoking in adolescence, as well as continuing smoking between adolescence and adulthood, was associated with greater PWV of the central aorta, but not the peripheral arm and leg arteries. In part, these associations seemed to be explained by smoking-related poorer levels of biological risk factors, mainly so of cardiorespiratory fitness. However, although continuing smoking was also associated with higher levels of inflammation and endothelial dysfunction in adulthood, these did not seem to explain the smoking-arterial stiffness association. Instead, smoking was likely a common antecedent for inflammation and endothelial dysfunction on the one hand and arterial stiffness on the other, while these were not interrelated in this young population. Our findings strengthen the importance of prevention of smoking among the young, as adolescents who engage in this unhealthy behaviour are also more likely to keep doing so in adulthood, leading to quantifiable and clinically relevant vascular (and general) health outcomes.

\section{METHODOLOGICAL CONSIDERATIONS}

\section{External validity}

The studies comprised in this thesis used data from the ongoing Amsterdam Growth and Health Longitudinal Study (AGAHLS) and the Northern Ireland Young Hearts 
Project (NIYHP), two longitudinal studies in which study participants' levels of lifestyle and biological risk factors were repeatedly measured from adolescence up to (young) adulthood and estimates of arterial stiffness were obtained during adulthood only. The AGAHLS started in 1976 by sampling 13-year-old students of two secondary schools in the Amsterdam region in the Netherlands. ${ }^{39}$ Only few of these students had a non-Caucasian ethnicity (i.e. less than $5 \%$ ), and were all characterized by relatively high education levels (i.e. most attended the higher or pre-university Dutch secondary-school education programs during adolescence and finished university or other form of higher education at adult age). In addition, the fact that they have been subject to multiple measurement rounds over a prolonged period of time, could have increased their health awareness leading to changes towards healthier behaviours. Such effects of multiple measurements have been shown to be inexistent or if anything negligible in this cohort, however. ${ }^{40,41}$ Still, the AGAHLS study population is not representative of the general Dutch population in which the prevalence of adverse lifestyle risk factors may be higher.

In contrast, in the NIYHP a sampling procedure was designed to select a representative sample of Northern Irish youngsters, taking into account geographical spread and different categories of school education levels in Northern Ireland. ${ }^{42,43}$ This resulted in the enrolment in 1989-1990 of a representative sample of boys and girls aged 12 and 15 years of Caucasian ethnicity mainly. Northern Ireland, however, is a region with relatively high rates of mortality from cardiovascular disease. ${ }^{43}$ Therefore, generalization of the main findings from the studies comprised in this thesis to populations with other education/social economic status, ethnicities and/or countries, should thus be done with caution.

In addition, the data from the AGAHLS that we have examined were first obtained in the late seventies of the last century up to the year 2000 when measures of arterial stiffness were obtained for the first time. Likewise, the NIYHP covers a longitudinal period that took place during the nineties. This may limit extrapolation of our findings to contemporary populations of adolescents and adults whose prevalence of adverse levels of lifestyle and other risk factors may differ. ${ }^{44}$ Nevertheless, this does not affect the pathobiological validity of our findings. In fact, considering the growing epidemic of sedentarism and obesity, ${ }^{45}$ it emphasizes the need for risk factor monitoring and prevention among the young.

\section{Internal validity}

In general, in observational research three potential sources of error, or bias, may obscure true associations, and thus inference of cause and effect associations. These are selection, information, and confounding bias. ${ }^{46,47}$

In longitudinal studies selection bias often results from drop out of study participants. Previous analyses have shown that selective drop-out has not threaten the AGAHLS which, including its more recent measurement round at the age of 42 years, currently extends over a 30 -year follow-up period. ${ }^{48}$ In the NIYHP participants 
who dropped out tended to belong to lower social-economic. ${ }^{49}$ Our studies were confined to the participants with arterial data during adulthood. We have also examined the extent to which these subjects differed with regard to the key lifestyle as well as biological risk factors at baseline (and each of the subsequent measurement rounds) from those excluded. No such differences in both the AGAHLS and the NIYHP study participants were observed, however, suggesting it is unlikely that selection bias has threatened the validity of our findings.

Information bias results from errors in measuring exposure and outcome variables. First, with respect to the methods adopted to assess arterial stiffness in the AGAHLS (i.e. local arterial stiffness) ${ }^{6}$ and the NIYHP (i.e. regional arterial stiffness), ${ }^{50}$ these have been shown to have been obtained with reasonable to good reliability in previous studies. Second, the lifestyle risk factors investigated in our studies were assessed by means of self-reported data obtained with the use of interviewer-administered questionnaires, which are subject to interviewer, recall and/or misclassification bias. $^{51,52}$ Throughout the years interviewers were trained with standardized and similar study protocols in an attempt to prevent interviewer bias. In addition, missclassification biases were most likely non-differential, because, throughout the years, subjects were unaware of their arterial stiffness levels (obtained at adult age only and of an asymptomatic nature). Still, some differential biases may have occurred, probably by giving social desirable answers, such as reporting of healthier behaviours by those with unhealthier lifestyles/risk factor profiles. Either way, if anything this could have led to an underestimation of the effect sizes reported in our studies. Finally, and specifically with respect to longitudinal cohort studies, information bias may result from period effects. ${ }^{53}$ Therefore, in the AGAHLS assessment of lifestyle and biological variables were performed during the same periods of the year, preventing any bias from certain seasonal influences (e.g. less physical activity during the winter as compared to the summer period) to have occurred. Even though assessment of the lifestyle and biological variables were performed using largely the similar standardized protocols and instruments throughout the years (see above), some differences in assessment throughout the years might have occurred. For instance, within the AGAHLS in the year 2000 computerized versions of the interviewer-administered questionnaires were introduced for the assessment of individuals' physical activity and dietary habits. In comparison with the usual questionnaires, the computerassisted assessments may reduce interviewer bias. ${ }^{54}$ However, it also might have reduced the comparability of the data with previous measurement rounds.

Confounding bias occurs when the effect of a variable of interest is mixed or blurred by that of a third variable (i.e. the actual determinant). ${ }^{46}$ This might result in both over- and underestimation of the true associations. In order to overcome this bias, in the studies comprised in this thesis we adjusted for several potential confounding factors by means of multivariable analyses. We cannot exclude the possibility that some residual confounding may have occurred, however. Of note, multivariable analyses were used also to investigate the mediating roles of biological 
risk factors in lifestyle behaviours-arterial stiffness associations. From a mathematical point of view, adjustment for potential confounders or mediating factors is essentially similar. Indeed, both confounding and mediating variables are associated with the exposure and the outcome. The two differ in the sense that mediating, but not confounding variables, are an intermediate link in the chain of causation between the exposure and outcome. In view of our research questions we have also included adjustments for potential mediators, making a clear a priori distinction between the variables considered as potential confounders and those as potential mediators. Such distinction is not always clear-cut, however, and need to be sustained by knowledge on pathobiology.

For instance, in all analyses conducted we adjusted, by means of multivariate modelling, the differences in the levels of the lifestyles risk factors found between subjects with stiffer vs. less stiff arteries for mean arterial pressure. Indeed, greater total peripheral vascular resistance, effectively reflected by higher levels of mean arterial pressure, especially in subjects younger than 50 years of age, may form an important determinant of arterial stiffness, ${ }^{55}$ something we actually demonstrated in Chapter 2. However, measures of arterial diameter and distension used for the determination of stiffness estimates are highly dependent on de background level of distending pressure (i.e. mean arterial pressure) at which they are obtained. It is therefore that the levels of mean arterial pressure should be taken into account when interpreting study findings. ${ }^{56,57}$ As such, mean arterial pressure, specifically its longitudinal measures from adolescence into adulthood, may act as an intermediate factor in the lifestyle-arterial stiffness associations, whereas mean arterial pressure during the ultrasound measurements could, in part, be a confounding factor as well. As both measures of blood pressure obtained within individuals are highly correlated, it is difficult to disentangle these two roles, and the adjustments for mean arterial pressure should thus be interpreted at the light of these considerations.

\section{Arterial stiffness as a clinical relevant outcome}

Stiffness of mainly central (i.e. elastic) arterial sites and segments have been shown to be associated with incident cardiovascular events and cardiovascular and/or all-cause mortality (see also Chapter 1). Most of this evidence derives from studies examining aortic PWV (Chapter 5) as a determinant of cardiovascular disease (reviewed in ${ }^{58,59}$ ). Similar evidence for local carotid stiffness is less straightforward, however. Recently, the ARIC study showed that greater carotid stiffness was associated with increased risk of incident stroke, but not coronary heart disease, among a large sample of middle-aged individuals free from prior CVD. ${ }^{60}$ Notably, these associations were independent of other cardiovascular risk factors. Other studies also found carotid stiffness to be associated with incident CVD and/or mortality among patients with end-stage renal disease, ${ }^{61}$ those who had received a renal transplant, ${ }^{62}$ elderly individuals with and without prior CVD, ${ }^{63}$ and patients with manifest CVD, but with normal systolic blood pressure. ${ }^{64}$ These findings were not corroborated by some other 
studies, however. ${ }^{65-67}$ The inconsistencies, at least in part, may be explained by differences in 1) sample size and duration of follow-up period; 2) devices and techniques used to process ultrasound signals; 3) use of brachial vs. local pulse pressure in the calculation of stiffness estimates; 4) the local arterial stiffness estimates and outcomes considered; and 5) characteristics of the study populations (e.g. old vs. middle aged, diseased vs. apparently healthy). Furthermore, the fact that, compared with aortic PWV, relatively few studies support the predictive value of local arterial stiffness might in part also be simply explained by the relatively lower number of studies investigating local estimates of arterial stiffness in epidemiological cohorts. This thus leads to a certain degree of publication bias. Indeed, compared with ultrasonography and dedicated imaging or wall-track systems software, measurements of PWV with the widely available commercial devices (e.g. Sphygmocor, Complior, etc.) are easier to perform as they require less technical/observer skills, time and have quality control inbuilt into the systems.

The extent to which stiffness estimates of muscular segments or sites predict incident CVD is actually largely unknown. So far, this has been investigated in one study only, where stiffness of central but not peripheral arterial segments was an independent predictor of death in a cohort of haemodialysis patients. ${ }^{68}$ Clearly, the literature may also be biased with the predictive value of femoral stiffness as the vast majority of cohort studies that have included in their designs estimates of arterial stiffness often confine these to one artery or segment only (most often the carotid or the aorta). Still, peripheral arterial stiffness may be clinically relevant as it has been shown to be closely associated with prevalent peripheral arterial disease, ${ }^{69,70}$ which is also a clinically important cardiovascular outcome. In addition, stiffened conduit arteries may contribute, indirectly, to increased cardiovascular risk to an extra-load imposed to the heart via earlier return of the pulse wave travelling through the arterial tree.

\section{Longitudinal data analyses approach to lifestyle risk factor exposure}

The studies described in this thesis investigated the extent to which lifelong exposure to biological and lifestyle risk factors from adolescence up to adulthood were associated with different levels of arterial stiffness in adulthood. By imposition of the AGAHLS study design, where measures of risk factors were measured repeatedly at the mean ages of $13,14,15,16,21,27,32$ and 36 years whereas arterial stiffness had been assessed at the age of 36 only, we used generalized estimating equations (GEE) to compare the mean levels and the trajectories of the risk factors throughout (part of) the 24-year longitudinal period between subjects with low (referent group), intermediate and higher levels of arterial stiffness (defined on the basis of sex-specific tertiles of each arterial stiffness estimate) (Chapters 2-4). These groups comprised subjects with distinct and potentially clinically relevant arterial phenotypes as the mean levels of the stiffness estimates in T1 and T3 were equivalent to those observed in populations that differ in approximately one decade of aging. ${ }^{71}$ In the GEE models, 
the risk factors of interest were thus considered as time-dependent outcome variables whereas the arterial stiffness groups were considered as a time-independent or fixed independent variable. ${ }^{53}$ The latter is an obvious simplification imposed by the study design (arterial data obtained at the age of 36 years only) as clearly, in the course of time, arterial stiffness will vary. In addition, conceptually the (lifestyle) risk factor is the true determinant of (subsequent) arterial stiffness. In practice our models thus answered a retrospective kind of research question - that is, to what extent did the levels of risk factors of subjects with different levels of arterial stiffness in adulthood (age 36 years) differ during the 24 preceding years? - without suffering from the limitations of retrospective study designs and by making efficient use of all risk factor exposure data that were obtained prospectively throughout the years (Figure 6.1).

\section{Calendar age}

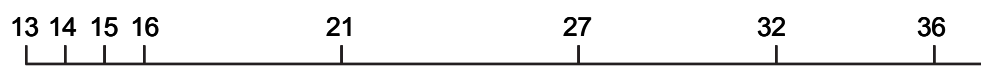

Lifestyle and biological variables

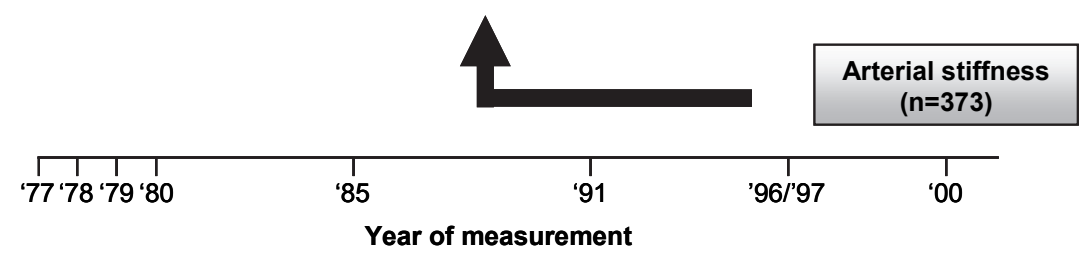

Figure 6.1 Data analyses approach used in studies conducted within the Amsterdam Growth and Health Longitudinal Study (Chapters 2-4).

In essence, the results obtained with this approach enable the same conclusions as those one could have obtained with the use of conventional linear regression or logistic analyses, but these methods would have required 8 repeated set of analyses, with lifestyle risk factors at each time point (and confined to the exact $\mathrm{n}$ with data at that time) as determinant of arterial stiffness at the age of 36 years, or, alternatively, reduction of carefully obtained longitudinal data into a 'cross-sectional' variable (e.g. the mean values, [mean] changes over time or an area under the curve) that would be used as a determinant of arterial stiffness levels. This approach suffices as a valid way of summarizing repeated risk exposure data if the dependent variable is measured at two points in time only (see for instance Chapter 5). However, GEE (Chapters 2-4) offers additional advantages over linear regression: 1) it enables the use of all data from study participants with varying numbers of observations throughout the whole longitudinal study period, properly accounting for the inter-dependence of repeated observations obtained in the same individuals; 2) it allows trajectory analyses 
(through modeling of interactions with time), that can be easily displayed graphically thereby enabling the identification of critical periods in the course of early life during which risk factors may start to differ and thus determine arterial stiffness at adult age; and 3) the results hereby obtained may more directly translate into public health meaningful messages as it expresses the exact difference in (mean) levels of the lifestyle risk factor of interest over the whole period or at each specific age (see trajectories); that is, "individuals with stiffer arteries (equivalent to those observed in the course of one decade of arterial ageing) spend, on average, less $32 \mathrm{~min} /$ week in vigorous intensity HPAs than those with less stiff arteries" instead of a "per each one more min/day spent in vigorous-intensity HPAs the Young's elastic modulus is $0.810^{-3} \mathrm{kPA}$ lower".

\section{PUBLIC HEALTH IMPLICATIONS}

Our studies add to a large body of evidence indicating that lifestyle behaviours, such as physical activity, dietary intake, and smoking behaviour, impact on cardiovascular health (as outlined in Chapter 1). The longitudinal assessment and analytical approach adopted in the investigation of lifestyle risk factors exposure allowed us specifically to identify adolescence and transition into adulthood as important periods in life during which lifestyle habits, at least in part, may determine arterial stiffness at adult age.

Many evidence support the importance of the adolescence-adulthood window with respect to cardiovascular health. ${ }^{72}$ First, as summarized above, poorer levels of lifestyle behaviours in individuals with higher arterial stiffness in adulthood were observed already in adolescence. Second, we observed, throughout the period from adolescence to adulthood, longitudinal associations of adverse levels of the lifestyle risk factors (i.e. [vigorous intensity] HPA, fibre intake, and adherence to a Mediterranean dietary pattern) with poorer levels of (some of the) biological risk factors considered (e.g. mean arterial pressure, (central) body fatness cholesterol, cardiopulmonary fitness. Each of these are known determinants of CVD and mortality, and form (therapeutic) targets in current cardiovascular risk management guidelines. $^{73}$ In fact, our studies suggest that lifestyle behaviours underlie, at least in part, the development of these risk factors already at young age, which in turn may trigger (i.e. mediate) the development of arterial stiffness at a later age. Third, adolescence is a period in life during which individuals become increasingly independent and lifelong unhealthy behaviours may then be already established. Indeed, lifestyle habits may track over time; that is, an individual with a poorer rank of a certain lifestyle will be more likely to have a poorer rank of the same variable at a later point of time too. ${ }^{74-76}$ Finally, the adolescents we have investigated are today's parents of children and adolescents at risk of engaging in risky health behaviours. Given their shared environment, at least in part, prevention of unhealthy lifestyles among the young may also disrupt any 'intergenerational' chains of risk with 
additional health potential in the long term. All in all, our data reinforce the importance of preventive programs among the young.

Two approaches towards prevention of cardiovascular disease may be considered. $^{73}$ A population level strategy aiming at reducing cardiovascular risk through lifestyle and environmental changes targeted at the population at large, or a high-risk population approach, where preventive measures are aimed at reducing risk factor levels in those at highest risk of developing disease. Even though in this strategy the individuals involved are more likely to benefit from the preventive interventions, the impact on the population level is limited. We feel that lifestyle prevention programs may be most effective when targeted at the population at large. Our findings indicate that relatively small changes in vigorous intensity HPA, television viewing, and dietary intake may translate into clinically meaningful differences in arterial stiffness (equivalent to approximately one decade of accelerated arterial ageing). At the population level, this might translate into decreases in the occurrence of chronic, disabling, and thus costly, cardiovascular diseases, which in times of the international financial crisis may form a useful approach to regulate the increasing health costs in the long term. More research on the cost-effectiveness of such approaches is thus warranted.

The success of prevention strategies at a population level might be hampered by the generally asymptomatic character of higher levels of arterial stiffness, as well as poorer levels of the biological risk factors, among young and generally healthy individuals, such as those included in our studies. Therefore, comprehensive health programs carrying out easy-to-grasp formulated health messages may be most likely effective. This requires an articulated involvement of actors at different levels: the micro level, that is, children/adolescents and their parents, which need to be (made) aware of the importance and acquire the tools for committing themselves to healthier behaviours; the meso level, for instance schools and employers, which may encourage students/employees to consume healthy foods and being physical activity, and health care providers, such as general practitioners who often have contact and thus the opportunity to detect and advice youngsters and their families with regard to necessary lifestyle changes (lifestyle as a 'drug' to be added to the prescription pad); and the macro level, that is, government and industry, which by adapting legislation and altering their marketing policies may alter consumers' behaviour.

The studies presented in this thesis indicate that each of the risk factors considered form potential separate targets for preventive health programs. To what extent targeting healthy lifestyles as a whole, rather than each separately, is more effective in reducing arterial stiffness, and cardiovascular health in general, deserves further investigation. Nevertheless, targets should be tailored to individuals' needs, and therefore either single or combination(s) of changes in various lifestyle factors may be needed. 


\section{FUTURE DIRECTIONS}

The observational studies presented in this thesis form convincing evidence for showing temporal associations between lifestyle behaviours and arterial stiffness. Indeed, extensive characterization of study participants' lifestyle and biological risk factor characteristics preceded that of their arterial properties, which thus allowed us to investigate long term exposure to lifestyle risk factors in relation to arterial stiffness at adult age. Nevertheless, our studies are limited by the fact that levels of arterial stiffness, as well as inflammation and endothelial dysfunction as included in Chapter 5 , were obtained in one point in time only. This thus limits making inferences regarding causality. Ideally larger longitudinal studies starting from (or even before) birth up to adulthood and in which participants lifestyle, biological, as well as arterial characteristics are repeatedly characterized over time can enable the investigation of the true longitudinal inter-relations between each of these risk factors and arterial adaptations. These may enable us to yield further insight into the early determinants of vascular changes and underlying pathobiological mechanisms. Such studies take a life-long to be conducted, however. The arterial data obtained in the most recent measurement round of the AGAHLS, in the year 2006, when participants' mean age was 42 years ${ }^{48}$ may enable further insights into these (early) vascular changes and their determinants. Indeed, some recent studies on these data have shown that: increases in subjects' central fat mass and decreases in peripheral fat mass, observed during the course of 6-years (between the ages of 36 and 42 years) were associated with accelerated arterial stiffening; ${ }^{3}$ a persistent and an incident positive metabolic syndrome status (i.e. clustering of elevated levels of central adiposity, blood pressure, glucose levels and dyslipidaemia) were associated maladaptive arterial remodelling and greater arterial stiffening; ${ }^{77}$ and biomarkers of low-grade inflammation and endothelial dysfunction were associated with greater levels of arterial stiffness throughout the 6-year follow-up period. ${ }^{78}$ Unfortunately, due to time and resources constraints dietary habits were only minimally assessed in the 2006 measurement round. On the other hand, in this last round physical activity and sedentary behaviours were measured more objectively by means of accelerometry. ${ }^{79}$ These changes in methods do not enable full comparability with the lifestyle data from previous years; in addition, these data only became available after the studies described in this studies had been conducted reason why we have not examined these data further.

Even though in our studies we intended to obtain more insight into the mechanisms linking lifestyle behaviours to arterial stiffness, future research should focus on obtaining more extensive knowledge on the mechanisms or mediators. Multiple mediation data analyses techniques, ${ }^{80-82}$ as performed in Chapters 4.1 \& 4.2, may form an important means to ascertain and tease apart the contribution of potential mediators (i.e. $M_{1}, M_{2}, M_{3}, \ldots, M_{n}$ ) of the associations between lifestyle and arterial stiffness (or in fact between any known risk factor and health outcome of interest). These can help in a better understanding of the pathophysiology at the molecular/cellular level, the details of which thus far are derived from basic research 
mainly, often carried out in animal models, and therefore do not always directly translate to humans. Several putative mechanism, such as insulin resistance, adipokines, oxidative stress, advanced glycation, and/or lipoxidation products, lowgrade inflammation and endothelial dysfunction, all of which are intertwined, have been proposed as potential explanatory mechanisms. ${ }^{83-85}$ However, evidence thus far is scattered, providing only fragmented insight on a myriad of pieces of an intricate 'puzzle'. No integrated view sustained by empirical data in large population-based studies is available, however.

In the studies described in this thesis, long-term exposure to each of the lifestyle risk factors were examined separately and adjusted for each other in order to ascertain their 'independent' associations with arterial stiffness. This dissection was thus done deliberately at the light of a lack of (consistent) information on the associations between long-term exposure to each of the lifestyle risk factors considered and adult arterial stiffness. This approach also enabled us to identify specific pathways that could link each of the lifestyle risk factors investigated to adult arterial stiffness. However, it might be of interest to identify subjects' lifestyle profile in a more comprehensive fashion for instance by means of a clustered lifestyle risk

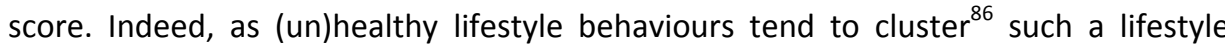
score may better capture the overall health effects of individuals lifestyle behaviour. In addition, such approach could be less prone to confounding bias, and could capture potential interacting effects of the different lifestyle behaviours.

Finally, and ideally, our study findings should be sustained by future large scaled clinical trials among, but not only confined, to the young, testing the effectiveness of relatively small and possibly integrated changes in lifestyle behaviours (e.g. increases in about $1 / 2$ an hour per week in vigorous intensity HPA, limit television time up to 2 hours per day, increase one piece or portion of fruit or vegetables intake or alter diet as a whole towards a more Mediterranean-like pattern) lead to clinically relevant beneficial changes in arterial stiffness. Such intervention studies can also be designed as to enable collection of data on the potential mediators so that more insight into the underlying pathophysiology can be obtained. Also, the targeted populations should be followed in the long-term to ascertain the extent to which any such lifestyle-related beneficial changes in arterial stiffness result in less hard cardiovascular outcomes. 


\section{REFERENCES}

1. Safar ME, O'Rourke MF, eds. Arterial Stiffness in Hypertension. Amsterdam: Elsevier; 2006. Birkenhäger WH, Reid JL, eds. Handbook of Hypertension; No. 23.

2. Ferreira I, Twisk JW, van Mechelen W, Kemper HC, Seidell JC, Stehouwer CD. Current and adolescent body fatness and fat distribution: relationships with carotid intima-media thickness and large artery stiffness at the age of 36 years. J Hypertens. 2004;22:145-155.

3. Schouten F, Twisk JW, de Boer MR, et al. Increases in central fat mass and decreases in peripheral fat mass are associated with accelerated arterial stiffening in healthy adults: the Amsterdam Growth and Health Longitudinal Study. Am J Clin Nutr. 2011;94:40-48.

4. Aggoun $Y$, Bonnet $D$, Sidi D, et al. Arterial mechanical changes in children with familial hypercholesterolemia. Arterioscler Thromb Vasc Biol. 2000;20:2070-2075.

5. Leeson $\mathrm{CP}$, Whincup $\mathrm{PH}$, Cook DG, et al. Cholesterol and arterial distensibility in the first decade of life: a population-based study. Circulation. 2000;101:1533-1538.

6. Ferreira I, Twisk JW, Van Mechelen W, Kemper HC, Stehouwer CD. Current and adolescent levels of cardiopulmonary fitness are related to large artery properties at age 36: the Amsterdam Growth and Health Longitudinal Study. Eur J Clin Invest. 2002;32:723-731.

7. Boreham CA, Ferreira I, Twisk JW, Gallagher AM, Savage MJ, Murray L. Cardiorespiratory fitness, physical activity, and arterial stiffness: the Northern Ireland Young Hearts Project. Hypertension. 2004;44:721-726.

8. Mozaffarian D, Wilson PW, Kannel WB. Beyond established and novel risk factors: lifestyle risk factors for cardiovascular disease. Circulation. 2008;117:3031-3038.

9. Schmidt-Trucksass AS, Grathwohl D, Frey I, et al. Relation of leisure-time physical activity to structural and functional arterial properties of the common carotid artery in male subjects. Atherosclerosis. 1999;145:107-114.

10. Tanaka H, Dinenno FA, Monahan KD, Clevenger CM, DeSouza CA, Seals DR. Aging, habitual exercise, and dynamic arterial compliance. Circulation. 2000;102:1270-1275.

11. Kozakova M, Palombo C, Mhamdi L, et al. Habitual physical activity and vascular aging in a young to middle-age population at low cardiovascular risk. Stroke. 2007;38:2549-2555.

12. Cameron JD, Dart AM. Exercise training increases total systemic arterial compliance in humans. Am J Physiol. 1994;266:H693-701.

13. Kakiyama T, Sugawara J, Murakami H, Maeda S, Kuno S, Matsuda M. Effects of short-term endurance training on aortic distensibility in young males. Med Sci Sports Exerc. 2005;37:267-271.

14. Hamilton MT, Hamilton DG, Zderic TW. Role of low energy expenditure and sitting in obesity, metabolic syndrome, type 2 diabetes, and cardiovascular disease. Diabetes. 2007;56:2655-2667.

15. Norton K, Norton L, Sadgrove D. Position statement on physical activity and exercise intensity terminology. J Sci Med Sport. 13:496-502.

16. Dunstan DW, Barr EL, Healy GN, et al. Television viewing time and mortality: the Australian Diabetes, Obesity and Lifestyle Study (AusDiab). Circulation. 2010;121:384-391.

17. Dunstan DW, Salmon J, Owen N, et al. Associations of TV viewing and physical activity with the metabolic syndrome in Australian adults. Diabetologia. 2005;48:2254-2261.

18. Hu FB, Li TY, Colditz GA, Willett WC, Manson JE. Television watching and other sedentary behaviors in relation to risk of obesity and type 2 diabetes mellitus in women. Jama. 2003;289:1785-1791.

19. Jakes RW, Day NE, Khaw KT, et al. Television viewing and low participation in vigorous recreation are independently associated with obesity and markers of cardiovascular disease risk: EPIC-Norfolk population-based study. Eur J Clin Nutr. 2003;57:1089-1096.

20. Biddle SJ. Sedentary behavior. Am J Prev Med. 2007;33:502-504.

21. Healy GN, Wijndaele K, Dunstan DW, et al. Objectively measured sedentary time, physical activity, and metabolic risk: the Australian Diabetes, Obesity and Lifestyle Study (AusDiab). Diabetes Care. 2008;31:369-371.

22. Anderson JW, Baird P, Davis RH, Jr., et al. Health benefits of dietary fiber. Nutr Rev. 2009;67:188-205.

23. Slavin JL. Position of the American Dietetic Association: health implications of dietary fiber. J Am Diet Assoc. 2008;108:1716-1731. 
24. Aatola $\mathrm{H}$, Koivistoinen $\mathrm{T}$, Hutri-Kahonen $\mathrm{N}$, et al. Lifetime fruit and vegetable consumption and arterial pulse wave velocity in adulthood: the Cardiovascular Risk in Young Finns Study. Circulation. 2010; 122:2521-2528.

25. Psaltopoulou T, Naska A, Orfanos P, Trichopoulos D, Mountokalakis T, Trichopoulou A. Olive oil, the Mediterranean diet, and arterial blood pressure: the Greek European Prospective Investigation into Cancer and Nutrition (EPIC) study. Am J Clin Nutr. 2004;80:1012-1018.

26. Estruch R, Martinez-Gonzalez MA, Corella D, et al. Effects of a Mediterranean-style diet on cardiovascular risk factors: a randomized trial. Ann Intern Med. 2006;145:1-11.

27. Nordmann AJ, Suter-Zimmermann K, Bucher HC, et al. Meta-analysis comparing mediterranean to low-fat diets for modification of cardiovascular risk factors. Am J Med. 2011;124:841-851 e842.

28. Romaguera D, Norat $T$, Vergnaud AC, et al. Mediterranean dietary patterns and prospective weight change in participants of the EPIC-PANACEA project. Am J Clin Nutr. 2010;92:912-921.

29. Fung TT, Rexrode KM, Mantzoros CS, Manson JE, Willett WC, Hu FB. Mediterranean diet and incidence of and mortality from coronary heart disease and stroke in women. Circulation. 2009; 119: 1093-1100.

30. Knoops KT, de Groot LC, Kromhout D, et al. Mediterranean diet, lifestyle factors, and 10-year mortality in elderly European men and women: the HALE project. JAMA. 2004;292:1433-1439.

31. Trichopoulou A, Costacou T, Bamia C, Trichopoulos D. Adherence to a Mediterranean diet and survival in a Greek population. N Engl J Med. 2003;348:2599-2608.

32. Trichopoulou A, Orfanos P, Norat T, et al. Modified Mediterranean diet and survival: EPIC-elderly prospective cohort study. BMJ. 2005;330:991.

33. van den Brandt PA. The impact of a Mediterranean diet and healthy lifestyle on premature mortality in men and women. Am J Clin Nutr. 2011;94:913-920.

34. Doonan RJ, Hausvater A, Scallan C, Mikhailidis DP, Pilote L, Daskalopoulou SS. The effect of smoking on arterial stiffness. Hypertens Res. 2010;33:398-410.

35. Rehill N, Beck CR, Yeo KR, Yeo WW. The effect of chronic tobacco smoking on arterial stiffness. Br J Clin Pharmacol. 2006;61:767-773.

36. Tomiyama $\mathrm{H}$, Hashimoto $\mathrm{H}$, Tanaka $\mathrm{H}$, et al. Continuous smoking and progression of arterial stiffening: a prospective study. J Am Coll Cardiol. 2010;55:1979-1987.

37. Wiesmann F, Petersen SE, Leeson PM, et al. Global impairment of brachial, carotid, and aortic vascular function in young smokers: direct quantification by high-resolution magnetic resonance imaging. J Am Coll Cardiol. 2004;44:2056-2064.

38. Yufu K, Takahashi N, Hara M, Saikawa T, Yoshimatsu H. Measurement of the brachial-ankle pulse wave velocity and flow-mediated dilatation in young, healthy smokers. Hypertens Res. 2007;30: 607-612.

39. Kemper HC. Amsterdam Growth and Health Longitudinal study (AGAHLS). A 23-year follow-up from teenager to adult about lifestyle and health. Basel: Karger; 2004.

40. de Vente W, Post GB, Twisk JW, Kemper HC, van Mechelen W. Effects of health measurements and health information in youth and young adulthood in dietary intake--20-y study results from the Amsterdam Growth and Health Longitudinal Study. Eur J Clin Nutr. 2001;55:819-823.

41. Kemper HC, Verhagen EA, Milo D, et al. Effects of health information in youth on adult physical activity: 20-year study results from the Amsterdam growth and health longitudinal study. Am J Hum Biol. 2002;14:448-456.

42. Boreham C, Savage JM, Primrose D, Cran G, Strain J. Coronary risk factors in schoolchildren. Arch Dis Child. 1993;68:182-186.

43. Gallagher AM, Savage JM, Murray LJ, et al. A longitudinal study through adolescence to adulthood: the Young Hearts Project, Northern Ireland. Public Health. 2002;116:332-340.

44. Watkins D, McCarron P, Murray L, et al. Trends in blood pressure over 10 years in adolescents: analyses of cross sectional surveys in the Northern Ireland Young Hearts project. BMJ. 2004;329:139.

45. Manson JE, Skerrett PJ, Greenland P, Vanltallie TB. The escalating pandemics of obesity and sedentary lifestyle. A call to action for clinicians. Arch Intern Med. 2004;164:249-258.

46. Grimes DA, Schulz KF. Bias and causal associations in observational research. Lancet. 2002;359: 248-252.

47. Rothman KJ. Epidemiology: an introduction. 1st ed. New York: Oxford University Press; 2002. 
48. Wijnstok NJ, Hoekstra T, van Mechelen W, Kemper HC, Twisk JW. Cohort profile: The Amsterdam Growth and Health Longitudinal Study. Int J Epidemiol. In press.

49. van Lenthe FJ, Boreham CA, Twisk JW, Savage MJ, Murray L, Smith GD. What determines drop out in prospective studies of coronary heart disease risk factors between youth and young adulthood: the Young Hearts Study. J Epidemiol Community Health. 2001;55:681-682.

50. Loukogeorgakis S, Dawson R, Phillips N, Martyn CN, Greenwald SE. Validation of a device to measure arterial pulse wave velocity by a photoplethysmographic method. Physiol Meas. 2002;23:581-596.

51. Ferrari P, Friedenreich C, Matthews CE. The role of measurement error in estimating levels of physical activity. Am J Epidemiol. 2007;166:832-840.

52. Macdiarmid J, Blundell J. Assessing dietary intake: Who, what and why of under-reporting. Nutr Res Rev. 1998;11:231-253.

53. Twisk JWR. Applied Longitudinal Data Analysis for Epidemiolgy: A Practical Guide. Cambridge: Cambridge University Press; 2003.

54. Bakker I, Twisk JW, van Mechelen W, Mensink GB, Kemper HC. Computerization of a dietary history interview in a running cohort; evaluation within the Amsterdam Growth and Health Longitudinal Study. Eur J Clin Nutr. 2003;57:394-404.

55. Izzo JL, Jr. Arterial stiffness and the systolic hypertension syndrome. Curr Opin Cardiol. 2004;19:341352.

56. McEniery CM, Wilkinson IB, Avolio AP. Age, hypertension and arterial function. Clin Exp Pharmacol Physiol. 2007;34:665-671.

57. Oliver JJ, Webb DJ. Noninvasive assessment of arterial stiffness and risk of atherosclerotic events. Arterioscler Thromb Vasc Biol. 2003;23:554-566.

58. Laurent S, Cockcroft J, Van Bortel L, et al. Expert consensus document on arterial stiffness: methodological issues and clinical applications. Eur Heart J. 2006;27:2588-2605.

59. Vlachopoulos C, Aznaouridis K, Stefanadis C. Prediction of cardiovascular events and all-cause mortality with arterial stiffness: a systematic review and meta-analysis. J Am Coll Cardiol. 2010; 55:1318-1327.

60. Yang EY, Chambless L, Sharrett AR, et al. Carotid Arterial Wall Characteristics Are Associated With Incident Ischemic Stroke But Not Coronary Heart Disease in the Atherosclerosis Risk in Communities (ARIC) Study. Stroke. 2012;43:103-108.

61. Blacher J, Guerin AP, Pannier B, Marchais SJ, London GM. Arterial calcifications, arterial stiffness, and cardiovascular risk in end-stage renal disease. Hypertension. 2001;38:938-942.

62. Barenbrock M, Kosch M, Joster E, Kisters K, Rahn KH, Hausberg M. Reduced arterial distensibility is a predictor of cardiovascular disease in patients after renal transplantation. J Hypertens. 2002;20:79-84.

63. Stork S, van den Beld AW, von Schacky C, et al. Carotid artery plaque burden, stiffness, and mortality risk in elderly men: a prospective, population-based cohort study. Circulation. 2004;110:344-348.

64. Dijk JM, Algra A, van der Graaf Y, Grobbee DE, Bots ML. Carotid stiffness and the risk of new vascular events in patients with manifest cardiovascular disease. The SMART study. Eur Heart J. 2005;26: 1213-1220.

65. Leone N, Ducimetiere P, Gariepy J, et al. Distension of the carotid artery and risk of coronary events: the three-city study. Arterioscler Thromb Vasc Biol. 2008;28:1392-1397.

66. Mattace-Raso FU, van der Cammen TJ, Hofman A, et al. Arterial stiffness and risk of coronary heart disease and stroke: the Rotterdam Study. Circulation. 2006;113:657-663.

67. van Dijk RA, Dekker JM, Nijpels G, Heine RJ, Bouter LM, Stehouwer CD. Brachial artery pulse pressure and common carotid artery diameter: mutually independent associations with mortality in subjects with a recent history of impaired glucose tolerance. Eur J Clin Invest. 2001;31:756-763.

68. Pannier B, Guerin AP, Marchais SJ, Safar ME, London GM. Stiffness of capacitive and conduit arteries: prognostic significance for end-stage renal disease patients. Hypertension. 2005;45:592-596.

69. Kizu A, Koyama H, Tanaka S, et al. Arterial wall stiffness is associated with peripheral circulation in patients with type 2 diabetes. Atherosclerosis. 2003;170:87-91.

70. Taniwaki H, Shoji T, Emoto M, et al. Femoral artery wall thickness and stiffness in evaluation of peripheral vascular disease in type 2 diabetes mellitus. Atherosclerosis. 2001;158:207-214.

71. Vermeersch SJ, Rietzschel ER, De Buyzere ML, et al. Age and gender related patterns in carotidfemoral PWV and carotid and femoral stiffness in a large healthy, middle-aged population. $J$ Hypertens. 2008;26:1411-1419. 
72. Lawlor DA, Chaturvedi N. Treatment and prevention of obesity--are there critical periods for intervention? Int J Epidemiol. 2006;35:3-9.

73. Perk J, De Backer G, Gohlke H, et al. European Guidelines on cardiovascular disease prevention in clinical practice (version 2012): The Fifth Joint Task Force of the European Society of Cardiology and Other Societies on Cardiovascular Disease Prevention in Clinical Practice (constituted by representatives of nine societies and by invited experts) * Developed with the special contribution of the European Association for Cardiovascular Prevention \& Rehabilitation (EACPR). Eur Heart J. 2012; 33:1635-1701.

74. Kelder SH, Perry CL, Klepp KI, Lytle LL. Longitudinal tracking of adolescent smoking, physical activity, and food choice behaviors. Am J Public Health. 1994;84:1121-1126.

75. Lake AA, Adamson AJ, Craigie AM, Rugg-Gunn AJ, Mathers JC. Tracking of dietary intake and factors associated with dietary change from early adolescence to adulthood: the ASH30 study. Obes Facts. 2009;2:157-165.

76. te Velde SJ, Twisk JW, Brug J. Tracking of fruit and vegetable consumption from adolescence into adulthood and its longitudinal association with overweight. Br J Nutr. 2007;98:431-438.

77. Ferreira I, Beijers HJ, Schouten F, Smulders YM, Twisk JW, Stehouwer CD. Clustering of metabolic syndrome traits is associated with maladaptive carotid remodeling and stiffening: a 6-year longitudinal study. Hypertension. 2012;60:542-549.

78. van Bussel BC, Schouten F, Henry RM, et al. Endothelial dysfunction and low-grade inflammation are associated with greater arterial stiffness over a 6-year period. Hypertension. 58:588-595.

79. Uijtdewilligen L, Singh AS, Twisk JW, Koppes LL, van Mechelen W, Chinapaw MJ. Adolescent predictors of objectively measured physical activity and sedentary behaviour at age 42: the Amsterdam Growth and Health Longitudinal Study (AGAHLS). Int J Behav Nutr Phys Act. 8:107.

80. Lockwood CM, DeFrancesco CA, Elliot DL, Beresford SA, Toobert DJ. Mediation analyses: applications in nutrition research and reading the literature. J Am Diet Assoc. 2010;110:753-762.

81. MacKinnon DP, Fairchild AJ, Fritz MS. Mediation analysis. Annu Rev Psychol. 2007;58:593-614.

82. Preacher KJ, Hayes AF. Asymptotic and resampling strategies for assessing and comparing indirect effects in multiple mediator models. Behav Res Methods. 2008;40:879-891.

83. Stehouwer CD, Henry RM, Ferreira I. Arterial stiffness in diabetes and the metabolic syndrome: a pathway to cardiovascular disease. Diabetologia. 2008;51:527-539.

84. Tsioufis C, Dimitriadis K, Selima M, et al. Low-grade inflammation and hypoadiponectinaemia have an additive detrimental effect on aortic stiffness in essential hypertensive patients. Eur Heart J. 2007;28: 1162-1169.

85. Safar ME, Czernichow S, Blacher J. Obesity, arterial stiffness, and cardiovascular risk. J Am Soc Nephrol. 2006;17 Suppl 2:S109-111.

86. de Vries $\mathrm{H}$, van 't Riet J, Spigt $\mathrm{M}$, et al. Clusters of lifestyle behaviors: results from the Dutch SMILE study. Prev Med. 2008;46:203-208. 
Samenvatting 


\section{SAMENVATTING}

Cardiovasculaire ziekten vormen een belangrijk gezondheidsprobleem in onze maatschappij. In 2008 stierven wereldwijd ongeveer 17.3 miljoen personen aan cardiovasculaire ziekten, zoals myocardinfarct, cerebrovasculaire accidenten en plotse hartdood. Dit komt overeen met circa een derde van de totale mortaliteit. In 2010 stierven in Nederland ongeveer 39000 personen (29\%) aan cardiovasculaire ziekten. Deze vormden de tweede meest voorkomende doodsoorzaak na kanker.

Hoewel bovengenoemde cardiovasculaire ziekten zich over het algemeen pas voordoen vanaf het vijftigste levensjaar, bestaat er steeds meer bewijs dat de processen die hieraan ten grondslag liggen veel eerder beginnen en gekenmerkt worden door een preklinische periode die enkele tientallen jaren kan duren.

Recentelijke technologische ontwikkelingen hebben het mogelijk gemaakt om deze processen in de subklinische fase te meten, dat wil zeggen als een uiteindelijke ziekte, zoals een myocardinfarct, zich nog niet daadwerkelijk heeft voorgedaan. Arteriële stijfheid, of in andere woorden verminderde elasticiteit van de slagaders, kan inderdaad leiden tot cardiovasculaire ziekten door bij te dragen aan systolische hypertensie, linker ventrikel hypertrofie en verminderde coronaire perfusie. Het meten van zulke surrogaat uitkomstmaten voor cardiovasculaire ziekten maken het mogelijk om: 1) personen met een hoog risico op ontwikkeling van cardiovasculaire ziekten al vroeg te identificeren (dus voor predictie onderzoeksvragen); en 2) de rol van risicofactoren in de vroege fasen van het ziekteproces te onderzoeken (dus voor etiologische onderzoeksvragen; zie dit boekje).

Leefstijlrisicofactoren vormen wellicht de meest fundamentele risicofactoren voor het ontwikkelen van cardiovasculaire ziekten. Er bestaat reeds overweldigend bewijs dat leefstijlrisicofactoren de traditionele biologische risicofactoren, zoals hypertensie, obesitas en dyslipidemie, negatief beïnvloeden, welke vervolgens kunnen bijdragen aan de ontwikkeling van cardiovasculaire ziekten. In welke mate leefstijlrisicofactoren al op jongere leeftijd, en meer specifiek het verloop van zulke risicofactoren van jonge tot volwassen leeftijd, een rol spelen bij de ontwikkeling van arteriële stijfheid blijft grotendeels onduidelijk.

Dit proefschrift bestaat uit een aantal epidemiologische studies die de invloed van leefstijl risicofactoren, specifiek in de periode van adolescentie tot en met volwassenheid, op de mate van arteriële stijfheid op volwassen leeftijd onderzoeken. Voor deze studies hebben we gebruik gemaakt van twee cohortstudies, namelijk de Amsterdam Growth and Health Longitudinal Study (Hoofdstuk 2-4) en de Northern Ireland Young Hearts Project (Hoofdstuk 5). Deze twee studies, alsook het begrip arteriële stijfheid, worden in Hoofdstuk 1 nader geïntroduceerd. Hierna worden de belangrijkste resultaten samengevat. 


\section{Biologische risicofactoren en arteriële stijfheid}

Hoofdstuk 2 beschrijft de longitudinale associaties tussen biologische risicofactoren, in het bijzonder bloeddruk, lichaamsgewicht en vetverdeling, lipiden, cardiorespiratoire fitheid en hartfrequentie, gemeten van leeftijd 13 tot en met 36 jaar in relatie tot arteriële stijfheid op het niveau van de halsslagader op 36 jarige leeftijd. Kort samengevat observeerden we dat, vergeleken met individuen met minder arteriële stijfheid (d.w.z. in het meest gunstige tertiel), personen met stijvere arteriën op 36jarige leeftijd (d.w.z. in het middelste en meest ongustige tertiel) gekarakteriseerd worden door gemiddeld ongunstigere waarden (bijv. hogere bloeddruk, maar lagere cardiorespiratoire fitheid) van elk van deze risicofactoren in de 24-jarige studieperiode, onafhankelijk van leefstijlrisicofactoren. Specifiek tonen we dat de verschillen in bloeddruk en een centrale vetverdeling tussen mensen met hogere vs. lagere arteriële stijfheid op 36-jarige leeftijd: 1) reeds aanwezig zijn in adolescentie; 2) groter worden in de periode van adolescentie naar volwassenheid; en 3) voorafgaan aan, en onafhankelijk zijn van, de verschillen waargenomen in de andere biologische risicofactoren, te weten lipiden, cardiorespiratoire fitness en hartslag. Deze data dragen bij aan het reeds beschikbare bewijs welke een associatie tussen biologische risicofactoren en arteriële stijfheid ondersteunt. Het longitudinale studie design maakt het mogelijk om adolescentie te identificeren als een periode waarin bloeddruk en centraal overgewicht reeds in belangrijke mate bijdragen aan arteriële stijfheid op volwassen leeftijd. Tevens suggereren onze data dat bloeddruk en centraal overgewicht kunnen bijdragen aan de ontwikkeling van andere biologische risicofactoren, zoals dyslipidemie en verminderde cardiorespiratoire fitheid, in de loop van het leven, ieder welke zelf arteriële stijfheid ook kunnen beïnvloeden.

Biologische risicofactoren kunnen in belangrijke mate het gevolg zijn van ongezonde leefstijlgewoonten. Enige associaties tussen leefstijlrisicofactoren tussen adolescentie en volwassenheid, en arteriële stijfheid op volwassen leeftijd kunnen dus, ten minste ten dele, worden verklaard via de biologische risicofactoren onderzocht in Hoofdstuk 2. Derhalve worden deze in de overige hoofdstukken als potentiële mediatoren gebruikt.

\section{Fysieke activiteit, sedentair gedrag en arteriële stijfheid}

In Hoofdstuk 3 bestuderen we de mogelijke impact van de tijd besteedt aan lichamelijke activiteiten van verschillende intensiteiten en sedentair gedrag op arteriële stijfheid. Ten eerste hebben we de associaties onderzocht tussen, enerzijds, de tijd in fysieke activiteit van licht tot matige en van hoge intensiteit uitgevoerd van adolescentie tot en met volwassenheid, en, anderzijds, de mate van arteriële stijfheid van de centrale hals- (Hoofdstuk 3.1), en de perifere arm- en liesslagaders (Hoofdstuk 3.2) op volwassen leeftijd. Samengevat tonen we dat fysieke activiteit uitgevoerd van adolescentie tot en met volwassenheid geassocieerd is met gunstige adaptaties van de arteriële vaatboom, en dat deze toe kunnen worden toegeschreven aan fysieke 
activiteit van een hoge intensiteit in het bijzonder. Inderdaad, vergeleken met personen met minder stijve halsslagaders hebben personen met stijvere halsslagaders op 36-jarige leeftijd gemiddeld meer tijd gespendeerd (ongeveer 20-30 minuten per week) aan fysieke activiteit van een hoge intensiteit in de voorgaande 24 jaar, en dit onafhankelijk van andere leefstijlrisicofactoren (d.w.z., totale energie-inname, rookgedrag en alcoholgebruik). Daarnaast tonen we dat deze verschillen reeds aanwezig zijn in adolescentie (d.w.z. op de leeftijd van 15 jaar), redelijk constant bleven tot in volwassenheid (d.w.z. tot de leeftijd van 36 jaar), en voor een groot deel verklaard (ofwel gemediëerd) werden door de gelijktijdige gunstige associaties van fysieke activiteit van een hoge intensiteit met de traditionele biologische risicofactoren welke onderzocht werden in Hoofdstuk 2. Kwalitatief vergelijkbare resultaten worden beschreven in Hoofdstuk 3.2 voor de perifere arm- en liesslagaders, hoewel deze gunstige associaties beperkt blijven tot de buffercapaciteit van deze vaten (d.w.z. compliance) en niet zozeer hun intrinsieke elasticiteit (d.w.z. distensibiliteit).

In tegenstelling tot (sportieve) fysieke activiteit, zoals joggen, fietsen, aerobics en tennis, bestaat er echter steeds meer bewijs dat sedentaire gedragingen, ofwel 'activiteiten' waarbij in principe veel wordt gezeten en welke tot beperkte energieverbranding leiden, een negatieve invloed hebben op cardiovasculaire gezondheid (zoals ook beschreven in Hoofdstuk 1). In het verlengde hiervan hebben we in Hoofdstuk 3.3 specifiek onderzocht of televisiekijken, de meest voorkomende sedentaire gedraging, geassocieerd is met arteriële stijfheid op volwassen leeftijd, en of zulke associatie onafhankelijk is van die eerder gevonden voor fysieke activiteit van een hoge intensiteit (Hoofdstuk 3.1 \& 3.2). Hiervoor hebben we dezelfde aanpak gebruikt als hiervoor beschreven, echter is de tijd gespendeerd aan televisiekijken in de Amsterdam Growth and Health Longitudinal Study enkel op de leeftijd van 32 en 36 jaar gemeten in respectievelijk 1996 en 2000 (en dus niet gedurende de gehele studieperiode van 13 tot en met 36 jaar). Samengevat vonden we dat, vergeleken met individuen met minder stijve slagaders, zij met stijvere hals- en liesslagaders op 36jarige leeftijd gemiddeld meer televisie hebben gekeken (circa 20 minuten per dag) op de leeftijd van 32 en 36 jaar, wat dus een ongustige associatie suggereert tussen televisiekijken en arteriële stijfheid. Specifiek waren de gevonden associaties onafhankelijk van de tijd gespendeerd in fysieke activiteit van een hoge intensiteit, en leken ze slecht ten dele gemediëerd te worden door, maar bleven in hoge mate onafhankelijk van, televisiekijken gerelateerde associaties met de biologische risicofactoren tijdens de 4-jarige studieperiode. Onze bevindingen ondersteunen de theorie dat sedentair gedrag enerzijds en fysieke activiteit (van een hoge intensiteit) anderzijds niet slechts elkaars tegenovergestelde zijn van één continuüm, maar twee typen gedragingen die naast elkaar bestaan, en elk tegengestelde effecten op arteriële stijfheid hebben in het bijzonder en cardiovasculaire gezondheid in het algemeen. 
Samengevat en vanuit het perspectief van primaire preventie tonen onze data dus dat niet enkel een gebrek aan fysieke activiteit van een hoge intensiteit, maar ook een overmaat aan sedentaire gedragingen moet worden vermeden om arteriële stijfheid en mogelijk cardiovasculaire ziekten in het algemeen te doen voorkomen.

\section{Voedingsgewoonten en arteriële stijfheid}

Hoofdstuk 4 beschrijft de longitudinale associaties tussen voedingsgewoonten van adolscentie tot en met volwassenheid en arteriële stijfheid op volwassenleeftijd. Specifiek hebben we ons gericht op het eten van vezels en vezelrijke producten (hoofdstuk 4.1) en het Mediterrane dieet (Hoofdstuk 4.2), waarvan bekend is dat deze een gunstig effect hebben op cardiovasculaire gezondheid.

In Hoofdstuk 4.1 tonen we dat, vergeleken met individuen met minder stijve slagaders, zij met stijvere halsslagaders en, in minder mate, liesslagaders op 36-jarige leeftijd gemiddeld minder vezels hebben ingenomen in de voorgaande 24-jarige periode. Deze verschillen waren onafhankelijk van andere leefstijlrisicofactoren, en werden bevestigd door kwalitatief vergelijkbare verschillen in de inname van vezelrijke voedingsmiddelen (d.w.z. fruit, groenten en volgranen producten). Het verschil in inname in vezels tussen mensen met 'stijvere' vs. 'minder stijve' slagaders bedroeg circa 2 tot 3 gram per dag, wat overeenkomt met de consumptie van een appel of banaan, of een half portie van broccoli of muesli. De longitudinale trajectanalyses tonen dat de verschillen in vezelinname tussen de groepen reeds aanwezig waren op 13-jarige leeftijd en hierna vrij stabiel bleven in de tijd. Samengevat suggereren deze dat redelijke beperkte toenames in vezelinname van adolescentie tot en met volwassenheid minder arteriële stijfheid kunnen bewerkstelligen op volwassen leeftijd, en dat preventiemaatregelen zich reeds moeten richten op kinderen van jonge leeftijd.

In Hoofdstuk 4.2 bestuderen we de invloed van het Mediterrane dieet van adolescentie tot en met volwassenheid op arteriële stijfheid op volwassen leeftijd. Om dit te onderzoeken werd voor iedere persoon en op ieder meetmoment een Mediterrane dieet score berekend gebaseerd op de verschillende componenten die dit dieet karakteriseren: d.w.z. groenten, fruit, volgranen, noten, peulvruchten, vis, rood vlees, olijfolie en alcohol. Vergeleken met personen met minder stijve slagaders, hielden zij met stijvere halsslagaders, en in mindere mate lies- en armslagaders, op 36-jarige leeftijd zich minder goed aan het Mediterrane dieetpatroon in de 24-jarige studieperiode. Ook nu toonden we dat verschillen tussen de groepen die werden vergeleken reeds op 13-jarige leeftijd aanwezig waren, en dat het Mediterrane dieetpatroon ook gunstig geassocieerd is met traditionele biologische risicofactoren, met name bloeddruk, gedurende de 24-jarige studieperiode. Bloeddruk bleek ook een significante mediator in de associatie tussen het Mediterraans dieet en arteriële stijfheid. 


\section{Roken en arteriële stijfheid}

In Hoofdstuk 5 onderzochten we in welke mate roken in adolescentie en in volwassenheid, en veranderingen in rookgedrag gedurende deze periode, van invloed zijn op arteriële stijfheid op volwassen leeftijd, en of zulke associaties verklaard kunnen worden door inflammatie en/of endotheeldysfunctie. We tonen dat roken in adolescentie en persisterend roken tussen adolescentie en volwassenheid geassocieerd zijn met hogere arteriële stijfheid, nu gemeten als pulse wave velocity, van de centrale aorta, maar niet de slagaders in armen en benen. Voor een deel worden deze associaties verklaard door roken gerelateerde associaties met biologische risicofactoren, met name cardiorespiratoire fitheid. Hoewel aanhoudend roken tussen adolescentie en volwassenheid ook in verband gebracht met een hoger niveau van inflammatie en endotheeldysfunctie, lijken deze twee mechanismen niet verklarend in jong volwassenen. In plaats daarvan lijkt roken een gemeenschappelijke antecedent voor ontsteking en endotheleeldysfunctie enerzijds en arteriële stijfheid anderzijds, maar zijn deze onderling niet gerelateerd in deze jonge populatie.

In Hoofdstuk 6 worden de belangrijkste bevindingen van dit proefschrift samengevat en bediscussieerd. Diverse methodologische kanttekeningen worden hierbij geplaatst. In het kort ondersteunen onze studies de gedachte dat leefstijlrisicofactoren een belangrijke rol spelen bij de ontwikkeling van cardiovasculaire ziekten (zie Hoofdstuk 1). Onze longitudinale aanpak maakt het mogelijk om aan te tonen dat adolescentie en de overgang naar volwassenheid belangrijke perioden zijn waarin leefgewoonten, tenminste ten dele, arteriële stijfheid bepalen op volwassen leeftijd. 
Dankwoord 


\section{DANKWOORD}

De totstandkoming van dit boekje zou niet mogelijk zijn geweest zonder de bewuste of onbewuste hulp en inzet van velen. Deze wil ik in dit laatste hoofdstuk van harte danken.

Ik wil beginnen met de leden van mijn promotieteam.

Dear dr. Ferreira, dear Isabel. You in particular I owe a great word of thanks! It started already with the WESP internship (i.e. the scientific participation in the final year of the medical training) during which you guided me taking my first steps into the world of epidemiology. Your enthusiasm was so contagious that applying for the PhDposition on lifestyle risk factors and arterial stiffness under your co-supervision wasn't a hard decision really. During this project, your enthusiasm and great knowledge on amongst others epidemiology, lifestyle and vascular function and biology, formed an important inspiration for me while doing this research. You know I can be picky, but your thoroughness and great sense of detail made it possible to often present our results and publish these in nice peer-reviewed journals. I very much liked our (long) conversations and discussions too about work-related as well as private matters during the Monday afternoons and many other moments. It is obvious for me that this project would not be the same without your help and great efforts the last couple of years. Many many thanks for everything!

Geachte Prof. dr. Stehouwer, beste Coen. De wijze waarop je meerdere (zeg maar zeer veel) ballen tegelijkertijd en met succes in de lucht houdt is werkelijk bewonderenswaardig! Ik sta telkens weer versteld van de (schijnbaar) onuitputtende kennis over zeer uiteenlopende onderwerpen, je oog voor detail en de enorme efficiëntie waarmee je te werk gaat. Je weet in zeer heldere bewoordingen de kern van een ingewikkeld verhaal weer te geven en stimuleert ons om nog eens goed na te denken over bepaalde formuleringen die we in presentaties en manuscripten hebben gebruikt. Ik heb hier veel van geleerd. Samen met Isabel heb je ons als promovendi ook gestimuleerd om daadwerkelijk 'opgeleid' te worden in statistiek, epidemiologie, cardiovasculaire ziekten in het algemeen enzovoorts tijdens onze projecten; iets waar ik ook op de lange termijn nog profijt van zal hebben. Voor dit alles ben ik je ontzettend dankbaar! Ik hoop ook de komende jaren als AIOS interne geneeskunde in Maastricht nog veel van je te leren.

Geachte Prof. dr. Twisk, beste Jos. Je was mijn promotor op (een letterlijke) afstand. De dagelijkse gang van zaken kon ik grotendeels regelen met mijn supervisoren in Maastricht, maar je interesse in mijn project heb ik bijzonder gewaardeerd en de kritische feedback die je me door de jaren heen hebt gegeven waren leerzaam. Ik ben blij de cursus longitudinale data analyse bij je gevolgd te hebben. Het is geweldig om te zien hoe je ingewikkelde materie op een heel heldere manier weet over te brengen. Dank daarvoor! 
Geachte Prof. dr. Prins, beste Martin. Dank voor het mogelijk maken van dit project en de interesse die je daarin hebt getoond. De positiviteit die je uitte bij de verschillende voortgangsbesprekingen tijdens dit project vormde een goede stimulans om er vrolijk mee door te gaan.

Dan mijn lieftallige collega's en kamergenootjes op kamer 5.312: Lian en Johanna. Min of meer tegelijkertijd zijn we begonnen aan onze promotietrajecten en ik ben de laatste van de 'Musketiers' die het nu dan (eindelijk) mag afsluiten. Ik ben dan ook vereerd dat jullie als paranimfen naast mij zullen staan tijdens de verdediging van dit boekje! We zaten vier jaar met zijn drieën op nog geen $10 \mathrm{~m}^{2}$ en in deze periode is er geen kwaad woord gezegd of gevallen. In tegendeel, ik vond het een ontzettend gezellige en fijne tijd, waarin we onder andere cursussen, tripjes, analyses, meer analyses, rebuttals, CATs, en nog veel meer analyses met elkaar hebben gedeeld. Mede dankzij jullie ben ik de laatste jaren met veel plezier naar mijn werk gegaan! De etentjes/borrels/kopjes koffie moeten we er zeker inhouden! Lian, je beschikt over belangrijke kwaliteiten om het ver te schoppen binnen onderzoeksland. Ik kan je alleen maar heel veel succes wensen bij alles wat je nog gaat doen in je toekomstige carrière! Ik hoop dat ik je nog eens mag bellen met een of andere suffe epi-vraag, of beter, dat we samen nog eens aan een project kunnen werken. Bedankt ook dat je mijn vaste maatje was om er altijd weer een feestje van te maken!! Johanna, ik heb veel respect voor de wijze waarop je van alles weet te bereiken in het leven. In de goede zin van het woord ben je een stille kracht die enkel vooruit gaat! Ik vind het leuk dat we ook de komende jaren nog collega's zullen zijn in het ziekenhuis.

Geachte Prof. dr. Schalkwijk, beste Casper. Je zit niet in mijn promotieteam, maar als hoofd van ons laboratorium heb je een zeer wezenlijke bijdrage geleverd aan dit proefschrift. Mede dankzij jouw interesse, enthousiasme en kritische vragen tijdens de velen werkbesprekingen voelde ik me meer dan thuis in de wereld van de (basale) wetenschap. Je geeft op een open manier leiding aan de afdeling en bent laagdrempelig in de omgang wat de sfeer op en de kwaliteit van het werk ten goede komt. Heel hartelijk dank daarvoor! Veel dank ook, ook aan Hermine en de kinderen, voor de gastvrijheid bij de gezellige barbecues en kerstdiners die we bij jullie thuis hebben gehad!

De leden van de leescommissie, Prof. dr. H.A.J. Struijker-Boudier, Prof. dr. ir. P.A. van den Brandt, Prof. dr. J. Brug, en Mw. Prof. dr. A. Schols, wil ik bedanken voor het lezen en goedkeuren van mijn proefschrift. Dear Prof. dr. S. Laurent, thank you for the time and effort spent on adjudicating this manuscript. I am honored you will be present during the public defense meeting in March. Beste Prof. dr. H.C.G. Kemper en Prof. dr. P.C. Dagnelie, dank dat u plaats wil nemen in de corona. 
Mijn andere collega's op het laboratorium interne geneeskunde wil ik van harte danken voor de fijne jaren die ik heb gehad. Er bestaat een enorme gedrevenheid, maar ook een bijzonder prettige en ontspannen sfeer. Mijn (oud-)collega-promovendi: Steven, Olaf, Katrien, Marjon, Bas, Marcelle, Nordin, Yvo, Elisabeth, Dennis, Hanneke, Nick, Thomas, Barry, Rianne, Amy, Matthijs, en Leon. Ik wil jullie allemaal heel erg bedanken voor de vele discussies en de leuke tijd die we samen hebben gehad. De gedrevenheid die er bij iedereen bestaat vormen een belangrijke drijfveer om een goed resultaat neer te zetten. Bas, samen hebben we nog gewerkt aan de laatste stukken van mijn proefschrift. Bedankt voor je inzet en leuke discussies die we hebben gehad. Veel succes met het afronden van je eigen boekje. Het is mooi dat we wederom collega's zijn in het ziekenhuis! Ook Jean, Carla, Marleen, Vicky, Petra, Marjo, Josephine, en Margee wil ik allemaal bedanken voor de interesse, gezellige tijd en bijdragen aan dit boekje. Bedankt allemaal!

Dear Prof. dr. Boreham, dear Collin. I will remember your very warm welcome when visiting your laboratory in Dublin in 2009. Your expert knowledge on exercise physiology were of great help in the beginning of my PhD-project. I want to thank you and Prof. dr. Murray also for giving me the opportunity to use the Northern Ireland Young Hearts Project data, which has led to publication of the manuscript presented in Chapter 5.

Mijn nieuwe 'bazen' en collega-AIOS van de afdeling interne geneeskunde in het ziekenhuis wil ik bedanken voor de interesse in mijn promotie en de fijne samenwerking in het afgelopen jaar. Een kort woord van dank in het bijzonder aan Dr. Pijpers, beste Evelien, Dr. Mulder, beste Wubbo, en Prof. dr. Nieuwenhuijzen Kruseman, beste Arie. Tijdens mijn stage bij de afdeling ouderengeneeskunde hebben jullie mijn interesse voor de wetenschap, maar ook voor de interne geneeskunde, mede weten te wekken. Mijn (beginnende) carrière zou er zonder jullie wellicht heel anders uit hebben gezien.

Tiny, top-Tiny! In de laatste fase van mijn promotie, dat wil zeggen bij het maken van het boekje zelf, heb je me ontzettend veel werk uit handen genomen! Je bent zeker zo precies als ikzelf. Heel erg veel dank daarvoor!

Mijn vrienden wil ik bedanken voor de vele gezellige momenten die we hebben gehad de laatste jaren! Sonny, Floris, Erik, Erwin, Thijs, Sander, Vi, Chun, Ingeborg, Nicole, Nienke, Magalie, Vivianne, Jan Peter. Allen bedankt voor de vele etentjes, weekendjes, skireizen, biertjes en avonden stappen die we hebben gehad. Jullie weten maar half hoe belangrijk het voor me is om zo af en toe zaken te relativeren en de gedachten te verzetten! Sonny, een speciaal woord van dank aan jou. We kennen elkaar vanaf de eerste dag van de geneeskunde opleiding. Die eerste maanden waren we zo'n beetje veroordeeld elkaar dagelijks te zien tijdens onderwijs- en 
introductiegroepen; de jaren erna is dat er niet echt minder op geworden. Ook jij bent na geneeskunde begonnen met je PhD-project en dit jaar nog zal je een ongetwijfeld indrukwekkend boekje kunnen verdedigen. Bedankt voor de vele plezierige momenten en goede gesprekken die we hebben gehad. Ik waardeer onze vriendschap zeer!

Als laatste mijn familie.

Familie van de Laar en van den Berkmortel. Eindelijk is hier dan een tastbaar bewijs van hetgeen waar ik me al die tijd mee bezig heb gehouden. Bedankt voor de interesse die jullie hebben getoond.

Lieve Anja en René, voor niet-ingewijden mijn mamma en pappa, dank voor de mogelijkheden die jullie ons hebben gegeven. Jullie hebben ons van kleins af aan gestimuleerd om te gaan studeren en veel van de wereld te zien. De prijs die jullie nu daarvoor betalen is dat heel Nederland doorkruist moet worden om het kroost te zien. Jullie hebben ons bijgebracht dat er hard gewerkt dient te worden, maar ook dat je moet genieten van de geneugten in het leven. Ik ben jullie daar heel erg dankbaar voor! Lieve Tom en Anne, ik ben ontzettend trots op jullie en blij dat we het met $z^{\prime} n$ drieën zo fijn hebben!! Jullie steun is heel erg belangrijk voor me. Thierry en Gert-Jan, jullie hebben mij er gratis bij gekregen... Ik hoop dat jullie dat tot in lengte van jaren kunnen (en zullen) waarderen! Ik houd van jullie allemaal! 
Curriculum Vitae 


\section{CURRICULUM VITAE}

Roel Johan Jozef Maria van de Laar was born on July $26^{\text {th }} 1983$ in Helmond, the Netherlands. In 2001 he graduated from pre-university secondary school at the Dr. Knippenbergcollege in Helmond. In the same year he started his medical training at Maastricht University, Maastricht, the Netherlands. In February 2008 he obtained his medical degree. From November 2007 Roel started to work as a PhD student for four years at the department of Internal Medicine of the Maastricht University Medical Centre, Maastricht, within the CAPHRI School for Public Health and Primary Care and the CARIM school of Cardiovascular diseases of the same institution. The results of his research are presented in this thesis. Roel's work was performed under the supervision of promotors Prof. dr. Coen Stehouwer, Prof. dr. Martin Prins, and Prof. dr. Jos Twisk, and copromotor Dr. Isabel Ferreira. From December 2012 he has worked as a resident Internal Medicine at the Department of Internal Medicine of the Maastricht University Medical Centre. 
Scientific output 


\section{SCIENTIFIC OUTPUT}

\section{Articles}

Van de Laar RJ, Stehouwer CD, Prins MH, van Mechelen W, Twisk JW, Ferreira I. Time spent watching television is associated with higher arterial stiffness in young adults: the Amsterdam Growth and Health Longitudinal Study. Submitted.

Engelen L, Ferreira I, Stehouwer CD, Boutouyrie P, Laurent S; on behalf of the Reference Values for Arterial Measurements Collaboration. Eur Heart J. 2012. In Press.

Van de Laar RJ, Stehouwer CD, van Bussel BC, Prins MH, Twisk JW, Ferreira I. Adherence to a Mediterranean dietary pattern in early life is associated with lower arterial stiffness in adulthood: the Amsterdam Growth and Health Longitudinal Study. J Intern Med. 2013;273:79-93.

Van de Laar RJ, Stehouwer CD, van Bussel BC, te Velde SJ, Prins MH, Twisk JW, Ferreira I. Lower lifetime dietary fiber intake is associated with carotid artery stiffness: the Amsterdam Growth and Health Longitudinal Study. Am J Clin Nutr. 2012; 96:14-23.

Hermeling E, Vermeersch SJ, Rietzschel ER, de Buyzere ML, Gillebert TC, van de Laar RJ, Ferreira I, Hoeks AP, van Bortel LM, Reneman RS, Segers P, Reesink KD. The change in arterial stiffness over the cardiac cycle rather than diastolic stiffness is independently associated with left ventricular mass index in healthy middle-aged individuals. J Hypertens. 2012; 30:396-402.

Ferreira I, van de Laar RJ, Prins MH, Twisk JW, Stehouwer CD. Carotid stiffness in young adults: a life-course analysis of its main determinants: the Amsterdam Growth and Health Longitudinal Study. Hypertension. 2012; 59:54-61.

Van de Laar RJ, Stehouwer CD, Boreham CA, Murray LM, Schalkwijk CG, Prins MH, Twisk JW, Ferreira I. Continuing smoking between adolescence and young adulthood is associated with higher arterial stiffness in young adults: the Northern Ireland Young Hearts Project. J Hypertens. 2011; 29:2201-9.

Van de Laar RJ, Ferreira I, van Mechelen W, Prins MH, Twisk JW, Stehouwer CD. Habitual physical activity and peripheral arterial compliance in young adults: the Amsterdam Growth and Health Longitudinal Study. Am J Hypertens. 2011; 24:200-8.

Van de Laar RJ, Ferreira I, van Mechelen W, Prins MH, Twisk JW, Stehouwer CD. Lifetime vigorous but not light-to-moderate habitual physical activity impacts favorably on carotid stiffness in young adults: the Amsterdam Growth and Health Longitudinal Study. Hypertension. 2010; 55:33-9. 
Pijpers E, Ferreira I, van de Laar RJ, Stehouwer CD, Nieiwenhuijzen-Kruseman AC. Predicting mortality of psychogeriatric patients: a simple prognostic frailty score. Postgrad Med J. 2009; 85:464-9.

\section{Oral presentations}

Artery 8, Artery Society, Ghent, Belgium, September 2008

Awarded with the 'Young Investigator Award' for the presentation entitled: "Lifecourse Physical Activity and its Impact on Arterial Stiffness: the Amsterdam Growth And Health Longitudinal Study"

WEON 2009, Netherlands Epidemiology Society, Amsterdam, the Netherlands, June 2009

Artery 9, Artery Society, Cambridge, United Kingdom, September 2009

WEON 2010, Netherlands Epidemiology Society, Nijmegen, the Netherlands, June 2010

Artery 11, Artery Society, Paris, France, October 2011

\section{Poster presentations}

EPI-NPAM 2010, American Heart Association, San Francisco, USA, March 2010 Artery 10, Verona, Italy, October 2010

WEON 2011, Netherlands Epidemiology Society, Ijmuiden, the Netherlands, June 2011 ESH 2011, European Society of Hypertension, Milan, Italy, June 2010 
